\title{
The identification of molecular guidance cues necessary for development of the central auditory system
}

\author{
David M. Howell \\ West Virginia University
}

Follow this and additional works at: https://researchrepository.wvu.edu/etd

\section{Recommended Citation}

Howell, David M., "The identification of molecular guidance cues necessary for development of the central auditory system" (2009). Graduate Theses, Dissertations, and Problem Reports. 2839.

https://researchrepository.wvu.edu/etd/2839

This Dissertation is protected by copyright and/or related rights. It has been brought to you by the The Research Repository @ WVU with permission from the rights-holder(s). You are free to use this Dissertation in any way that is permitted by the copyright and related rights legislation that applies to your use. For other uses you must obtain permission from the rights-holder(s) directly, unless additional rights are indicated by a Creative Commons license in the record and/ or on the work itself. This Dissertation has been accepted for inclusion in WVU Graduate Theses, Dissertations, and Problem Reports collection by an authorized administrator of The Research Repository @ WVU.

For more information, please contact researchrepository@mail.wvu.edu. 


\title{
The Identification of Molecular Guidance Cues Necessary for Development of the Central Auditory System
}

\author{
David M. Howell \\ Dissertation submitted to the School of Medicine at West Virginia University \\ In partial fulfillment of the requirements for the degree of \\ Doctor of Philosophy \\ in \\ Biochemsitry and Molecular Biology
}

Committee Members:
Peter H. Mathers, Ph.D., Chair
Albert S. Berrebi, Ph.D.
Lisa Salati, Ph.D.
Maxim Sokolov, Ph.D.
George A. Spirou, Ph.D.

\author{
Department of Biochemistry \\ Morgantown, West Virginia \\ 2009
}

Keywords: cochlear nucleus, medial nucleus of the trapezoid body, netrin, DCC, superior olivary complex, development 


\title{
Abstract \\ The Identification of Molecular Guidance Cues Necessary for Development of the Central Auditory System
}

\author{
David M. Howell
}

Developing neurons utilize multiple guidance cues to reach their appropriate destination. Although much is known about the anatomy and electrophysiology of auditory brainstem neurons, the molecular factors directing migration of these cells and the targeting of their axons are only beginning to be explored. Ventral cochlear nucleus (VCN) neurons have axons that project bilaterally to the superior olivary complex (SOC) in the ventral acoustic stria (VAS). The circumferential trajectory taken by developing VCN axons is similar to the path of spinal commissural neurons (SCNs). Therefore, we reasoned that netrin-DCC and slit-robo signaling systems may function, similar to SCNs, in the guidance of VCN axons. We found that VCN axons extend toward the midline as early as E13, with many axons crossing the midline by E14.5. During this interval, netrin-1 and slit-1 RNAs are expressed at the brainstem midline, VCN neurons express RNAs for DCC, robo-1 and robo-2 receptors and VCN axons in the VAS are immunoreactive for DCC. Additionally, VCN axons fail to reach the midline in netrin-1- or DCC-deficient mice. The lack of VCN axonal outgrowth in DCC-deficient mice is not explained by the modest reduction ( $10 \%)$ of VCN neurons. Taken together, these data show that a functional netrin-DCC signaling system is required for establishing proper VCN axonal projections in the auditory brainstem.

During our characterization of VCN axonal projections, we found that the neurons comprising the medial nucleus of the trapezoid body (MNTB), a component of the SOC, are absent in mice carrying no functional netrin-1 or DCC alleles. Since DCC is known to direct cellular migration in other regions of the central nervous system, we hypothesized that netrin-DCC and slit-robo signaling systems may function in the migration and positioning of MNTB neurons. RNAs for DCC, robo-1 and robo-2 are expressed in columns of cells that extend from the rostral brainstem to the developing SOC. MNTB and other superior olivary complex (SOC) neurons maintain expression of these guidance receptors during the formation of discreate SOC nuclei. Additionally, mice carrying only one functional copy of the netrin-1 or DCC allele have a laterally displaced MNTB and express half the quantity of DCC found in wild-type animals. The displaced MNTB is maintained in adult animals carrying only one functional DCC allele and is not explained by a difference in the number of MNTB neurons, as determined by unbiased stereology. In addition, the trochlear nucleus and ventral tegmental nucleus are significantly displaced, medially and laterally, respectively, in these adult heterozygous animals. We found that the tonotopic organization of the laterally displaced MNTB is preserved in mice carrying only one functional DCC allele. Therefore, these auditory circuits have sufficient 
plasticity to properly form in the presence of a significantly displaced MNTB. We propose that netrin-DCC and slit-robo signaling is necessary for the migration of SOC neurons and that medial-to-lateral positioning of the SOC and other central nervous system nuclei occurs in a dose-dependent manner, based on a cell's programmed response to midline signals. This work will have clinical implications for future research in the repair/regeneration of central nervous system circuits. 


\section{Dedication}

This work is dedicated to the memory of my father, Peter M. Howell, who passed away on January 18, 1991. 


\section{Acknowledgements}

I would like to thank my advisor, Dr. Peter Mathers, for all of the advice, encouragement and support that he has provided me over the years. He fostered an environment of learning and gave me sufficient freedom to develop my project along lines that I found interesting and rewarding. The breadth of training that I received has greatly enhanced my development as a scientist. I will always be grateful for these reasons and many others.

I would also like to thank the members of my committee, Dr. Albert Berrebi, Dr. Lisa Salati, Dr. Maxim Sokolov and Dr. George Spirou for all of their advice and time that they have provided over the years. They have helped me grow as a scientist and I am thankful for all the advice and support they have provided me. I would like to thank Dr. Janet Cyr for her participation and support that she has provided in the development of my project. I greatly appreciate all of the valuable contributions that were made by members of the labs with which I collaborated. I have truly benefited from these interactions and experiences with such a diverse group of colleagues.

Finally, I would like to thank my family and friends that have supported me throughout the years. I am thankful for my mother, Martha, who has always provided me with love and support. I am thankful for my wife, Jodie, and our children, Lucas, Lauren and Alexandra, who continue to be a source of love and joy in my life. They have always been understanding and provided me with perspective and purpose. I could not have done this without the help from my family and friends. To everyone that has made this possible, I thank you all. 


\section{Table of contents}

Abstract.

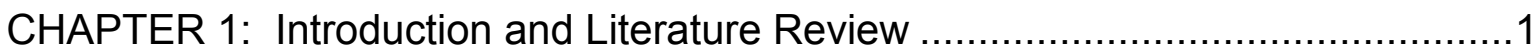

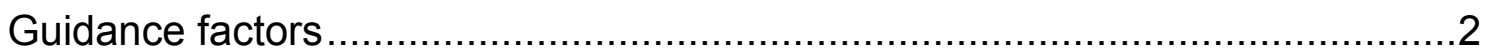

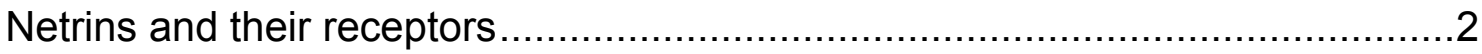

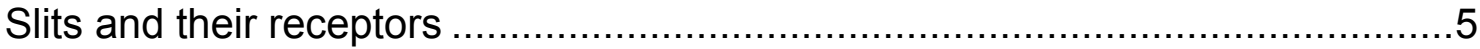

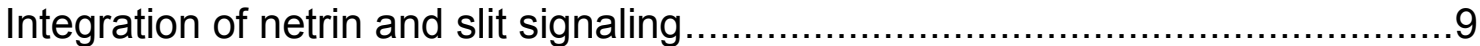

Eph receptors and their ephrin ligands …..............................................

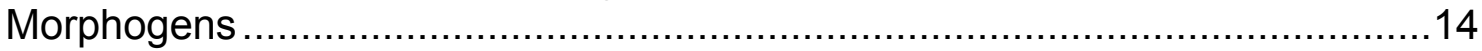

The hedgehog family ....................................................................

The decapentaplegic/bone morphogenic protein/transforming growth

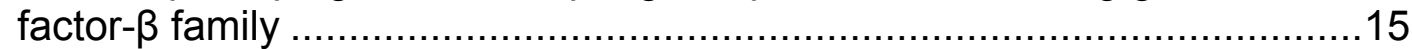

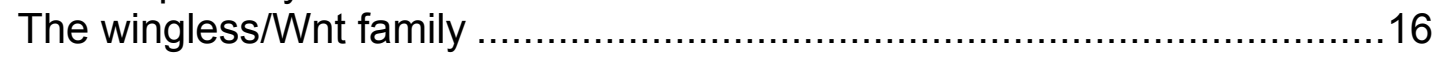

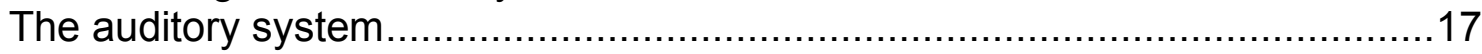

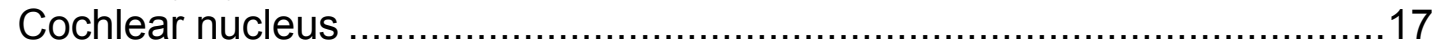

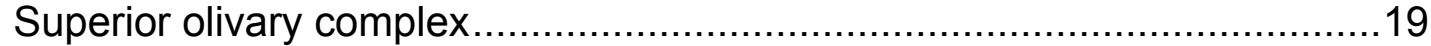

Cochlear nucleus and superior olivary complex neurogenesis ......................21

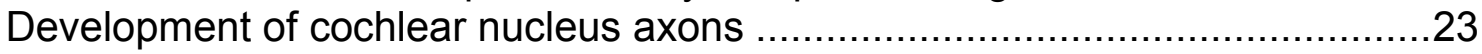

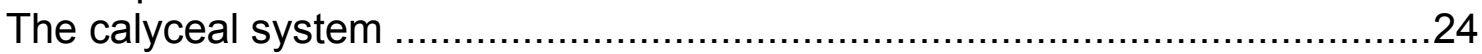

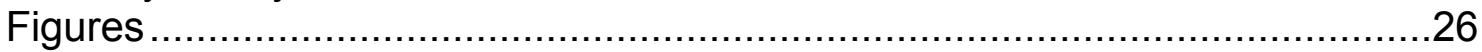

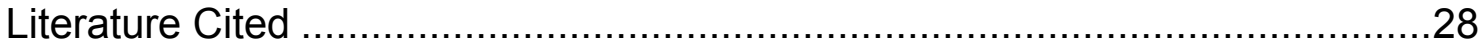

CHAPTER 2: Molecular Guidance Cues Necessary for Axon Pathfinding From the Ventral Cochlear Nucleus ..........................................52

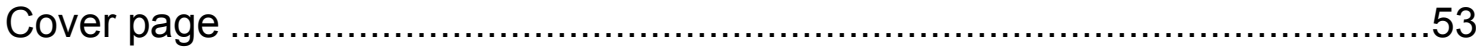

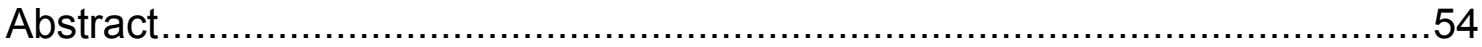

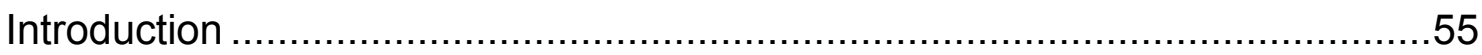

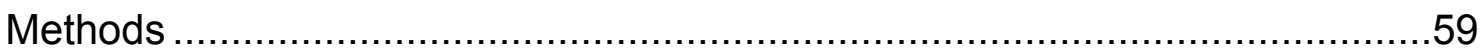

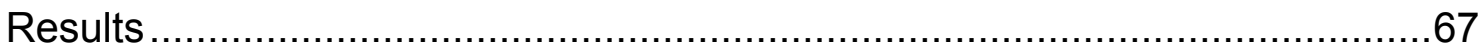

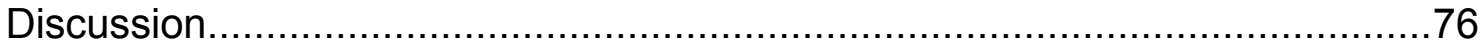

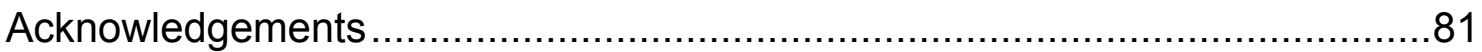

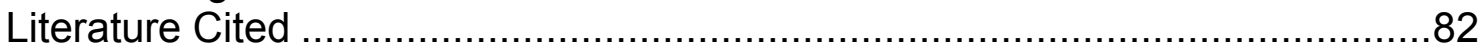

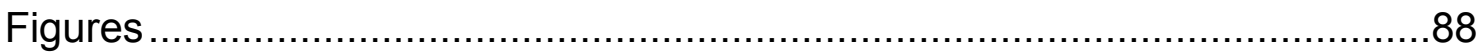

CHAPTER 3: Guidance Cues Regulating Medial-Lateral Positioning of Midbrain And Hindbrain Nuclei ..............................................................103

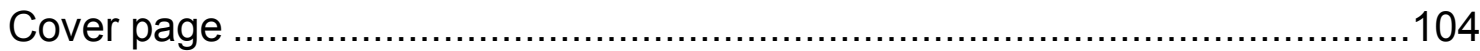

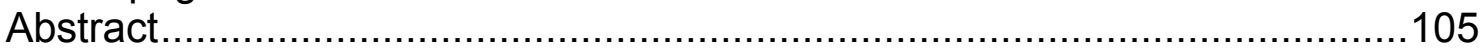




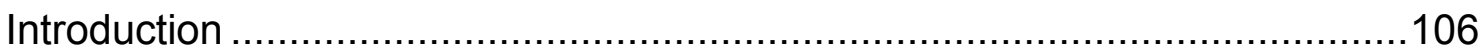

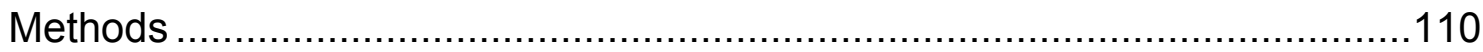

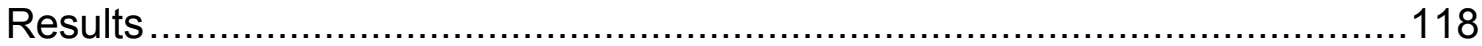

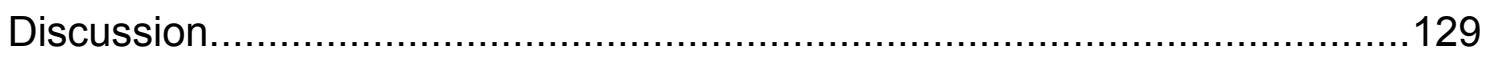

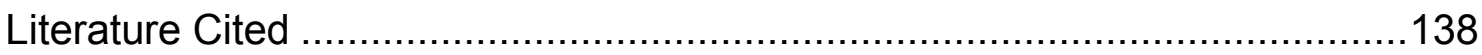

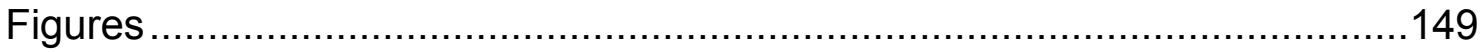

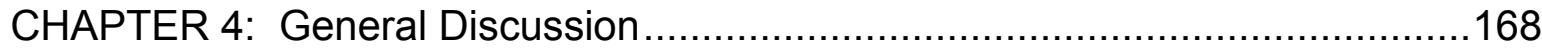

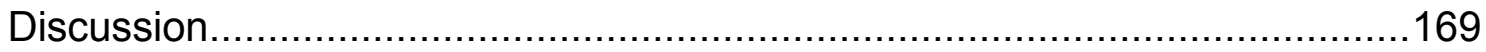

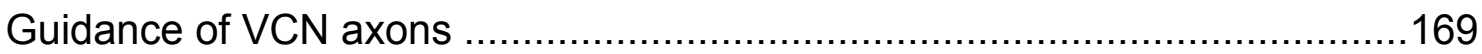

Medial-lateral positioning of SOC neurons ...............................................173

Clinical significance of guidance cues and disease processes ....................177

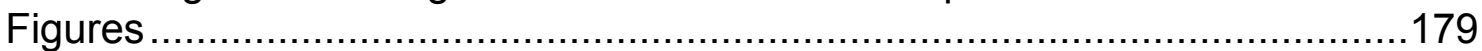

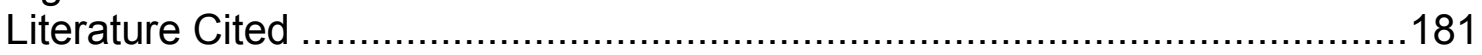

APPENDIX A: Protein Expression in the Superior Olive and Ventral Cochlear Nucleus .......................................................................... 185

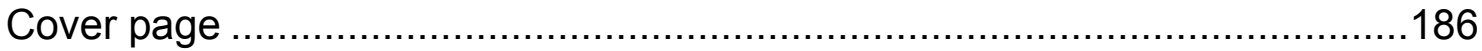

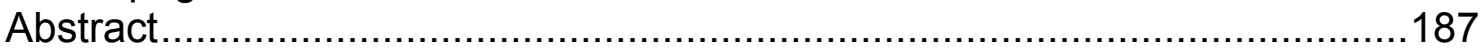

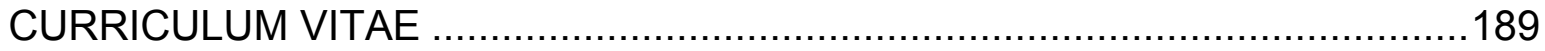




\section{List of Figures}

\section{Chapter 1}

Figure 1. Schematic diagram of auditory circuits that encode ITD and ILD for the localization of sound

\section{Chapter 2}

Figure 1. RNA and protein expression of mafB identifies the embryonic cochlear nucleus .88

Figure 2. Outgrowth of axons from the ventral cochlear nucleus 89

Figure 3. Netrin-1 and DCC are expressed in the developing auditory brainstem

Figure 4. Robo and Slit family members are expressed in the developing auditory brainstem

Figure 5. VAS projections are disrupted in DCC-deficient mice

Figure 6. VAS projections are disrupted in netrin-1-deficient mice..................97

Figure 7. Characterization of the VCN in the DCC-mutant strain 99

Supplemental Figure 1. mafB-positive VCN cells express neural markers 101

\section{Chapter 3}

Figure 1. DCC- and netrin-1-deficient mice lack identifiable MNTB neurons 149

Figure 2. Medial-lateral positioning of the MNTB depends on DCC gene dosage 151

Figure 3. DCC gene dosage changes adult MNTB morphology 153

Figure 4. DCC protein expression is proportional to the number of functional $D C C$ alleles 155

Figure 5. Migrating SOC neurons express $D C C$ 157

Figure 6. DCC gene dosage alters the tonotopic positioning of MNTB neurons 159

Figure 7. DCC gene dosage alters the position of midbrain nuclei 161

Supplemental Figure 1. Adult MNTB neurons are labeled by Engrailed1cre reporter system

Supplemental Figure 2. Medial-lateral positioning of the MNTB requires netrin-1 function

Supplemental Figure 3. DCC gene dosage changes adult MNTB morphology ..... 165

Supplemental Figure 4. robo1 and robo2 are expressed in the developing SOC 166

\section{Chapter 4}

Figure 1. Proposed model establishing the relative position of SOC neurons with guidance receptors 


\section{List of Abbreviations}

\begin{tabular}{|c|c|}
\hline $8^{\text {th }}$ & vestibulocochlear nerve \\
\hline ANOVA & analysis of variance \\
\hline AVCN & anteroventral cochlear nucleus \\
\hline BMP & bone morphogenic protein \\
\hline $\mathrm{Cb}$ & cerebellum \\
\hline $\mathrm{CN}$ & cochlear nucleus \\
\hline Comm & commissureless \\
\hline $\mathrm{CP}$ & choroid plexus \\
\hline DAB & 3,3'-diaminobenzidine tetrahydrochloride \\
\hline DCC & deleted in colorectal cancer \\
\hline DCN & dorsal cochlear nucleus \\
\hline Dhh & desert hedgehog \\
\hline DiD & 1,1'-dioctadecyl-3,3,3',3'-tetramethylindodicarbocyanine perchlorate \\
\hline Dil & 1,1'-dioctadecyl-3,3,3',3'-tetramethylindocarbocyanine perchlorate \\
\hline DMPO & dorsomedial periolivary nucleus \\
\hline DNLL & dorsal nucleus of the lateral lemniscus \\
\hline Dpp & decapentaplegic \\
\hline $\mathrm{Drl}$ & derailed \\
\hline $\mathrm{E}$ & embryonic age \\
\hline GBC & globular bushy cell \\
\hline GFAP & glial fibrillary acidic protein \\
\hline GPI & glycosyl phosphatidylinositol \\
\hline HGPPS & horizontal gaze palsy and progressive scoliosis \\
\hline Hip & Hedgehog interacting protein \\
\hline IC & inferior colliculus \\
\hline Ihh & indian hedgehog \\
\hline ILD & interaural level difference \\
\hline INLL & intermediate nucleus of the lateral lemniscus \\
\hline IPD & interaural phase difference \\
\hline ITD & interaural time difference \\
\hline LF & lateral funiculus \\
\hline LNTB & lateral nucleus of the trapezoid body \\
\hline LSO & lateral superior olive \\
\hline MNTB & medial nucleus of the trapezoid body \\
\hline MSO & medial superior olive \\
\hline NL & nucleus laminaris \\
\hline NM & nucleus magnocellularis \\
\hline $\mathrm{P}$ & postnatal age \\
\hline PBS & phosphate buffered saline \\
\hline PBT & phosphate buffered saline $+0.1 \%$ Tween- 20 \\
\hline PFA & paraformaldehyde \\
\hline PMS & pontine migratory stream \\
\hline PVCN & posteroventral cochlear nucleus \\
\hline $\mathrm{R}$ & rhombomere \\
\hline
\end{tabular}




$\begin{array}{ll}\text { Robo } & \text { roundabout receptor } \\ \text { RT } & \text { room temperature } \\ \text { SBC } & \text { spherical bushy cell } \\ \text { SCN } & \text { spinal commissural neuron } \\ \text { SEM } & \text { standard error of the mean } \\ \text { Shh } & \text { sonic hedgehog } \\ \text { SOC } & \text { superior olivary complex } \\ \text { SPL } & \text { sound pressure level } \\ \text { SPON } & \text { superior paraolivary nucleus } \\ \text { SPV } & \text { spinal nucleus of the trigeminal nerve } \\ \text { TB } & \text { trapezoid body } \\ \text { TGF- } \beta & \text { transforming growth factor- } \beta \\ \text { VAS } & \text { ventral acoustic stria } \\ \text { VCN } & \text { ventral cochlear nucleus } \\ \text { VNLL } & \text { ventral nucleus of the lateral lemniscus } \\ \text { VNTB } & \text { ventral nucleus of the trapezoid body } \\ \text { TIFF } & \text { tagged-image file format }\end{array}$




\section{CHAPTER 1}

\section{Introduction and Literature Review}




\section{Introduction}

\section{Guidance factors}

During development, neurons extend their axons through a myriad of signaling molecules that are expressed by surrounding cells before the axons can reach their appropriate targets. The ability to recognize and respond to directional cues is paramount to the pathfinding process. Neurons use intermediate targets to simplify complex trajectories by separating the navigation into smaller, more manageable segments (Tessier-Lavigne and Goodman, 1996). Growth cones, the specialized tip of a developing axon, are presented with a variety of directional cues along the migratory path. The directional signals may be secreted factors that participate in long-range signaling or membrane-associated molecules that function in short-range guidance. These cues are presented as combinations of attractive and repulsive signals, with the complement of receptors on the growth cone ultimately determining the response. A combination of genetic and biochemical methods has led to the discovery of several important classes of axon guidance systems: (1) Netrins and their receptors, (2) Slits and their receptors, (3) Eph receptors and their ephrins ligands, and more recently (4) Morphogens. Each of these signaling systems will be discussed below.

\section{Netrins and their receptors}

Netrins are a highly conserved family of proteins that mediate axon pathfinding and neural migration in the developing nervous system. Originally identified in Caenorhabditis elegans, unc- 6 was found to encode a secreted protein required for circumferential axon pathfinding (Hedgecock et al., 1990; Ishii et al., 1992). Two vertebrate homologues were subsequently purified from chick brain, named netrin-1 and netrin-2 (Kennedy et al., 1994; Serafini et al., 1994). These factors directed axonal extension in cultured embryonic rat spinal cord explants (Kennedy et al., 1994; Serafini et al., 1994). In Drosophila, two netrins, Netrin-A and Netrin-B, have been implicated in the guidance of commissural axons (Harris et al., 1996; Mitchell et al., 1996). Vertebrates express six netrin family members that are either secreted (netrin-1, netrin-2, netrin-3 and netrin-4) or membrane-associated 
(netrin-G1 and netrin-G2). Membrane-associated netrins are attached to the membrane via a glycosyl phosphatidylinositol-(GPI-) anchor (Nakashiba et al., 2000; Nakashiba et al., 2002). All netrin genes encode an approximately 600 amino acid protein with a predicted molecular weight of approximately $70 \mathrm{kD}$. These proteins share sequence homology to laminins (Ishii et al., 1992; Yurchenco and Wadsworth, 2004). Mammals express netrin-1, -3, -4, -G1 and -G2; the netrin-2 family member has only been identified in chicken and zebrafish. Orthologues of netrin-1 and -3 , the classical netrins, have now been additionally identified in the flatworm Schmidea mediterranea, the leach Hirudo medicinalis, and the sea anemone Nematostella vectensis (Cebria and Newmark, 2005; Gan et al., 1999; Matus et al., 2006). The more divergent family members, netrin-4, netrin-G1 and netrin-G2, have only been identified in vertebrates (Nakashiba et al., 2000; Nakashiba et al., 2002; Yin et al., 2000).

Netrin-mediated cell migration and axon pathfinding occur upon binding to membrane-bound netrin receptors. In vertebrates, classical netrins bind to several receptors, including deleted in colorectal cancer (DCC), neogenin, a paralogue of DCC and four UNC5 receptors (UNC5A-D) (Ackerman et al., 1997; Engelkamp, 2002; Keino-Masu et al., 1996; Leonardo et al., 1997; Przyborski et al., 1998; Shen et al., 2002; Vielmetter et al., 1994). DCC homologues have been identified in Drosophila (frazzled) and C. elegans (Unc-40) where they mediate axon guidance through netrin binding (Chan et al., 1996; Kolodziej et al., 1996). The majority of studies in vertebrates have examined the attractive response to netrin-1 that occurs through binding to DCC receptors. UNC5 receptors are mediators of repellant responses in the presence of netrin (Hedgecock et al., 1990; Hong et al., 1999; Keleman and Dickson, 2001; Leung-Hagesteijn et al., 1992). However, UNC5mediated repellant activity requires co-expression of DCC in some cases, but not all (Guijarro et al., 2006; Hamelin et al., 1993; Hong et al., 1999; Merz et al., 2001). Neogenin binds netrin-1, netrin-4 and repulsive guidance molecules (Guijarro et al., 2006; Rajagopalan et al., 2004). The recent identification of repulsive guidance molecules as ligands for neogenin has implicated neogenin in a variety of developmental processes throughout the nervous system (reviewed in Cole et al., 
2007; De Vries and Cooper, 2008). Netrin-G1 and netrin-G2 have not been shown to interact with DCC, neogenin or UNC5 receptors; instead these proteins bind transmembrane proteins called netrin-G ligands (Kim et al., 2006; Lin et al., 2003; Nakashiba et al., 2000; Zhang et al., 2008).

During embryonic development, netrins are implicated in numerous systems that establish contralateral or crossed neural pathways, as well as the orientation of neuronal and non-neuronal structures relative to the midline. In Drosophila, attractive netrin signaling through the frazzled receptor is required for commissural axons to appropriately cross the midline, for innervation of body wall musculature through motor axon guidance in the periphery and for proper migration of the developing salivary glands, as well as other developmental processes (Dorsten and VanBerkum, 2008; Kolesnikov and Beckendorf, 2005; Kolodziej et al., 1996). In C. elegans, netrin-mediated attraction is required for proper migration of cell bodies and axons in ventral, and to a lesser extent dorsal, directions (Chan et al., 1996; Hedgecock et al., 1990). In mammals, netrin-1 and DCC are expressed throughout the central nervous system. The global importance of this signaling system is appreciated in analysis of netrin-1- and DCC-deficient mice that demonstrate a loss of commissural projections throughout the central nervous system (Deiner et al., 1997; Deiner and Sretavan, 1999; Fazeli et al., 1997; Serafini et al., 1996). Specifically, the corpus callosum, hippocampal and anterior commisures fail to form and retinal ganglion cells axons no longer efficiently locate to the optic disc. In addition, errors are present in the corticospinal tract, thalamocortical projections and spinal commissural neurons (SCN) fail to efficiently reach the floor plate (Barallobre et al., 2000; Braisted et al., 2000; Deiner and Sretavan, 1999; Fazeli et al., 1997; Finger et al., 2002; Serafini et al., 1996). Furthermore, netrin signaling is utilized in the development of the peripheral and enteric nervous systems (Ratcliffe et al., 2006; Seaman et al., 2001). However, the habenular and posterior commissures are present and appear normal in netrin-1-mutant mice, and a new commissure near the midbrain-hindbrain junction is present in these mutant animals (Fazeli et al., 1997; Serafini et al., 1996). 
In addition to the defects in axonal pathfinding described above, pontine and inferior olivary neurons fail to reach their adult location in the absence of a functional netrin signaling system (Bloch-Gallego et al., 1999; Yee et al., 1999). The circumferential migration of pontine nuclei is unique because the migration occurs through a very long leading process (Yee et al., 1999). The trajectory of this leading process is mediated by a gradient of netrin protein (Yee et al., 1999). Additionally, netrins also direct the migration of LHRH neurons, cerebellar granule cells, spinal accessory neurons and oligodendrocyte precursors (Alcantara et al., 2000; Dillon et al., 2005; Jarjour et al., 2003; Schwarting et al., 2001; Schwarting et al., 2004; Tsai et al., 2003). Pontine and inferior olivary nuclei are located rostral and caudal, respectively, to the lower auditory brainstem nuclei, the cochlear nucleus $(\mathrm{CN})$ and superior olivary complex (SOC). Poe and Brunso-Bechtold (1998) evaluated the axonal outgrowth of $\mathrm{CN}$ explants in collagen gel cultures. They found that directed $\mathrm{CN}$ axonal outgrowth did not occur in the presence of a recombinant source of netrin-1, but was observed when $\mathrm{CN}$ explants were cultured with floor plate from the brainstem. Characterization of ventral cochlear nucleus (VCN) axonal projections was accomplished in netrin-1- and DCC-mutant mice (Chapter 2: Howell et al., 2007). We found that VCN axons fail to reach the midline of the brainstem in the absence of a functional netrin-DCC signaling system. In summary, netrins guide numerous developing populations of neurons and axons in a variety of species with a highly conserved signaling system through binding of netrin family members to receptors that mediate attractive and repulsive extensions.

\section{Slits and their receptors}

Similar to the netrin family, slits are a highly conserved family of proteins that function in axon guidance and cell migration. Slit protein was originally identified in Drosophila and found to be expressed by midline glial cells in the fly central nervous system (Kidd et al., 1999; Rothberg et al., 1988; Rothberg et al., 1990; Simpson et al., 2000b). Since this identification, slits have been found in numerous species. A single slit is present in C. elegans while three slits (slit-1, slit-2 and slit-3) are present in vertebrates, including amphibians, fish, birds and mammals (Brose et al., 1999; 
Holmes and Niswander, 2001; Holmes et al., 1998; Itoh et al., 1998; Li et al., 1999; Vargesson et al., 2001). Some slit family members undergo alternative splicing, but the signaling activity appears unchanged (Itoh et al., 1998; Little et al., 2002; Rothberg and Artavanis-Tsakonas, 1992; Tanno et al., 2004). Additionally, the presence of two slit-1 isoforms in zebrafish is the result of gene duplication (Hutson et al., 2003). All slit family members encode an approximately $200 \mathrm{kD}$ extracellular glycoprotein. Slit-2, as well as other slits, can undergo proteolytic cleavage by an undetermined process that appears the change the functional activity (Nguyen BaCharvet et al., 2001; Wang et al., 1999a; Whitford et al., 2002).

The slits signal through a family of membrane-bound receptors named robo, short for the Drosophila mutant, roundabout. The first robo family member was identified in Drosophila in a screen for genes involved in the midline crossing of axons (Seeger et al., 1993). A combination of genetic and biochemical results, in Drosophila, conclude that slit is a secreted ligand for robo receptors (Kidd et al., 1998a; Rajagopalan et al., 2000a; Rajagopalan et al., 2000b; Simpson et al., 2000a; Simpson et al., 2000b). Robo receptors belong to the immunoglobulin superfamily. $S A X-3$, the robo homologue in C. elegans, prevents repeated midline crossing, similar to Drosophila robo, and guides some axons to the ventral nerve cord (Hao et al., 2001; Zallen et al., 1998). Three robo family members (robo1, robo2, robo3/rig-1) are present in Drosophila, zebrafish, chick and mammals (Brose et al., 1999; Jen et al., 2004; Kidd et al., 1998a; Lee et al., 2001; Li et al., 1999; Rajagopalan et al., 2000a; Rajagopalan et al., 2000b; Simpson et al., 2000a; Simpson et al., 2000b; Vargesson et al., 2001; Yuan et al., 1999b). Similarly, all mammalian robo receptors bind secreted slit family members (Brose et al., 1999; Li et al., 1999; Sabatier et al., 2004). Robo4, magic robo, is a fourth family member identified in mammals that is highly expressed on endothelial cells and appears important for vascular development; however, robo4 has a questionable ability to bind slits (Bedell et al., 2005; Huminiecki et al., 2002; Jones et al., 2008; Park et al., 2003; Suchting et al., 2006). Additionally, mouse robo3/rig-1 may have splice variants that include a secreted form (Yuan et al., 1999a). In Drosophila and rodents, robo expression is 
observed on longitudinal axons and absent from commissural axon segments in the midline (Kidd et al., 1998a; Kidd et al., 1998b; Sabatier et al., 2004).

In the Drosophila nervous system, the transmembrane protein commissureless (Comm) is the means that restricts robo to the post-crossing portion of commissural axons (Kidd et al., 1998b; Tear et al., 1996). Comm was originally thought to be expressed by midline cells to mediate appropriate midline crossing (Georgiou and Tear, 2002). Further analysis indicates that comm is coexpressed with robo receptors by commissural axons (Keleman et al., 2002; Keleman et al., 2005). Comm recruits robo receptors to an internal endosomal compartment that prevents delivery of robo protein to the membrane surface of the growth cone for participation in axonal guidance (Keleman et al., 2005). The internal signaling that mediates these events is an area of active research. The ubiquitin ligase, dNedd4, was necessary to localize comm to an internal environment in a cell culture model, but further analysis is not well defined as to the in vivo requirement for this protein (Georgiou and Tear, 2003; Ing et al., 2007; Keleman et al., 2005; Myat et al., 2002). No comm homologue has been identified in vertebrates. In the mouse spinal cord, commissural neurons are only responsive to slits once they have crossed the midline where robo 1 and robo2 expression is increased and robo3/rig-1 expression is reduced (Long et al., 2004; Tamada et al., 2008; Zou et al., 2000). Increasing evidence indicates that robo3/rig-1 is responsible for permitting commissural axons to cross the midline. Commissural axons in robo3/rig-1 knockout mice, like those in Drosophila that lack functional comm protein, fail to cross the midline, perhaps indicating that these axons are prematurely sensitive to slit-mediated repellant activity (Long et al., 2004; Marillat et al., 2004; Sabatier et al., 2004; Tamada et al., 2008). Individuals with a rare autosomal recessive neurologic condition, horizontal gaze palsy and progressive scoliosis (HGPPS) have multiple $R O B O 3$ mutations (Abu-Amero et al., 2009; Amoiridis et al., 2006; Chan et al., 2006; Jen et al., 2004). Individuals with this condition have appropriately crossed pathways and inappropriately uncrossed pathways that include, corticospinal tracts, trapezoid body (TB) fibers, somatosensory fibers and the superior cerebellar peduncle (Abu-Amero et al., 2009; Amoiridis et al., 2006; Di Meglio et al., 2008; Jen et al., 2004; 
MacDonald et al., 2004; Sicotte et al., 2006). The TB is a collection of commissural auditory axons in the brainstem that are important for sound localization (discussed further below). Evaluation of brainstem auditory evoked potentials in a series of patients with HGPPS demonstrated failed connections from the $\mathrm{CN}$ to the contralateral $\mathrm{SOC}$ indicating a requirement for $\mathrm{ROBO} 3$ in humans for the formation of this circuit (Di Meglio et al., 2008). Unlike comm, robo3/rig-1 does not repress slit responsiveness through an internalization of the robo receptor in the growth cone (Chen et al., 2008; Sabatier et al., 2004). However, alternative splicing of the robo3/rig-1 transcript in the growth cone is proposed to mediate the conversion from slit-insensitivity to slit-mediated axon repulsion (Chen et al., 2008).

In Drosophila, loss of midline slit expression leads to a collapse of longitudinal axons in the midline with the inability of these axons to leave the midline; these axons now only sense midline-attractant activities and thereby fail to exit the still attractive intermediate target. A deletion of robo or robo2 causes commissural axons to repeatedly cross the midline while deletion of both robo and robo2 produces a slitlike phenotype with the axons trapped at the midline (Simpson et al., 2000b). The role of Drosophila robo3 in midline crossing is not currently described. In addition to midline crossing, the complement of robo receptors specifies the lateral position of longitudinal axons relative to the midline. The more medial tracts express only robo, the most lateral tracts express robo, robo2 and robo3 and intermediate longitudinal axons express robo and robo3 (Simpson et al., 2000a).

The expression patterns of slit genes in the developing central nervous system suggests a function in, but not limited to, guiding SCN axons, retinal ganglion cell axons and olfactory bulb axons (Erskine et al., 2000; Li et al., 1999; Marillat et al., 2002; Yuan et al., 1999b). The complementary expression of robo1 and robo2 genes supports the utilization of slit-robo signaling in these pathways. In the mouse spinal cord, all three slit family members are expressed in the floor plate during the development of SCN axons (Yuan et al., 1999b). No apparent SCN axon guidance defects were observed in the spinal cord of mice deficient for slit-1, slit-2, or slit-1/-2 indicating that continued expression of slit-3 in this region could compensate for the loss of the other two family members (Plump et al., 2002). Furthermore, fewer SCN 
axons exit the floor plate in slit triple mutant mice (Long et al., 2004). Axonal guidance defects are present in the developing visual system of slit-1/2-deficient mice due to the absence of slit-3 expression in the region of the developing visual system (Plump et al., 2002). Additionally, slit-2 and slit-1/-2-deficient mice contain axon guidance errors in corticofugal, callosal, and thalamocortical pathways (Bagri et al., 2002). Mice deficient in either robo1 or robo2 have an increased number of SCN growth cones that fail to exit the midline of the spinal cord (Long et al., 2004). As described above, mutation in the $\mathrm{ROBO}$ gene in humans produces a number of midline crossing defects that are similar to midline crossing defects in robo3/rig-1 mutant mice.

Similar to netrins, slits have a role in the guidance of neuronal migration. In mammals, slit signaling is important for the migration of neural crest cells and neuroblasts that will give rise to olfactory bulb interneurons (Nguyen-Ba-Charvet et al., 2008; Nguyen-Ba-Charvet et al., 2004; Nguyen-Ba-Charvet et al., 2002; Yuan et al., 1999b). In the mammalian brainstem, development of the lateral reticular and basilar pons is compromised in robo3/rig-1 mutant mice (Di Meglio et al., 2008; Marillat et al., 2004). Additionally, the projection from inferior olivary neurons to the contralateral cerebellum remains ipsilateral in robo3/rig-1 mutant mice (Di Meglio et al., 2008; Marillat et al., 2004). In summary, slits mediate the guidance of numerous populations of cells and axons in a variety of species. The slit signaling system is highly conserved across a number of species, although some notable differences exist. Netrin and slit signaling systems are implicated in an increasing number of biological processes; recently roles in angiogenesis and tumorigenesis have been documented for these signaling systems (reviewed in Legg et al., 2008; Chedotal et al., 2005; Wang et al., 2003).

\section{Integration of netrin and slit signaling}

Production of long-range, secreted guidance cues by an intermediate target is one method to direct axons toward or away from a specific region. The floorplate, a specialized midline structure, produces attractive (netrin) and repulsive (slit) molecular cues (discussed above). The midline represents an important 
developmental barrier such that only commissural axons are permitted to cross. Axonal growth cones must alter their responsiveness to guidance molecules as they navigate a chain of intermediate targets (Tessier-Lavigne and Goodman, 1996). In this case, responding to a slit-mediated repellent activity will aid in this progression, but the loss of netrin-mediated attractant signaling also needs to occur (Stein and Tessier-Lavigne, 2001). The proper coordination of these events is necessary to prevent stalling at one target before progressing to subsequent targets. Netrin and slit both stimulate axon elongation (Stein and Tessier-Lavigne, 2001). The growth cones of commissural neurons increase the level of robo protein as they cross the floor plate and commissural axons lose responsiveness to netrins in the contralateral brainstem (Long et al., 2004; Shirasaki et al., 1998; Stein and Tessier-Lavigne, 2001). The process of increasing slit-mediated repulsion and decreasing netrinmediated attraction are linked through an intracellular interaction between robo and DCC receptors (Stein and Tessier-Lavigne, 2001). The binding of slit to robo in the presence of DCC receptors results in an interaction between the cytoplasmic domains of DCC and robo that effectively silences the signaling for netrin-mediated attraction and slit-mediated repulsion without altering the signaling events responsible for increasing the rate of elongation (Stein and Tessier-Lavigne, 2001). This complex provides a mechanism to reprogram growth cones to exit a once attractive environment. It will be important to understand how this ternary complex and robo3/rig-1 receptors mediate the signaling events necessary for axons to cross the midline of the central nervous system.

\section{Eph receptors and their ephrins ligands}

Eph receptors, named for their expression in a erythropoietin-producing human hepatocellular carcinoma cell line, comprise the largest family of tyrosine kinase receptors. There are $16 \mathrm{Eph}$ receptor family members in vertebrates that are divided into two groups, EphA receptors (EphA1 through EphA10) and EphB receptors (EphB1 through EphB6) (Eph Nomenclature Committee, 1997). All Eph receptors have an approximately 500-600 amino acid extracellular domain, a single pass transmembrane domain and an approximately 400 amino acid cytoplasmic 
domain. Eph receptors bind a family of ephrin ligands. There are 9 membrane-bound ephrin ligand family members in vertebrates that are divided into two groups, ephrinA ligands (ephrin-A1 through ephrin-A6) and ephrin-B ligands (ephrin-B1 through ephrin-B3) (Eph Nomenclature Committee, 1997). Ephrin ligands all have a conserved extracellular domain with 4 invariant cysteine residues. Ephrin-A ligands are attached to the cell membrane through a GPI anchor while ephrin-B ligands have a single-pass transmembrane domain and a cytoplasmic domain and may participate in bidirectional signaling (Davy et al., 1999). EphA receptors preferentially bind ephrin-A ligands and EphB receptors preferentially bind ephrin-B ligands. However, EphA4 does interact with ephrin-B2 and ephrin-B3 ligands and EphB2 interacts with ephrin-A5 ligand (Gale et al., 1996; Himanen et al., 2004; Wilkinson, 2000).

Eph receptors and their ephrin ligands are highly conserved across a number of species that include: sponges, Drosophila, zebrafish, frog, C. elegans, marsupials, amphioxus, hagfish and lamprey (Chin-Sang et al., 1999; George et al., 1998; Suga et al., 1999; Vidovic et al., 1999; Wang et al., 1999b). Eph-ephrin signaling participates in a variety of developmental processes in the nervous system that include: migration of neural crest cells, boundary formation in the hindbrain (rhombomeres), axon guidance, formation of the corticospinal tract, formation of topographic maps, dendritic spine formation and neuroregeneration, as well as other processes (Dodelet and Pasquale, 2000; Flanagan and Vanderhaeghen, 1998; Lemke and Reber, 2005; McLaughlin and O'Leary, 2005; Wilkinson, 2001; Yamaguchi and Pasquale, 2004). Like the netrin-DCC and slit-robo signaling systems, Eph-ephrin signaling participates in axon guidance at the midline to prevent inappropriate crossing. In the corticospinal tract, midline expression of ephrin-B3 in the spinal cord confines the EphA4-positive corticospinal axons in the appropriate side of the spinal cord (Coonan et al., 2001; Dottori et al., 1998; Kullander et al., 2001). In the optic chiasm, midline glial cells express ephrin-B2 (Nakagawa et al., 2000). Temporal retinal ganglion cell axons are prevented from crossing the midline in the chiasm due to the expression of EphB1 (Nakagawa et al., 2000; Williams et al., 2003). Maintenance of these ipsilateral connections is 
necessary for binocular vision. Hippocamposeptal projections, motor axons and dorsal root ganglion projections are additional pathways that appear to require ephrin-Eph receptor signaling for proper migration (Donoghue et al., 1996; Gao et al., 1999; Gao et al., 1998; Kilpatrick et al., 1996; Zhang et al., 1996).

Eph receptor and ephrin ligands are critical for the maintenance of topographic maps throughout the central nervous system. The axonal projections of retinal ganglion cells to the optic tectum in the midbrain, retinotectal connections, are oriented in two orthogonally sets of axes. The temporal-to-nasal axis of the retina maps to the anterior-to-posterior axis in the optic tectum and the dorsal-to-ventral retinal axis maps to the lateral-to-medial optic tectum axis (reviewed in O'Leary and McLaughlin, 2005 and O'Leary and Wilkinson, 1999). The presence of anteriorposterior and dorsal-ventral gradients of ephrin and Eph receptors in the optic tectum and retina indicates that this signaling may establish the retinotopic map in the optic tectum (Braisted et al., 1997; Cheng et al., 1995; Holash and Pasquale, 1995; Kenny et al., 1995; Marcus et al., 1996). A low-to-high nasal-to-temporal graded expression of EphA receptors (4, 5 and 6 ) occurs in the retina and low-tohigh anterior-to-posterior graded expression of ephrin-A ligands (2 and 5) occurs in the optic tectum. In this system, topographic connections are established by axon repulsion. Recently, opposing gradients of ephrinAs in the retina and EphAs in the optic tectum are proposed to increase the specificity of topographic branching observed in the optic tectum (O'Leary and McLaughlin, 2005; Rashid et al., 2005). A low-to-high dorsal-to-ventral graded expression of EphB receptors occurs in the retina and a high-to-low medial-to-lateral graded expression of ephrin-B ligands occurs in the optic tectum. A counter gradient of a high-to-low dorsal-to-ventral graded expression of ephrin-B ligands occurs in the retina and a low-to-high medialto-lateral graded expression of EphB receptors occurs in the optic tectum (Hindges et al., 2002; McLaughlin et al., 2003; O'Leary and McLaughlin, 2005). As in the anterior-to-posterior axis of the optic tectum, the presence of countergradients of ephrins and Eph receptors is expected to refine the topographic representation of the retina in the medial-to-lateral axis of the optic tectum (O'Leary and McLaughlin, 2005). 
More recently, Ephrin-Eph receptor signaling has been implicated in the formation of auditory circuits (Cramer et al., 2004; Cramer et al., 2006; Cramer et al., 2002; Huffman and Cramer, 2007; Miko et al., 2008; Miko et al., 2007). In the avian auditory brainstem, the nucleus magnocellularis (NM), homologous to the mouse VCN, receives input from the cochlea and sends tonotopic projections to the dorsal dendrites of the ipsilateral nucleus laminaris $(\mathrm{NL})$, homologous to the mouse medial superior olive (MSO), and the ventral dendrites of the contralateral NL. During the growth of these projections, EphA4 is expressed in a high dorsomedial-to-low caudolateral gradient in NL that corresponds to the high frequency dorsomedial-tolower frequency caudolateral tonotopic axis of NL (Cramer et al., 2002; Cramer et al., 2000b; Person et al., 2004). EphB2, EphB5 and ephrin-B1 are also expressed in NL during the formation of this circuit (Cramer et al., 2002; Person et al., 2004). Additionally, Ephrin-B2 is expressed in NM and NL as well as their axonal projections (Cramer et al., 2002; Person et al., 2004). NM axons extend through the midline prior to EphB receptor expression (Cramer et al., 2006). Misexpression of EphA4 in the developing brainstem alters the topography of NM to NL projections bilaterally (Huffman and Cramer, 2007). EphA4, with other Eph receptors and ephrins, participates in the formation of auditory topography.

In mice, VCN axons normally project to the contralateral medial nucleus of the trapezoid body (MNTB) (this projection is discussed further below), but neonatal cochlear ablation induces the contralateral VCN axons to innervate the MNTB bilaterally (Hsieh et al., 2007; Kitzes et al., 1995; Russell and Moore, 1995). EphA4 is expressed in the VCN and MNTB (Hsieh et al., 2007). VCN axons in EphA4-null mice strictly innervated the contralateral MNTB, but cochlear ablation in this mutant strain results in increased quantities of ectopic sprouting into the ispilateral MNTB (Hsieh et al., 2007). Although EphA4 does not appear to participate in the formation of this projection, it does appear to function to restrict target selection in response to deafferentation. More recently, the tonotopic organization of the dorsal cochlear nucleus (DCN) and MNTB was analyzed in EphA4 and ephrin-B2 mutant mice (Miko et al., 2008; Miko et al., 2007). Changes, relative to wild-type, in the number of neurons responsive to acoustic stimuli and the width of the isofrequency region were 
present (Miko et al., 2007). Additionally, auditory brainstem responses had elevated thresholds and reduced peak amplitudes in these mutants indicating the presence of a hearing deficit (Miko et al., 2008). These findings support a role for EphA4 and ephrin-B2 in establishing the topographic organization of the mammalian central auditory system. Like other guidance systems, ephrin-Eph signaling participates in a variety of biological processes during development. The large number of Eph receptors and ephrin ligands allows multiple gradients to be established within neural structures. This expression facilitates the formation of complex topographically organized neural circuits. More recently, Eph receptors and ephrin ligands are observed in a variety of human cancers; a high expression level of Eph receptor or ephrin ligand correlates with tumor progression/metastasis and a poor clinical outcome for some human cancers (Surawska et al., 2004; Wimmer-Kleikamp and Lackmann, 2005).

\section{Morphogens}

Morphogens are secreted molecules that are produced in a restricted location that provide positional information through the development of a concentration gradient. All morphogens exert concentration-dependant effects on target cells and direct actions at a distance. Thus far, several protein families meet these requirements: Wingless/Wnt, Hedgehog and Decapentaplegic/Bone Morphogenic Protein/Transforming Growth Factor- $\beta$ (Dpp/BMP/TGF- $\beta$ ) families (Teleman et al., 2001). More recently, members of these families of secreted molecules were shown to additionally function as axon guidance cues (reviewed in Charron and TessierLavigne, 2005 and Charron and Tessier-Lavigne, 2007). Each of these families will be discussed below in the context of their role in axonal guidance.

\section{The hedgehog family}

There are three mammalian hedgehog family members: Sonic hedgehog (Shh), Indian hedgehog $(I h h)$ and Desert hedgehog (Dhh). Drosophila has a single hedgehog gene. Shh is secreted from the notochord and floor plate to establish a gradient within the neural tube that generates classes of ventral neurons (Ingham 
and McMahon, 2001; Jessell, 2000; Roelink et al., 1995). In mammals, Shh rather than Ihh and Dhh, appears to provide the hedgehog family member signals that are utilized for central nervous system development. Binding of Patched to a Hedgehog family member blocks Patched-mediated inhibition of Smoothened, a membranebound protein that activates downstream Shh signaling events. In the spinal cord of netrin-1- or DCC-mutant mice, most SCN axons fail to reach the floorplate, but a small population of SCN axons reaches the midline and cross appropriately (Fazeli et al., 1997; Serafini et al., 1996). A search was conducted to identify an addition attractant activity in the floor plate. Shh was found to mediate this activity, and Smoothened activation is required for Shh-mediated axon attraction (Charron et al., 2003). Retinal ganglion cell axons fail to cross the optic chiasm in Pax2-null mice due to the maintenance of an ectopic expression domain of Shh (Torres et al., 1996; Trousse et al., 2001). In addition to the guidance of projections to the floor plate (dorsoventral axis), Shh directs commissural axons on the contralateral side to project rostrally (Bourikas et al., 2005). Disruption of Shh signal resulted in axons stalling after crossing the floor plate, as well as axons oriented randomly in the rostral and caudal plane. Repulsion in the anterior-posterior axis appears to occur through Hedgehog interacting protein (Hip) and is not mediated by Smoothened or Patched receptors (Bourikas et al., 2005).

\section{The Dpp/BMP/TGF- $\beta$ family}

Dpp/BMP/TGF- $\beta$ family members are expressed in the roof plate at the dorsal midline where they specify dorsal cell fates (Lee and Jessell, 1999; Lee et al., 1998). This family of proteins signals through the dimerization of type I and II TGF- $\beta$ receptors, which are membrane-bound serine-threonine kinases. In the spinal cord of netrin-1- or DCC-mutant mice, most SCN axons initially extend ventrally before becoming disorganized (Fazeli et al., 1997; Serafini et al., 1996). A repellant may mediate the initial appropriate ventral migration. BMP6 and BMP7 were found to mimic the repellant activity, and both are expressed by the roof plate in the dorsal midline of the spinal cord (Augsburger et al., 1999). Further characterization of the dorsal repellant found that BMP7 exists as a complex with GDF7 and this 
heterodimer is necessary for roof plate repellant activity (Butler and Dodd, 2003). In C. elegans, mutation of unc-129, a TGF- $\beta$ family member, blocks the dorsally directed trajectory of pioneer motor axons along the dorsoventral axis (Colavita and Culotti, 1998; Colavita et al., 1998). However, the signaling mechanisms that mediate dorsal attractant activity in this system are not established. In the cases identified so far, Dpp/BMP/TGF- $\beta$ signaling appears to act in parallel with Shh or netrin-DCC signaling systems thereby providing a push from behind and a pull toward the developmental target.

\section{The Wingless/Wnt family}

Wnt family members are expressed in the roof plate at the dorsal midline where they specify dorsal cell fates (Lee and Jessell, 1999; Muroyama et al., 2002). $W n t$ ligands signal through canonical ( $\beta$-catenin-dependent) and non-canonical ( $\beta$ catenin-independent) pathways. In the canonical pathway, Wnt family members bind Frizzled proteins that activate Dishevelled. Active Dishevelled suppresses GSK-3ßmediated phosphorylation of $\beta$-catenin, thereby allowing $\beta$-catinin to activate lymphoid enhancer factor. In Drosophila, commissural axons cross in the anterior or posterior commissure in each body segment. Commissural axons expressing Derailed ( $D r l)$, a receptor tyrosine kinase, cross in the anterior commissure, and misexpression of $\mathrm{Drl}$ in posterior commissure neurons redirects them to the anterior commissure (Bonkowsky et al., 1999; Callahan et al., 1995). Drl is able to bind Wnt proteins at a Wnt inhibitory factor domain (Patthy, 2000). Subsequently, wnt5 was identified as the Drl ligand responsible for commissural axons to enter the anterior commissure (Yoshikawa et al., 2003). Wnt4, in addition to Shh, participates in anterior-posterior chemoattraction of commissural axons through an increasing posterior-to-anterior gradient (Lyuksyutova et al., 2003). Guidance in the anteriorposterior axis occurs through the Wnt receptor, Frizzled3. Additionally, mice lacking Frizzled3 have a complete loss of thalamocortical, corticothalamic and nigrostriatal tracts and variable loss of the corpus callosum (Lyuksyutova et al., 2003). Wnts can also function as anterior-posterior axis chemorepellants. Wnt1 and Wnt5a are expressed in a decreasing anterior-to-posterior gradient in the dorsal midline of the 
spinal cord. In the spinal cord, corticospinal tract axons are repelled down the spinal cord by a wnt-mediated repellant activity that requires Ryk, the vertebrate homologue of $\mathrm{Drl}$ (Liu et al., 2005).

\section{The auditory system}

\section{Introduction}

At the conception of this project, very little information was known concerning the molecular cues necessary for the formation of central auditory circuits. Poe and Brunso-Bechtold (1998) had first examined the importance of netrin-1 for the outgrowth of $\mathrm{CN}$ axons in collagen-gel cultures (discussed above). Additionally, Cramer et al. (2000b) found that ephrin and Eph receptors were expressed in vertebrate central auditory nuclei. However, none of these early studies defined whether a cue was necessary for the formation of auditory circuits. To identify guidance molecules required for the formation of the mammalian central auditory system, we selected the connection from the VCN to the contralateral MNTB (discussed further below) to identify factors that mediate midline attraction, midline crossing and target selection. This auditory circuit is anatomically similar to the path taken by developing SCN axons. In both cases, a dorsolaterally located cell body projects an axon ventromedially toward the floorplate. Therefore, we reasoned that cues mediating midline attraction and midline crossing of SCN axons may also participate in these events for this auditory circuit. The termination of these VCN axons in the contralateral MNTB are specifically arranged (discussed further below), thereby facilitating the identification of cues necessary for target selection to be studied in the mammalian central auditory system.

\section{Central auditory system}

\section{Cochlear nucleus}

The $\mathrm{CN}$ is the first and only central auditory nucleus to receive inputs from the cochlea (Lorente de No, 1933; Powell and Cowan, 1962; Ryugo and Parks, 2003; Sando, 1965; Webster, 1971). The coclear nucleus complex is divided into ventral and dorsal division, VCN and DCN, respectively. The DCN is anatomically separated 
from the VCN by a large number of granule cells (Brawer et al., 1974; Mugnaini et al., 1980). The DCN is a laminated structure that is composed of multiple neuronal types. Most DCN neurons that send information to higher auditory nuclei do so by axonal projections that exit the DCN and travel in the dorsal acoustic stria, stria of Monalow (reviewed in Cant and Benson, 2003; Adams and Warr, 1976; Brawer et al., 1974; Cesar Fernandez, 1967; Osen, 1969; Strominger, 1973). The VCN, the entry point for the vestibulocochlear nerve, is further anatomically divided into anterior (AVCN) and posterior (PVCN) divisions by vestibulocochlear nerve fibers extending through the VCN. The VCN contains multiple neuronal types with many of these types projecting an axon to higher auditory center via the ventral acoustic stria (VAS) and intermediate acoustic stria, stria of Held (reviewed in Cant and Benson, 2003; Brawer et al., 1974; Cant and Morest, 1979; Harrison and Irving, 1965; Kane, 1973; Osen, 1969; Tolbert et al., 1982). Octopus cells and multipolar cells that are located in the PVCN mainly project axons in the stria of Held (Harrison and Irving, 1966b; Kane, 1973; Osen, 1972; Smith and Rhode, 1989; Warr, 1972). There are three major cell types within the AVCN that contribute axons to the VAS: globular bushy cells (GBC), spherical bushy cells (SBC) and multipolar cells (Brawer et al., 1974; Brownell, 1975; Cant and Casseday, 1986; Harrison and Irving, 1966a; Harrison and Warr, 1962; Smith and Rhode, 1987; Spirou et al., 1990; Tolbert and Morest, 1982; Tolbert et al., 1982; Webster and Trune, 1982). As the axons traveling in the VAS approach the ventral midline, they become part of a structure known as the trapezoid body (TB).

The mechanical properties of the basilar membrane in the cochlea establish a place-code (cochleotopy) that is dependent on frequency (Greenwood, 1961). The frequency selective organization (tonotopy) in turn specifies the characteristic frequency which individual auditory nerve axons will be most responsive (Liberman, 1982). Spiral ganglion axons terminate within all divisions of the $\mathrm{CN}$ in a highly organized manner that maintains the cochleotopic, and thereby tonotopic, organization of input (Evans and Nelson, 1973a; Evans and Nelson, 1973b; Lorente de No, 1933; Lorente de No, 1981; Ramón y Cajal, 1909; Sando, 1965; Webster, 1971). In each division of the $\mathrm{CN}$, neurons that receive input from the apex of the 
cochlea, low-frequency region, are present in the ventrolateral region that is sensitive of low-frequency stimuli (Rose et al., 1959). Conversly, the neurons in each division of the $\mathrm{CN}$ that receive input from the base of the cochlea, high-frequency region, are present in a dorsomedial region that is sensitive to high frequency stimuli (Rose et al., 1959). Intermediate frequencies are represented in an ordered arrangement between these extremes in all divisions of the $\mathrm{CN}$.

\section{Superior olivary complex}

The integration of information from each ear first occurs in SOC neurons (Harrison and Warr, 1962; Stotler, 1953). The SOC is located in the pons and is composed of three main nuclei: the MNTB, the lateral superior olivary nucleus (LSO) and the medial superior olivary nucleus (MSO) (Irving and Harrison, 1967; Morest, 1968a; Ramón y Cajal, 1909). Additional periolivary nuclei are positioned between and surrounding the main nuclei of the SOC (Schofield and Cant, 1991; Warr, 1972). The SOC is highly conserved among mammalian species, although the relative size of SOC component nuclei varies among species and is dependent upon the audible hearing range (Glendenning and Masterton, 1998; Goldberg and Brown, 1968; Harrison and Feldman, 1970; Heffner and Heffner, 1992a; Heffner and Heffner, 1992b; Moore, 2000). The MNTB principal neurons receive input from GBCs located in the contralateral AVCN (discussed further below). MNTB neurons use the inhibitory neurotransmitter glycine and send projections to the ipsilateral LSO, MSO, periolivary cell groups and the intermediate nucleus of the lateral lemniscus (INLL) (Adams and Mugnaini, 1990; Bledsoe et al., 1990; Glendenning et al., 1981; Kuwabara and Zook, 1992; Morest, 1968a; Spangler et al., 1985; Spirou and Berrebi, 1997).

The LSO is composed of multiple neuronal types with principal neurons receiving input from SBCs in the ipsilateral AVCN and ipsilateral MNTB neurons (Cant and Casseday, 1986; Spangler et al., 1985). LSO neuron axonal projections mostly go to the inferior colliculus (IC) (Elverland, 1978; Glendenning et al., 1981; Glendenning et al., 1985; Glendenning and Masterton, 1983). The MSO is primarily composed of bipolar neurons whose lateral dendrites receive input from SBCs in the 
ipsilateral AVCN and medial dendrites receive input from SBCs in the contralateral AVCN (Perkins, 1973; Stotler, 1953). Animals that rely on lower-frequency hearing generally have a more developed MSO and the size of the MSO usually increases with head size (Irving and Harrison, 1967; Masterton et al., 1975; Moore and Moore, 1971). The majority of MSO neurons send axonal projections to the ipsilateral IC and dorsal nucleus of the lateral lemniscus (DNLL) (Adams, 1979; Glendenning et al., 1981).

These connections between the AVCN and the SOC establish neural circuits that are capable of localizing sound. On a horizontal plane (2 dimensional environment), the most simplified situation, sound can be localized by two processes that are dependent upon the frequency of sound. (1) Low-frequency sounds arrive at each ear at slightly different times thereby creating an interaural time difference (ITD) that is dependent upon the relative separation between the two ears. The preservation of these small differences in sound arrival at each ear is a requirement for sound localization (Johnson et al., 1990). Additionally, for low-frequency sounds, the phase of the sound reaching the two ears will also be separated thereby creating an interaural phase difference (IPD). Animals with larger heads or more developed low-frequency hearing localize sounds using mainly ITD and IPD cues. MSO neurons receive mostly low frequency input and are sensitive to ITD and IPD cues (Goldberg and Brown, 1968; Goldberg and Brown, 1969). This circuit is diagramed in Figure 1A. (2) High-frequency sounds will have a small or undetectable ITD and IPD; however, since the two ears are separated by a physical barrier, the head, sound reaching the proximal ear is higher in intensity than the sound reaching the distal ear. This difference creates an interaural level difference (ILD). Animals with better developed high-frequency hearing are able to utilize these cues for sound localization. LSO neurons receive high-frequency information and are sensitive to ILD cues due to the convergence of ipsilateral excitatory input and contralateral inhibitory input via the MNTB (Goldberg and Brown, 1968; Goldberg and Brown, 1969). This circuit is diagramed in Figure 1B. The duplex theory of sound localization proposes that low frequency sounds are localized by ITD and high frequency sounds are localized by ILD (Masterton and Imig, 1984; Rayleigh, 1907; Thompson, 1882). 
In practice, both of these circuits can and often will be utilized simultaneously for the localization of sounds, however, additional spectral cues and circuits are necessary to fully localize a sound in a three dimensional space. The auditory system is unique in that spatial coordinates are not located on the sensory organ, but instead arise from a series of neural computations that requires the convergence of bilateral input.

\section{Cochlear nucleus and superior olivary complex neurogenesis}

Despite the wealth of information describing the anatomy and physiology of cell types present in the $\mathrm{CN}$ and $\mathrm{SOC}$, surprisingly little information is available concerning the developmental origins of these neurons that are necessary for sound localization. Several studies have examined the birth order for these neurons with tritiated-thymidine autoradiography or bromodeoxyuridine (Altman and Bayer, 1980; Kudo et al., 1996; Kudo et al., 2000; Martin and Rickets, 1981; Pierce, 1967; Pierce, 1973). In mice, most CN neurons are born between embryonic day 10 (E10) and E14. Mouse DCN neurons are born between E10 and E14.5, with the birth of specific cell types found to be temporally distinct (Martin and Rickets, 1981). The birth of mouse VCN neurons occurs in a bimodal distribution; the majority of globular bushy cells, spherical bushy cells and multipolar cells are born on E12-13 while the majority of granule cells and small cells that reside throughout the VCN are born on E14.5 (Martin and Rickets, 1981). The birth of CN neurons appears to progress in an ordered arrangement according to cell size rather than the location within the mature nucleus (Martin and Rickets, 1981; Pierce, 1967; Pierce, 1973). In rat, DCN neuronal birth begins on E12 and continues at least through the embryonic period (E19) (Altman and Bayer, 1980). Here, the birth order of DCN neurons appears to establish a lamination pattern that resembles the cerebellum. As a result of the similar anatomical laminar structure, cell types that express identical markers, and cellular changes present in specific mouse mutations, a common embryonic origin has been proposed for cerebellar and DCN neurons (reviewed in Dunn et al., 1996; Altman and Bayer, 1978; Altman and Bayer, 1980; Berrebi et al., 1990; Berrebi and Mugnaini, 1988; Berrebi and Mugnaini, 1991; Berrebi and Mugnaini, 1993; Ivanova and Yuasa, 1998; Mugnaini et al., 1987; Oertel and Young, 2004). The birth of rat 
VCN neurons ranges from E13 through E17, however, the majority of cells are born on E15 (Altman and Bayer, 1980).

The timing of SOC neurogenesis has also been examined in the mouse and rat (Altman and Bayer, 1980; Kudo et al., 1996; Kudo et al., 2000; Pierce, 1973). Mouse SOC neurons are born between E9 and E14 (Pierce, 1973). The birth order appears to begin with MSO neurons and then progress from MNTB neurons to LSO neurons (Pierce, 1973). The birth order of rat SOC neurons appears to follow a similar progression with MSO neurons (peak E13) preceding the birth of MNTB neurons (peak E15) and LSO neurons (peak E16) (Altman and Bayer, 1980; Kudo et al., 1996; Kudo et al., 2000). The development of the MNTB has been further characterized through the application of the rapid golgi technique in developing brains (Morest, 1968b). Using this technique, contact of a GBC axon with an MNTB neuron appears to initiate a dorsal migration that is required for MNTB neurons to reach their adult location, although this model remains to be experimentally validated (Morest, 1968b). However, none of these studies addresses the birth location of CN or SOC neurons or migratory routes that allow these neurons to reach their adult location. Additionally, the molecular cues that mediate these neuronal migrations are not yet established.

In the chick, Cramer et al. (2000a) injected the lipophilic dye, Dil, into chick rhombomeres $(R)$ to determine the origin of the neurons that populate auditory nuclei. These investigators found that nucleus magnocellularis (NM), homologous to the mammalian AVCN, neurons arise from R5-7 and nucleus laminaris (NL), homologous to the mammalian MSO, neurons arise from R5-6. Although R5 contributes to both nuclei, precursors for these nuclei reside in distinct regions of R5 suggesting that the precursors to NM and NL are specified within the rhombic lip (Cramer et al., 2000a). Fate-mapping studies like this are relatively straight-forward in chick, but the physical marking of cells by direct injection of tracer is not a feasible approach for studying intrauterine mammalian development. An initial fate-mapping study using site-specific recombination found that the IC derives from the midbrainhindbrain border (Zinyk et al., 1998). To date, the most comprehensive fate map for the mouse $\mathrm{CN}$ used an intersectional lineage analysis to examine contribution from 
the Wnt1-positive region of the rhombic lip from R2 plus R3 and R5 (Farago et al., 2006). These investigators determined that $A V C N$ neurons arise from R2-3, PVCN neurons arise mostly from R4 (although this was presumed due to the lack of an R4 lineage label) with contributions from R3 and R5. The DCN neurons arise mostly from R5 (Farago et al., 2006). This indicates these neurons do not share a common

origin with the cerebellum as has been previously proposed (R1 derived, discussed above). Nichols and Bruce (2006) used a similar approach to find that the cochlear nuclei arise from the Wnt-1-positive rhombic lip of R2-6. More specifically, R2-3 contributes to the AVCN and R4-6 contributes to the PVCN and DCN (Nichols and Bruce, 2006). Both studies arrived at similar conclusions about the developmental origins of the cochlear nucleus, although contributions to the PVCN and DCN are more extensive in Nichols and Bruce (2006) than determined in Farago et al. (2006). However, neither study makes reference to the developmental origin of the SOC nuclei. Two explanations may explain this result. (1) SOC neurons are derived from these rhombomeres, but not within the Wnt-1-positive rhombic lip. This is supported by the homologous structures in chick NM and NL arising from distinct regions of R5 (Cramer et al., 2000a). (2) SOC neurons are derived from R1 which was not examined in these studies. Additionally, these explanations need not be mutually exclusive due to the number of nuclei that comprise the SOC.

\section{Development of cochlear nucleus axons}

The anatomy of adult auditory pathways has been extensively analyzed, however, the development of these circuits are relatively unexplored. Kandler and Friauf, (1993) provide a detailed description of VCN axon development with carbocyanine dye and biocytin tracers in the rat. At E15, a limited number of axons extend from the VCN in the VAS, and the majority of these axons terminate in growth cones in the ipsilateral brainstem, although a few axons have entered the contralateral brainstem by this age (Kandler and Friauf, 1993). Niblock et al. (1995) examined this projection at E13 in rat and found that VCN axons are present in the VAS possibly before the neurons have left the ventricular zone. Additionally, some axons have already entered the contralateral brainstem at E13 (Niblock et al., 1995). 
Kandler and Friauf (1993) divide the development of cochlear nucleus axons into three periods: (1) axon outgrowth (E15-E17), (2) collateral branching (E18-P5) and (3) maturation of terminal structures (P5-P14). We have examined these pathways in mice with similar results. We found that VCN neurons extend an axon in the VAS, as early as E13 (Chapter 2: Howell et al., 2007). In mice, labeled VCN axons make a rostral turn to travel in the lateral lemniscus as early as E13.5 and reach the IC by E16.5 (Chapter 2: Howell et al., 2007). Mouse and rat VCN axons develop structurally at similar rates. Functional synaptic connections are present on MNTB neurons as early as $\mathrm{P} 1$ and rapidly progress to form young calyces over the next three days (Hoffpauir et al., 2006). Afferent projections into the SOC from the VCN are established during embryogenesis and early postnatal periods, well before the onset of hearing at P8 (Chapter 2: Howell et al., 2007; Kandler and Friauf, 1993; Niblock et al., 1995). Identification of the molecules necessary for development of these circuits is a goal of auditory developmental neuroscience. The same guidance molecules necessary for the formation of other central nervous system pathways are appropriate candidate molecules to mediate the formation of auditory circuits.

\section{The calyceal system}

The calyx of Held is the axon terminal complex of a GBC axon onto an MNTB neuron (Held, 1893; Ramón y Cajal, 1909). To establish this circuit, GBCs that reside in the AVCN project an axon ventromedially in the VAS through or around the ipsilateral SOC, including the ipsilateral MNTB, before crossing the midline in the TB. On the contralateral side, each GBC axon innervates one, or rarely two, MNTB neurons via specialized synaptic contacts known as the calyx of Held (Held, 1893; Kuwabara et al., 1991; Morest, 1968b; Ramón y Cajal, 1909; Smith et al., 1991; Spirou et al., 1990). The large diameter calyceal axon, one of the largest in the CNS, rapidly transmits auditory information to the MNTB. The massive number of synaptic terminals in each calyx, probably the largest synaptic terminal complex in the CNS, has been proposed to relay auditory impulses with little loss of intensity or temporal resolution (Morest, 1968a). However, recent results indicate this may not be entirely accurate due to other inhibitory inputs to MNTB neurons (Guinan and Li, 1990). The calyceal projection is an important component for the localization of high-frequency 
sounds (discussed above and figure 1B). The inhibitory projection to the LSO from the contralateral AVCN via the MNTB is important for preserving ILDs necessary to localize high-frequency sounds (Boudreau and Tsuchitani, 1968; Tollin and Yin, 2002a; Tollin and Yin, 2002b; Tsuchitani, 1988a; Tsuchitani, 1988b). Like most other auditory circuits, the calyceal projection preserves the tonotopic organization of information from the AVCN to contralateral MNTB (Rose et al., 1959; Sommer et al., 1993). GBCs in the dorsal region of the AVCN, which receive high-frequency input from the cochlea, relay this information to the medial region of the contralateral MNTB. Similarly, GBCs in the ventral region of the AVCN, which receive lowfrequency input from the cochlea, relay this information to the lateral region of the contralateral MNTB. Therefore, neurons in the medial region of the MNTB are responsive to high-frequency sounds with neurons responsive to lower characteristic frequencies occurring in a decreasing lateral gradient (Guinan Jr et al., 1972; Sommer et al., 1993). Additionally, the topography of MNTB axonal projections maintains the established tonotopic organization of information that is sent to the LSO. The anatomy and accessibility of the developing calyceal circuit makes this projection an ideal target to characterize the role of guidance molecules necessary for the completion of key steps in the calyceal projection. These events include: midline attraction, midline crossing, axonal branching, growth cone turning and target innervation. The identification and characterization of signaling molecules necessary for GBC development may lead to a better understanding of how other auditory circuits develop. Furthermore, these results may generalize to other central nervous system pathways that could lead to novel therapeutic approaches for central nervous system injuries and diseases. 
Figures
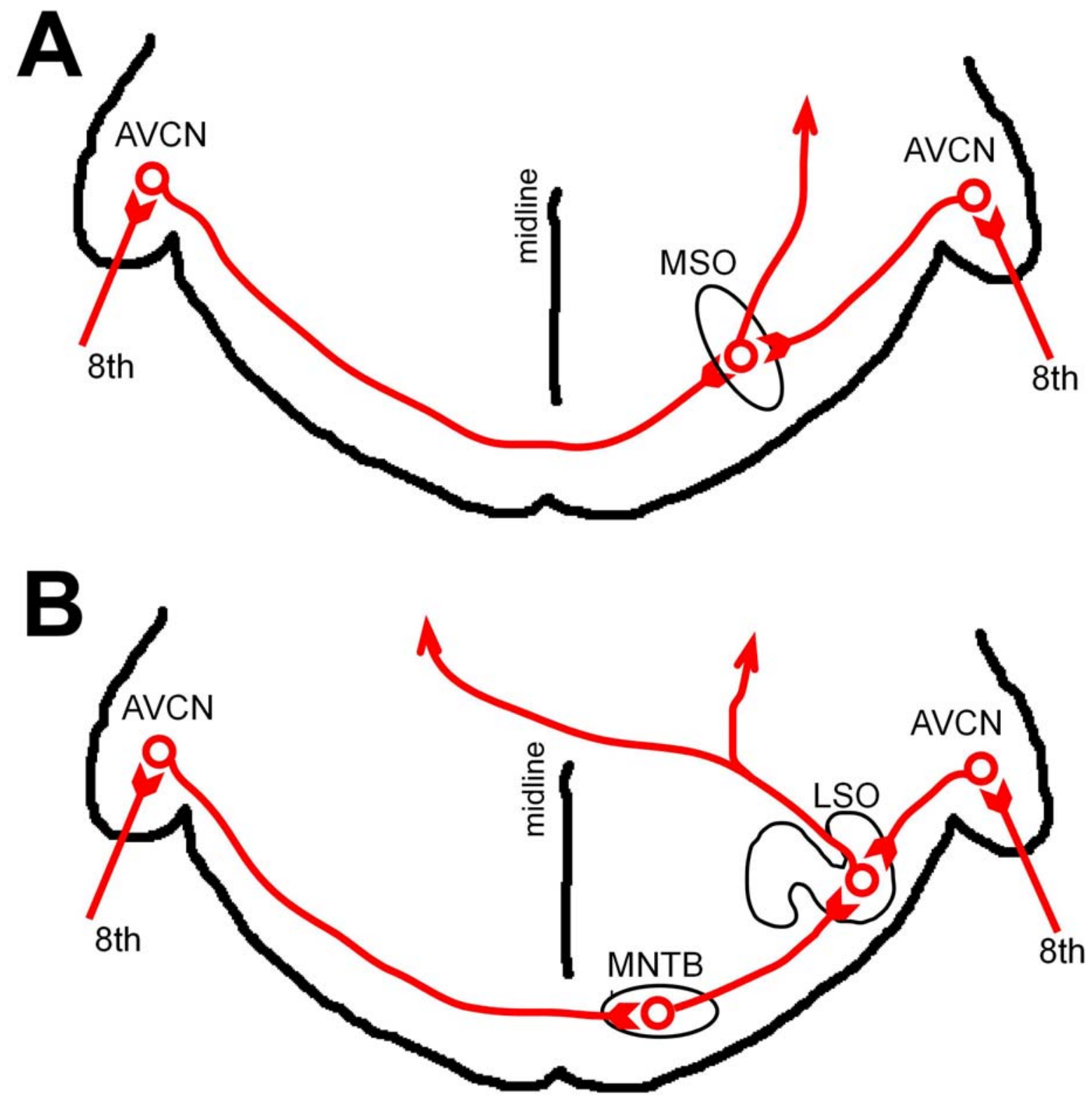

Figure 1. Schematic diagram of auditory circuits that encode ITD and ILD for the localization of sound. (A) Localization of low-frequency sounds through the use of interaural time differences (ITDs). Only one set of circuits is diagramed for simpliciity. Vestibulocochlear (8th) nerve fibers from the cochlea contact SBCs in the AVCN bilaterally. The MSO is made up of neurons which receive input from the lowfrequency fibers of the left and right $\mathrm{AVCN}$. The ipsilateral SBC axons (right side) 
project to the lateral dendrites of ipsilateral MSO neurons while contralateral SBC axons (left side) project to the medial dendrites of MSO neurons. MSO neurons send axonal projections to the ipsilateral inferior colliculus and dorsal nucleus of the lateral lemniscus (arrow). The neurons in the MSO are sensitive to the difference in the arrival time of sound at each ear, and are thereby sensitive to ITD localization cues. (B) Localization of high-frequency sounds through the use of interaural level differences (ILDs). Only one set of circuits is diagramed for simpliciity. 8th nerve fibers from the cochlea contact SBCs in the ipsilateral AVCN (right side), which project an axon to the ipsilateral LSO (right side). In the contralateral AVCN (left side), 8th nerve fibers contact GBCs, which project an axon to the MNTB. The ipsilateral LSO receives inhibitory input from the MNTB. LSO neuron axonal projections mostly go to the inferior colliculus bilaterally (arrows). LSO neurons receive high-frequency information and sensitivity to ILD cues is achieved by the convergence of ipsilateral excitatory input and contralateral inhibitory input via the MNTB. 


\section{Literature Cited}

Abu-Amero, K. K., al Dhalaan, H., al Zayed, Z., Hellani, A., and Bosley, T. M. (2009). Five new consanguineous families with horizontal gaze palsy and progressive scoliosis and novel ROBO3 mutations. J Neurol Sci 276, 22-26.

Ackerman, S. L., Kozak, L. P., Przyborski, S. A., Rund, L. A., Boyer, B. B., and Knowles, B. B. (1997). The mouse rostral cerebellar malformation gene encodes an UNC-5-like protein. Nature 386, 838-842.

Adams, J. C. (1979). Ascending projections to the inferior colliculus. J Comp Neurol 183, 519-538.

Adams, J. C., and Mugnaini, E. (1990). Immunocytochemical evidence for inhibitory and disinhibitory circuits in the superior olive. Hear Res 49, 281-298.

Adams, J. C., and Warr, W. B. (1976). Origins of axons in the cat's acoustic striae determined by injection of horseradish peroxidase into severed tracts. J Comp Neurol 170, 107-121.

Alcantara, S., Ruiz, M., De Castro, F., Soriano, E., and Sotelo, C. (2000). Netrin 1 acts as an attractive or as a repulsive cue for distinct migrating neurons during the development of the cerebellar system. Development 127, 1359-1372.

Altman, J., and Bayer, S. A. (1978). Prenatal development of the cerebellar system in the rat. I. Cytogenesis and histogenesis of the deep nuclei and the cortex of the cerebellum. J Comp Neurol 179, 23-48.

Altman, J., and Bayer, S. A. (1980). Development of the brain stem in the rat. III. Thymidine-radiographic study of the time of origin of neurons of the vestibular and auditory nuclei of the upper medulla. J Comp Neurol 194, 877-904.

Amoiridis, G., Tzagournissakis, M., Christodoulou, P., Karampekios, S., Latsoudis, H., Panou, T., Simos, P., and Plaitakis, A. (2006). Patients with horizontal gaze palsy and progressive scoliosis due to $\mathrm{ROBO} 3 \mathrm{E} 319 \mathrm{~K}$ mutation have both uncrossed and crossed central nervous system pathways and perform normally on neuropsychological testing. J Neurol Neurosurg Psychiatry 77, 1047-1053.

Augsburger, A., Schuchardt, A., Hoskins, S., Dodd, J., and Butler, S. (1999). BMPs as mediators of roof plate repulsion of commissural neurons. Neuron 24, 127-141.

Bagri, A., Marin, O., Plump, A. S., Mak, J., Pleasure, S. J., Rubenstein, J. L., and Tessier-Lavigne, M. (2002). Slit proteins prevent midline crossing and determine the dorsoventral position of major axonal pathways in the mammalian forebrain. Neuron $33,233-248$.

Barallobre, M. J., Del Rio, J. A., Alcantara, S., Borrell, V., Aguado, F., Ruiz, M., Carmona, M. A., Martin, M., Fabre, M., Yuste, R., et al. (2000). Aberrant 
development of hippocampal circuits and altered neural activity in netrin 1-deficient mice. Development 127, 4797-4810.

Bedell, V. M., Yeo, S. Y., Park, K. W., Chung, J., Seth, P., Shivalingappa, V., Zhao, J., Obara, T., Sukhatme, V. P., Drummond, I. A., et al. (2005). roundabout4 is essential for angiogenesis in vivo. Proc Natl Acad Sci U S A 102, 6373-6378.

Berrebi, A. S., Morgan, J. I., and Mugnaini, E. (1990). The Purkinje cell class may extend beyond the cerebellum. J Neurocytol 19, 643-654.

Berrebi, A. S., and Mugnaini, E. (1988). Effects of the murine mutation 'nervous' on neurons in cerebellum and dorsal cochlear nucleus. J Neurocytol 17, 465-484.

Berrebi, A. S., and Mugnaini, E. (1991). Distribution and targets of the cartwheel cell axon in the dorsal cochlear nucleus of the guinea pig. Anat Embryol (Berl) 183, 427454.

Berrebi, A. S., and Mugnaini, E. (1993). Alterations in the dorsal cochlear nucleus of cerebellar mutant mice. In The Mammalian Cochlar Nuclei: Organization and Function, M.A. Merchán, et al. eds. (New York, Plenum Press), pp. 107-119.

Bledsoe, S. C., Jr., Snead, C. R., Helfert, R. H., Prasad, V., Wenthold, R. J., and Altschuler, R. A. (1990). Immunocytochemical and lesion studies support the hypothesis that the projection from the medial nucleus of the trapezoid body to the lateral superior olive is glycinergic. Brain Res 517, 189-194.

Bloch-Gallego, E., Ezan, F., Tessier-Lavigne, M., and Sotelo, C. (1999). Floor plate and netrin-1 are involved in the migration and survival of inferior olivary neurons. $J$ Neurosci 19, 4407-4420.

Bonkowsky, J. L., Yoshikawa, S., O'Keefe, D. D., Scully, A. L., and Thomas, J. B. (1999). Axon routing across the midline controlled by the Drosophila Derailed receptor. Nature 402, 540-544.

Boudreau, J. C., and Tsuchitani, C. (1968). Binaural interaction in the cat superior olive S segment. J Neurophysiol 31, 442-454.

Bourikas, D., Pekarik, V., Baeriswyl, T., Grunditz, A., Sadhu, R., Nardo, M., and Stoeckli, E. T. (2005). Sonic hedgehog guides commissural axons along the longitudinal axis of the spinal cord. Nat Neurosci 8, 297-304.

Braisted, J. E., Catalano, S. M., Stimac, R., Kennedy, T. E., Tessier-Lavigne, M., Shatz, C. J., and O'Leary, D. D. (2000). Netrin-1 promotes thalamic axon growth and is required for proper development of the thalamocortical projection. J Neurosci 20 , $5792-5801$. 
Braisted, J. E., McLaughlin, T., Wang, H. U., Friedman, G. C., Anderson, D. J., and O'Leary D, D. (1997). Graded and lamina-specific distributions of ligands of EphB receptor tyrosine kinases in the developing retinotectal system. Dev Biol 191, 14-28.

Brawer, J. R., Morest, D. K., and Kane, E. C. (1974). The neuronal architecture of the cochlear nucleus of the cat. J Comp Neurol 155, 251-300.

Brose, K., Bland, K. S., Wang, K. H., Arnott, D., Henzel, W., Goodman, C. S., Tessier-Lavigne, M., and Kidd, T. (1999). Slit proteins bind Robo receptors and have an evolutionarily conserved role in repulsive axon guidance. Cell 96, 795-806.

Brownell, W. E. (1975). Organization of the cat trapezoid body and the discharge characteristics of its fibers. Brain Res 94, 413-433.

Butler, S. J., and Dodd, J. (2003). A role for BMP heterodimers in roof platemediated repulsion of commissural axons. Neuron 38, 389-401.

Callahan, C. A., Muralidhar, M. G., Lundgren, S. E., Scully, A. L., and Thomas, J. B. (1995). Control of neuronal pathway selection by a Drosophila receptor proteintyrosine kinase family member. Nature 376, 171-174.

Cant, N. B., and Benson, C. G. (2003). Parallel auditory pathways: projection patterns of the different neuronal populations in the dorsal and ventral cochlear nuclei. Brain Res Bull 60, 457-474.

Cant, N. B., and Casseday, J. H. (1986). Projections from the anteroventral cochlear nucleus to the lateral and medial superior olivary nuclei. J Comp Neurol 247, 457476.

Cant, N. B., and Morest, D. K. (1979). Organization of the neurons in the anterior division of the anteroventral cochlear nucleus of the cat. Light-microscopic observations. Neuroscience 4, 1909-1923.

Cebria, F., and Newmark, P. A. (2005). Planarian homologs of netrin and netrin receptor are required for proper regeneration of the central nervous system and the maintenance of nervous system architecture. Development 132, 3691-3703.

Cesar Fernandez, F. K. (1967). The course and termination of the striae of Monakow and held in the cat. The Journal of Comparative Neurology 131, 371-385.

Chan, S. S., Zheng, H., Su, M. W., Wilk, R., Killeen, M. T., Hedgecock, E. M., and Culotti, J. G. (1996). UNC-40, a C. elegans homolog of DCC (Deleted in Colorectal Cancer), is required in motile cells responding to UNC-6 netrin cues. Cell 87, 187195.

Chan, W. M., Traboulsi, E. I., Arthur, B., Friedman, N., Andrews, C., and Engle, E. C. (2006). Horizontal gaze palsy with progressive scoliosis can result from compound heterozygous mutations in ROBO3. J Med Genet 43, e11. 
Charron, F., Stein, E., Jeong, J., McMahon, A. P., and Tessier-Lavigne, M. (2003). The morphogen sonic hedgehog is an axonal chemoattractant that collaborates with netrin-1 in midline axon guidance. Cell 113, 11-23.

Charron, F., and Tessier-Lavigne, M. (2005). Novel brain wiring functions for classical morphogens: a role as graded positional cues in axon guidance. Development 132, 2251-2262.

Charron, F., and Tessier-Lavigne, M. (2007). The Hedgehog, TGF-beta/BMP and Wnt families of morphogens in axon guidance. Adv Exp Med Biol 621, 116-133.

Chedotal, A., Kerjan, G., and Moreau-Fauvarque, C. (2005). The brain within the tumor: new roles for axon guidance molecules in cancers. Cell Death Differ 12, 1044-1056.

Chen, Z., Gore, B. B., Long, H., Ma, L., and Tessier-Lavigne, M. (2008). Alternative splicing of the Robo3 axon guidance receptor governs the midline switch from attraction to repulsion. Neuron 58, 325-332.

Cheng, H. J., Nakamoto, M., Bergemann, A. D., and Flanagan, J. G. (1995). Complementary gradients in expression and binding of ELF-1 and Mek4 in development of the topographic retinotectal projection map. Cell 82, 371-381.

Chin-Sang, I. D., George, S. E., Ding, M., Moseley, S. L., Lynch, A. S., and Chisholm, A. D. (1999). The ephrin VAB-2/EFN-1 functions in neuronal signaling to regulate epidermal morphogenesis in C. elegans. Cell 99, 781-790.

Colavita, A., and Culotti, J. G. (1998). Suppressors of ectopic UNC-5 growth cone steering identify eight genes involved in axon guidance in Caenorhabditis elegans. Dev Biol 194, 72-85.

Colavita, A., Krishna, S., Zheng, H., Padgett, R. W., and Culotti, J. G. (1998).

Pioneer axon guidance by UNC-129, a C. elegans TGF-beta. Science 281, 706-709.

Cole, S. J., Bradford, D., and Cooper, H. M. (2007). Neogenin: A multi-functional receptor regulating diverse developmental processes. Int J Biochem Cell Biol 39, $1569-1575$.

Coonan, J. R., Greferath, U., Messenger, J., Hartley, L., Murphy, M., Boyd, A. W., Dottori, M., Galea, M. P., and Bartlett, P. F. (2001). Development and reorganization of corticospinal projections in EphA4 deficient mice. J Comp Neurol 436, 248-262.

Cramer, K. S., Bermingham-McDonogh, O., Krull, C. E., and Rubel, E. W. (2004). EphA4 signaling promotes axon segregation in the developing auditory system. Dev Biol 269, 26-35.

Cramer, K. S., Cerretti, D. P., and Siddiqui, S. A. (2006). EphB2 regulates axonal growth at the midline in the developing auditory brainstem. Dev Biol 295, 76-89. 
Cramer, K. S., Fraser, S. E., and Rubel, E. W. (2000a). Embryonic origins of auditory brain-stem nuclei in the chick hindbrain. Dev Biol 224, 138-151.

Cramer, K. S., Karam, S. D., Bothwell, M., Cerretti, D. P., Pasquale, E. B., and Rubel, E. W. (2002). Expression of EphB receptors and EphrinB ligands in the developing chick auditory brainstem. J Comp Neurol 452, 51-64.

Cramer, K. S., Rosenberger, M. H., Frost, D. M., Cochran, S. L., Pasquale, E. B., and Rubel, E. W. (2000b). Developmental regulation of EphA4 expression in the chick auditory brainstem. J Comp Neurol 426, 270-278.

Davy, A., Gale, N. W., Murray, E. W., Klinghoffer, R. A., Soriano, P., Feuerstein, C., and Robbins, S. M. (1999). Compartmentalized signaling by GPI-anchored ephrinA5 requires the Fyn tyrosine kinase to regulate cellular adhesion. Genes Dev 13, 3125-3135.

De Vries, M., and Cooper, H. M. (2008). Emerging roles for neogenin and its ligands in CNS development. J Neurochem 106, 1483-1492.

Deiner, M. S., Kennedy, T. E., Fazeli, A., Serafini, T., Tessier-Lavigne, M., and Sretavan, D. W. (1997). Netrin-1 and DCC mediate axon guidance locally at the optic disc: loss of function leads to optic nerve hypoplasia. Neuron 19, 575-589.

Deiner, M. S., and Sretavan, D. W. (1999). Altered midline axon pathways and ectopic neurons in the developing hypothalamus of netrin-1- and DCC-deficient mice. J Neurosci 19, 9900-9912.

Di Meglio, T., Nguyen-Ba-Charvet, K. T., Tessier-Lavigne, M., Sotelo, C., and Chedotal, A. (2008). Molecular mechanisms controlling midline crossing by precerebellar neurons. J Neurosci 28, 6285-6294.

Dillon, A. K., Fujita, S. C., Matise, M. P., Jarjour, A. A., Kennedy, T. E., Kollmus, H., Arnold, H. H., Weiner, J. A., Sanes, J. R., and Kaprielian, Z. (2005). Molecular control of spinal accessory motor neuron/axon development in the mouse spinal cord. J Neurosci 25, 10119-10130.

Dodelet, V. C., and Pasquale, E. B. (2000). Eph receptors and ephrin ligands: embryogenesis to tumorigenesis. Oncogene 19, 5614-5619.

Donoghue, M. J., Lewis, R. M., Merlie, J. P., and Sanes, J. R. (1996). The Eph kinase ligand AL-1 is expressed by rostral muscles and inhibits outgrowth from caudal neurons. Mol Cell Neurosci 8, 185-198.

Dorsten, J. N., and VanBerkum, M. F. (2008). Frazzled cytoplasmic P-motifs are differentially required for axon pathway formation in the Drosophila embryonic CNS. Int J Dev Neurosci 26, 753-761. 
Dottori, M., Hartley, L., Galea, M., Paxinos, G., Polizzotto, M., Kilpatrick, T., Bartlett, P. F., Murphy, M., Kontgen, F., and Boyd, A. W. (1998). EphA4 (Sek1) receptor tyrosine kinase is required for the development of the corticospinal tract. Proc Natl Acad Sci U S A 95, 13248-13253.

Dunn, M. E., Vetter, D. E., Berrebi, A. S., Krider, H. M., and Mugnaini, E. (1996). The mossy fiber-granule cell-cartwheel cell system in the mammalian cochlear nuclear ccomplex. In Advances in Speech, Hearing, and Language Processing. Vol. 3 (JAl Press), pp. 63-87.

Elverland, H. H. (1978). Ascending and intrinsic projections of the superior olivary complex in the cat. Exp Brain Res 32, 117-134.

Engelkamp, D. (2002). Cloning of three mouse Unc5 genes and their expression patterns at mid-gestation. Mech Dev 118, 191-197.

Eph Nomenclature Committee. (1997). Unified nomenclature for Eph family receptors and their ligands, the ephrins. Cell 90, 403-404.

Erskine, L., Williams, S. E., Brose, K., Kidd, T., Rachel, R. A., Goodman, C. S., Tessier-Lavigne, M., and Mason, C. A. (2000). Retinal ganglion cell axon guidance in the mouse optic chiasm: expression and function of robos and slits. J Neurosci 20, 4975-4982.

Evans, E. F., and Nelson, P. G. (1973a). On the functional relationship between the dorsal and ventral divisions of the cochlear nucleus of the cat. Exp Brain Res 17, 428-442.

Evans, E. F., and Nelson, P. G. (1973b). The responses of single neurones in the cochlear nucleus of the cat as a function of their location and the anaesthetic state. Exp Brain Res 17, 402-427.

Farago, A. F., Awatramani, R. B., and Dymecki, S. M. (2006). Assembly of the brainstem cochlear nuclear complex is revealed by intersectional and subtractive genetic fate maps. Neuron 50, 205-218.

Fazeli, A., Dickinson, S. L., Hermiston, M. L., Tighe, R. V., Steen, R. G., Small, C. G., Stoeckli, E. T., Keino-Masu, K., Masu, M., Rayburn, H., et al. (1997). Phenotype of mice lacking functional Deleted in colorectal cancer (Dcc) gene. Nature 386, 796804.

Finger, J. H., Bronson, R. T., Harris, B., Johnson, K., Przyborski, S. A., and Ackerman, S. L. (2002). The netrin 1 receptors Unc5h3 and Dcc are necessary at multiple choice points for the guidance of corticospinal tract axons. J Neurosci 22, 10346-10356.

Flanagan, J. G., and Vanderhaeghen, P. (1998). The ephrins and Eph receptors in neural development. Annu Rev Neurosci 21, 309-345. 
Gale, N. W., Holland, S. J., Valenzuela, D. M., Flenniken, A., Pan, L., Ryan, T. E., Henkemeyer, M., Strebhardt, K., Hirai, H., Wilkinson, D. G., et al. (1996). Eph receptors and ligands comprise two major specificity subclasses and are reciprocally compartmentalized during embryogenesis. Neuron 17, 9-19.

Gan, W. B., Wong, V. Y., Phillips, A., Ma, C., Gershon, T. R., and Macagno, E. R. (1999). Cellular expression of a leech netrin suggests roles in the formation of longitudinal nerve tracts and in regional innervation of peripheral targets. J Neurobiol 40, 103-115.

Gao, P. P., Yue, Y., Cerretti, D. P., Dreyfus, C., and Zhou, R. (1999). Ephrindependent growth and pruning of hippocampal axons. Proc Natl Acad Sci U S A 96, 4073-4077.

Gao, W. Q., Shinsky, N., Armanini, M. P., Moran, P., Zheng, J. L., MendozaRamirez, J. L., Phillips, H. S., Winslow, J. W., and Caras, I. W. (1998). Regulation of hippocampal synaptic plasticity by the tyrosine kinase receptor, REK7/EphA5, and its ligand, AL-1/Ephrin-A5. Mol Cell Neurosci 11, 247-259.

George, S. E., Simokat, K., Hardin, J., and Chisholm, A. D. (1998). The VAB-1 Eph receptor tyrosine kinase functions in neural and epithelial morphogenesis in $\mathrm{C}$. elegans. Cell 92, 633-643.

Georgiou, M., and Tear, G. (2002). Commissureless is required both in commissural neurones and midline cells for axon guidance across the midline. Development 129, 2947-2956.

Georgiou, M., and Tear, G. (2003). The N-terminal and transmembrane domains of Commissureless are necessary for its function and trafficking within neurons. Mech Dev 120, 1009-1019.

Glendenning, K. K., Brunso-Bechtold, J. K., Thompson, G. C., and Masterton, R. B. (1981). Ascending auditory afferents to the nuclei of the lateral lemniscus. J Comp Neurol 197, 673-703.

Glendenning, K. K., Hutson, K. A., Nudo, R. J., and Masterton, R. B. (1985). Acoustic chiasm II: Anatomical basis of binaurality in lateral superior olive of cat. J Comp Neurol 232, 261-285.

Glendenning, K. K., and Masterton, R. B. (1983). Acoustic chiasm: efferent projections of the lateral superior olive. J Neurosci 3, 1521-1537.

Glendenning, K. K., and Masterton, R. B. (1998). Comparative morphometry of mammalian central auditory systems: variation in nuclei and form of the ascending system. Brain Behav Evol 51, 59-89. 
Goldberg, J. M., and Brown, P. B. (1968). Functional organization of the dog superior olivary complex: an anatomical and electrophysiological study. $\mathrm{J}$ Neurophysiol 31, 639-656.

Goldberg, J. M., and Brown, P. B. (1969). Response of binaural neurons of dog superior olivary complex to dichotic tonal stimuli: some physiological mechanisms of sound localization. J Neurophysiol 32, 613-636.

Greenwood, D. D. (1961). Critical Bandwidth and the Frequency Coordinates of the Basilar Membrane. The Journal of the Acoustical Society of America 33, 1344-1356.

Guijarro, P., Simo, S., Pascual, M., Abasolo, I., Del Rio, J. A., and Soriano, E. (2006). Netrin1 exerts a chemorepulsive effect on migrating cerebellar interneurons in a Dcc-independent way. Mol Cell Neurosci 33, 389-400.

Guinan, J. J., Jr., and Li, R. Y. (1990). Signal processing in brainstem auditory neurons which receive giant endings (calyces of Held) in the medial nucleus of the trapezoid body of the cat. Hear Res 49, 321-334.

Guinan Jr, J., Norris, B., and Guinan, S. (1972). Single auditory units in the superior olivary complex. II: Location of unit categories and tonotopic organization. Int $\mathrm{J}$ Neurosci 4, 147-166.

Hamelin, M., Zhou, Y., Su, M. W., Scott, I. M., and Culotti, J. G. (1993). Expression of the UNC-5 guidance receptor in the touch neurons of $\mathrm{C}$. elegans steers their axons dorsally. Nature 364, 327-330.

Hao, J. C., Yu, T. W., Fujisawa, K., Culotti, J. G., Gengyo-Ando, K., Mitani, S., Moulder, G., Barstead, R., Tessier-Lavigne, M., and Bargmann, C. I. (2001). C. elegans slit acts in midline, dorsal-ventral, and anterior-posterior guidance via the SAX-3/Robo receptor. Neuron 32, 25-38.

Harris, R., Sabatelli, L. M., and Seeger, M. A. (1996). Guidance cues at the Drosophila CNS midline: identification and characterization of two Drosophila Netrin/UNC-6 homologs. Neuron 17, 217-228.

Harrison, J. M., and Feldman, M. L. (1970). Anatomical aspects of the cochlear nucleus and superior olivary complex. Contrib Sens Physiol 4, 95-142.

Harrison, J. M., and Irving, R. (1965). The Anterior Ventral Cochlear Nucleus. J Comp Neurol 124, 15-41.

Harrison, J. M., and Irving, R. (1966a). Ascending connections of the anterior ventral cochlear nucleus in the rat. J Comp Neurol 126, 51-63.

Harrison, J. M., and Irving, R. (1966b). The organization of the posterior ventral cochlear nucleus in the rat. J Comp Neurol 126, 391-401. 
Harrison, J. M., and Warr, W. B. (1962). A study of the cochlear nuclei and ascending auditory pathways of the medulla. J Comp Neurol 119, 341-379.

Hedgecock, E. M., Culotti, J. G., and Hall, D. H. (1990). The unc-5, unc-6, and unc40 genes guide circumferential migrations of pioneer axons and mesodermal cells on the epidermis in C. elegans. Neuron 4, 61-85.

Heffner, R. S., and Heffner, H. E. (1992a). Hearing and sound localization in blind mole rats (Spalax ehrenbergi). Hear Res 62, 206-216.

Heffner, R. S., and Heffner, H. E. (1992b). Hearing in large mammals: soundlocalization acuity in cattle (Bos taurus) and goats (Capra hircus). J Comp Psychol 106, 107-113.

Held, H. (1893). Die centrale Gehörleitung. Arch Physiol Anat 17, 201-248.

Himanen, J. P., Chumley, M. J., Lackmann, M., Li, C., Barton, W. A., Jeffrey, P. D., Vearing, C., Geleick, D., Feldheim, D. A., Boyd, A. W., et al. (2004). Repelling class discrimination: ephrin-A5 binds to and activates EphB2 receptor signaling. Nat Neurosci 7, 501-509.

Hindges, R., McLaughlin, T., Genoud, N., Henkemeyer, M., and O'Leary, D. D. (2002). EphB forward signaling controls directional branch extension and arborization required for dorsal-ventral retinotopic mapping. Neuron 35, 475-487.

Hoffpauir, B. K., Grimes, J. L., Mathers, P. H., and Spirou, G. A. (2006). Synaptogenesis of the calyx of Held: rapid onset of function and one-to-one morphological innervation. J Neurosci 26, 5511-5523.

Holash, J. A., and Pasquale, E. B. (1995). Polarized expression of the receptor protein tyrosine kinase Cek5 in the developing avian visual system. Dev Biol 172, 683-693.

Holmes, G., and Niswander, L. (2001). Expression of slit-2 and slit-3 during chick development. Dev Dyn 222, 301-307.

Holmes, G. P., Negus, K., Burridge, L., Raman, S., Algar, E., Yamada, T., and Little, M. H. (1998). Distinct but overlapping expression patterns of two vertebrate slit homologs implies functional roles in CNS development and organogenesis. Mech Dev 79, 57-72.

Hong, K., Hinck, L., Nishiyama, M., Poo, M. M., Tessier-Lavigne, M., and Stein, E. (1999). A ligand-gated association between cytoplasmic domains of UNC5 and DCC family receptors converts netrin-induced growth cone attraction to repulsion. Cell 97, 927-941. 
Howell, D. M., Morgan, W. J., Jarjour, A. A., Spirou, G. A., Berrebi, A. S., Kennedy, T. E., and Mathers, P. H. (2007). Molecular guidance cues necessary for axon pathfinding from the ventral cochlear nucleus. J Comp Neurol 504, 533-549.

Hsieh, C. Y., Hong, C. T., and Cramer, K. S. (2007). Deletion of EphA4 enhances deafferentation-induced ipsilateral sprouting in auditory brainstem projections. $\mathrm{J}$ Comp Neurol 504, 508-518.

Huffman, K. J., and Cramer, K. S. (2007). EphA4 misexpression alters tonotopic projections in the auditory brainstem. Dev Neurobiol 67, 1655-1668.

Huminiecki, L., Gorn, M., Suchting, S., Poulsom, R., and Bicknell, R. (2002). Magic roundabout is a new member of the roundabout receptor family that is endothelial specific and expressed at sites of active angiogenesis. Genomics 79, 547-552.

Hutson, L. D., Jurynec, M. J., Yeo, S. Y., Okamoto, H., and Chien, C. B. (2003). Two divergent slit1 genes in zebrafish. Dev Dyn 228, 358-369.

Ing, B., Shteiman-Kotler, A., Castelli, M., Henry, P., Pak, Y., Stewart, B., Boulianne, G. L., and Rotin, D. (2007). Regulation of Commissureless by the ubiquitin ligase DNedd4 is required for neuromuscular synaptogenesis in Drosophila melanogaster. Mol Cell Biol 27, 481-496.

Ingham, P. W., and McMahon, A. P. (2001). Hedgehog signaling in animal development: paradigms and principles. Genes Dev 15, 3059-3087.

Irving, R., and Harrison, J. M. (1967). The superior olivary complex and audition: a comparative study. J Comp Neurol 130, 77-86.

Ishii, N., Wadsworth, W. G., Stern, B. D., Culotti, J. G., and Hedgecock, E. M. (1992). UNC-6, a laminin-related protein, guides cell and pioneer axon migrations in C. elegans. Neuron 9, 873-881.

Itoh, A., Miyabayashi, T., Ohno, M., and Sakano, S. (1998). Cloning and expressions of three mammalian homologues of Drosophila slit suggest possible roles for Slit in the formation and maintenance of the nervous system. Brain Res Mol Brain Res 62, 175-186.

Ivanova, A., and Yuasa, S. (1998). Neuronal migration and differentiation in the development of the mouse dorsal cochlear nucleus. Dev Neurosci 20, 495-511.

Jarjour, A. A., Manitt, C., Moore, S. W., Thompson, K. M., Yuh, S. J., and Kennedy, T. E. (2003). Netrin-1 is a chemorepellent for oligodendrocyte precursor cells in the embryonic spinal cord. J Neurosci 23, 3735-3744.

Jen, J. C., Chan, W. M., Bosley, T. M., Wan, J., Carr, J. R., Rub, U., Shattuck, D., Salamon, G., Kudo, L. C., Ou, J., et al. (2004). Mutations in a human ROBO gene 
disrupt hindbrain axon pathway crossing and morphogenesis. Science 304, 15091513.

Jessell, T. M. (2000). Neuronal specification in the spinal cord: inductive signals and transcriptional codes. Nat Rev Genet 1, 20-29.

Johnson, D. H., Dabak, A., and Tsuchitani, C. (1990). Function-based modeling of binaural processing: interaural level. Hear Res 49, 301-319.

Jones, C. A., London, N. R., Chen, H., Park, K. W., Sauvaget, D., Stockton, R. A., Wythe, J. D., Suh, W., Larrieu-Lahargue, F., Mukouyama, Y. S., et al. (2008). Robo4 stabilizes the vascular network by inhibiting pathologic angiogenesis and endothelial hyperpermeability. Nat Med 14, 448-453.

Kandler, K., and Friauf, E. (1993). Pre- and postnatal development of efferent connections of the cochlear nucleus in the rat. J Comp Neurol 328, 161-184.

Kane, E. C. (1973). Octopus cells in the cochlear nucleus of the cat: heterotypic synapses upon homeotypic neurons. Int J Neurosci 5, 251-279.

Keino-Masu, K., Masu, M., Hinck, L., Leonardo, E. D., Chan, S. S., Culotti, J. G., and Tessier-Lavigne, M. (1996). Deleted in Colorectal Cancer (DCC) encodes a netrin receptor. Cell 87, 175-185.

Keleman, K., and Dickson, B. J. (2001). Short- and long-range repulsion by the Drosophila Unc5 netrin receptor. Neuron 32, 605-617.

Keleman, K., Rajagopalan, S., Cleppien, D., Teis, D., Paiha, K., Huber, L. A., Technau, G. M., and Dickson, B. J. (2002). Comm sorts robo to control axon guidance at the Drosophila midline. Cell 110, 415-427.

Keleman, K., Ribeiro, C., and Dickson, B. J. (2005). Comm function in commissural axon guidance: cell-autonomous sorting of Robo in vivo. Nat Neurosci 8, 156-163.

Kennedy, T. E., Serafini, T., de la Torre, J. R., and Tessier-Lavigne, M. (1994). Netrins are diffusible chemotropic factors for commissural axons in the embryonic spinal cord. Cell 78, 425-435.

Kenny, D., Bronner-Fraser, M., and Marcelle, C. (1995). The receptor tyrosine kinase QEK5 mRNA is expressed in a gradient within the neural retina and the tectum. Dev Biol 172, 708-716.

Kidd, T., Bland, K. S., and Goodman, C. S. (1999). Slit is the midline repellent for the robo receptor in Drosophila. Cell 96, 785-794.

Kidd, T., Brose, K., Mitchell, K. J., Fetter, R. D., Tessier-Lavigne, M., Goodman, C. S., and Tear, G. (1998a). Roundabout controls axon crossing of the CNS midline 
and defines a novel subfamily of evolutionarily conserved guidance receptors. Cell 92, 205-215.

Kidd, T., Russell, C., Goodman, C. S., and Tear, G. (1998b). Dosage-sensitive and complementary functions of roundabout and commissureless control axon crossing of the CNS midline. Neuron 20, 25-33.

Kilpatrick, T. J., Brown, A., Lai, C., Gassmann, M., Goulding, M., and Lemke, G. (1996). Expression of the Tyro4/Mek4/Cek4 gene specifically marks a subset of embryonic motor neurons and their muscle targets. Mol Cell Neurosci 7, 62-74.

Kim, S., Burette, A., Chung, H. S., Kwon, S. K., Woo, J., Lee, H. W., Kim, K., Kim, H., Weinberg, R. J., and Kim, E. (2006). NGL family PSD-95-interacting adhesion molecules regulate excitatory synapse formation. Nat Neurosci 9, 1294-1301.

Kitzes, L. M., Kageyama, G. H., Semple, M. N., and Kil, J. (1995). Development of ectopic projections from the ventral cochlear nucleus to the superior olivary complex induced by neonatal ablation of the contralateral cochlea. J Comp Neurol 353, 341363.

Kolesnikov, T., and Beckendorf, S. K. (2005). NETRIN and SLIT guide salivary gland migration. Dev Biol 284, 102-111.

Kolodziej, P. A., Timpe, L. C., Mitchell, K. J., Fried, S. R., Goodman, C. S., Jan, L. Y., and Jan, Y. N. (1996). frazzled encodes a Drosophila member of the DCC immunoglobulin subfamily and is required for CNS and motor axon guidance. Cell 87, 197-204.

Kudo, M., Kitao, Y., Okoyama, S., Moriya, M., and Kawano, J. (1996). Crossed projection neurons are generated prior to uncrossed projection neurons in the lateral superior olive of the rat. Brain Res Dev Brain Res 95, 72-78.

Kudo, M., Sakurai, H., Kurokawa, K., and Yamada, H. (2000). Neurogenesis in the superior olivary complex in the rat. Hear Res 139, 144-152.

Kullander, K., Croll, S. D., Zimmer, M., Pan, L., McClain, J., Hughes, V., Zabski, S., DeChiara, T. M., Klein, R., Yancopoulos, G. D., and Gale, N. W. (2001). Ephrin-B3 is the midline barrier that prevents corticospinal tract axons from recrossing, allowing for unilateral motor control. Genes Dev 15, 877-888.

Kuwabara, N., DiCaprio, R. A., and Zook, J. M. (1991). Afferents to the medial nucleus of the trapezoid body and their collateral projections. J Comp Neurol 314, 684-706.

Kuwabara, N., and Zook, J. M. (1992). Projections to the medial superior olive from the medial and lateral nuclei of the trapezoid body in rodents and bats. J Comp Neurol 324, 522-538. 
Lee, J. S., Ray, R., and Chien, C. B. (2001). Cloning and expression of three zebrafish roundabout homologs suggest roles in axon guidance and cell migration. Dev Dyn 221, 216-230.

Lee, K. J., and Jessell, T. M. (1999). The specification of dorsal cell fates in the vertebrate central nervous system. Annu Rev Neurosci 22, 261-294.

Lee, K. J., Mendelsohn, M., and Jessell, T. M. (1998). Neuronal patterning by BMPs: a requirement for GDF7 in the generation of a discrete class of commissural interneurons in the mouse spinal cord. Genes Dev 12, 3394-3407.

Legg, J. A., Herbert, J. M., Clissold, P., and Bicknell, R. (2008). Slits and Roundabouts in cancer, tumour angiogenesis and endothelial cell migration. Angiogenesis 11, 13-21.

Lemke, G., and Reber, M. (2005). Retinotectal mapping: new insights from molecular genetics. Annu Rev Cell Dev Biol 21, 551-580.

Leonardo, E. D., Hinck, L., Masu, M., Keino-Masu, K., Ackerman, S. L., and TessierLavigne, M. (1997). Vertebrate homologues of C. elegans UNC-5 are candidate netrin receptors. Nature 386, 833-838.

Leung-Hagesteijn, C., Spence, A. M., Stern, B. D., Zhou, Y., Su, M. W., Hedgecock, E. M., and Culotti, J. G. (1992). UNC-5, a transmembrane protein with immunoglobulin and thrombospondin type 1 domains, guides cell and pioneer axon migrations in C. elegans. Cell 71, 289-299.

Li, H. S., Chen, J. H., Wu, W., Fagaly, T., Zhou, L., Yuan, W., Dupuis, S., Jiang, Z. H., Nash, W., Gick, C., et al. (1999). Vertebrate slit, a secreted ligand for the transmembrane protein roundabout, is a repellent for olfactory bulb axons. Cell 96 , 807-818.

Liberman, M. C. (1982). The cochlear frequency map for the cat: labeling auditorynerve fibers of known characteristic frequency. J Acoust Soc Am 72, 1441-1449.

Lin, J. C., Ho, W. H., Gurney, A., and Rosenthal, A. (2003). The netrin-G1 ligand NGL-1 promotes the outgrowth of thalamocortical axons. Nat Neurosci 6, 12701276.

Little, M., Rumballe, B., Georgas, K., Yamada, T., and Teasdale, R. D. (2002). Conserved modularity and potential for alternate splicing in mouse and human Slit genes. Int J Dev Biol 46, 385-391.

Liu, Y., Shi, J., Lu, C. C., Wang, Z. B., Lyuksyutova, A. I., Song, X. J., and Zou, Y. (2005). Ryk-mediated Wnt repulsion regulates posterior-directed growth of corticospinal tract. Nat Neurosci 8, 1151-1159. 
Long, H., Sabatier, C., Ma, L., Plump, A., Yuan, W., Ornitz, D. M., Tamada, A., Murakami, F., Goodman, C. S., and Tessier-Lavigne, M. (2004). Conserved roles for Slit and Robo proteins in midline commissural axon guidance. Neuron 42, 213-223.

Lorente de No, R. (1933). "Anatomy of the eighth nerve." The central projection of the nerve endings of the internal ear. Laryngoscope 43, 1-38.

Lorente de No, R. (1981). The primary acoustic nuclei. (New York, Raven Press).

Lyuksyutova, A. I., Lu, C. C., Milanesio, N., King, L. A., Guo, N., Wang, Y., Nathans, J., Tessier-Lavigne, M., and Zou, Y. (2003). Anterior-posterior guidance of commissural axons by Wnt-frizzled signaling. Science 302, 1984-1988.

MacDonald, D. B., Streletz, L. J., Al-Zayed, Z., Abdool, S., and Stigsby, B. (2004). Intraoperative neurophysiologic discovery of uncrossed sensory and motor pathways in a patient with horizontal gaze palsy and scoliosis. Clin Neurophysiol 115, 576-582.

Marcus, R. C., Gale, N. W., Morrison, M. E., Mason, C. A., and Yancopoulos, G. D. (1996). Eph family receptors and their ligands distribute in opposing gradients in the developing mouse retina. Dev Biol 180, 786-789.

Marillat, V., Cases, O., Nguyen-Ba-Charvet, K. T., Tessier-Lavigne, M., Sotelo, C., and Chedotal, A. (2002). Spatiotemporal expression patterns of slit and robo genes in the rat brain. $\mathrm{J}$ Comp Neurol 442, 130-155.

Marillat, V., Sabatier, C., Failli, V., Matsunaga, E., Sotelo, C., Tessier-Lavigne, M., and Chedotal, A. (2004). The slit receptor Rig-1/Robo3 controls midline crossing by hindbrain precerebellar neurons and axons. Neuron 43, 69-79.

Martin, M. R., and Rickets, C. (1981). Histogenesis of the cochlear nucleus of the mouse. J Comp Neurol 197, 169-184.

Masterton, B., Thompson, G. C., Bechtold, J. K., and RoBards, M. J. (1975). Neuroanatomical basis of binaural phase-difference analysis for sound localization: a comparative study. J Comp Physiol Psychol 89, 379-386.

Masterton, R. B., and Imig, T. J. (1984). Neural mechanisms for sound localization. Annu Rev Physiol 46, 275-287.

Matus, D. Q., Pang, K., Marlow, H., Dunn, C. W., Thomsen, G. H., and Martindale, M. Q. (2006). Molecular evidence for deep evolutionary roots of bilaterality in animal development. Proc Natl Acad Sci U S A 103, 11195-11200.

McLaughlin, T., Hindges, R., Yates, P. A., and O'Leary, D. D. (2003). Bifunctional action of ephrin-B1 as a repellent and attractant to control bidirectional branch extension in dorsal-ventral retinotopic mapping. Development 130, 2407-2418. 
McLaughlin, T., and O'Leary, D. D. (2005). Molecular gradients and development of retinotopic maps. Annu Rev Neurosci 28, 327-355.

Merz, D. C., Zheng, H., Killeen, M. T., Krizus, A., and Culotti, J. G. (2001). Multiple signaling mechanisms of the UNC-6/netrin receptors UNC-5 and UNC-40/DCC in vivo. Genetics 158, 1071-1080.

Miko, I. J., Henkemeyer, M., and Cramer, K. S. (2008). Auditory brainstem responses are impaired in EphA4 and ephrin-B2 deficient mice. Hear Res 235, 3946.

Miko, I. J., Nakamura, P. A., Henkemeyer, M., and Cramer, K. S. (2007). Auditory brainstem neural activation patterns are altered in EphA4- and ephrin-B2-deficient mice. J Comp Neurol 505, 669-681.

Mitchell, K. J., Doyle, J. L., Serafini, T., Kennedy, T. E., Tessier-Lavigne, M., Goodman, C. S., and Dickson, B. J. (1996). Genetic analysis of Netrin genes in Drosophila: Netrins guide CNS commissural axons and peripheral motor axons. Neuron 17, 203-215.

Moore, J. K. (2000). Organization of the human superior olivary complex. Microsc Res Tech 51, 403-412.

Moore, J. K., and Moore, R. Y. (1971). A comparative study of the superior olivary complex in the primate brain. Folia Primatol (Basel) 16, 35-51.

Morest, D. K. (1968a). The collateral system of the medial nucleus of the trapezoid body of the cat, its neuronal architecture and relation to the olivo-cochlear bundle. Brain Res 9, 288-311.

Morest, D. K. (1968b). The growth of synaptic endings in the mammalian brain: a study of the calyces of the trapezoid body. Z Anat Entwicklungsgesch 127, 201-220.

Mugnaini, E., Berrebi, A. S., Dahl, A. L., and Morgan, J. I. (1987). The polypeptide PEP-19 is a marker for Purkinje neurons in cerebellar cortex and cartwheel neurons in the dorsal cochlear nucleus. Arch Ital Biol 126, 41-67.

Mugnaini, E., Warr, W. B., and Osen, K. K. (1980). Distribution and light microscopic features of granule cells in the cochlear nuclei of cat, rat, and mouse. J Comp Neurol 191, 581-606.

Muroyama, Y., Fujihara, M., Ikeya, M., Kondoh, H., and Takada, S. (2002). Wnt signaling plays an essential role in neuronal specification of the dorsal spinal cord. Genes Dev 16, 548-553.

Myat, A., Henry, P., McCabe, V., Flintoft, L., Rotin, D., and Tear, G. (2002). Drosophila Nedd4, a ubiquitin ligase, is recruited by Commissureless to control cell surface levels of the roundabout receptor. Neuron 35, 447-459. 
Nakagawa, S., Brennan, C., Johnson, K. G., Shewan, D., Harris, W. A., and Holt, C. E. (2000). Ephrin-B regulates the Ipsilateral routing of retinal axons at the optic chiasm. Neuron 25, 599-610.

Nakashiba, T., Ikeda, T., Nishimura, S., Tashiro, K., Honjo, T., Culotti, J. G., and Itohara, S. (2000). Netrin-G1: a novel glycosyl phosphatidylinositol-linked mammalian netrin that is functionally divergent from classical netrins. J Neurosci 20 , 6540-6550.

Nakashiba, T., Nishimura, S., Ikeda, T., and Itohara, S. (2002). Complementary expression and neurite outgrowth activity of netrin-G subfamily members. Mech Dev $111,47-60$.

Nguyen-Ba-Charvet, K. T., Di Meglio, T., Fouquet, C., and Chedotal, A. (2008). Robos and slits control the pathfinding and targeting of mouse olfactory sensory axons. J Neurosci 28, 4244-4249.

Nguyen-Ba-Charvet, K. T., Picard-Riera, N., Tessier-Lavigne, M., Baron-Van Evercooren, A., Sotelo, C., and Chedotal, A. (2004). Multiple roles for slits in the control of cell migration in the rostral migratory stream. J Neurosci 24, 1497-1506.

Nguyen-Ba-Charvet, K. T., Plump, A. S., Tessier-Lavigne, M., and Chedotal, A. (2002). Slit1 and slit2 proteins control the development of the lateral olfactory tract. J Neurosci 22, 5473-5480.

Nguyen Ba-Charvet, K. T., Brose, K., Ma, L., Wang, K. H., Marillat, V., Sotelo, C., Tessier-Lavigne, M., and Chedotal, A. (2001). Diversity and specificity of actions of Slit2 proteolytic fragments in axon guidance. J Neurosci 21, 4281-4289.

Niblock, M. M., Brunso-Bechtold, J. K., and Henkel, C. K. (1995). Fiber outgrowth and pathfinding in the developing auditory brainstem. Brain Res Dev Brain Res 85, 288-292.

Nichols, D. H., and Bruce, L. L. (2006). Migratory routes and fates of cells transcribing the Wnt-1 gene in the murine hindbrain. Dev Dyn 235, 285-300.

O'Leary, D. D., and McLaughlin, T. (2005). Mechanisms of retinotopic map development: Ephs, ephrins, and spontaneous correlated retinal activity. Prog Brain Res 147, 43-65.

O'Leary, D. D., and Wilkinson, D. G. (1999). Eph receptors and ephrins in neural development. Curr Opin Neurobiol 9, 65-73.

Oertel, D., and Young, E. D. (2004). What's a cerebellar circuit doing in the auditory system? Trends Neurosci 27, 104-110.

Osen, K. K. (1969). Cytoarchitecture of the cochlear nuclei in the cat. J Comp Neurol 136, 453-484. 
Osen, K. K. (1972). Projection of the cochlear nuclei on the inferior colliculus in the cat. J Comp Neurol 144, 355-372.

Park, K. W., Morrison, C. M., Sorensen, L. K., Jones, C. A., Rao, Y., Chien, C. B., Wu, J. Y., Urness, L. D., and Li, D. Y. (2003). Robo4 is a vascular-specific receptor that inhibits endothelial migration. Dev Biol 261, 251-267.

Patthy, L. (2000). The WIF module. Trends Biochem Sci 25, 12-13.

Perkins, R. E. (1973). An electron microscopic study of synaptic organization in the medial superior olive of normal and experimental chinchillas. J Comp Neurol 148, 387-415.

Person, A. L., Cerretti, D. P., Pasquale, E. B., Rubel, E. W., and Cramer, K. S. (2004). Tonotopic gradients of Eph family proteins in the chick nucleus laminaris during synaptogenesis. J Neurobiol 60, 28-39.

Pierce, E. T. (1967). Histogenesis of the dorsal and ventral cochlear nuclei in the mouse. An autoradiographic study. J Comp Neurol 131, 27-54.

Pierce, E. T. (1973). Time of origin of neurons in the brain stem of the mouse. Prog Brain Res 40, 53-65.

Plump, A. S., Erskine, L., Sabatier, C., Brose, K., Epstein, C. J., Goodman, C. S., Mason, C. A., and Tessier-Lavigne, M. (2002). Slit1 and Slit2 cooperate to prevent premature midline crossing of retinal axons in the mouse visual system. Neuron 33, 219-232.

Poe, B. H., and Brunso-Bechtold, J. K. (1998). Directed outgrowth from a subset of cochlear nucleus fibers in a collagen-gel matrix. Brain Res Dev Brain Res 105, 153157.

Powell, T. P., and Cowan, W. M. (1962). An experimental study of the projection of the cochlea. J Anat 96, 269-284.

Przyborski, S. A., Knowles, B. B., and Ackerman, S. L. (1998). Embryonic phenotype of Unc5h3 mutant mice suggests chemorepulsion during the formation of the rostral cerebellar boundary. Development 125, 41-50.

Rajagopalan, S., Deitinghoff, L., Davis, D., Conrad, S., Skutella, T., Chedotal, A., Mueller, B. K., and Strittmatter, S. M. (2004). Neogenin mediates the action of repulsive guidance molecule. Nat Cell Biol.

Rajagopalan, S., Nicolas, E., Vivancos, V., Berger, J., and Dickson, B. J. (2000a). Crossing the midline: roles and regulation of Robo receptors. Neuron 28, 767-777. 
Rajagopalan, S., Vivancos, V., Nicolas, E., and Dickson, B. J. (2000b). Selecting a longitudinal pathway: Robo receptors specify the lateral position of axons in the Drosophila CNS. Cell 103, 1033-1045.

Ramón y Cajal, R. (1909). Histologie du Système Nerveux de l'Homme et des Vertébrés. (Madrid, Instituto Ramón y Cajal).

Rashid, T., Upton, A. L., Blentic, A., Ciossek, T., Knoll, B., Thompson, I. D., and Drescher, U. (2005). Opposing gradients of ephrin-As and EphA7 in the superior colliculus are essential for topographic mapping in the mammalian visual system. Neuron 47, 57-69.

Ratcliffe, E. M., Setru, S. U., Chen, J. J., Li, Z. S., D'Autreaux, F., and Gershon, M. D. (2006). Netrin/DCC-mediated attraction of vagal sensory axons to the fetal mouse gut. J Comp Neurol 498, 567-580.

Rayleigh, L. (1907). On our perception of sound direction. Philos Mag 13, 214-232.

Roelink, H., Porter, J. A., Chiang, C., Tanabe, Y., Chang, D. T., Beachy, P. A., and Jessell, T. M. (1995). Floor plate and motor neuron induction by different concentrations of the amino-terminal cleavage product of sonic hedgehog autoproteolysis. Cell 81, 445-455.

Rose, J. E., Galambos, R., and Hughes, J. R. (1959). Microelectrode studies of the cochlear nuclei of the cat. Bull Johns Hopkins Hosp 104, 211-251.

Rothberg, J. M., and Artavanis-Tsakonas, S. (1992). Modularity of the slit protein. Characterization of a conserved carboxy-terminal sequence in secreted proteins and a motif implicated in extracellular protein interactions. J Mol Biol 227, 367-370.

Rothberg, J. M., Hartley, D. A., Walther, Z., and Artavanis-Tsakonas, S. (1988). slit: an EGF-homologous locus of D. melanogaster involved in the development of the embryonic central nervous system. Cell 55, 1047-1059.

Rothberg, J. M., Jacobs, J. R., Goodman, C. S., and Artavanis-Tsakonas, S. (1990). slit: an extracellular protein necessary for development of midline glia and commissural axon pathways contains both EGF and LRR domains. Genes Dev 4, 2169-2187.

Russell, F. A., and Moore, D. R. (1995). Afferent reorganisation within the superior olivary complex of the gerbil: development and induction by neonatal, unilateral cochlear removal. J Comp Neurol 352, 607-625.

Ryugo, D. K., and Parks, T. N. (2003). Primary innervation of the avian and mammalian cochlear nucleus. Brain Res Bull 60, 435-456.

Sabatier, C., Plump, A. S., Le, M., Brose, K., Tamada, A., Murakami, F., Lee, E. Y., and Tessier-Lavigne, M. (2004). The divergent Robo family protein rig-1/Robo3 is a 
negative regulator of slit responsiveness required for midline crossing by commissural axons. Cell 117, 157-169.

Sando, I. (1965). The Anatomical Interrelationships of the Cochlear Nerve Fibers. Acta Oto-Laryngologica 59, 417 - 436.

Schofield, B. R., and Cant, N. B. (1991). Organization of the superior olivary complex in the guinea pig. I. Cytoarchitecture, cytochrome oxidase histochemistry, and dendritic morphology. J Comp Neurol 314, 645-670.

Schwarting, G. A., Kostek, C., Bless, E. P., Ahmad, N., and Tobet, S. A. (2001). Deleted in colorectal cancer (DCC) regulates the migration of luteinizing hormonereleasing hormone neurons to the basal forebrain. J Neurosci 21, 911-919.

Schwarting, G. A., Raitcheva, D., Bless, E. P., Ackerman, S. L., and Tobet, S. (2004). Netrin 1-mediated chemoattraction regulates the migratory pathway of LHRH neurons. Eur J Neurosci 19, 11-20.

Seaman, C., Anderson, R., Emery, B., and Cooper, H. M. (2001). Localization of the netrin guidance receptor, DCC, in the developing peripheral and enteric nervous systems. Mech Dev 103, 173-175.

Seeger, M., Tear, G., Ferres-Marco, D., and Goodman, C. S. (1993). Mutations affecting growth cone guidance in Drosophila: genes necessary for guidance toward or away from the midline. Neuron 10, 409-426.

Serafini, T., Colamarino, S. A., Leonardo, E. D., Wang, H., Beddington, R., Skarnes, W. C., and Tessier-Lavigne, M. (1996). Netrin-1 is required for commissural axon guidance in the developing vertebrate nervous system. Cell 87, 1001-1014.

Serafini, T., Kennedy, T. E., Galko, M. J., Mirzayan, C., Jessell, T. M., and TessierLavigne, M. (1994). The netrins define a family of axon outgrowth-promoting proteins homologous to C. elegans UNC-6. Cell 78, 409-424.

Shen, H., Illges, H., Reuter, A., and Stuermer, C. A. (2002). Cloning, expression, and alternative splicing of neogenin1 in zebrafish. Mech Dev 118, 219-223.

Shirasaki, R., Katsumata, R., and Murakami, F. (1998). Change in chemoattractant responsiveness of developing axons at an intermediate target. Science 279, 105107.

Sicotte, N. L., Salamon, G., Shattuck, D. W., Hageman, N., Rub, U., Salamon, N., Drain, A. E., Demer, J. L., Engle, E. C., Alger, J. R., et al. (2006). Diffusion tensor MRI shows abnormal brainstem crossing fibers associated with $\mathrm{ROBO} 3$ mutations. Neurology 67, 519-521. 
Simpson, J. H., Bland, K. S., Fetter, R. D., and Goodman, C. S. (2000a). Shortrange and long-range guidance by Slit and its Robo receptors: a combinatorial code of Robo receptors controls lateral position. Cell 103, 1019-1032.

Simpson, J. H., Kidd, T., Bland, K. S., and Goodman, C. S. (2000b). Short-range and long-range guidance by slit and its Robo receptors. Robo and Robo2 play distinct roles in midline guidance. Neuron 28, 753-766.

Smith, P. H., Joris, P. X., Carney, L. H., and Yin, T. C. (1991). Projections of physiologically characterized globular bushy cell axons from the cochlear nucleus of the cat. J Comp Neurol 304, 387-407.

Smith, P. H., and Rhode, W. S. (1987). Characterization of HRP-labeled globular bushy cells in the cat anteroventral cochlear nucleus. J Comp Neurol 266, 360-375.

Smith, P. H., and Rhode, W. S. (1989). Structural and functional properties distinguish two types of multipolar cells in the ventral cochlear nucleus. J Comp Neurol 282, 595-616.

Sommer, I., Lingenhohl, K., and Friauf, E. (1993). Principal cells of the rat medial nucleus of the trapezoid body: an intracellular in vivo study of their physiology and morphology. Exp Brain Res 95, 223-239.

Spangler, K. M., Warr, W. B., and Henkel, C. K. (1985). The projections of principal cells of the medial nucleus of the trapezoid body in the cat. J Comp Neurol 238, 249262.

Spirou, G. A., and Berrebi, A. S. (1997). Glycine immunoreactivity in the lateral nucleus of the trapezoid body of the cat. J Comp Neurol 383, 473-488.

Spirou, G. A., Brownell, W. E., and Zidanic, M. (1990). Recordings from cat trapezoid body and HRP labeling of globular bushy cell axons. J Neurophysiol 63, 1169-1190.

Stein, E., and Tessier-Lavigne, M. (2001). Hierarchical organization of guidance receptors: silencing of netrin attraction by slit through a Robo/DCC receptor complex. Science 291, 1928-1938.

Stotler, W. A. (1953). An experimental study of the cells and connections of the superior olivary complex of the cat. J Comp Neurol 98, 401-431.

Strominger, N. L. (1973). The origins, course and distribution of the dorsal and intermediate acoustic striae in the rhesus monkey. J Comp Neurol 147, 209-233.

Suchting, S., Bicknell, R., and Eichmann, A. (2006). Neuronal clues to vascular guidance. Exp Cell Res 312, 668-675. 
Suga, H., Hoshiyama, D., Kuraku, S., Katoh, K., Kubokawa, K., and Miyata, T. (1999). Protein tyrosine kinase cDNAs from amphioxus, hagfish, and lamprey: isoform duplications around the divergence of cyclostomes and gnathostomes. $\mathrm{J} \mathrm{Mol}$ Evol 49, 601-608.

Surawska, H., Ma, P. C., and Salgia, R. (2004). The role of ephrins and Eph receptors in cancer. Cytokine Growth Factor Rev 15, 419-433.

Tamada, A., Kumada, T., Zhu, Y., Matsumoto, T., Hatanaka, Y., Muguruma, K., Chen, Z., Tanabe, Y., Torigoe, M., Yamauchi, K., et al. (2008). Crucial roles of Robo proteins in midline crossing of cerebellofugal axons and lack of their up-regulation after midline crossing. Neural Dev 3, 29.

Tanno, T., Takenaka, S., and Tsuyama, S. (2004). Expression and function of Slit1alpha, a novel alternative splicing product for slit1. J Biochem 136, 575-581.

Tear, G., Harris, R., Sutaria, S., Kilomanski, K., Goodman, C. S., and Seeger, M. A. (1996). commissureless controls growth cone guidance across the CNS midline in Drosophila and encodes a novel membrane protein. Neuron 16, 501-514.

Teleman, A. A., Strigini, M., and Cohen, S. M. (2001). Shaping morphogen gradients. Cell 105, 559-562.

Tessier-Lavigne, M., and Goodman, C. S. (1996). The molecular biology of axon guidance. Science 274, 1123-1133.

Thompson, S. (1882). On the function of the two ears in the perception of space. Philos Mag 13, 406-416.

Tolbert, L. P., and Morest, D. K. (1982). The neuronal architecture of the anteroventral cochlear nucleus of the cat in the region of the cochlear nerve root: Golgi and Nissl methods. Neuroscience 7, 3013-3030.

Tolbert, L. P., Morest, D. K., and Yurgelun-Todd, D. A. (1982). The neuronal architecture of the anteroventral cochlear nucleus of the cat in the region of the cochlear nerve root: horseradish peroxidase labelling of identified cell types. Neuroscience 7, 3031-3052.

Tollin, D. J., and Yin, T. C. (2002a). The coding of spatial location by single units in the lateral superior olive of the cat. I. Spatial receptive fields in azimuth. J Neurosci 22, 1454-1467.

Tollin, D. J., and Yin, T. C. (2002b). The coding of spatial location by single units in the lateral superior olive of the cat. II. The determinants of spatial receptive fields in azimuth. J Neurosci 22, 1468-1479.

Torres, M., Gomez-Pardo, E., and Gruss, P. (1996). Pax2 contributes to inner ear patterning and optic nerve trajectory. Development 122, 3381-3391. 
Trousse, F., Marti, E., Gruss, P., Torres, M., and Bovolenta, P. (2001). Control of retinal ganglion cell axon growth: a new role for Sonic hedgehog. Development 128, 3927-3936.

Tsai, H. H., Tessier-Lavigne, M., and Miller, R. H. (2003). Netrin 1 mediates spinal cord oligodendrocyte precursor dispersal. Development 130, 2095-2105.

Tsuchitani, C. (1988a). The inhibition of cat lateral superior olive unit excitatory responses to binaural tone bursts. I. The transient chopper response. J Neurophysiol 59, 164-183.

Tsuchitani, C. (1988b). The inhibition of cat lateral superior olive unit excitatory responses to binaural tone bursts. II. The sustained discharges. J Neurophysiol 59, 184-211.

Vargesson, N., Luria, V., Messina, I., Erskine, L., and Laufer, E. (2001). Expression patterns of Slit and Robo family members during vertebrate limb development. Mech Dev 106, 175-180.

Vidovic, M., Marotte, L. R., and Mark, R. F. (1999). Marsupial retinocollicular system shows differential expression of messenger RNA encoding EphA receptors and their ligands during development. J Neurosci Res 57, 244-254.

Vielmetter, J., Kayyem, J. F., Roman, J. M., and Dreyer, W. J. (1994). Neogenin, an avian cell surface protein expressed during terminal neuronal differentiation, is closely related to the human tumor suppressor molecule deleted in colorectal cancer. J Cell Biol 127, 2009-2020.

Wang, B., Xiao, Y., Ding, B. B., Zhang, N., Yuan, X., Gui, L., Qian, K. X., Duan, S., Chen, Z., Rao, Y., and Geng, J. G. (2003). Induction of tumor angiogenesis by SlitRobo signaling and inhibition of cancer growth by blocking Robo activity. Cancer Cell 4, 19-29.

Wang, K. H., Brose, K., Arnott, D., Kidd, T., Goodman, C. S., Henzel, W., and Tessier-Lavigne, M. (1999a). Biochemical purification of a mammalian slit protein as a positive regulator of sensory axon elongation and branching. Cell 96, 771-784.

Wang, X., Roy, P. J., Holland, S. J., Zhang, L. W., Culotti, J. G., and Pawson, T. (1999b). Multiple ephrins control cell organization in C. elegans using kinasedependent and -independent functions of the VAB-1 Eph receptor. Mol Cell 4, 903913.

Warr, W. B. (1972). Fiber degeneration following lesions in the multipolar and globular cell areas in the ventral cochlear nucleus of the cat. Brain Res 40, 247-270.

Webster, D. B. (1971). Projection of the cochlea to cochlear nuclei in Merriam's kangaroo rat. J Comp Neurol 143, 323-340. 
Webster, D. B., and Trune, D. R. (1982). Cochlear nuclear complex of mice. Am J Anat 163, 103-130.

Whitford, K. L., Marillat, V., Stein, E., Goodman, C. S., Tessier-Lavigne, M., Chedotal, A., and Ghosh, A. (2002). Regulation of cortical dendrite development by Slit-Robo interactions. Neuron 33, 47-61.

Wilkinson, D. G. (2000). Topographic mapping: organising by repulsion and competition? Curr Biol 10, R447-451.

Wilkinson, D. G. (2001). Multiple roles of EPH receptors and ephrins in neural development. Nat Rev Neurosci 2, 155-164.

Williams, S. E., Mann, F., Erskine, L., Sakurai, T., Wei, S., Rossi, D. J., Gale, N. W., Holt, C. E., Mason, C. A., and Henkemeyer, M. (2003). Ephrin-B2 and EphB1 mediate retinal axon divergence at the optic chiasm. Neuron 39, 919-935.

Wimmer-Kleikamp, S. H., and Lackmann, M. (2005). Eph-modulated cell morphology, adhesion and motility in carcinogenesis. IUBMB Life 57, 421-431.

Yamaguchi, Y., and Pasquale, E. B. (2004). Eph receptors in the adult brain. Curr Opin Neurobiol 14, 288-296.

Yee, K. T., Simon, H. H., Tessier-Lavigne, M., and O'Leary, D. M. (1999). Extension of long leading processes and neuronal migration in the mammalian brain directed by the chemoattractant netrin-1. Neuron 24, 607-622.

Yin, Y., Sanes, J. R., and Miner, J. H. (2000). Identification and expression of mouse netrin-4. Mech Dev 96, 115-119.

Yoshikawa, S., McKinnon, R. D., Kokel, M., and Thomas, J. B. (2003). Wntmediated axon guidance via the Drosophila Derailed receptor. Nature 422, 583-588.

Yuan, S. S., Cox, L. A., Dasika, G. K., and Lee, E. Y. (1999a). Cloning and functional studies of a novel gene aberrantly expressed in RB-deficient embryos. Dev Biol 207, 62-75.

Yuan, W., Zhou, L., Chen, J. H., Wu, J. Y., Rao, Y., and Ornitz, D. M. (1999b). The mouse SLIT family: secreted ligands for ROBO expressed in patterns that suggest a role in morphogenesis and axon guidance. Dev Biol 212, 290-306.

Yurchenco, P. D., and Wadsworth, W. G. (2004). Assembly and tissue functions of early embryonic laminins and netrins. Curr Opin Cell Biol 16, 572-579.

Zallen, J. A., Yi, B. A., and Bargmann, C. I. (1998). The conserved immunoglobulin superfamily member SAX-3/Robo directs multiple aspects of axon guidance in C. elegans. Cell 92, 217-227. 
Zhang, J. H., Cerretti, D. P., Yu, T., Flanagan, J. G., and Zhou, R. (1996). Detection of ligands in regions anatomically connected to neurons expressing the Eph receptor Bsk: potential roles in neuron-target interaction. J Neurosci 16, 7182-7192.

Zhang, W., Rajan, I., Savelieva, K. V., Wang, C. Y., Vogel, P., Kelly, M., Xu, N., Hasson, B., Jarman, W., and Lanthorn, T. H. (2008). Netrin-G2 and netrin-G2 ligand are both required for normal auditory responsiveness. Genes Brain Behav 7, 385392.

Zinyk, D. L., Mercer, E. H., Harris, E., Anderson, D. J., and Joyner, A. L. (1998). Fate mapping of the mouse midbrain-hindbrain constriction using a site-specific recombination system. Curr Biol 8, 665-668.

Zou, Y., Stoeckli, E., Chen, H., and Tessier-Lavigne, M. (2000). Squeezing axons out of the gray matter: a role for slit and semaphorin proteins from midline and ventral spinal cord. Cell 102, 363-375. 


\section{CHAPTER 2}

Molecular Guidance Cues Necessary for Axon Pathfinding from the Ventral Cochlear Nucleus 


\section{Molecular Guidance Cues Necessary for Axon Pathfinding from the Ventral Cochlear Nucleus}

David M. Howell ${ }^{1,2}$, Warren J. Morgan ${ }^{1,2}$, Andrew A. Jarjour ${ }^{3}$, George A. Spirou $^{1,4,5}$, Albert S. Berrebi ${ }^{1,4,6}$, Timothy E. Kennedy ${ }^{3}$ and Peter H. Mathers ${ }^{1,2,4}$

1) Sensory Neuroscience Research Center, West Virginia University, Morgantown, West Virginia 26506, USA;

2) Department of Biochemistry and Molecular Pharmacology, West Virginia University, Morgantown, West Virginia 26506, USA;

3) Department of Neurology and Neurosurgery, Montreal Neurological Institute, McGill University, Montreal, Quebec, Canada H3A 2B4;

4) Department of Otolaryngology-Head and Neck Surgery, West Virginia University, Morgantown, West Virginia 26506, USA;

5) Department of Physiology and Pharmacology, West Virginia University, Morgantown, West Virginia 26506, USA;

6) Department of Neurobiology and Anatomy, West Virginia University, Morgantown, West Virginia 26506, USA.

This manuscript was published in The Journal of Comparative Neurology, 2007 Oct 10; 504(5): 533-549.

Relative contributions:

Peter $\mathrm{H}$. Mathers - provided laboratory space and funding, made many helpful comments and gave important advice on the experiments, the data interpretation and the manuscript.

George A. Spirou and Albert S. Berrebi - provided laboratory space, gave advice when possible on experiments and data interpretation, made comments on the manuscript.

Timothy E. Kennedy - provided netrin-1 mutant samples and helpful comments on the manuscript.

Andrew A. Jarjour - prepared netrin-1 mutant samples, performed netrin-1 genotype reactions, and provided helpful comments on the manuscript.

Warren J. Morgan - performed mafB immunohistochemistry and in situ hybridization reactions pictured in Figure 1.

David M. Howell - performed all other experiments, collected all experimental data/images, assembled all figures, responsible for document preparation, revision and submission to The Journal of Comparative Neurology.

Molecular guidance cues necessary for axon pathfinding from the ventral cochlear nucleus. Howell, D. M., Morgan, W. J., Jarjour, A. A., Spirou, G. A., Berrebi, A. S., Kennedy, T. E., and Mathers, P. H. (2007). J Comp Neurol 504, 533-549. Reprinted with Permission of Wiley-Liss, Inc. a subsidiary of John Wiley \& Sons, Inc." 


\section{Abstract}

During development, multiple guidance cues direct the formation of appropriate synaptic connections. Factors that guide developing axons are known for various pathways throughout the mammalian brain; however, signals necessary to establish auditory connections are largely unknown. In the auditory brainstem, the neurons whose axons traverse the midline in the ventral acoustic stria (VAS) are primarily located in the ventral cochlear nucleus (VCN) and project bilaterally to the superior olivary complex (SOC). The circumferential trajectory taken by developing VCN axons is similar to that of growing axons of spinal commissural neurons. Therefore, we reasoned that netrin-DCC and slit-robo signaling systems function in the guidance of VCN axons. VCN neurons express the transcription factor, mafB, as early as embryonic day $(E) 13.5$, thereby identifying the embryonic VCN for these studies. VCN axons extend toward the midline as early as E13, with many axons crossing by E14.5. During this time, netrin-1 and slit-1 RNAs are expressed at the brainstem midline. Additionally, neurons within the VCN express RNA for DCC, robo-1 and robo-2, and axons in the VAS are immunoreactive for DCC. VCN axons do not reach the midline of the brainstem in mice mutant for either the netrin-1 or DCC gene. VCN axons extend in pups lacking netrin-1, but most $D C C$-mutant samples lack VCN axonal outgrowth. Stereological cell estimates indicate only a modest reduction of VCN neurons in DCC-mutant mice. Taken together, these data show that a functional netrin-DCC signaling system is required for establishing proper VCN axonal projections in the auditory brainstem.

Molecular guidance cues necessary for axon pathfinding from the ventral cochlear nucleus. Howell, D. M., Morgan, W. J., Jarjour, A. A., Spirou, G. A., Berrebi, A. S., Kennedy, T. E., and Mathers, P. H. (2007). J Comp Neurol 504, 533-549. Reprinted with Permission of Wiley-Liss, Inc. a subsidiary of John Wiley \& Sons, Inc." 


\section{Introduction}

During central nervous system development, multiple molecular cues guide the formation of neuronal networks. Axons are proposed to migrate through a series of intermediate targets as a means of simplifying complicated, long-distance pathways (Tessier-Lavigne and Goodman, 1996). Growth cones, the distal tips of developing axons, are specialized to recognize and respond to directional signals present at these intermediate targets and are thought to change their affinity to these targets during migration (Shirasaki et al., 1998). The interaction of guidance cues with receptors present on growth cones results in attractive or repulsive movements. There are four major classes of axon guidance molecules: ephrins, netrins, semaphorins and slits, which signal through one or more specific receptors (reviewed in Dickson, 2002). More recently, attractive and repulsive axon guidance activities have been identified for molecules originally characterized as morphogens, such as bone morphogenic proteins, sonic hedgehog and wingless/wnt proteins (reviewed in Schnorrer and Dickson, 2004; Charron and Tessier-Lavigne, 2005; Sanchez-Camacho et al., 2005).

Specific axonal guidance cues necessary for the development of multiple neuronal systems have been extensively studied, but relatively little is known about the guidance cues directing mammalian central auditory neurons. In mammals, the ventral acoustic stria (VAS) is a collection of axons in the brainstem that have important roles in hearing, including the ability to localize sound sources in space (Jenkins and Masterton, 1982). The VAS is primarily comprised of axons emanating from three cell types in the ventral cochlear nucleus (VCN): globular bushy cells, multipolar cells and spherical bushy cells (Osen, 1969; Warr, 1982; Webster and Trune, 1982). Axons from these cells exit the cochlear nucleus and extend along the lateral and ventral surface of the brainstem toward the midline. Major terminations of these $\mathrm{VCN}$ axons within the superior olivary complex $(\mathrm{SOC})$ include: the ipsilateral lateral superior olive (LSO), the contralateral medial nucleus of the trapezoid body (MNTB) and superior paraolivary nucleus (SPON) and the bilateral medial superior

Molecular guidance cues necessary for axon pathfinding from the ventral cochlear nucleus. Howell, D. M., Morgan, W. J., Jarjour, A. A., Spirou, G. A., Berrebi, A. S., Kennedy, T. E., and Mathers, P. H. (2007). J Comp Neurol 504, 533-549. Reprinted with Permission of Wiley-Liss, Inc. a subsidiary of John Wiley \& Sons, Inc." 
olive (MSO) (Fig. 2A and reviewed in Cant and Benson, 2003). A notable VAS circuit is the connection of large-diameter globular bushy cell (GBC) axons with the contralateral MNTB, where axons terminate as calyces of Held (Tolbert et al., 1982; Friauf and Ostwald, 1988; Spirou et al., 1990; Smith et al., 1991). Additional projections of VCN axons are found within other ipsilateral and contralateral periolivary nuclei, as well as midbrain auditory centers like the ventral nucleus of the lateral lemniscus and the inferior colliculus (Fig. 2A and reviewed in Cant and Benson, 2003).

Ascending axons traveling in the VAS display a decussating pattern similar to that taken by spinal commissural neurons ( $\mathrm{SCN}$ ). In the spinal cord, a dorsally positioned SCN extends an axon ventromedially to the midline, where it crosses and proceeds to its termination. SCNs require functional netrin-DCC and slit-robo signaling systems for their axons to reach and cross the midline (Kennedy et al., 1994; Serafini et al., 1994; Long et al., 2004; Sabatier et al., 2004). These signaling systems also function in axon pathfinding in the hindbrain. The initial attraction of inferior olivary axons to netrin-1 requires the DCC receptor (Bloch-Gallego et al., 2005). In addition, the axons of motor nuclei in the brainstem that contain branchiomotor and visceral motor neurons do not normally cross the midline. However, these axons inappropriately enter the midline and fail to reach their exit location when slit-robo signaling is attenuated (Hammond et al., 2005). The presence of axons in the brainstem utilizing netrin-DCC and slit-robo signaling for guidance, as well as the similar path taken by SCN and VCN axons, led us to question whether these signals guide the midline attraction and crossing of VCN axons in the VAS.

Netrins comprise a family of well-conserved, diffusible guidance molecules (Ishii et al., 1992; Kennedy et al., 1994; Serafini et al., 1994; Harris et al., 1996; Mitchell et al., 1996). The mouse genome possesses five netrin family members (netrin-1, -3, -4, -g1 and -g2) (Serafini et al., 1996; Wang et al., 1999; Nakashiba et al., 2000; Yin et al., 2000; Nakashiba et al., 2002). In vertebrates, netrin-mediated and Mathers, P. H. (2007). J Comp Neurol 504, 533-549. Reprinted with Permission of Wiley-Liss, Inc. a subsidiary of John Wiley \& Sons, Inc." 
attraction occurs through the deleted in colorectal cancer (DCC) receptor (KeinoMasu et al., 1996). The generalized utilization of this signaling pathway in the formation of commissural projections is evident from analyses of netrin-1- and DCCdeficient mice; errors are present in the corticospinal tract and retinotectal projections, with the absence of the corpus callosum and hippocampal commissure in these mice (Serafini et al., 1996; Deiner et al., 1997; Fazeli et al., 1997; Barallobre et al., 2000).

Cells at the midline also express molecules that function in axon repulsion. This activity prevents axons from inappropriately crossing the midline and aids the extension of commissural axons through the midline (Stein and Tessier-Lavigne, 2001). Slit proteins comprise a family of secreted molecules that repel axons expressing roundabout (robo) receptors. Like netrins and their receptors, slit and robo family members are highly conserved (Rothberg et al., 1990; Seeger et al., 1993; Itoh et al., 1998; Kidd et al., 1998; Zallen et al., 1998; Hao et al., 2001). All three mammalian slit homologues (slit-1, slit-2 and slit-3) are expressed at the spinal cord midline (Yuan et al., 1999). The three mammalian robo family members (robo1, robo-2 and robo-3/rig-1) are implicated in the guidance of spinal commissural axons (Brose et al., 1999; Long et al., 2004; Marillat et al., 2004; Sabatier et al., 2004). The absence of either robo-1 or robo-2 increases the number of SCN growth cones that fail to exit the midline of the spinal cord (Long et al., 2004).

In order for a cue to be used in the guidance of VCN axons, it must be expressed in the correct spatial and temporal distribution during VAS formation. Cochlear nucleus axons are present along the ventral surface of the rat E15 brainstem, with several axons reaching the midline, as seen by lipophilic dye labeling (Kandler and Friauf, 1993; Niblock et al., 1995). Additionally, while many rat cochlear neurons are still present in the ventricular zone at E13, dye-labeled axons of these neurons are found along the ventral surface of the brainstem (Niblock et al., 1995). A systematic analysis of outgrowth from the mouse embryonic cochlear nucleus has not been performed. Therefore, we set out to characterize the

Molecular guidance cues necessary for axon pathfinding from the ventral cochlear nucleus. Howell, D. M., Morgan, W. J., Jarjour, A. A., Spirou, G. A., Berrebi, A. S., Kennedy, T. E., and Mathers, P. H. (2007). J Comp Neurol 504, 533-549. Reprinted with Permission of Wiley-Liss, Inc. a subsidiary of John Wiley \& Sons, Inc." 
development of this projection in mice, with the goal of identifying key periods where guidance factors would be required.

Eph/Ephrin signaling is known to play an important role in the establishment of auditory brainstem circuits, including midline patterning effects (Cramer et al., 2002; Cramer et al., 2006). In contrast, only one study to date has examined the importance of the midline guidance factors, netrin-1, DCC, slit, and robo, in the formation of auditory brainstem circuits. Poe and Brunso-Bechtold (1998) utilized collagen gel cultures to evaluate axonal outgrowth from cochlear nucleus explants. They found that directed outgrowth was observed when cochlear nucleus explants were cultured with floor plate from the brainstem, but not toward a recombinant source of netrin-1. This result suggests that netrin-1 is not sufficient to direct VCN axon outgrowth (Poe and Brunso-Bechtold, 1998), although that study was not designed to address whether netrin-1 is necessary for VCN axon pathfinding. We examined the functional importance of netrin-1 and DCC in developing auditory brainstem circuits by examining the VCN axonal projections in mice lacking each of these genes and found that both components of the signaling pathway are required for midline attraction of VCN axons.

Molecular guidance cues necessary for axon pathfinding from the ventral cochlear nucleus. Howell, D. M., Morgan, W. J., Jarjour, A. A., Spirou, G. A., Berrebi, A. S., Kennedy, T. E., and Mathers, P. H. (2007). J Comp Neurol 504, 533-549. Reprinted with Permission of Wiley-Liss, Inc. a subsidiary of John Wiley \& Sons, Inc." 


\section{Methods}

\section{Animals}

Mice were maintained in an AAALAC-accredited animal facility at West Virginia University in compliance with IACUC regulations on a 12-hr light/dark cycle. FVB/NJ breeding pairs were obtained from The Jackson Laboratory (Bar Harbor, ME). DCC-deficient founders were a gift from Dr. Marc Tessier-Lavigne and maintained on a CD-1 background (Charles River Laboratories, Inc., Wilmington, $M A)$. Embryonic age (E) was calculated such that E0.5 denotes noon on the day following mating. Crown-rump measurements were used to confirm embryonic age, and $\mathrm{E} 19.5$ is equivalent to postnatal day $(\mathrm{P})$, the day of birth. $D C C$-deficient mice were genotyped as previously described (Fazeli et al., 1997). Briefly, standard PCR reagents were used with the following primers: forward DCC wild-type 5'GGCCATTGAGGTTCCTTT-3', forward DCC mutant 5'TCCTCGTGCTTTACGGTATC-3' and reverse DCC 5'-AAGACGACCACACGCGAG3'. Samples were first incubated at $94^{\circ} \mathrm{C}$ for 3 minutes and then taken 40 cycles at $94^{\circ} \mathrm{C}, 59^{\circ} \mathrm{C}$, and $74^{\circ} \mathrm{C}$. PCR products were visualized on a $1.6 \%$ agarose gel.

Pregnant mice were sacrificed by cervical dislocation on the appropriate gestational day. Embryos were collected, staged and decapitated. Their heads were immersion-fixed in a $4 \%$ paraformaldehyde/phosphate-buffered saline (PBS) solution ( $\mathrm{pH} 7.4)$ overnight at $4^{\circ} \mathrm{C}$. Postnatal mice (P0) were anesthetized by hypothermia (Phifer and Terry, 1986) and either transcardially perfused with PBS followed by $4 \%$ paraformaldehyde/PBS or decapitated and their heads immersed in the same fixative. Immersion-fixed heads from netrin-1-deficient and littermate control pups were prepared at McGill University and genotyped as previously described (Serafini et al., 1996). Briefly, standard PCR reagents were used with the following primers: forward 5'-CGCTGATGTGCCCGGCTTCTG-3' and reverse 5'GGTCGGCTTACGGCGGTGATTTTG-3'. Samples were incubated for 24 cycles at $92^{\circ} \mathrm{C}, 62^{\circ} \mathrm{C}$, and $72^{\circ} \mathrm{C}$. Reactions with equal quantities of genomic DNA were 
stopped within the linear amplification range to differentiate samples carrying one or two copies of the $\beta$-galactosidase gene in the netrin-1 locus.

\section{Labeling cochlear nucleus and midline glial projections}

Fibers traversing the cochlear nucleus were visualized with the lipophilic carbocyanine dyes, 1,1'-dioctadecyl-3,3,3',3'-tetramethylindocarbocyanine perchlorate (Dil, Molecular Probes, Eugene, OR) and 1,1'-dioctadecyl-3,3,3',3'tetramethylindodicarbocyanine perchlorate (DiD, Molecular Probes) in fixed embryonic and postnatal brains ( $n \geq 5$ for each age). Based on the location of mafB staining (see below), the cochlear nucleus was carefully exposed with the aid of a dissecting microscope and approximately $10-20 \mathrm{~nL}$ of a Dil or DiD solution (2 $\mathrm{mg} / \mathrm{mL}$ in $100 \%$ DMSO) were loaded into the cochlear nucleus with finely pulled glass pipettes and a picospritzer (General Valve Corporation). Labeled samples were transferred to fresh $4 \%$ paraformaldehyde/PBS solution and placed in the dark at $37^{\circ} \mathrm{C}$ for at least 1 month. After that time, brains were removed from the skull and the fluorescent dyes imaged with a digital camera (Magnafire, Optronics, Goleta, CA) attached to a fluorescence stereomicroscope (MZFLIII, Leica). Brains were then either blocked in 3\% agar/PBS for sectioning on a vibratome at $100-200 \mu \mathrm{m}$ or transferred to $30 \%$ sucrose in PBS and then immersed in TBS tissue freezing medium (Triangle Biomedical Sciences, Durham, NC) for sectioning on a cryostat at $20 \mu \mathrm{m}$. Fluorescence images were captured with a laser scanning confocal microscope (LSM510 Meta, Zeiss) or an upright fluorescence microscope (AX70, Olympus). Placement of tracer molecules and image capture were conducted with the investigator blind to genotype. Littermates or age-matched wild-type mice served as controls.

In addition to labeling cochlear nucleus projections, visualization of midline glial cell processes with $\mathrm{DiD}$ and Dil was performed in isolated E13.5 to P0 brainstems. For these, $2-5 \mathrm{~nL}$ of DiD or Dil solutions were applied to the ventral midline and samples were transferred to fresh $4 \%$ paraformaldehyde/PBS solution and placed in the dark at $37^{\circ} \mathrm{C}$ for $1-2$ weeks. Brainstems were then oriented in $3 \%$ 
agar/PBS, sectioned on a vibratome at $150 \mu \mathrm{m}$ and incubated with SYTOX green (Molecular Probes), as described by the manufacturer, prior to image capture on a LSM510 Meta confocal microscope.

\section{Cloning of cDNAs encoding axon guidance molecules}

Total RNA from an E15.5 or P0 mouse brainstem was isolated with Trizol (Invitrogen, Carlsbad, CA) and reverse transcribed with random hexamer oligonucleotides. Gene-specific primers were picked using primer3 software (Rozen and Skaletsky, 2000) for each gene of interest to yield approximately $900 \mathrm{bp}$ fragments. The gene-specific primers are as follows: netrin-1 (GI:1730292, nucleotides 575 to 1451) forward 5'-TCACCAAACAGAACGAGCAG-3', reverse 5'ATCTTCAGCTTGCCTTTGGA-3'; DCC (Gl:1405921, nucleotides 3394 to 4287) forward 5'-CTCTCAACGAACCACCCATT-3', reverse 5'GTCCTGGCTGAGACAAAAGC-3'; slit-1 (Gl:5532492, nucleotides 1954 to 2854) forward 5'-TCATTCCAGGGACAGAGGAC-3', reverse 5'TTGTTGCTCAAGTCCACGAG-3'; robo-1 (Gl:2811215, nucleotides 3588 to 4487) forward 5'-CAGCAACAGCGAGGAATACA-3', reverse 5'TGGACACTGGGCGATTTTAT-3'; robo-2 (Gl:6164830, nucleotides 2389 to 3234) forward 5'-TGTTCGTCTCCACAATCCAG-3', reverse 5'-

TTGGGGTCGCCAGTATTTAG-3'; mafB (Gl:31543225, nucleotides 1809 to 2708) forward 5'-GGAGAACACTGGCTCTCAGC-3', reverse 5'TGCCAATGTGTGGGTTTCTA-3'. PCR fragments were gel isolated and cloned with a PCR-Script kit (Stratagene, La Jolla, CA). All products were confirmed by sequencing (Northwoods DNA Inc., Solway, MN) and subsequently used for the production of in situ hybridization probes.

\section{In situ hybridization}

Digoxigenin-labeled RNA probes were prepared as described by the manufacturer (Roche Applied Science, Indianapolis, IN), purified with a nucleotide removal kit (Qiagen, Valencia, CA) and diluted in hybridization solution. Brains from 
immersion-fixed FVB and CD1 heads ranging in age from E12.5 through P0 were removed and placed in $4 \%$ paraformaldehyde/PBS at $4{ }^{\circ} \mathrm{C}$ overnight. Whole-mount in situ hybridization was performed essentially as previously described (Cygan et al., 1997). Briefly, following storage in $100 \%$ ethanol at $-20^{\circ} \mathrm{C}$, brains were incubated with proteinase $\mathrm{K}$, rinsed with glycine, and fixed with paraformaldehyde and glutaraldehyde, with PBT (PBS + 0.1\% Tween-20) washes between steps at room temperature (RT). Brains were transferred to hybridization solution and incubated at $63^{\circ} \mathrm{C}$ for two hours. Digoxigenin-labeled antisense RNA probes were added and brains were returned to $63^{\circ} \mathrm{C}$ for 16 hours. Samples were taken through a series of stringent sodium citrate washes at $70^{\circ} \mathrm{C}$, incubated with RNAse A (Sigma-Aldrich Co., St. Louis, MO) and RNAse T1 (Sigma) and followed by another series of stringent sodium citrate washes at $65^{\circ} \mathrm{C}$. Samples were then blocked with normal lamb serum and incubated at $4{ }^{\circ} \mathrm{C}$ overnight with an alkaline phosphataseconjugated anti-digoxigenin antibody (1:4000, cat. Number 11093274910, Roche Applied Science). Expression was visualized with BM purple (Roche Applied Science) following a series of washes. Whole brains were digitally photographed using a stereomicroscope (MZFLIII, Leica). To perform in situ hybridization reactions on cryostat sections, slides were immersed in PBT at RT, incubated in hybridization solution at $63^{\circ} \mathrm{C}$ for three hours and reacted with labeled sense or antisense RNA probes at $63^{\circ} \mathrm{C}$ for 16 hours. Slides were taken through a series of stringent sodium citrate washes at $70^{\circ} \mathrm{C}$, incubated with RNAse A (Sigma) and then another series of stringent sodium citrate washes at $65^{\circ} \mathrm{C}$. Slides were then blocked with normal lamb serum, incubated with an alkaline phosphatase-conjugated antidigoxigenin antibody (1:4000, Roche Applied Science) at $4^{\circ} \mathrm{C}$ overnight and expression was visualized with BM purple (Roche Applied Science) following a series of washes. Slides were dried, coverslipped with cytoseal (Richard-Allan Scientific, Kalamazoo, MI) and digitally photographed on an upright microscope (AX70, Olympus). At least three brains at each age were processed together and and Mathers, P. H. (2007). J Comp Neurol 504, 533-549. Reprinted with Permission of Wiley-Liss, Inc. a subsidiary of John Wiley \& Sons, Inc." 
reactions were repeated at least three times (i.e. $-n \geq 9$ for each probe at every age analyzed). Control samples were processed identically with a sense RNA probe; no hybridization signal was detected in these samples (see results).

\section{Immunohistochemistry}

Immersion-fixed heads ( $n=3$ to 6 at each age) were cyroprotected in $30 \%$ sucrose in PBS, oriented in TBS tissue freezing medium and stored at $-80^{\circ} \mathrm{C}$ until sectioned in the coronal plane at 14-20 $\mu \mathrm{m}$ on a cryostat. To block nonspecific labeling, sections were immersed in PBS containing $0.6 \% \mathrm{H}_{2} \mathrm{O}_{2}$ and $5 \%$ methanol for $1 \mathrm{hr}$ at RT. Samples were washed in PBS and then further blocked in PBS containing $5 \%$ heat-inactivated normal serum and $0.1 \%$ Triton X-100 at RT for $1-2$ hours. Primary antibodies were diluted in PBS containing $4 \%$ serum and $0.1 \%$ Triton $\mathrm{X}-100$. Samples were incubated overnight in the primary antibody solution at $4^{\circ} \mathrm{C}$. The antibodies used in this study were: DCC (1:2000, SC-6535, Santa Cruz Biotechnology, Inc., Santa Cruz, CA), mafB (1:2000, SC-10022, Santa Cruz Biotechnology), class III $\beta$-tubulin (1:200, CBL412, Chemicon International, Temecula, CA), NeuN (1:2000, MAB377, Chemicon International), and glial fibrillary acidic protein (GFAP, 1:200, Z0334, Dako, Glostrup, Denmark). Slides were rinsed with PBS and incubated with appropriate biotinylated secondary antibodies (1:200, Vector Laboratories, Burlingame, CA) or appropriate Alexa Fluor dye-conjugated secondary antibodies (1:200, Molecular Probes) in the same vehicle as the primary antibody. Slides were then rinsed with PBS and digitally photographed on a LSM 510 Meta confocal microscope (fluorescent) or incubated with elite $A B C$ reagent (Vector Laboratories) as described by the manufacturer (biotinylated). Immunoreactivity was visualized with $0.05 \% 3,3$ '-diaminobenzidine tetrahydrochloride (DAB, Sigma) with $0.01 \% \mathrm{H}_{2} \mathrm{O}_{2}$ in $0.5 \mathrm{M}$ Tris $\mathrm{pH}$ 7.65. Slides were digitally photographed on an upright microscope (AX70, Olympus). A subset of 
adjacent sections was stained for Nissl substance with $1 \%$ cresyl violet using standard protocols.

The DCC antibody was raised against a peptide corresponding to amino acids 1,390-1,409 of the human DCC protein (GI:1169233) and labels a single band around $190 \mathrm{kDa}$ on Western blots of whole E14.5 mouse brain extracts (Ratcliffe et al., 2006; manufacturer's technical information; our unpublished observations). Additionally, we find that the staining of DCC antibody and in situ hybridization probes are consistent. The peptide used to generate this antibody shares $60 \%$ sequence identity to neogenin, and we find that this DCC antibody is cross-reactive to neogenin by Western blotting. However, brainstems from DCC-deficient mice are not immunoreactive with this DCC antibody (see results). Furthermore, immunolabeling is abolished when DCC antibody is incubated with a competitive peptide (Dalvin et al., 2003; Mazelin et al., 2004). The antibody to mafB was raised against a peptide corresponding to amino acids 2-15 from human mafB (Gl:4809134). This mafB antibody has been well characterized and shown to be specific for only mafB (Matsuoka et al., 2003; Sevinsky et al., 2004). Addition of mafB antibody previously incubated with mafB immunizing peptides for $1 \mathrm{hr}$ at RT abolished immunoreactivity (data not shown). Furthermore, structures positive for mafB immunoreactivity are also labeled with mafB in situ hybridization probes (see results and Farago et al., 2006). The mouse monoclonal antibody to class III $\beta$ tubulin was raised against the peptide, ESESQGPK, from the human class III $\beta$ tubulin sequence ( $\mathrm{Gl}: 16755780)$. This antibody is well characterized and shown to be specific for only the class III $\beta$-tubulin isotype in neurons; no reactivity is observed in glial cells (manufacturer's technical information and Draberova et al., 1998). The mouse monoclonal antibody to NeuN was raised against purified mouse brain nuclei and the neuronal specificity has been well characterized (Mullen et al., 1992). Rabbit polyclonal GFAP antibody was raised against isolated full-length cow GFAP protein and is known to specifically label astrocytes (manufacturer's technical information). This GFAP antibody detects a single 50-53 kDa polypeptide band by Western blot and Mathers, P. H. (2007). J Comp Neurol 504, 533-549. Reprinted with Permission of Wiley-Liss, Inc. a subsidiary of John Wiley \& Sons, Inc." 
(Baker et al., 2006; Toma et al., 2001). Primary antibody was omitted in control samples; no immunoreactivity was detected in these samples.

\section{VCN neuronal estimation}

Perfusion-fixed P0 brains were cryoprotected in 30\% sucrose in PBS and sectioned in the coronal plane at a thickness of $40 \mu \mathrm{m}$ on a freezing microtome. Floating tissue sections were processed as described above for mafB immunohistochemistry. Sections were mounted in serial order on glass slides, air dried and coverslipped with cytoseal. Unbiased stereology was performed essentially as previously described (Kulesza et al., 2002). Briefly, we implemented the optical fractionator protocol in Stereo Investigator (MBF Bioscience, Williston, VT). Contours were traced using a 10X objective lens and counting frames (625 $\mu \mathrm{m}^{2}$ ) were created to sample from each contour. The section thickness was measured at several locations with a 100X oil immersion objective lens (NA 1.35) and determined to be between 8 and $10 \mu \mathrm{m}$ after shrinkage. The top and bottom 1 $\mu \mathrm{m}$ of the section were reserved as guard zones. Cell counts were made on a total of 5 brains for each $D C C$ genotype. We counted approximately 300 mafB-positive neurons in the $\mathrm{VCN}$ (one side only) from a total of 5-6 sections from each brain. Average cell counts were grouped according to $D C C$ genotype and analyzed by a student's t-test and a one-way analysis of variance (ANOVA). Average cell counts are rounded to the nearest ten and presented as mean \pm SEM (Gundersen and Jensen, 1987). The coefficient of error ranged from 0.06 to 0.07 for all samples counted.

\section{Image analysis}

All images were stored in Tagged-Image File Format (TIFF) and examined with Adobe Photoshop 7.0 (Adobe Systems Inc., San Jose, CA), where brightness, contrast and color balance were optimized uniformly, if necessary. Regions surrounding tissues processed for immunohistochemistry or in situ hybridization 
were changed to a uniform appearance with the magic wand, paint bucket and pencil tools. Figure compilations were prepared by importing the final images into Freehand 11 (Macromedia, Inc., San Francisco, CA). and Mathers, P. H. (2007). J Comp Neurol 504, 533-549. Reprinted with Permission of Wiley-Liss, Inc. a subsidiary of John Wiley \& Sons, Inc." 


\section{Results}

\section{Identification of the embryonic ventral cochlear nucleus}

Although the entry point of the vestibulocochlear nerve accurately defines the location of the cochlear nucleus, we sought a marker that could identify VCN neurons at early embryonic ages for the studies presented here. Previously, mafB was shown to be expressed in embryonic chick auditory brainstem and the P10 mouse VCN (Eichmann et al., 1997; Farago et al., 2006). mafB, also known as kreisler, is a member of the maf family of basic leucine zipper-containing transcription factors (Cordes and Barsh, 1994; Kataoka et al., 1994). Expression of mafB is necessary for both hindbrain segmentation and rhombomeric anteroposterior specification; in addition, mice carrying two mutant mafB alleles have hearing and vestibular defects that are attributed to errors in hindbrain segmentation (Deol, 1964; Frohman et al., 1993; Manzanares et al., 1999; McKay et al., 1994). Therefore, we decided to further characterize the developmental expression of this gene in the mouse VCN. We isolated a mafB cDNA fragment from a P0 cDNA pool to produce digoxigenin-labeled antisense RNA probes for in situ hybridization reactions. We found that $\mathrm{VCN}$ neurons express mafB as early as E13.5 (Fig. 1A). The VCN continues to express mafB at later embryonic and neonatal stages (Figs. $1 \mathrm{~B}$ and $1 \mathrm{C}$ ) with continued expression in the adult VCN (data not shown). Like the gene, mafB protein is expressed in the VCN as early as E13.5 (Fig. 1D). VCN neurons continue to express mafB in later stages of embryonic development (Figs. $1 \mathrm{E}$ and $1 \mathrm{~F}$ ) and in the adult (data not shown). Based on these labeling patterns, mafB is an appropriate marker for the VCN in embryonic stages though adulthood.

\section{Development of ventral cochlear nucleus efferent projections}

We injected the lipophilic tracers, Dil and DiD, into the presumptive cochlear nucleus of fixed FVB/NJ wild-type embryonic brains at different developmental stages (E12.5 to P0) to determine the timing of VAS axonal outgrowth, as well as the extent of the axonal projections. At all ages, the presumptive cochlear nucleus was 
identified by the entry point of the vestibulocochlear nerve and/or its expression of mafB (Fig. 1). The earliest time point examined was E12.5 because the cells whose projections make up the VAS (globular bushy, spherical bushy and multipolar) are not born until E12-13 (Pierce, 1967; Martin and Rickets, 1981). In addition, this is the earliest time point at which we were able to identify the presumptive cochlear nucleus in the intact brain. The brains were later sectioned to confirm that the application site included the presumptive cochlear nucleus (data not shown).

Labeled VCN axons extending toward the midline along the ventral surface were first observed at E13.0, with most axons visible near the ventral surface on the ipsilateral side of the brainstem (Fig. 2B). Occasionally, axons reach the midline by E13.0; however, this was more readily apparent by E13.5 (Fig. 2C). At E13.5, the most advanced contralateral fibers make a rostral turn to extend dorsolaterally toward the lateral lemniscus (data not shown). Numerous labeled axons reach and cross the midline by E14.5, with a subset making a rostral turn to enter the lateral lemniscus (arrowhead in Fig. 2D). Other labeled fibers continue to extend laterally within the contralateral superior olivary complex (SOC) with occasional fibers proceeding toward the contralateral cochlear nucleus (data not shown). Labeled axons in the lateral lemniscus are clearly seen at E15.5 (Fig. 2E). The most advanced axons extending in the lateral lemniscus reach the inferior colliculus as early as E16.5 (data not shown). Collateral axonal projections are first observed at E15.5 within the lateral region of the ipsilateral SOC (Fig. 2E). The LSO is recognizable as a distinct cell group in this position by E17.5. However, some of these collaterals could also be located within nearby nuclei. Greater numbers of collateral projections in the ipsilateral and contralateral SOC are observed at later developmental stages (data not shown).

\section{netrin-1 expression in the auditory brainstem}

The Dil and DiD labeling studies indicate that axonal outgrowth by VCN neurons occurs as early as E13 in the mouse, with larger numbers of axons crossing 
the midline over the next two days. To examine whether a netrin family member might mediate the midline attraction of cochlear nucleus axons, we used in situ hybridization to examine the expression of netrin family members. We isolated a cDNA fragment for each of the netrin genes from an E15.5 brainstem cDNA pool. These fragments were used to produce digoxigenin-labeled antisense RNA probes for in situ hybridization. Only netrin-1 mRNA was detectable at the midline of the brainstem.

In situ hybridization with a netrin-1 antisense probe labels a group of cells at the dorsal midline that is continuous from spinal cord to midbrain (Fig. 3A and data not shown). Labeling at the midline is best visualized in coronal tissue sections (Fig. 3B). Netrin-1 is expressed as early as E11.5 and persists through P0, the oldest age analyzed (E13.5 shown in Figs. 3A and 3B). At the level of the auditory brainstem, netrin-1 is expressed by cells located at the dorsal midline, as well as by more lateral cells in the germinative zone lining the ventricular space (Fig. 3B). The morphology of these netrin-1-positive midline cells is visualized by applying the lipophilic tracers, DiD or Dil, to the midline at the ventral surface of the auditory brainstem (Fig. 3C). Labeled processes extend to the dorsal surface of the midline where cell bodies are visualized (Fig. 3C). Since netrin-1 protein may be secreted from any location along these midline cells, the spatial and temporal distribution of netrin-1 protein expression (but not mRNA expression) is consistent with a role in the attraction of VCN axons to the ventral midline.

\section{$D C C$ is expressed in the ventral cochlear nucleus}

Netrin-mediated axon attraction occurs through its binding to the DCC receptor (Keino-Masu et al., 1996). The presence of netrin-1 expressing cells along the migratory path of VCN axons led us to analyze the expression of $D C C$ in the mouse auditory brainstem from E12.5 through P0, including the period of axonal outgrowth from the cochlear nucleus. In situ hybridization with a DCC antisense probe labels cells in the lateral brainstem that correspond to the location of the 
developing cochlear nucleus (compare Figs. 3D and 3F with mafB expression in Fig. 1). DCC expression is observed in the presumptive cochlear nucleus as early as E12.5 (data not shown), closely corresponding to the birthdates reported for globular bushy cells, multipolar cells and spherical bushy cells of the VCN (Pierce, 1967; Martin and Rickets, 1981). At E13.5, DCC is expressed in the presumptive cochlear nucleus (Figs. 3D and 3F). The cerebellum and pontine migratory stream, two regions known to express $D C C$ during their development (Cooper et al., 1995; Yee et al., 1999), are also DCC-positive at this stage (Fig. 3D). However, no clear boundary exists between the DCC expression within the cochlear nucleus and cerebellum (Fig. 3D). A row of cells in the subventricular space is DCC-positive at E13.5 (arrow in Fig. 3F). DCC expression in the cochlear nucleus is maintained through P0 (data not shown). No staining is observed in samples processed with a $D C C$ sense probe (Fig. 3E).

DCC protein expression follows a time course similar to that observed for DCC RNA expression, although with several key differences. DCC immunohistochemistry on auditory brainstem sections labels a group of axons that exit the cochlear nucleus and extend along the ventral surface from E12.5 through E16.5 (E13.5 and E15.5 shown in Figs. 3G and 3I, respectively). Despite the intense labeling of axons leaving the cochlear nucleus, cell bodies in the cochlear nucleus are not DCC-immunoreactive (Figs. 3G and 3I). No DCC-immunoreactive axons exiting the cochlear nucleus are observed in DCC-deficient brainstems (Fig. $3 \mathrm{H}$ ). Localization of the DCC-positive axons to the VAS was confirmed by processing adjacent sections from a brain injected with Dil in the cochlear nucleus at E15.5 for either DCC immunohistochemistry or Dil epifluorescence (compare Figs. 3I and 3J). Additionally, DCC immunoreactivity, unlike DCC mRNA signal, decreases at E17.5 and is not detected on VAS axons at PO (data not shown). The timing and location of $D C C$ mRNA in the cochlear nucleus and DCC protein on axons extending from the cochlear nucleus is consistent with a role for netrin-DCC signaling in the midline attraction of VCN projections that travel in the VAS.

Molecular guidance cues necessary for axon pathfinding from the ventral cochlear nucleus. Howell, D. M., Morgan, W. J., Jarjour, A. A., Spirou, G. A., Berrebi, A. S., Kennedy, T. E., and Mathers, P. H. (2007). J Comp Neurol 504, 533-549. Reprinted with Permission of Wiley-Liss, Inc. a subsidiary of John Wiley \& Sons, Inc." 


\section{slit and robo expression in the lower auditory brainstem}

At the midline, DCC-positive axons must alter their responsiveness to the midline attractant, netrin-1, to extend through the midline and enter the contralateral brainstem. Spinal commissural neurons require a functional slit-robo repulsive signal to efficiently exit the midline (Long et al., 2004). In addition, slit-robo signals silence netrin-DCC-mediated attraction, thereby permitting growth cones to extend through the midline (Stein and Tessier-Lavigne, 2001). Therefore, we analyzed the expression of slit and robo family members in the developing auditory brainstem as possible mediators of contralateral auditory projections.

As with the netrin family, we isolated a cDNA fragment for each slit family member from an E15.5 mouse brainstem cDNA pool. Antisense RNA probes for all three slit genes were produced for in situ hybridization. However, only slit-1 was found in the embryonic auditory brainstem. In situ hybridization with a slit-1 antisense probe labels cells at the dorsal midline at E13.5 that are continuous from spinal cord to midbrain (Fig. 4A and data not shown). The expression of slit-1 is better revealed in coronal sections (Fig. 4B). Slit-1 is expressed as early as E12.5 and persists through $\mathrm{P0}$ (E13.5 and E14.5 shown in Figs. 4A and 4B, respectively). Similar to the expression pattern for netrin-1, slit-1 expression extends laterally to a group of cells lining the ventricular space (Figs. 4A and 4B), and slit-1 protein expression is presumed to spread to the ventral surface of the brainstem through ventrally extended cellular processes (Fig $3 C$ ).

Mouse cDNA fragments for robo-1 and robo-2 were also obtained and used to produce antisense in situ hybridization probes. Robo-1 is expressed in the presumptive cochlear nucleus as early as E13.5 (Fig. 4C). The wedge-shaped cluster of cells closely resembles the size and shape of the cell cluster labeled with the $D C C$ antisense probe at this age (compare Figs. $4 C$ and 3D). Labeled coronal sections are also consistent with robo-1 expression in the presumptive cochlear nucleus (Fig. 4D). The presumptive cochlear nucleus continues to express robo-1

Molecular guidance cues necessary for axon pathfinding from the ventral cochlear nucleus. Howell, D. M., Morgan, W. J., Jarjour, A. A., Spirou, G. A., Berrebi, A. S., Kennedy, T. E., and Mathers, P. H. (2007). J Comp Neurol 504, 533-549. Reprinted with Permission of Wiley-Liss, Inc. a subsidiary of John Wiley \& Sons, Inc." 
through P0 (data not shown). Similar to the pattern of DCC expression, robo-1 is present in the presumptive cerebellum, but the pontine migratory stream does not express robo-1 and a clear division exists between the presumptive cerebellum and cochlear nucleus (Fig. 4C). In situ hybridization with a robo-2 antisense probe labels the presumptive cochlear nucleus as early as E13.5 (Fig. 4E). The robo-2-positive cell group overlaps a portion of the DCC-positive cluster of cells (compare Figs. 4E and $3 \mathrm{D}$ ), as well as a portion of the robo-1-positive region (compare Figs. 4E and $4 \mathrm{C})$. Coronal sections confirm that the location of the robo-2-positive cell group is the cochlear nucleus (Fig. 4F). Cochlear nucleus expression of robo-2 persists through P0 (data not shown). Like robo-1, robo-2 is expressed in the presumptive cerebellum at the ages analyzed (Fig. 4E). The expression of robo-1 and robo-2 in the presumptive cochlear nucleus and slit-1 at the midline of the auditory brainstem supports the potential utilization of slit-robo signaling in the progression of VCN axons from the midline into the contralateral brainstem.

\section{Analysis of cochlear nucleus projections in DCC and netrin-1 knockout mice}

The expression of netrin-1 at the midline and $D C C$ in the cochlear nucleus suggests this signaling system is used to attract the axons of $\mathrm{VCN}$ neurons to the midline. A previous study suggested that netrin-1 was not sufficient to attract VCN axons (Poe and Brunso-Bechtold, 1998). To determine the functional importance of netrin-1 and DCC signals, we characterized the cochlear nucleus projections in the respective knockout mouse lines (Serafini et al., 1996; Fazeli et al., 1997). The extent of cochlear nucleus projections in the DCC-mutant brainstem was evaluated with Dil and DiD placements in the cochlear nucleus at E14.5, E16.5, and P0. The analysis of the netrin-1-deficient brainstem was performed at $\mathrm{P} 0$. This time point represents the latest stage possible for study due to the perinatal lethality associated with pups homozygous for DCC or netrin-1 mutant alleles (Serafini et al., 1996; Fazeli et al., 1997).

Molecular guidance cues necessary for axon pathfinding from the ventral cochlear nucleus. Howell, D. M., Morgan, W. J., Jarjour, A. A., Spirou, G. A., Berrebi, A. S., Kennedy, T. E., and Mathers, P. H. (2007). J Comp Neurol 504, 533-549. Reprinted with Permission of Wiley-Liss, Inc. a subsidiary of John Wiley \& Sons, Inc." 
At E14.5, dye-labeled VCN axons traveling in the VAS of wild-type CD-1 mice, the parent strain of the $D C C$ mutant, closely matched the extent of labeling in FVB/NJ mice (Fig. 1D and data not shown). We observed that labeled VCN axons traveling in the VAS cross the ventral midline in brainstems carrying two functional $D C C$ alleles $(D C C+/+)$ at all ages analyzed $(n=14, P 0$ shown in Figs. $5 A, 5 B$ and $\left.5 B^{\prime}\right)$. Similarly, contralateral VCN axons are labeled in brainstems heterozygous for a mutant $D C C$ allele $\left(D C C+/-, n=16, P 0\right.$ shown in Figs. $5 C, 5 D$ and $\left.5 D^{\prime}\right)$. Labeled VCN axons appear qualitatively identical in embryos carrying two or one functional DCC alleles at all ages analyzed (Fig. 5). In contrast to these control samples, no axons are seen exiting the $\mathrm{VCN}$ in brainstems homozygous for the $D C C$ mutation $(D C C-/-)$ at E14.5 $(n=3)$, E16.5 $(n=4)$ and the majority of P0 pups $(n=9 / 12$, Figs. $5 \mathrm{E}, 5 \mathrm{~F}$ and $\left.5 \mathrm{~F}^{\prime}\right)$. In each of these cases, Dil and DiD placements successfully labeled the vestibulocochlear nerve to the spiral ganglion (data not shown), and coronal sections confirm that dye placements were within the VCN (Fig. 5F). Axons are occasionally observed exiting the VCN in DCC-null mice, but only at P0 $(\mathrm{n}=$ $3 / 12$, Figs. $5 \mathrm{G}$ and $5 \mathrm{H}$ ). These labeled axons are observed entering the lateral region of the ipsilateral SOC (Fig. $5 \mathrm{H}$ ). In these few DCC-null pups with axons exiting the $\mathrm{VCN}$, no axons reach the midline, whereas many contralateral axons are observed in pups with functional $D C C$ alleles (compare Figs. 5B', 5D' and $5 \mathrm{H}^{\prime}$ ).

As in the DCC wild-type brainstem, PO pups carrying two functional netrin-1 alleles (netrin-1 +/+) contain dye-labeled VCN axons in the VAS that cross the ventral midline $\left(n=6\right.$, Figs. $6 A, 6 B$ and $\left.6 B^{\prime}\right)$. Contralateral VCN axonal projections are also labeled in mice heterozygous for a netrin-1 mutant allele (netrin-1 +/-, $n=6$, Figs. $6 \mathrm{C}, 6 \mathrm{D}$ and $\left.6 \mathrm{D}^{\prime}\right)$. Mice homozygous for the netrin-1 wild-type allele could not be distinguished from heterozygotes on the basis of VCN axonal projections (Fig. 6). Unlike the DCC-null brainstems, labeled VCN axons are always observed in the VAS in P0 mice homozygous for the netrin-1 mutation (netrin-1 -/-, $\mathrm{n}=4$, Figs. $6 \mathrm{E}$ and $6 \mathrm{~F}$ ). Axons traveling in the VAS enter the lateral region of the ipsilateral SOC similar to the pattern occasionally observed in DCC-null PO brainstems (compare

Molecular guidance cues necessary for axon pathfinding from the ventral cochlear nucleus. Howell, D. M., Morgan, W. J., Jarjour, A. A., Spirou, G. A., Berrebi, A. S., Kennedy, T. E., and Mathers, P. H. (2007). J Comp Neurol 504, 533-549. Reprinted with Permission of Wiley-Liss, Inc. a subsidiary of John Wiley \& Sons, Inc." 
arrow in Figs. 6F and 5H). However, labeled VCN axons are never observed reaching the midline in netrin-1-deficient mice (Fig. 6F').

\section{Analysis of ventral cochlear nucleus cell number}

The complete absence of VCN axonal projections in the embryonic DCCdeficient brainstem contrasts the disorganized outgrowth of $\mathrm{SCN}$ axons observed in the spinal cord. The failure of axons to exit the VCN in most (84\%) DCC mutants analyzed at all stages suggests that $\mathrm{VCN}$ neurons may require netrin-DCC signaling for additional aspects of development beyond midline attraction. Given the documented role for netrin-DCC signaling in cellular migration (Bloch-Gallego et al., 1999; Yee et al., 1999), we reasoned that DCC activity could be required for the migration of newly born neurons into the cochlear nucleus. A qualitative inspection of the cochlear nucleus using mafB immunoreactivity (Figs. 7A-C) and Nissl staining (Figs. 7D-F) did not reveal any gross morphological abnormalities in the VCN of PO pups carrying two, one or no functional DCC alleles. However, we sought to determine if there were differences in the number of $\mathrm{VCN}$ neurons across genotypes in the DCC mutant strain.

To quantify any potential differences among animals of different $D C C$ genotypes, we used unbiased stereology to estimate the number of mafBimmunoreactive VCN neurons in P0 pups from the DCC mutant strain (Fig. 7G). The lack of early specific markers for the subtypes of cells present in the VCN prevents a direct analysis of whether specific neuronal populations are absent or deficient. At embryonic and neonatal ages, few markers exist for $\mathrm{VCN}$ neurons, except mafB (Fig. 1). At P0, many mafB-immunoreactive VCN neurons are also positive for NeuN (Sup. Figs. $1 \mathrm{~A}-\mathrm{C}$ ). At this early age, portions of the VCN (as defined by Nissl staining and mafB immunoreactivity) do not contain NeuN-positive cells (Sup. Figs. 1B and 1C). NeuN is not expressed by all neurons (Mullen et al., 1992), and the VCN may contain one or more cell types that are not reactive for NeuN. However, all mafBpositive cells are additionally positive for neuron-specific class III $\beta$-tubulin (Sup.

Molecular guidance cues necessary for axon pathfinding from the ventral cochlear nucleus. Howell, D. M., Morgan, W. J., Jarjour, A. A., Spirou, G. A., Berrebi, A. S., Kennedy, T. E., and Mathers, P. H. (2007). J Comp Neurol 504, 533-549. Reprinted with Permission of Wiley-Liss, Inc. a subsidiary of John Wiley \& Sons, Inc." 
Figs. 1D-F), and no mafB-positive cells are reactive for glial fibrillary acidic protein (Sup. Figs. 1G-I). Taken together, this indicates that mafB is specific for VCN neurons and furthermore appears to label the vast majority of VCN neurons. Because of its neuronal specificity of expression within the PO VCN, we selected tissue processed for mafB immunohistochemistry for unbiased stereology. The spinal nucleus of the trigeminal nerve (Figs. 7A-C) and the SOC (data not shown) are the only other mafB-immunoreactive structures in the P0 hindbrain. We found that mice carrying two functional $D C C$ alleles contain $22,970 \pm 190(n=5)$ neurons per VCN, while mice heterozygous for the $D C C$ mutation contain a statistically similar number of neurons per VCN $(22,480 \pm 200 ; n=5 ; p=0.455)$. However, mice homozygous for the DCC mutation have $\sim 10 \%$ fewer neurons per VCN $(20,430 \pm 150 ; n=5)$. An analysis of variance (one-way ANOVA) indicates this reduction is statistically significant $(p=0.002)$. Thus, most $(\sim 90 \%) \mathrm{VCN}$ neurons do not require netrin-DCC signaling to reach the cochlear nucleus.

Molecular guidance cues necessary for axon pathfinding from the ventral cochlear nucleus. Howell, D. M., Morgan, W. J., Jarjour, A. A., Spirou, G. A., Berrebi, A. S., Kennedy, T. E., and Mathers, P. H. (2007). J Comp Neurol 504, 533-549. Reprinted with Permission of Wiley-Liss, Inc. a subsidiary of John Wiley \& Sons, Inc." 


\section{Discussion}

The present study was undertaken to identify axonal guidance cues necessary for the development of the mammalian auditory brainstem. We report that initial axonal outgrowth of VCN neurons occurs as early as E13.0 in mice, with larger numbers of axons crossing the midline over the next two days. Netrin-1 and slit-1 are expressed at the midline of the auditory brainstem during the growth of VCN axonal projections. DCC, robo-1 and robo-2 are expressed in the cochlear nucleus, and axons exiting the cochlear nucleus that travel along the ventral surface of the brainstem express DCC during the formation of the VAS. Furthermore, the VAS is disrupted in mice homozygous for mutations in the netrin-1 or DCC genes. Mice deficient in DCC activity possess $\sim 10 \%$ fewer neurons per VCN, although this loss is not sufficient to explain the disruption of the ventral acoustic stria (see below). Our results suggest that netrin-DCC signaling is indeed necessary to direct $\mathrm{VCN}$ axonal outgrowth and midline crossing.

\section{Development of VCN neurons}

Tritiated-thymidine labeling of newborn neurons determined that the birth dates of globular bushy, multipolar and spherical bushy cells of the ventral cochlear nucleus occur between E12 and E13 in mouse (Pierce, 1967; Martin and Rickets, 1981). In rat, VCN neurons are born between $E 13$ and $E 15$ with the appearance of an axon occurring shortly after birth of the neuron (Altman and Bayer, 1980; Weber et al., 1991; Kandler and Friauf, 1993; Niblock et al., 1995). Many VCN neurons may still reside in the germinitive zone at this stage of development. We find mouse VCN neurons extend an axon as early as E13.0; this occurs within one day of their birth. As in rat, mouse VCN axons travel at or near the ventral surface of the brainstem before crossing the midline and turning rostrally toward the lateral lemniscus. Mouse and rat VAS development follows a similar time course, with events in the mouse occurring one or two days earlier than rat. Ipsilateral collateral branches are first observed at E15.5 in a region corresponding to the future LSO, two days after the

Molecular guidance cues necessary for axon pathfinding from the ventral cochlear nucleus. Howell, D. M., Morgan, W. J., Jarjour, A. A., Spirou, G. A., Berrebi, A. S., Kennedy, T. E., and Mathers, P. H. (2007). J Comp Neurol 504, 533-549. Reprinted with Permission of Wiley-Liss, Inc. a subsidiary of John Wiley \& Sons, Inc." 
main axons crossed the midline. Additional ipsilateral and contralateral collaterals are observed with increasing developmental age. It appears that branching of VCN axons within the SOC nuclei occurs subsequent to the initial pathfinding events that establish more distant connections. However, a detailed analysis of collateral development within the mouse superior olivary complex will require further study.

\section{Attracting VCN axons to the midline}

Similar to its expression in the spinal cord midline, netrin-1 is expressed at the midline of the auditory brainstem during VCN axonal outgrowth. Contributions from other netrin family members for the long-range guidance of VCN axons appear unlikely. No brainstem regions express netrin-3 and netrin-4 in the developing mouse (Puschel, 1999; Yin et al., 2000; and our unpublished observations). The other netrin family members, netrin-g1 and netrin-g2, differ from the classical netrins (netrin-1, -3 and -4) through the addition of a glycosylphosphatidyl inositol tag (Nakashiba et al., 2002). This tag anchors these proteins to the plasma membrane, thereby limiting the effective diffusion gradient available for long range attraction. Additionally, netrin-g1 and netrin-g2 do not bind to classical netrin receptors like DCC (Nakashiba et al., 2000; Nakashiba et al., 2002). Finally, the lack of contralateral VCN axonal projections in netrin-1 homozygous mutants (Fig. 6) suggests that there is no compensation from other netrin family members in directing VAS formation. These findings are consistent with only netrin-1 attracting VCN axons to the midline.

The presence of the DCC receptor is required for netrin-mediated attraction to occur (Keino-Masu et al., 1996; de la Torre et al., 1997; Deiner et al., 1997; Ming et al., 1997). DCC RNA is present in the cochlear nucleus during initial axonal outgrowth and subsequent development of VAS projections. In addition, VCN axons are immunoreactive for DCC as they extend toward the midline. While DCC immunoreactivity is limited to the ipsilateral axonal segment, cell bodies within the cochlear nucleus are not readily identified with DCC immunohistochemistry (Figs.

Molecular guidance cues necessary for axon pathfinding from the ventral cochlear nucleus. Howell, D. M., Morgan, W. J., Jarjour, A. A., Spirou, G. A., Berrebi, A. S., Kennedy, T. E., and Mathers, P. H. (2007). J Comp Neurol 504, 533-549. Reprinted with Permission of Wiley-Liss, Inc. a subsidiary of John Wiley \& Sons, Inc." 
3G and 3I). Seaman et al. (2001) interpreted weak immunostaining of the DCC receptor within cell bodies of developing mouse sensory ganglia as a consequence of axonal targeting of DCC protein. Given the lack of DCC immunoreactivity in cochlear nucleus cell bodies, VCN neurons may employ a similar targeting scheme for the DCC receptor.

Expression alone of netrin-1 and DCC, however, does not prove involvement in midline attraction of VCN axons. Analysis of mice homozygous for a netrin-1 mutation revealed that $\mathrm{VCN}$ axons traveling in the VAS are disrupted (Fig. 6). A more severe disruption of VCN axons is observed in DCC-deficient mice (Fig. 5 and discussed below). VCN axons are able to reach the lateral region of the ipsilateral SOC in netrin-1-deficient mice (Fig. 6F), but axons reaching the midline are never observed in these mice (Fig. 6F'). These data contrast observations made in the developing spinal cord of netrin-1 mutants, where SCN axon trajectories become disorganized after an initial appropriate extension, but the ability for some SCN axons to cross the midline suggests the presence of either residual netrin-1 activity or another midline attractant (Serafini et al., 1996). Mice homozygous for the netrin-1 mutant allele are severe hypomorphs (Serafini et al., 1996), and thus, the residual netrin-1 activity in the auditory brainstem may be able to stimulate VCN axon outgrowth, but it is not sufficient for these axons to reach the midline (Fig. 6). While it appears to be necessary, netrin-1 may not be sufficient to elicit VCN axonal outgrowth, since no directed outgrowth was observed when rat cochlear nucleus explants were cultured with a recombinant source of netrin-1 (Poe and BrunsoBechtold, 1998). These data and those presented in Fig. 6 are consistent with an additional guidance factor mediating the initial outgrowth of VCN axons, followed by netrin-1-mediated midline attraction. An additional attractant activity found in the spinal cord of netrin-1-deficient mice was identified as the morphogen, sonic hedgehog (Charron et al., 2003). We find that sonic hedgehog is expressed at the midline of the auditory brainstem during the outgrowth of VCN axons (unpublished observations). Even though sonic hedgehog lacked the ability to promote SCN axon and Mathers, P. H. (2007). J Comp Neurol 504, 533-549. Reprinted with Permission of Wiley-Liss, Inc. a subsidiary of John Wiley \& Sons, Inc." 
outgrowth in culture (Charron et al., 2003), it may play a role in VCN axon pathfinding, although additional guidance factors may also be involved. Given the long distance between the presumptive cochlear nucleus and the midline, even in an E13.5 embryo, a more likely explanation is an unidentified factor expressed in the lateral auditory brainstem that promotes axonal outgrowth from the cochlear nucleus.

\section{VCN axon pathfinding requires netrin-DCC function}

We have shown that netrin-1 and $D C C$ are expressed in the auditory brainstem, and mice deficient for either DCC or netrin-1 have disrupted VCN axon projections. Mice carrying one or two functional netrin-1 or DCC alleles could not be differentiated on the basis of axonal labeling patterns. Like SCN axon pathfinding, the loss of one allele does not alter the pathfinding ability of VCN axons (Serafini et al., 1996; Fazeli et al., 1997). VCN axons, however, are more severely disrupted in $D C C$-deficient mice than in netrin-1-deficient mice. In DCC-deficient mice, no VCN axonal outgrowth is observed at any embryonic age analyzed $(n=7)$, and outgrowth was present in only $25 \%$ of those analyzed at P0 (Fig. 5 ). This result suggests that DCC may have other roles for cochlear nucleus neurons in addition to axonal pathfinding. In the hindbrain, DCC function is necessary for proper migration of pontine and inferior olive neurons (Bloch-Gallego et al., 1999; Yee et al., 1999).

Based on these functions elsewhere in the brainstem, DCC activity may be necessary for the proper migration of neurons into the cochlear nucleus. In support of this role for DCC, a group of DCC-positive cells in the subventricular zone at E13.5 (Fig. 3F) may represent newly born cochlear nucleus neurons. To determine whether migrating $\mathrm{VCN}$ neurons require DCC activity, we quantified the number of mafB-positive VCN neurons in the DCC-mutant strain at PO (Fig. 7G). The number of mafB-positive VCN neurons in mice carrying two or one functional $D C C$ alleles is similar to that obtained in the adult rat VCN, exclusive of granule cells (Kulesza et al., 2002). The entire VCN of $D C C$-null mice only contain $\sim 2,000$ fewer neurons,

Molecular guidance cues necessary for axon pathfinding from the ventral cochlear nucleus. Howell, D. M., Morgan, W. J., Jarjour, A. A., Spirou, G. A., Berrebi, A. S., Kennedy, T. E., and Mathers, P. H. (2007). J Comp Neurol 504, 533-549. Reprinted with Permission of Wiley-Liss, Inc. a subsidiary of John Wiley \& Sons, Inc." 
even though $D C C$-null mice lack VAS projections. There are an estimated 4,000 to 6,000 neurons in the rat MNTB which would be innervated by a similar number of GBCs (Kulesza et al., 2002; Rodriguez-Contreras et al., 2006). Since GBCs make up only a portion of the VAS-projecting neurons, this small reduction of VCN neurons in DCC-null pups is not sufficient to account for even the potential loss of GBCs and much less for the complete loss of VAS fibers. Given the proposed role of DCC as a dependence receptor (Mehlen and Mazelin, 2003), the VCN cellular reduction may reflect increased cell death due to the loss of netrin-DCC signaling in the absence of axonal processes. We suggest that the primary defect in $D C C$ homozygous mutants is impaired VCN axon outgrowth rather than the misrouting of newly born neurons that would normally occupy the VCN.

In addition to axonal guidance and neuronal migration, netrin-DCC signaling also functions in axon formation by regulating asymmetric neuronal outgrowth (Adler et al., 2006). The axons of $C$. elegans HSN neurons, like wild type SCNs, utilize netrin-DCC signaling to extend ventrally toward the ventral nerve cord, where the axon makes an anterior turn toward the vulva (Desai et al., 1988; Hedgecock et al., 1990; Adler et al., 2006). Characterization of HSN neuron development revealed that axon specification was delayed in the absence of $D C C$, and the axon that eventually formed was misguided (Adler et al., 2006). The lack of axonal outgrowth from the cochlear nucleus in DCC-mutant embryonic samples may represent similarly delayed axon specification. Axons failed to exit the cochlear nucleus in all embryonic brainstems as well as the majority $(75 \%)$ of $\mathrm{PO}$ brainstems lacking a functional $D C C$ allele. The appearance of labeled axons in the $D C C$-deficient brainstem only at PO is consistent with delayed axonal outgrowth. In this case, axonal outgrowth is delayed 6 days-much longer than the 2 days of delay for axon specification/outgrowth observed in C. elegans HSN neurons and mouse SCNs (Adler et al., 2006; Serafini et al., 1996). The prolonged delay in axon specification is another difference in the utilization of netrin-DCC signaling in developing VCN neurons and SCNs. Wiley-Liss, Inc. a subsidiary of John Wiley \& Sons, Inc." 


\section{Getting VCN axons through the midline}

The conversion from netrin-mediated attraction to slit-mediated repulsion is important for SCN axons to efficiently exit the midline. Stein and Tessier-Lavigne (2001) found that the interaction of DCC and robo in the presence of slit ligand silences attractive and repulsive signals while preserving the rate of axonal extension, thus allowing growth cones to enter the contralateral brain. Slit-1 is expressed at the midline of the auditory brainstem during VCN axon extension. In addition, cells within the cochlear nucleus express RNA for both robo-1 and robo-2 from $\mathrm{E} 13.5$ to $\mathrm{P} 0$, a period in which $\mathrm{VCN}$ axons are crossing the brainstem midline. At E13.5, the group of cochlear nucleus cells that express robo-1 overlaps the region of $D C C$ expression, with robo-2 expression occurring in a different, but overlapping, domain of the cochlear nucleus. At this time, we are unable to determine whether these early expression domains correspond to different divisions within the cochlear nucleus (i.e.- anteroventral cochlear nucleus, posteroventral cochlear nucleus and dorsal cochlear nucleus) or discrete populations of cochlear nucleus neurons (i.e.globular bushy, multipolar, spherical bushy, etc). The expression of slit-1 at the midline of the lower auditory brainstem and robo-1 and robo-2 in the cochlear nucleus supports the utilization of slit-robo signaling by $\mathrm{VCN}$ axons. We propose that netrin-DCC signaling is necessary to attract $\mathrm{VCN}$ axons to the midline of the brainstem with slit-robo signaling responsible for these axons to efficiently cross the midline to enter the contralateral brainstem. Analysis of slit and robo mutant mice will be necessary to determine their functional role in establishing contralateral VAS projections.

\section{Acknowledgements}

We thank Dr. Marc Tessier-Lavigne for kindly providing the founder DCC mutant mice, Colette McNickle, Eric Christenson, Tina Randolph, Kathleen Lopez-Kim and Dennis Cole for expert technical assistance, and Drs. Janet Cyr and Randy J. Kulesza for helpful comments on the manuscript. 


\section{Literature Cited}

Adler CE, Fetter RD, Bargmann Cl. 2006. UNC-6/Netrin induces neuronal asymmetry and defines the site of axon formation. Nat Neurosci 9:511-518.

Altman J, Bayer SA. 1980. Development of the brain stem in the rat. III. Thymidineradiographic study of the time of origin of neurons of the vestibular and auditory nuclei of the upper medulla. J Comp Neurol 194:877-904.

Baker KL, Daniels SB, Lennington JB, Lardaro T, Czap A, Notti RQ, Cooper O, Isacson O, Frasca S, Jr., Conover JC. 2006. Neuroblast protuberances in the subventricular zone of the regenerative MRL/MpJ mouse. J Comp Neurol 498:747-761.

Barallobre MJ, Del Rio JA, Alcantara S, Borrell V, Aguado F, Ruiz M, Carmona MA, Martin M, Fabre M, Yuste R, Tessier-Lavigne M, Soriano E. 2000. Aberrant development of hippocampal circuits and altered neural activity in netrin 1deficient mice. Development 127:4797-4810.

Bloch-Gallego E, Causeret F, Ezan F, Backer S, Hidalgo-Sanchez M. 2005. Development of precerebellar nuclei: instructive factors and intracellular mediators in neuronal migration, survival and axon pathfinding. Brain Res Brain Res Rev 49:253-266.

Bloch-Gallego E, Ezan F, Tessier-Lavigne M, Sotelo C. 1999. Floor plate and netrin1 are involved in the migration and survival of inferior olivary neurons. J Neurosci 19:4407-4420.

Brose K, Bland KS, Wang KH, Arnott D, Henzel W, Goodman CS, Tessier-Lavigne M, Kidd T. 1999. Slit proteins bind Robo receptors and have an evolutionarily conserved role in repulsive axon guidance. Cell 96:795-806.

Cant NB, Benson CG. 2003. Parallel auditory pathways: projection patterns of the different neuronal populations in the dorsal and ventral cochlear nuclei. Brain Res Bull 60:457-474.

Charron F, Stein E, Jeong J, McMahon AP, Tessier-Lavigne M. 2003. The morphogen sonic hedgehog is an axonal chemoattractant that collaborates with netrin-1 in midline axon guidance. Cell 113:11-23.

Charron F, Tessier-Lavigne M. 2005. Novel brain wiring functions for classical morphogens: a role as graded positional cues in axon guidance. Development 132:2251-2262.

Cooper HM, Armes P, Britto J, Gad J, Wilks AF. 1995. Cloning of the mouse homologue of the deleted in colorectal cancer gene (mDCC) and its expression in the developing mouse embryo. Oncogene 11:2243-2254.

Cordes SP, Barsh GS. 1994. The mouse segmentation gene $\mathrm{kr}$ encodes a novel basic domain-leucine zipper transcription factor. Cell 79:1025-1034.

Cramer KS, Cerretti DP, Siddiqui SA. 2006. EphB2 regulates axonal growth at the midline in the developing auditory brainstem. Dev Biol 295:76-89.

Cramer KS, Karam SD, Bothwell M, Cerretti DP, Pasquale EB, Rubel EW. 2002. Expression of EphB receptors and EphrinB ligands in the developing chick auditory brainstem. J Comp Neurol 452:51-64.

Molecular guidance cues necessary for axon pathfinding from the ventral cochlear nucleus. Howell, D. M., Morgan, W. J., Jarjour, A. A., Spirou, G. A., Berrebi, A. S., Kennedy, T. E., and Mathers, P. H. (2007). J Comp Neurol 504, 533-549. Reprinted with Permission of Wiley-Liss, Inc. a subsidiary of John Wiley \& Sons, Inc." 
Cygan JA, Johnson RL, McMahon AP. 1997. Novel regulatory interactions revealed by studies of murine limb pattern in Wnt-7a and En-1 mutants. Development 124:5021-5032.

Dalvin S, Anselmo MA, Prodhan P, Komatsuzaki K, Schnitzer JJ, Kinane TB. 2003. Expression of Netrin-1 and its two receptors DCC and UNC5H2 in the developing mouse lung. Gene Expr Patterns 3:279-283.

de la Torre JR, Hopker VH, Ming GL, Poo MM, Tessier-Lavigne M, HemmatiBrivanlou A, Holt CE. 1997. Turning of retinal growth cones in a netrin-1 gradient mediated by the netrin receptor DCC. Neuron 19:1211-1224.

Deiner MS, Kennedy TE, Fazeli A, Serafini T, Tessier-Lavigne M, Sretavan DW. 1997. Netrin-1 and DCC mediate axon guidance locally at the optic disc: loss of function leads to optic nerve hypoplasia. Neuron 19:575-589.

Deol MS. 1964. The Abnormalities Of The Inner Ear In Kreisler Mice. J Embryol Exp Morphol 12:475-490.

Desai C, Garriga G, Mclntire SL, Horvitz HR. 1988. A genetic pathway for the development of the Caenorhabditis elegans HSN motor neurons. Nature 336:638-646.

Dickson BJ. 2002. Molecular mechanisms of axon guidance. Science 298:19591964.

Draberova E, Lukas Z, Ivanyi D, Viklicky V, Draber P. 1998. Expression of class III beta-tubulin in normal and neoplastic human tissues. Histochem Cell Biol 109:231-239.

Eichmann A, Grapin-Botton A, Kelly L, Graf T, Le Douarin NM, Sieweke M. 1997. The expression pattern of the mafB/kr gene in birds and mice reveals that the kreisler phenotype does not represent a null mutant. Mech Dev 65:111-122.

Farago AF, Awatramani RB, Dymecki SM. 2006. Assembly of the brainstem cochlear nuclear complex is revealed by intersectional and subtractive genetic fate maps. Neuron 50:205-218.

Fazeli A, Dickinson SL, Hermiston ML, Tighe RV, Steen RG, Small CG, Stoeckli ET, Keino-Masu K, Masu M, Rayburn H, Simons J, Bronson RT, Gordon JI, Tessier-Lavigne M, Weinberg RA. 1997. Phenotype of mice lacking functional Deleted in colorectal cancer (Dcc) gene. Nature 386:796-804.

Friauf E, Ostwald J. 1988. Divergent projections of physiologically characterized rat ventral cochlear nucleus neurons as shown by intra-axonal injection of horseradish peroxidase. Exp Brain Res 73:263-284.

Frohman MA, Martin GR, Cordes SP, Halamek LP, Barsh GS. 1993. Altered rhombomere-specific gene expression and hyoid bone differentiation in the mouse segmentation mutant, kreisler (kr). Development 117:925-936.

Gundersen HJ, Jensen EB. 1987. The efficiency of systematic sampling in stereology and its prediction. J Microsc 147 (Pt 3):229-263.

Hammond R, Vivancos V, Naeem A, Chilton J, Mambetisaeva E, Andrews W, Sundaresan V, Guthrie S. 2005. Slit-mediated repulsion is a key regulator of motor axon pathfinding in the hindbrain. Development 132:4483-4495.

Molecular guidance cues necessary for axon pathfinding from the ventral cochlear nucleus. Howell, D. M., Morgan, W. J., Jarjour, A. A., Spirou, G. A., Berrebi, A. S., Kennedy, T. E., and Mathers, P. H. (2007). J Comp Neurol 504, 533-549. Reprinted with Permission of Wiley-Liss, Inc. a subsidiary of John Wiley \& Sons, Inc." 
Hao JC, Yu TW, Fujisawa K, Culotti JG, Gengyo-Ando K, Mitani S, Moulder G, Barstead R, Tessier-Lavigne M, Bargmann Cl. 2001. C. elegans slit acts in midline, dorsal-ventral, and anterior-posterior guidance via the SAX-3/Robo receptor. Neuron 32:25-38.

Harris R, Sabatelli LM, Seeger MA. 1996. Guidance cues at the Drosophila CNS midline: identification and characterization of two Drosophila Netrin/UNC-6 homologs. Neuron 17:217-228.

Hedgecock EM, Culotti JG, Hall DH. 1990. The unc-5, unc-6, and unc-40 genes guide circumferential migrations of pioneer axons and mesodermal cells on the epidermis in C. elegans. Neuron 4:61-85.

Ishii N, Wadsworth WG, Stern BD, Culotti JG, Hedgecock EM. 1992. UNC-6, a laminin-related protein, guides cell and pioneer axon migrations in $\mathrm{C}$. elegans. Neuron 9:873-881.

Itoh A, Miyabayashi T, Ohno M, Sakano S. 1998. Cloning and expressions of three mammalian homologues of Drosophila slit suggest possible roles for Slit in the formation and maintenance of the nervous system. Brain Res Mol Brain Res 62:175-186.

Jenkins WM, Masterton RB. 1982. Sound localization: effects of unilateral lesions in central auditory system. J Neurophysiol 47:987-1016.

Kandler K, Friauf E. 1993. Pre- and postnatal development of efferent connections of the cochlear nucleus in the rat. J Comp Neurol 328:161-184.

Kataoka K, Fujiwara KT, Noda M, Nishizawa M. 1994. MafB, a new Maf family transcription activator that can associate with Maf and Fos but not with Jun. Mol Cell Biol 14:7581-7591.

Keino-Masu K, Masu M, Hinck L, Leonardo ED, Chan SS, Culotti JG, TessierLavigne M. 1996. Deleted in Colorectal Cancer (DCC) encodes a netrin receptor. Cell 87:175-185.

Kennedy TE, Serafini T, de la Torre JR, Tessier-Lavigne M. 1994. Netrins are diffusible chemotropic factors for commissural axons in the embryonic spinal cord. Cell 78:425-435.

Kidd T, Brose K, Mitchell KJ, Fetter RD, Tessier-Lavigne M, Goodman CS, Tear G. 1998. Roundabout controls axon crossing of the CNS midline and defines a novel subfamily of evolutionarily conserved guidance receptors. Cell 92:205215.

Kulesza RJ, Vinuela A, Saldana E, Berrebi AS. 2002. Unbiased stereological estimates of neuron number in subcortical auditory nuclei of the rat. Hear Res 168:12-24.

Long H, Sabatier C, Ma L, Plump A, Yuan W, Ornitz DM, Tamada A, Murakami F, Goodman CS, Tessier-Lavigne M. 2004. Conserved roles for Slit and Robo proteins in midline commissural axon guidance. Neuron 42:213-223.

Manzanares M, Trainor PA, Nonchev S, Ariza-McNaughton L, Brodie J, Gould A, Marshall H, Morrison A, Kwan CT, Sham MH, Wilkinson DG, Krumlauf R.

Molecular guidance cues necessary for axon pathfinding from the ventral cochlear nucleus. Howell, D. M., Morgan, W. J., Jarjour, A. A., Spirou, G. A., Berrebi, A. S., Kennedy, T. E., and Mathers, P. H. (2007). J Comp Neurol 504, 533-549. Reprinted with Permission of Wiley-Liss, Inc. a subsidiary of John Wiley \& Sons, Inc." 
1999. The role of kreisler in segmentation during hindbrain development. Dev Biol 211:220-237.

Marillat V, Sabatier C, Failli V, Matsunaga E, Sotelo C, Tessier-Lavigne M, Chedotal A. 2004. The slit receptor Rig-1/Robo3 controls midline crossing by hindbrain precerebellar neurons and axons. Neuron 43:69-79.

Martin MR, Rickets C. 1981. Histogenesis of the cochlear nucleus of the mouse. J Comp Neurol 197:169-184.

Matsuoka TA, Zhao L, Artner I, Jarrett HW, Friedman D, Means A, Stein R. 2003. Members of the large Maf transcription family regulate insulin gene transcription in islet beta cells. Mol Cell Biol 23:6049-6062.

Mazelin L, Bernet A, Bonod-Bidaud C, Pays L, Arnaud S, Gespach C, Bredesen DE, Scoazec JY, Mehlen P. 2004. Netrin-1 controls colorectal tumorigenesis by regulating apoptosis. Nature 431:80-84.

McKay IJ, Muchamore I, Krumlauf R, Maden M, Lumsden A, Lewis J. 1994. The kreisler mouse: a hindbrain segmentation mutant that lacks two rhombomeres. Development 120:2199-2211.

Mehlen P, Mazelin L. 2003. The dependence receptors DCC and UNC5H as a link between neuronal guidance and survival. Biol Cell 95:425-436.

Ming GL, Song HJ, Berninger B, Holt CE, Tessier-Lavigne M, Poo MM. 1997. cAMPdependent growth cone guidance by netrin-1. Neuron 19:1225-1235.

Mitchell KJ, Doyle JL, Serafini T, Kennedy TE, Tessier-Lavigne M, Goodman CS, Dickson BJ. 1996. Genetic analysis of Netrin genes in Drosophila: Netrins guide CNS commissural axons and peripheral motor axons. Neuron 17:203215.

Mullen RJ, Buck CR, Smith AM. 1992. NeuN, a neuronal specific nuclear protein in vertebrates. Development 116:201-211.

Nakashiba T, Ikeda T, Nishimura S, Tashiro K, Honjo T, Culotti JG, Itohara S. 2000. Netrin-G1: a novel glycosyl phosphatidylinositol-linked mammalian netrin that is functionally divergent from classical netrins. J Neurosci 20:6540-6550.

Nakashiba T, Nishimura S, Ikeda T, Itohara S. 2002. Complementary expression and neurite outgrowth activity of netrin-G subfamily members. Mech Dev 111:47-60.

Niblock MM, Brunso-Bechtold JK, Henkel CK. 1995. Fiber outgrowth and pathfinding in the developing auditory brainstem. Brain Res Dev Brain Res 85:288-292.

Osen KK. 1969. Cytoarchitecture of the cochlear nuclei in the cat. J Comp Neurol 136:453-484.

Phifer CB, Terry LM. 1986. Use of hypothermia for general anesthesia in preweanling rodents. Physiol Behav 38:887-890.

Pierce ET. 1967. Histogenesis of the dorsal and ventral cochlear nuclei in the mouse. An autoradiographic study. J Comp Neurol 131:27-54.

Poe BH, Brunso-Bechtold JK. 1998. Directed outgrowth from a subset of cochlear nucleus fibers in a collagen-gel matrix. Brain Res Dev Brain Res 105:153157.

85

Molecular guidance cues necessary for axon pathfinding from the ventral cochlear nucleus.

Howell, D. M., Morgan, W. J., Jarjour, A. A., Spirou, G. A., Berrebi, A. S., Kennedy, T. E., and Mathers, P. H. (2007). J Comp Neurol 504, 533-549. Reprinted with Permission of Wiley-Liss, Inc. a subsidiary of John Wiley \& Sons, Inc." 
Puschel AW. 1999. Divergent properties of mouse netrins. Mech Dev 83:65-75.

Ratcliffe EM, Setru SU, Chen JJ, Li ZS, D'Autreaux F, Gershon MD. 2006. Netrin/DCC-mediated attraction of vagal sensory axons to the fetal mouse gut. J Comp Neurol 498:567-580.

Rodriguez-Contreras A, de Lange RP, Lucassen PJ, Borst JG. 2006. Branching of calyceal afferents during postnatal development in the rat auditory brainstem. J Comp Neurol 496:214-228.

Rothberg JM, Jacobs JR, Goodman CS, Artavanis-Tsakonas S. 1990. slit: an extracellular protein necessary for development of midline glia and commissural axon pathways contains both EGF and LRR domains. Genes Dev 4:2169-2187.

Rozen S, Skaletsky H. 2000. Primer3 on the WWW for general users and for biologist programmers. Methods Mol Biol 132:365-386.

Sabatier C, Plump AS, Le M, Brose K, Tamada A, Murakami F, Lee EY, TessierLavigne M. 2004. The divergent Robo family protein rig-1/Robo3 is a negative regulator of slit responsiveness required for midline crossing by commissural axons. Cell 117:157-169.

Sanchez-Camacho C, Rodriguez J, Ruiz JM, Trousse F, Bovolenta P. 2005. Morphogens as growth cone signalling molecules. Brain Res Brain Res Rev 49:242-252.

Schnorrer F, Dickson BJ. 2004. Axon guidance: morphogens show the way. Curr Biol 14:R19-21.

Seaman C, Anderson R, Emery B, Cooper HM. 2001. Localization of the netrin guidance receptor, DCC, in the developing peripheral and enteric nervous systems. Mech Dev 103:173-175.

Seeger M, Tear G, Ferres-Marco D, Goodman CS. 1993. Mutations affecting growth cone guidance in Drosophila: genes necessary for guidance toward or away from the midline. Neuron 10:409-426.

Serafini T, Colamarino SA, Leonardo ED, Wang H, Beddington R, Skarnes WC, Tessier-Lavigne M. 1996. Netrin-1 is required for commissural axon guidance in the developing vertebrate nervous system. Cell 87:1001-1014.

Serafini T, Kennedy TE, Galko MJ, Mirzayan C, Jessell TM, Tessier-Lavigne M. 1994. The netrins define a family of axon outgrowth-promoting proteins homologous to C. elegans UNC-6. Cell 78:409-424.

Sevinsky JR, Whalen AM, Ahn NG. 2004. Extracellular signal-regulated kinase induces the megakaryocyte GPIlb/CD41 gene through MafB/Kreisler. Mol Cell Biol 24:4534-4545.

Shirasaki R, Katsumata R, Murakami F. 1998. Change in chemoattractant responsiveness of developing axons at an intermediate target. Science 279:105-107.

Smith PH, Joris PX, Carney LH, Yin TC. 1991. Projections of physiologically characterized globular bushy cell axons from the cochlear nucleus of the cat. J Comp Neurol 304:387-407.

86

Molecular guidance cues necessary for axon pathfinding from the ventral cochlear nucleus.

Howell, D. M., Morgan, W. J., Jarjour, A. A., Spirou, G. A., Berrebi, A. S., Kennedy, T. E., and Mathers, P. H. (2007). J Comp Neurol 504, 533-549. Reprinted with Permission of Wiley-Liss, Inc. a subsidiary of John Wiley \& Sons, Inc." 
Spirou GA, Brownell WE, Zidanic M. 1990. Recordings from cat trapezoid body and HRP labeling of globular bushy cell axons. J Neurophysiol 63:1169-1190.

Stein E, Tessier-Lavigne M. 2001. Hierarchical organization of guidance receptors: silencing of netrin attraction by slit through a Robo/DCC receptor complex. Science 291:1928-1938.

Tessier-Lavigne M, Goodman CS. 1996. The molecular biology of axon guidance. Science 274:1123-1133.

Tolbert LP, Morest DK, Yurgelun-Todd DA. 1982. The neuronal architecture of the anteroventral cochlear nucleus of the cat in the region of the cochlear nerve root: horseradish peroxidase labelling of identified cell types. Neuroscience 7:3031-3052.

Toma JG, Akhavan M, Fernandes KJ, Barnabe-Heider F, Sadikot A, Kaplan DR, Miller FD. 2001. Isolation of multipotent adult stem cells from the dermis of mammalian skin. Nat Cell Biol 3:778-784.

Wang H, Copeland NG, Gilbert DJ, Jenkins NA, Tessier-Lavigne M. 1999. Netrin-3, a mouse homolog of human NTN2L, is highly expressed in sensory ganglia and shows differential binding to netrin receptors. J Neurosci 19:4938-4947.

Warr WB. 1982. Parallel ascending pathways from the cochlear nucleus: Neuroanatomical evidence of functional specialization. In: Neff WD, editor. Contributions to Sensory Physiology. New York: Academic Press. p 1-38.

Weber F, Zillus H, Friauf E. 1991. Neuronal birth in the rat auditory brainstem. In: Elsner N, Singer W, editors. Synapse, Transmission, Modulation Proceedings of the 19th Gottingen Neurobiology Conference, George Thieme Verlag. Stuttgart, New York. p 123.

Webster DB, Trune DR. 1982. Cochlear nuclear complex of mice. Am J Anat 163:103-130.

Yee KT, Simon HH, Tessier-Lavigne M, O'Leary DM. 1999. Extension of long leading processes and neuronal migration in the mammalian brain directed by the chemoattractant netrin-1. Neuron 24:607-622.

Yin Y, Sanes JR, Miner JH. 2000. Identification and expression of mouse netrin-4. Mech Dev 96:115-119.

Yuan W, Zhou L, Chen JH, Wu JY, Rao Y, Ornitz DM. 1999. The mouse SLIT family: secreted ligands for ROBO expressed in patterns that suggest a role in morphogenesis and axon guidance. Dev Biol 212:290-306.

Zallen JA, Yi BA, Bargmann Cl. 1998. The conserved immunoglobulin superfamily member SAX-3/Robo directs multiple aspects of axon guidance in $\mathrm{C}$. elegans. Cell 92:217-227.

Molecular guidance cues necessary for axon pathfinding from the ventral cochlear nucleus. Howell, D. M., Morgan, W. J., Jarjour, A. A., Spirou, G. A., Berrebi, A. S., Kennedy, T. E., and Mathers, P. H. (2007). J Comp Neurol 504, 533-549. Reprinted with Permission of Wiley-Liss, Inc. a subsidiary of John Wiley \& Sons, Inc." 


\section{Figure Legends}
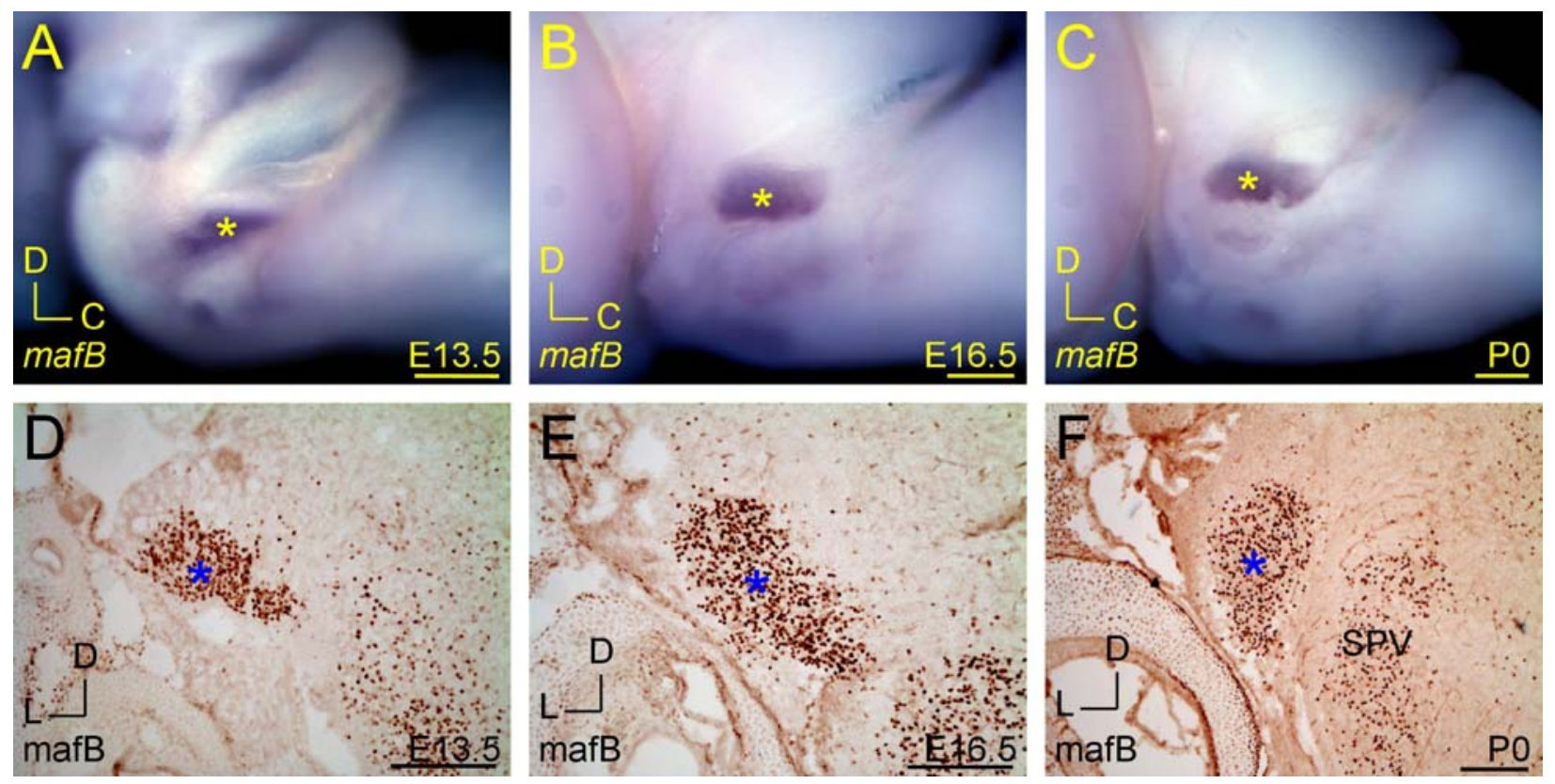

Fig. 1. RNA and protein expression of mafB identifies the embryonic cochlear nucleus. A-C: Lateral view of isolated E13.5 (A), E16.5 (B) and P0 (C) brainstems hybridized with mafB antisense probe. At each age, the cochlear nucleus (asterisk) is positive for mafB. Additional expression of mafB is present in the spinal nucleus of the trigeminal nerve (SPV). D-F: Coronal section through E13.5 (D), E16.5 (E) and PO (F) auditory brainstems processed for mafB immunohistochemistry. Numerous nuclei within the VCN (asterisk) express mafB at these developmental stages. The spinal nucleus of the trigeminal nerve (SPV) is an additional region of mafB immunoreactivity. Scale bars are $400 \mu \mathrm{m}$ (A-C) and $200 \mu \mathrm{m}$ (D-F).

Molecular guidance cues necessary for axon pathfinding from the ventral cochlear nucleus. Howell, D. M., Morgan, W. J., Jarjour, A. A., Spirou, G. A., Berrebi, A. S., Kennedy, T. E., and Mathers, P. H. (2007). J Comp Neurol 504, 533-549. Reprinted with Permission of Wiley-Liss, Inc. a subsidiary of John Wiley \& Sons, Inc." 

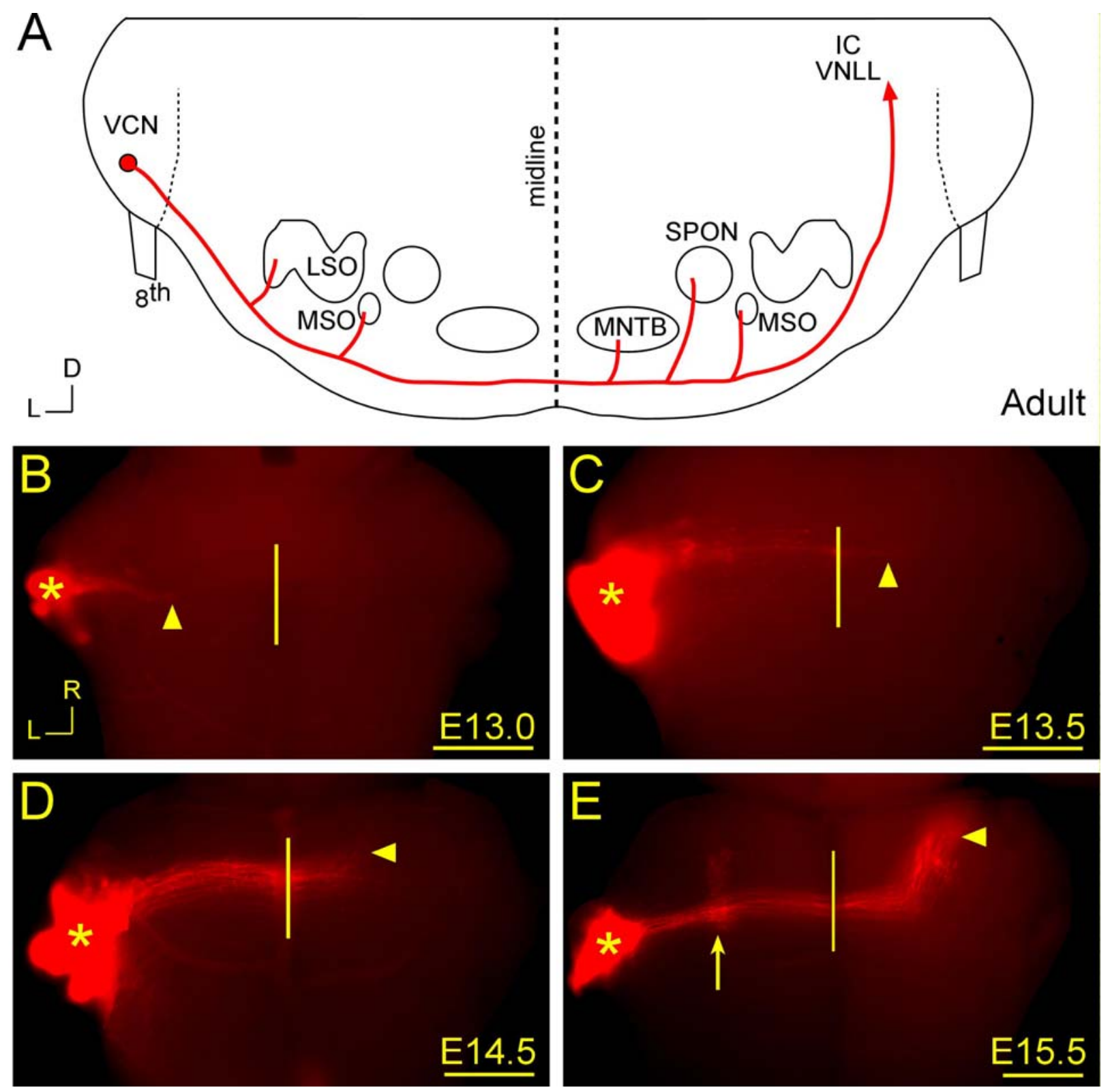

Fig. 2. Outgrowth of axons from the ventral cochlear nucleus. A: Composite of the ascending projections (red lines) made by axons of the adult ventral acoustic stria (VAS). The major axon terminations for globular bushy, multipolar and spherical bushy cells in the adult rodent are combined for simplicity. Diagram is not drawn to scale. Dorsal (D) and lateral (L) directions are indicated. IC, inferior colliculus; LSO, lateral superior olive; MNTB, medial nucleus of the trapezoid body; MSO, medial

Molecular guidance cues necessary for axon pathfinding from the ventral cochlear nucleus. Howell, D. M., Morgan, W. J., Jarjour, A. A., Spirou, G. A., Berrebi, A. S., Kennedy, T. E., and Mathers, P. H. (2007). J Comp Neurol 504, 533-549. Reprinted with Permission of Wiley-Liss, Inc. a subsidiary of John Wiley \& Sons, Inc." 
superior olive; SPON, superior paraolivary nucleus; VCN, ventral cochlear nucleus; VNLL, ventral nucleus of the lateral lemniscus; $8^{\text {th }}$, vestibulocochlear nerve. B-E: Ventral view of the brainstem under epifluorescent illumination following lipophilic tracer injection into the cochlear nucleus (asterisk) at the indicated embryonic (E) age. The same image orientation is used throughout with rostral $(R)$ and lateral $(L)$ directions indicated in B. Solid line in each panel denotes the midline. B: At E13.0, VCN axons exit the cochlear nucleus and extend toward the midline near the brainstem ventral surface. Arrowhead indicates the leading edge of labeled fibers. C: Greater numbers of labeled VAS axons exit the cochlear nucleus by E13.5, with some labeled axons (arrowhead) crossing the midline. D: At E14.5, more labeled VCN axons reach or extend beyond the midline. Arrowhead indicates a subset of labeled axons that turn rostrally and dorsally to travel within the lateral lemniscus. E: Labeled axons at E15.5 extend further in the lateral lemniscus (arrowhead). VCN axon collaterals (arrow) are first observed at E15.5 in a lateral region of the ipsilateral SOC. The scale bars are $500 \mu \mathrm{m}$ (B-E). and Mathers, P. H. (2007). J Comp Neurol 504, 533-549. Reprinted with Permission of Wiley-Liss, Inc. a subsidiary of John Wiley \& Sons, Inc." 


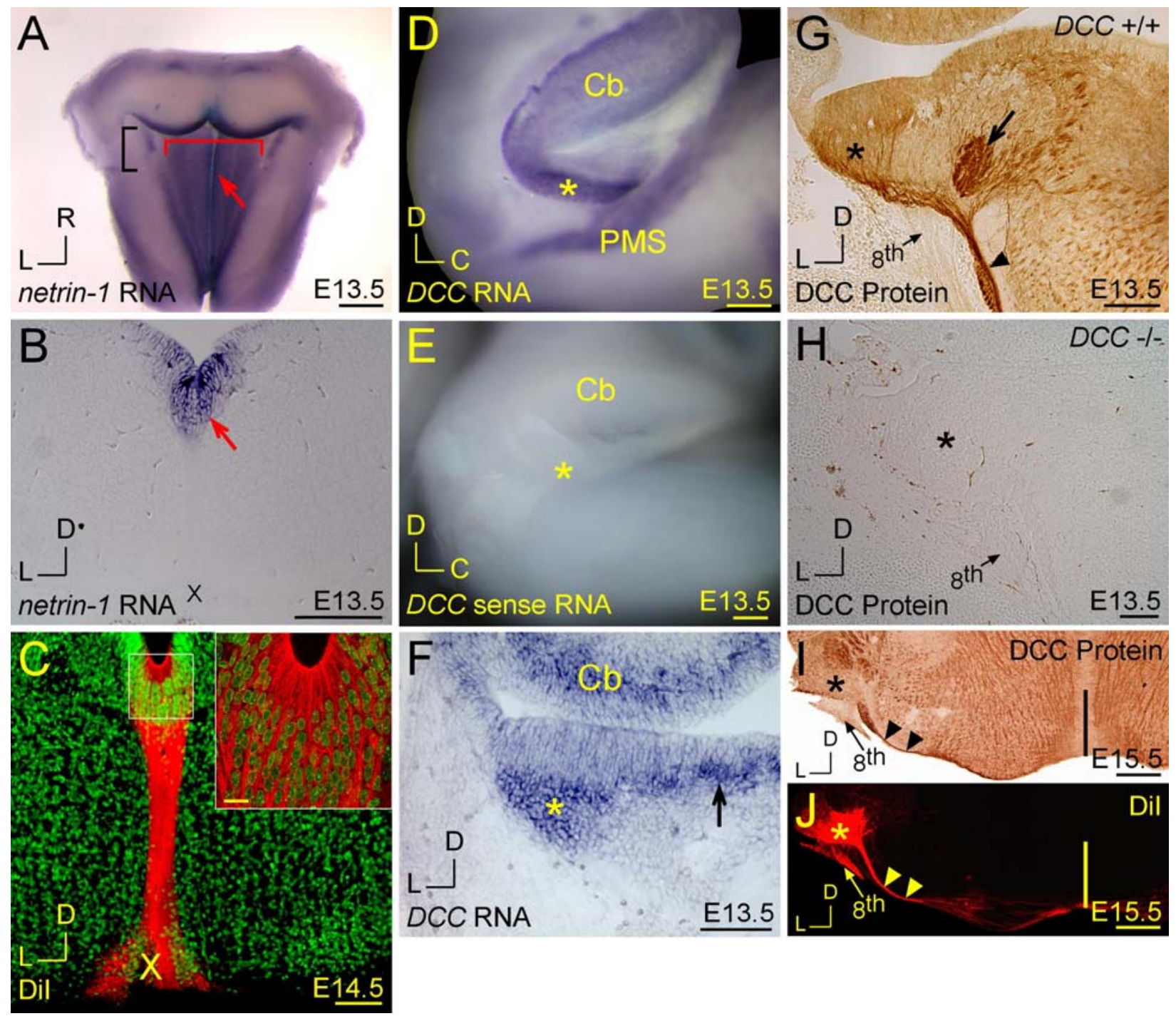

Fig. 3. Netrin-1 and DCC are expressed in the developing auditory brainstem. A: Dorsal view of E13.5 brainstem hybridized with netrin-1 antisense probe, with the cerebellum and tectum removed to visualize the midline and floor of the fourth ventricle. Netrin-1 is expressed at the dorsal midline of the brainstem (red arrow), including the auditory region (black bracket) and extends laterally along the ventricular surface (red bracket). B: Coronal section through E13.5 brainstem, within the black bracketed region in (A) hybridized with a netrin-1 antisense probe with labeled cells at the dorsal midline (red arrow). The brainstem ventral edge is

Molecular guidance cues necessary for axon pathfinding from the ventral cochlear nucleus. Howell, D. M., Morgan, W. J., Jarjour, A. A., Spirou, G. A., Berrebi, A. S., Kennedy, T. E., and Mathers, P. H. (2007). J Comp Neurol 504, 533-549. Reprinted with Permission of Wiley-Liss, Inc. a subsidiary of John Wiley \& Sons, Inc." 
indicated $(X)$. C: Coronal section through E14.5 brainstem with DiD injected at the ventral midline $(X)$ and counterstained with SYTOX green. DiD-labeled processes span the full dorsal to ventral extent of the midline. Inset: collapsed z-stack of the dorsal midline (white box in panel C) where the cell bodies of these DiD-labeled processes reside. D,E: Lateral view of E13.5 brainstem hybridized with DCC antisense (D) or sense (E) probe. D: Cochlear nucleus, pontine migratory stream (PMS) and cerebellum express DCC. E: No signal is present in samples hybridized with a DCC sense probe. F: Coronal section from E13.5 embryo hybridized with $D C C$ antisense probe labels the cochlear nucleus, cerebellum and a row of cells in the subventricular zone (arrow). G,H: Coronal section through E13.5 brainstem carrying two (G, DCC +/+) or no (H, DCC -/-) functional DCC alleles processed for DCC immunohistochemistry. G: DCC immunoreactivity is present in a group of axons (arrowhead) exiting the cochlear nucleus and a group of axons within one of the cerebellar peduncles (arrow). DCC-positive cell bodies are not observed within the cochlear nucleus. $\mathrm{H}$ : No immunoreactivity is observed in the cochlear nucleus or elsewhere in DCC-deficient mice. I,J: Adjacent coronal sections through E15.5 brainstem injected with Dil in one cochlear nucleus, then processed for DCC immunohistochemistry (I) or epifluorescent illumination (J). DCC-positive axons (I, arrowheads) extending from the cochlear nucleus align with the Dil-labeled axons traveling in the VAS (J, arrowheads). Cochlear nucleus (asterisk), cerebellum ( $\mathrm{Cb}$ ), midline (solid line) and vestibulocochlear nerve $\left(8^{\text {th }}\right)$ are labeled. Caudal (C), dorsal $(D)$, lateral $(L)$ and rostral $(R)$ directions are indicated. The scale bars are $400 \mu \mathrm{m}$ (A), $200 \mu \mathrm{m}$ (B, D, E, I and J), $100 \mu \mathrm{m}$ (C, F, G and H) and $20 \mu \mathrm{m}$ (inset in C). and Mathers, P. H. (2007). J Comp Neurol 504, 533-549. Reprinted with Permission of Wiley-Liss, Inc. a subsidiary of John Wiley \& Sons, Inc." 

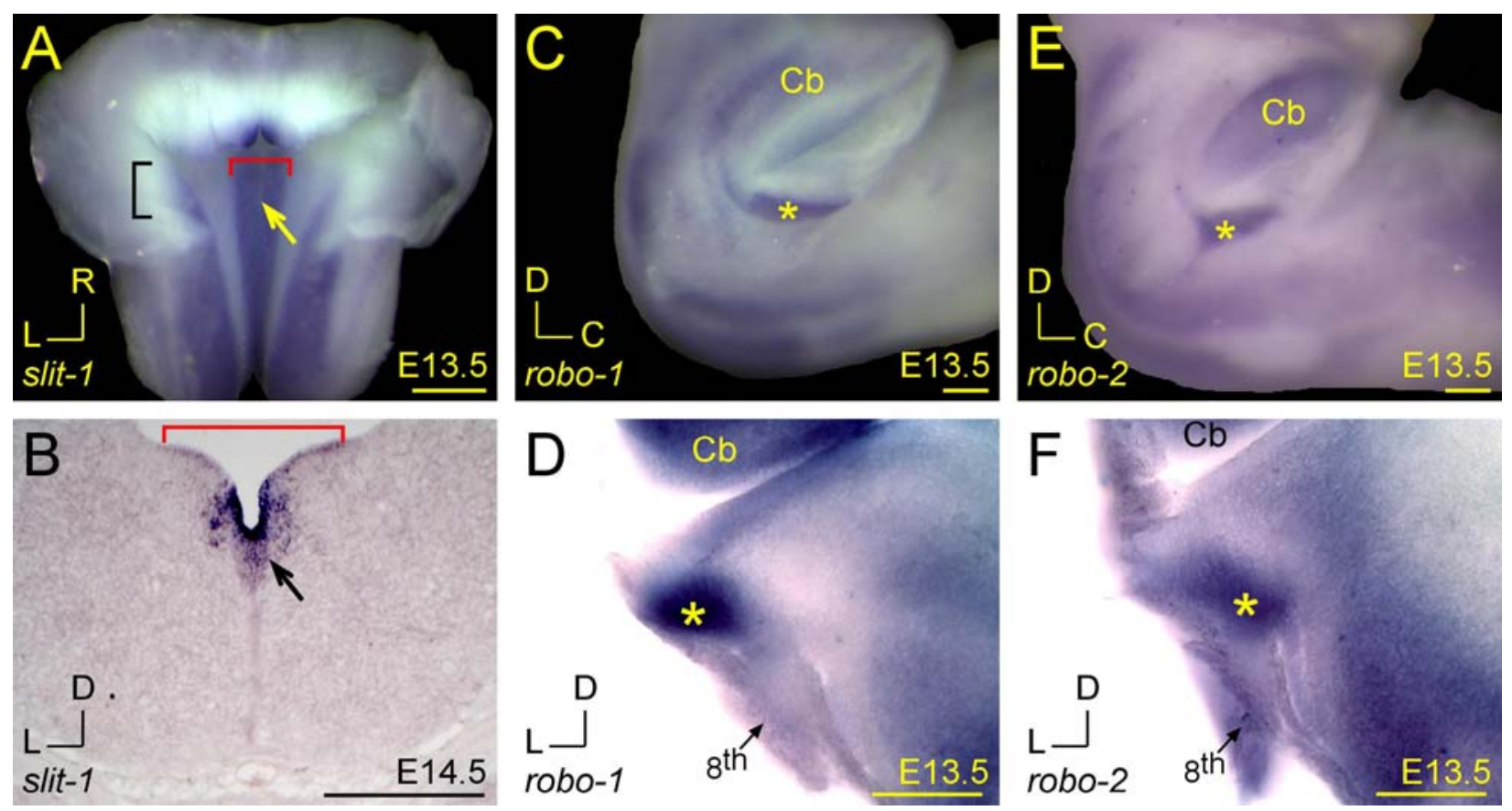

Fig. 4. Robo and Slit family members are expressed in the developing auditory brainstem. A: Dorsal view of an E13.5 brainstem hybridized with a slit-1 antisense probe. The cerebellum and tectum are removed to visualize the midline and ventricular space. Slit-1 is expressed by cells at the dorsal midline (yellow arrow) with strong expression extending laterally along the ventricular surface (red bracket) within the auditory portion of the brainstem (black bracket). B: Coronal section through the E14.5 auditory brainstem, within the black bracketed region in (A), hybridized with a slit-1 antisense probe that labels cells at the dorsal midline (black arrow). As seen in the whole mount, slit-1 expression extends laterally along the ventricular surface (red bracket). C,D: Lateral view of E13.5 brainstem (C) or coronal vibratome section through E13.5 auditory brainstem (D) hybridized with a robo-1 antisense probe. C: Robo-1 expression is present in the presumptive cochlear nucleus and cerebellum. The cerebellar expression of robo-1 is restricted to the dorsal cerebellum with expression not present at the lateral edge of the cerebellum.

D: Coronal sections confirm the expression of robo-1 within the cochlear nucleus. E,F: Lateral view E13.5 brainstem (E) or coronal vibratome section through E13.5

Molecular guidance cues necessary for axon pathfinding from the ventral cochlear nucleus. Howell, D. M., Morgan, W. J., Jarjour, A. A., Spirou, G. A., Berrebi, A. S., Kennedy, T. E., and Mathers, P. H. (2007). J Comp Neurol 504, 533-549. Reprinted with Permission of Wiley-Liss, Inc. a subsidiary of John Wiley \& Sons, Inc." 
auditory brainstem (F) hybridized with a robo-2 antisense probe. E: Robo-2 expression is also present in the presumptive cochlear nucleus and cerebellum. The expression of robo-2 in the cerebellum occurs caudal to the domain of robo-1 expression and extends to the lateral edge of the cerebellum. F: Coronal sections confirm the cochlear nucleus expresses robo-2. Cochlear nucleus (asterisk), cerebellum $(\mathrm{Cb})$ and vestibulocochlear nerve $\left(8^{\text {th }}\right)$ are labeled. Caudal (C), dorsal (D) and lateral $(\mathrm{L})$ directions are indicated. The scale bars are $400 \mu \mathrm{m}$ (A and B) and $200 \mu \mathrm{m}(\mathbf{C}-\mathrm{F})$.

Molecular guidance cues necessary for axon pathfinding from the ventral cochlear nucleus. Howell, D. M., Morgan, W. J., Jarjour, A. A., Spirou, G. A., Berrebi, A. S., Kennedy, T. E., and Mathers, P. H. (2007). J Comp Neurol 504, 533-549. Reprinted with Permission of Wiley-Liss, Inc. a subsidiary of John Wiley \& Sons, Inc." 

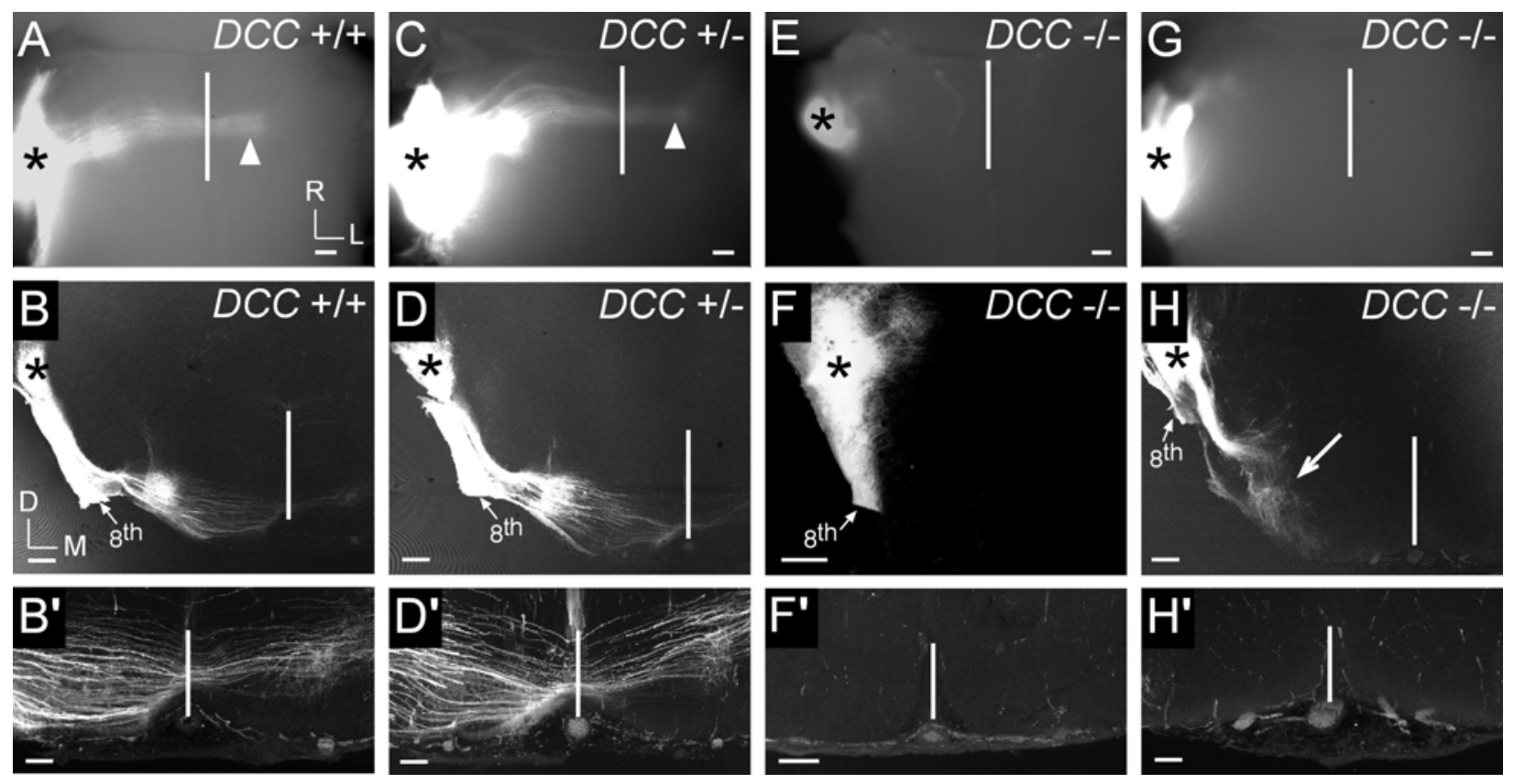

Fig. 5. VAS projections are disrupted in DCC-deficient mice. The ventral cochlear nucleus (asterisk) was injected with $\mathrm{DiD}$ or Dil in P0 mice carrying two (A, B, $\left.\mathbf{B}^{\prime}\right)$, one (C, D, D') or no (E-H, F', H') functional copies of the DCC allele. A,C,E,G: Ventral view of the brainstem under epifluorescent illumination. Rostral $(R)$ and lateral (L) directions indicated in $\mathbf{A}$ are used for all four panels. B,D,F,H: Coronal vibratome sections verify that tracer placements included the $\mathrm{VCN}$ and better reveal labeling of axons and branches. Dorsal (D) and medial (M) directions indicated in B are used for all four panels. $\mathbf{B}^{\prime}, \mathbf{D}^{\prime}, \mathbf{F}^{\prime}, \mathrm{H}^{\prime}$ : Higher magnification view of the midline shown in $\mathbf{B}, \mathbf{D}, \mathbf{F}$ and $\mathbf{H}$, respectively. Tracer placement is to the left of the image and dorsal is to the top of the image. A,B,B': Mice carrying two functional $D C C$ alleles $(n=14)$ have labeled axons (arrowhead) that cross the midline. Coronal sections confirm labeled axons originating in the VCN extend through the ipsilateral SOC toward the midline. Numerous labeled axons cross the midline in these mice (B'). No apparent differences are observed in the brainstem of wild-type (A, B, B') or DCC heterozygous (C, D, $\left.\mathbf{D}^{\prime}\right)$ animals $(\mathrm{n}=16)$. E,F,F': Labeled axons are typically not observed exiting the VCN of DCC-deficient mice $(n=9 / 12$ at P0). Midline in $F$ is and Mathers, P. H. (2007). J Comp Neurol 504, 533-549. Reprinted with Permission of Wiley-Liss, Inc. a subsidiary of John Wiley \& Sons, Inc." 
to the right of the image, but beyond the field of view. $\mathbf{G}, \mathbf{H}, \mathbf{H}^{\prime}$ : Only at P0, labeled axons are occasionally observed exiting the VCN of DCC-deficient mice $(n=3 / 12)$. When present, labeled $\mathrm{VCN}$ axons enter the lateral region of the ipsilateral SOC (arrow in $\mathbf{H}$ ). Labeled $\mathrm{VCN}$ axons never reach the midline in these $D C C$-deficient mice $\left(\mathbf{H}\right.$ and $\left.\mathbf{H}^{\prime}\right)$. Solid line denotes the midline, and the vestibulocochlear nerve $\left(8^{\text {th }}\right)$ is marked. Scale bars are $200 \mu \mathrm{m}(\mathbf{A}-\mathbf{H})$ and $100 \mu \mathrm{m}$ (B', D', F' and $\left.\mathbf{H}^{\prime}\right)$.

Molecular guidance cues necessary for axon pathfinding from the ventral cochlear nucleus. Howell, D. M., Morgan, W. J., Jarjour, A. A., Spirou, G. A., Berrebi, A. S., Kennedy, T. E., and Mathers, P. H. (2007). J Comp Neurol 504, 533-549. Reprinted with Permission of Wiley-Liss, Inc. a subsidiary of John Wiley \& Sons, Inc." 

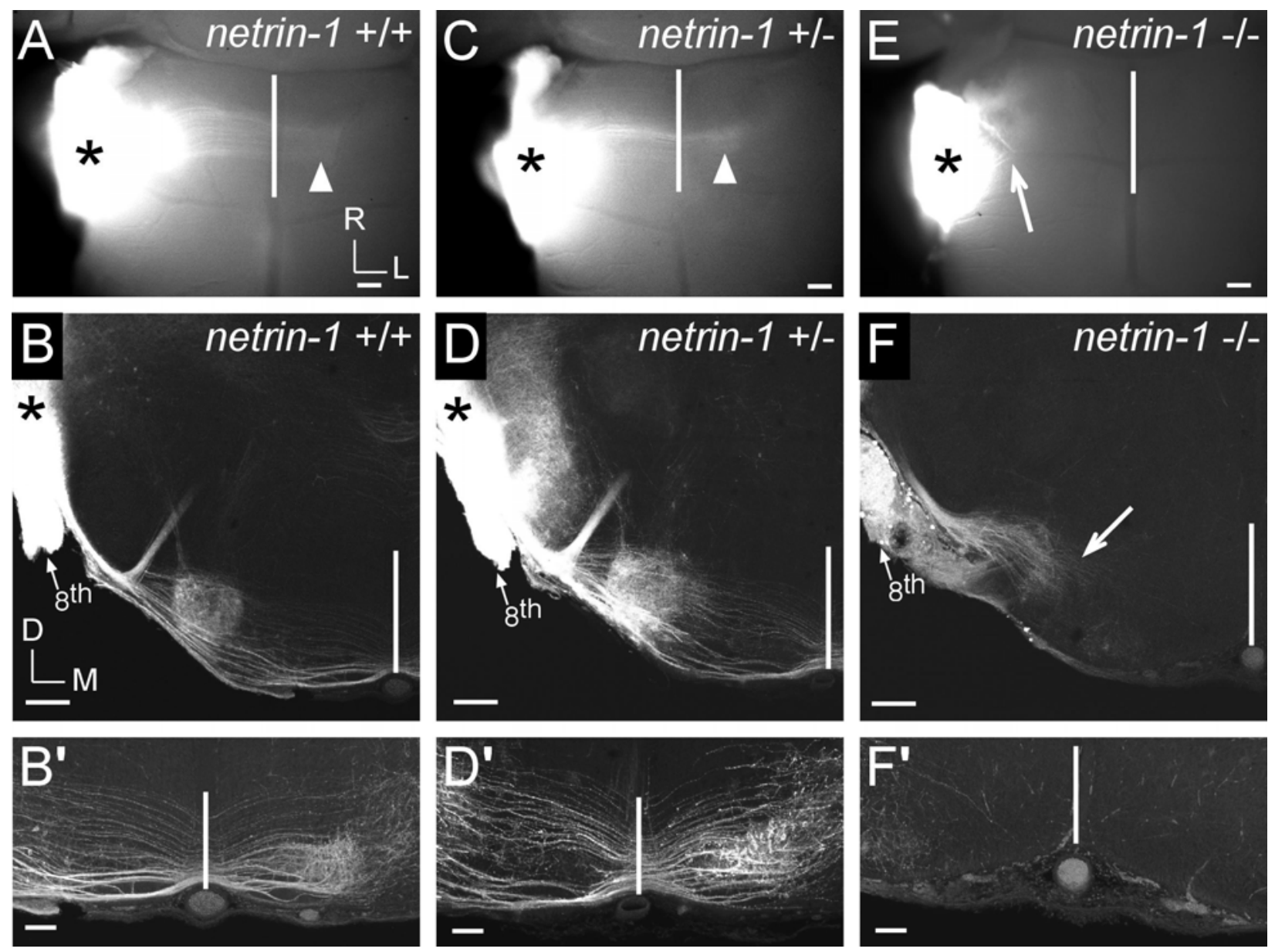

Fig. 6. VAS projections are disrupted in netrin-1-deficient mice. The ventral cochlear nucleus (asterisk) was injected with $\mathrm{DiD}$ or Dil in P0 mice carrying two (A, B, $\left.\mathbf{B}^{\prime}\right)$, one (C, D, $\left.\mathbf{D}^{\prime}\right)$ or no (E, F, F') functional copies of the netrin-1 allele. A,C,E: Ventral view of the brainstem under epifluorescent illumination. Rostral $(R)$ and lateral $(L)$ directions indicated in A are used for all three panels. B,D,F: Coronal vibratome sections verify that tracer placements included the VCN and better reveal labeling of axons and branches. Dorsal (D) and medial (M) directions indicated in B are used for all three panels. $\mathbf{B}^{\prime}, \mathbf{D}^{\prime}, \mathbf{F}^{\prime}$ : Higher magnification view of the midline shown in $\mathbf{B}, \mathbf{D}$ and F, respectively. Tracer placement is to the left of the image and dorsal is to the top of the image. A,B,B': Labeled axons (arrowhead) from the VCN extend through the ipsilateral SOC and cross the midline in mice with two functional netrin-1 alleles

Molecular guidance cues necessary for axon pathfinding from the ventral cochlear nucleus. Howell, D. M., Morgan, W. J., Jarjour, A. A., Spirou, G. A., Berrebi, A. S., Kennedy, T. E., and Mathers, P. H. (2007). J Comp Neurol 504, 533-549. Reprinted with Permission of Wiley-Liss, Inc. a subsidiary of John Wiley \& Sons, Inc." 
$(n=6)$. Closer examination of the midline $\left(B^{\prime}\right)$ in coronal sections reveals numerous labeled axons entering the contralateral brainstem in these mice. C,D,D': Like wildtype animals, VCN axons extend through the ipsilateral SOC, cross the midline and enter the contralateral brainstem in mice heterozygous for the netrin-1 mutant allele $(n=6)$. E,F,F': Labeled axons always exit the VCN in mice homozygous for the netrin-1 mutant allele $(n=4)$. Labeled axons enter the lateral region of the ipsilateral SOC (arrow), but never reach the midline in mice homozygous for the netrin-1 mutant allele ( $\mathbf{F}$ and $\left.\mathbf{F}^{\prime}\right)$. Solid line denotes the midline, and the vestibulocochlear nerve $\left(8^{\text {th }}\right)$ is marked. Scale bars are $200 \mu \mathrm{m}(\mathbf{A}-\mathbf{F})$ and $100 \mu \mathrm{m}\left(\mathbf{B}^{\prime}, \mathbf{D}^{\prime}\right.$ and $\left.\mathbf{F}^{\prime}\right)$. and Mathers, P. H. (2007). J Comp Neurol 504, 533-549. Reprinted with Permission of Wiley-Liss, Inc. a subsidiary of John Wiley \& Sons, Inc." 

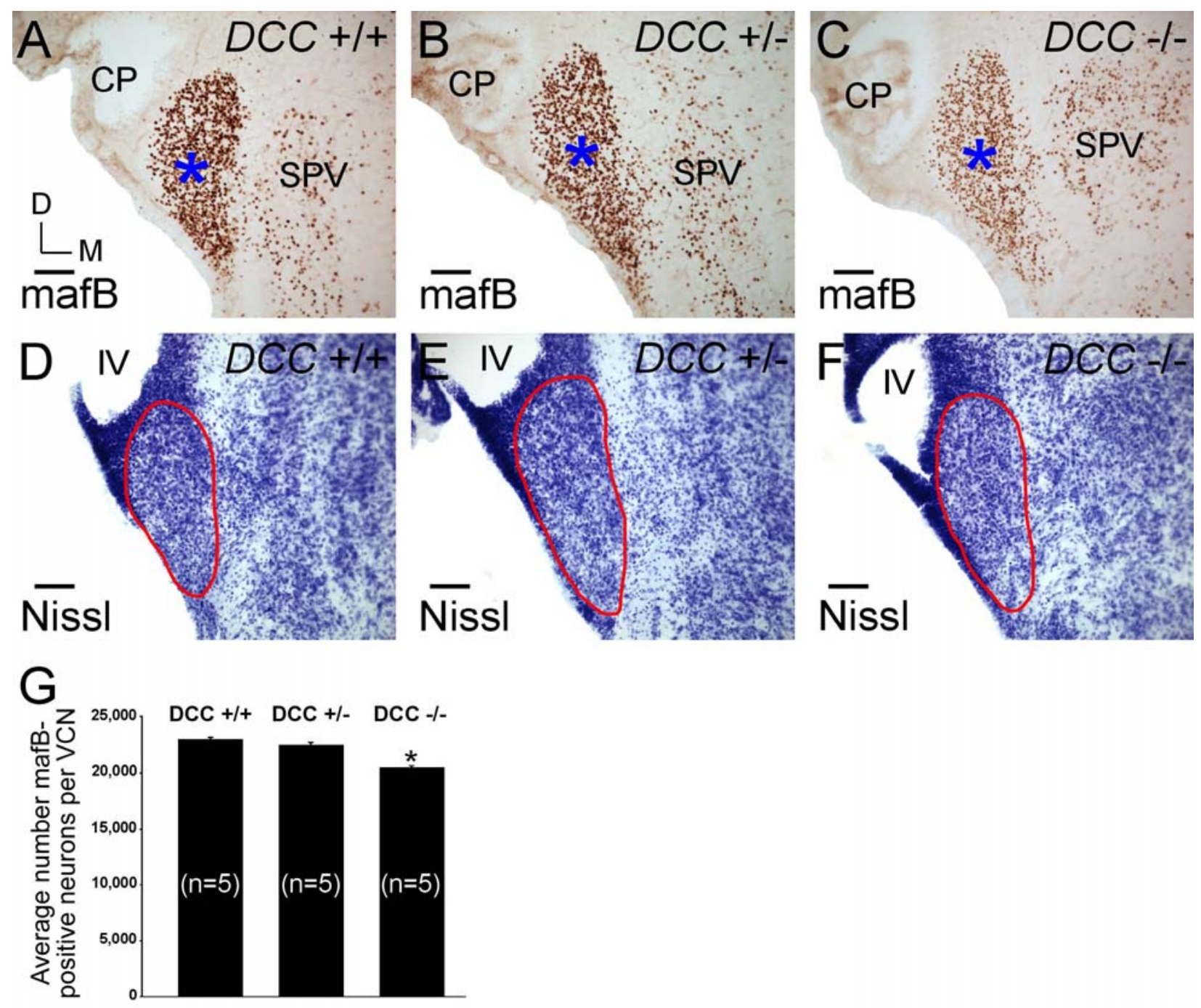

Fig. 7. Characterization of the VCN in the DCC-mutant strain. Coronal brain sections processed for mafB immunohistochemistry (A-C) or Nissl staining (D-F) from P0 mice carrying two $(\mathbf{A}, \mathbf{D})$, one $(\mathbf{B}, \mathbf{E})$ or no $(\mathbf{C}, \mathbf{F})$ functional copies of the DCC allele. A-C: Most neurons in the VCN (asterisk) are positive for mafB protein in mice carrying different numbers of functional DCC alleles. Neurons in the spinal nucleus of the trigeminal nerve (SPV) are also mafB-positive. D-F: The VCN (outlined in red) is easily identified with Nissl staining in mice of each geneotype. The size and shape of the VCN, as determined by mafB immunohistochemistry (A-C) and Nissl staining (D-F), are similar in mice carrying different numbers of functional DCC alleles. The

Molecular guidance cues necessary for axon pathfinding from the ventral cochlear nucleus. Howell, D. M., Morgan, W. J., Jarjour, A. A., Spirou, G. A., Berrebi, A. S., Kennedy, T. E., and Mathers, P. H. (2007). J Comp Neurol 504, 533-549. Reprinted with Permission of Wiley-Liss, Inc. a subsidiary of John Wiley \& Sons, Inc." 
choroid plexus (CP) or the lateral recess of the fourth ventricle (IV) is labeled. Dorsal (D) and medial (M) directions and the scale bar $(100 \mu \mathrm{m})$ in $\mathbf{A}$ are the same for all panels. G: Quantification of mafB-positive VCN neurons by unbiased stereology. The 22,970 \pm 190 mafB-positive neurons in the wild-type (DCC +/+, n = 5) VCN is not statistically different from the $22,480 \pm 200$ neurons estimated in DCC heterozygotes (DCC +/-, $\mathrm{n}=5, \mathrm{p}=0.455$ ). $D C C$ homozygous mutants (DCC -/-, $\mathrm{n}=5$ ) have $20,430 \pm 150$ neurons per $V C N$. The $\sim 10 \%$ decrease in VCN cell number is statistically significant $\left({ }^{*} p=0.002 ;\right.$ ANOVA). and Mathers, P. H. (2007). J Comp Neurol 504, 533-549. Reprinted with Permission of Wiley-Liss, Inc. a subsidiary of John Wiley \& Sons, Inc." 

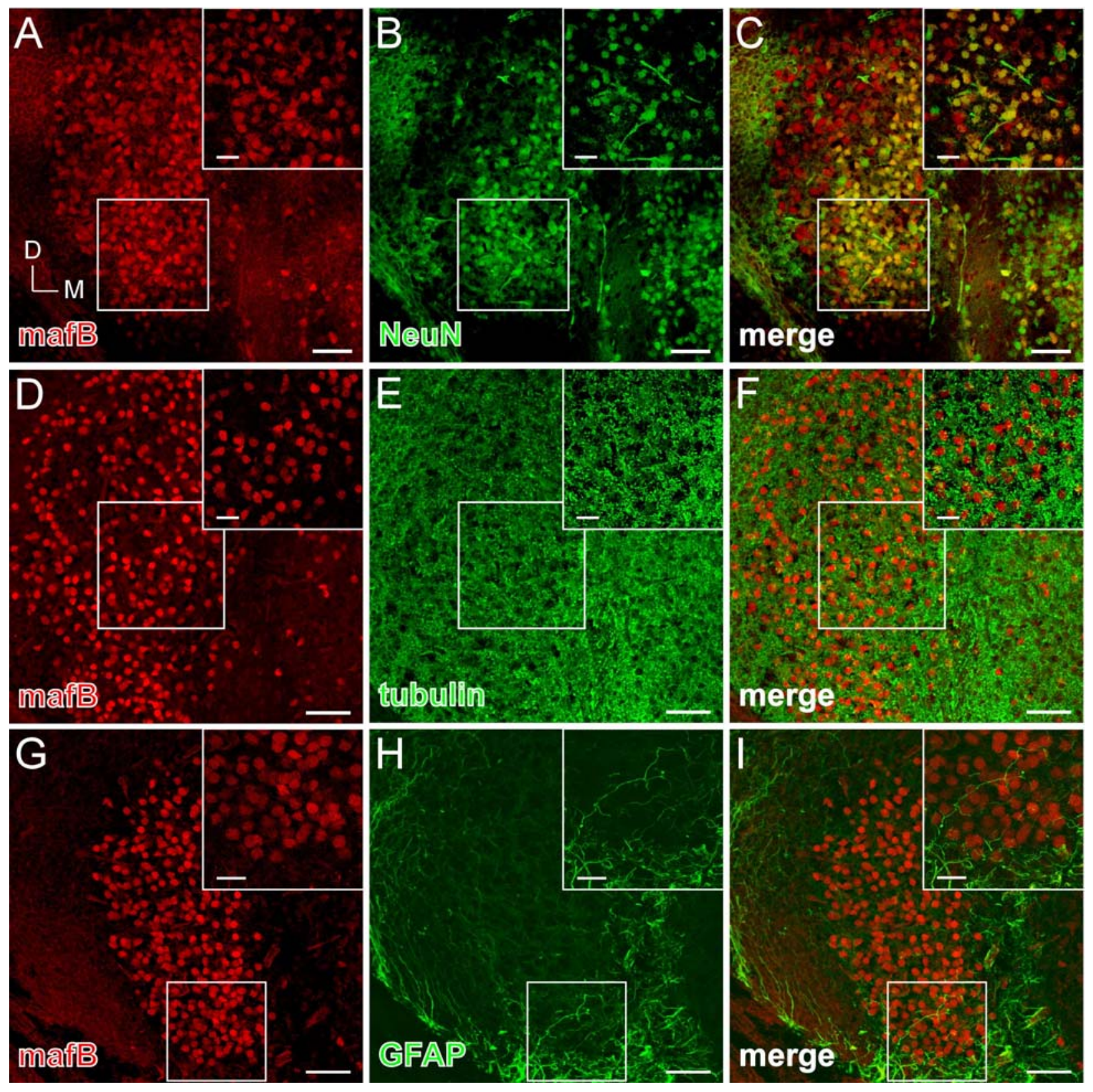

Sup. Fig. 1. mafB-positive VCN cells express neural markers. A-C: P0 coronal section through the cochlear nucleus showing mafB ( $A$, red), NeuN (B, green) and both channels (C). Inset in A-C: Collapsed $z$ stack of the boxed region in the main panels. Numerous cells within the cochlear nucleus are positive for both mafB and NeuN (yellow cells in C). No NeuN immunoreactivity is observed in some portions of

Molecular guidance cues necessary for axon pathfinding from the ventral cochlear nucleus. Howell, D. M., Morgan, W. J., Jarjour, A. A., Spirou, G. A., Berrebi, A. S., Kennedy, T. E., and Mathers, P. H. (2007). J Comp Neurol 504, 533-549. Reprinted with Permission of Wiley-Liss, Inc. a subsidiary of John Wiley \& Sons, Inc." 
the VCN, while occasional nuclei within the cochlear nucleus are immunoreactive for only NeuN. D-F: P0 coronal section through the cochlear nucleus showing mafB (D, red), $\beta$-III Tubulin (E, green) and both channels (F). Inset in D-F: Collapsed $z$ stack of the boxed region in the main panels. In all cases, regions adjacent to mafBpositive nuclei are immunoreactive for $\beta$-III Tubulin. G-H: P0 coronal section through the cochlear nucleus showing mafB ( $\mathbf{G}$, red), GFAP ( $\mathbf{H}$, green) and both channels (I). Inset in G-I: Collapsed z stack of the boxed region in the main panels. No mafB-positive cells are immunoreactive for the glial marker, glial fibrillary acidic protein (GFAP). Dorsal (D) and medial (M) directions indicated in A are the same for all panels. Scale bars are $50 \mu \mathrm{m}(\mathrm{A}-\mathrm{I})$ and $20 \mu \mathrm{m}$ (inset in A-I). and Mathers, P. H. (2007). J Comp Neurol 504, 533-549. Reprinted with Permission of Wiley-Liss, Inc. a subsidiary of John Wiley \& Sons, Inc." 


\section{CHAPTER 3}

Guidance Cues Regulating Medial-Lateral Positioning of Midbrain and Hindbrain Nuclei 


\section{Guidance Cues Regulating Medial-Lateral Positioning of Midbrain and Hindbrain Nuclei}

\section{David M. Howell ${ }^{1,2}$, Warren J. Morgan ${ }^{1,2}$, George A. Spirou ${ }^{1,3,4}$, Albert S.}

Berrebi $^{1,3,5}$, and Peter $\mathrm{H}$. Mathers ${ }^{1,2,3}$

1) Sensory Neuroscience Research Center, West Virginia University, Morgantown, West Virginia 26506, USA;

2) Department of Biochemistry, West Virginia University, Morgantown, West Virginia 26506, USA;

3) Department of Otolaryngology-Head and Neck Surgery, West Virginia University, Morgantown, West Virginia 26506, USA;

4) Department of Physiology and Pharmacology, West Virginia University, Morgantown, West Virginia 26506, USA;

5) Department of Neurobiology and Anatomy, West Virginia University, Morgantown, West Virginia 26506, USA.

This manuscript is in preparation for submission 


\section{Abstract}

Neurons migrate from their birth place to their adult location through the use of guidance cues. However, the molecular factors directing cell migration and positioning in the lower auditory brainstem are not well characterized. During our characterization of ventral cochlear nucleus axonal projections (Howell et al., (2007) J Comp Neurol 504, 533-549), we determined that DCC- and netrin-1-deficient mouse pups lack identifiable medial nucleus of the trapezoid body (MNTB) neurons. Developing MNTB and other superior olivary complex (SOC) neurons express RNAs for DCC, robo-1 and robo-2 cell surface receptors, which are known mediators of axon guidance and neuronal migration throughout the nervous system. Probes for these molecules label columns of cells that extend from the rostral-most domain of the brainstem along the ventral surface toward the future SOC. Expression of these receptor molecules is maintained as discrete SOC nuclei position along a mediallateral plane. A gradient of DCC RNA expression within the MNTB is present by E17.5 with highest levels occurring medially. Pups carrying only one functional copy of the DCC or netrin-1 allele have a laterally displaced MNTB. The displaced MNTB is maintained in adult animals and stereologic cell counts indicate the total number of MNTB neurons is similar in mice carrying two or one functional copies of the DCC allele. Despite the laterally displaced MNTB, the tonotopic organization of the MNTB, as determined by c-fos immunoreactivity, is preserved in DCC heterozygous animals. Therefore, sufficient plasticity exists for these auditory brainstem circuits to properly form even though the MNTB is significantly displaced. Additionally, both the trochlear nucleus and ventral tegmental nucleus are significantly displaced, medially and laterally, respectively, in mice carrying only one functional copy of the DCC allele. We propose that netrin-DCC and slit-robo signaling is necessary for the migration of SOC neurons and that medial-to-lateral positioning of the SOC as well as other central nervous system nuclei occurs in a dose-dependent manner, based on a cell's programmed response to midline-derived signals. 


\section{Introduction}

Many details concerning the anatomy and functional circuitry of the superior olivary complex (SOC) are known for various animal species, although molecular signals underlying the development, including tonotopy, are relatively unexplored for this population of neurons. SOC neurons develop from the dorsal medullary epithelium between E12 and E16 in the rat and between E9 and E14 in the mouse followed by migration to their adult location in the ventral brainstem (Altman and Bayer, 1980; Kudo et al., 1996; Kudo et al., 2000; Pierce, 1973). The birth order in the mouse appears to begin with medial superior olive (MSO) neurons and then progress from medial nucleus of the trapezoid body (MNTB) neurons to lateral superior olive (LSO) neurons (Pierce, 1973). Similarly, the birth order of rat SOC neurons follows a similar progression with MSO neurons (peak E13) preceding the birth of MNTB neurons (peak E15) and LSO neurons (peak E16) (Altman and Bayer, 1980; Kudo et al., 1996; Kudo et al., 2000). However, the migratory route taken by SOC neurons to reach their adult location as well as the guidance cues that mediate the migration of SOC neurons are not established.

Most central auditory nuclei contain neurons that are organized based on their sensitivity to the frequency of sound. This organization is fundamental to the auditory system. The mechanical properties of the basilar membrane in the cochlea establishes a place-code (cochleotopic) that specifies the characteristic frequency (tonotopic) of auditory nerve axons (Greenwood, 1961; Liberman, 1982). In the ventral cochlear nucleus (VCN), spiral ganglion axons terminate in a highly organized manner that maintains the cochleotopic and thereby tonotopic organization (Lorente de No, 1933; Lorente de No, 1981; Ramón y Cajal, 1909; Sando, 1965; Webster, 1971). Globular bushy cells (GBC) in the dorsal region of the anteroventral cochlear nucleus (AVCN) receive high-frequency information, and GBCs in the ventral region of the AVCN receive low-frequency information (Rose et al., 1959). Similarly, the axon terminals of GBCs located in the dorsal region of the AVCN connect with neurons in the medial (high-frequency) region of the MNTB, and GBCs in the ventral region of the AVCN connect with neurons in the lateral (low frequency) region of the MNTB. Therefore, neurons in the medial region of the 
MNTB are responsive to high-frequency sounds with neurons responsive to lower characteristic frequencies occurring in a decreasing lateral gradient (Guinan Jr et al., 1972; Sommer et al., 1993).

The calyx of Held is the axon terminal complex of a GBC axon onto an MNTB neuron (Held, 1893; Ramón y Cajal, 1909). GBC axons project ventromedially through or around the ipsilateral SOC, including the MNTB, before crossing the midline in the trapezoid body. On the contralateral side, GBC axons innervate the intermediate nucleus of the lateral lemniscus and form a functional synapse on one, or rarely two, cell within the MNTB (Friauf and Ostwald, 1988; Held, 1893; Kuwabara et al., 1991; Ramón y Cajal, 1909; Smith et al., 1993; Spirou et al., 1990). The inhibitory projection to the LSO from the contralateral AVCN via the MNTB is important for preserving interaural level differences that are necessary to localize high-frequency sounds (Boudreau and Tsuchitani, 1968; Tollin and Yin, 2002a; Tollin and Yin, 2002b; Tsuchitani, 1988a; Tsuchitani, 1988b; Tsuchitani, 1997).

An elaborate array of neural circuits is established during central nervous system development. Proper positioning of neurons and correct axonal pathfinding and synapse formation are strict requirements for the nervous system to function properly. Many of the early studies examined the role of molecular guidance cues for axonal pathfinding and the importance of the midline in the central nervous system. Two important signaling systems that mediate the midline attraction, netrin-DCC, and repulsion, slit-robo, of commissural axons throughout the central nervous system (Dickson, 2002; Dickson and Gilestro, 2006; Livesey, 1999; Nguyen-BaCharvet and Chedotal, 2002). Netrins are a well conserved family of diffusible guidance molecules. Netrin-mediated attraction occurs through binding to the deleted in colorectal cancer (DCC) receptor (Keino-Masu et al., 1996; Leonardo et al., 1997). Numerous commissural projections are absent or remarkably diminished in netrin-1- or DCC-deficient mice (Deiner et al., 1997; Deiner and Sretavan, 1999; Fazeli et al., 1997; Howell et al., 2007; Serafini et al., 1996). Slits are a well conserved family of guidance molecules that function in repulsive signaling through binding to a roundabout (robo) receptor family member (Brose et al., 1999; Kidd et al., 1999; Kidd et al., 1998; Li et al., 1999; Simpson et al., 2000b; Yuan et al., 1999). 
More recently, these axonal guidance cues have been found to participate in neuronal migration. The vast majority of neurons reach their adult location in the central nervous system by a migration from their birth location in the subventricular zone. Examination of netrin-1- and DCC-deficient mouse lines has identified multiple neuronal populations that are dependent on this attractive signaling for proper neural migration (Fazeli et al., 1997; Serafini et al., 1996). The neurons that comprise the pontine nuclei are unable to reach their adult location in mice lacking functional DCC receptors (Fazeli et al., 1997; Serafini et al., 1996; Yee et al., 1999). Inferior olivary neurons are unable to perform the circumferential migration in the absence of functional DCC signaling (Bloch-Gallego et al., 2005; Bloch-Gallego et al., 1999; de Diego et al., 2002; Di Meglio et al., 2008). In netrin-1-deficient mice, some trochlear nucleus neurons, whose axons are repelled in the presence of netrin-1, are found in the midline, rather than migrating into a more lateral position (Colamarino and Tessier-Lavigne, 1995; Serafini et al., 1996). The more recent creation of mice that are deficient in functional slit or robo family members will likely lead to the further identification of neural populations that are dependent on this repulsive signaling system for neuronal migration as well (Bagri et al., 2002; Di Meglio et al., 2008; Geisen et al., 2008; Long et al., 2004; Marillat et al., 2004; Plump et al., 2002; Sabatier et al., 2004).

SOC neurons reside in the adult between the pontine nucleus and inferior olive in the ventral brainstem. Like their rostral and caudal neighbors, SOC neurons are found adjacent to the midline and therefore may utilize similar guidance factors for proper migration. Additionally, we found that netrin-DCC and slit-robo guidance receptors were expressed in lower auditory brainstem nuclei during our characterization of VCN axonal projections. Therefore, we examined the functional importance of a netrin-DCC signaling system in the development of SOC nuclei by examining these nuclei in mice carrying no functional copies of the DCC or netrin-1 allele. We found that the neurons that comprise the MNTB, the most medial component of the SOC, are displaced laterally in mice carrying only one functional copy of the netrin-1 or DCC allele and are not identifiable in mice carrying no functional copies of the netrin-1 or DCC allele. Although the laterally displaced 
MNTB is maintained in adult animals, an apparently normal tonotopic organization exists within the displaced MNTB. Medial-lateral displacements are also seen in the trochlear and the ventral tegmental nuclei in $D C C$ heterozygous animals compared with controls, suggesting a dose-dependent mechanism for the proper placement of nuclei along the medial-lateral axis of the brain. 


\section{Methods}

\section{Animals}

All mice, except netrin-1-deficient breading pairs, were maintained at West Virginia University in compliance with IACUC regulations on a 12-hr light/dark cycle. Embryonic age $(E)$ was calculated such that noon the day following the mating denotes E0.5. Embryonic age was confirmed by crown-rump measurements and E19.5 was set equivalent to postnatal day $(P) 0$, the day of birth. FVB/NJ breeding pairs were obtained from The Jackson Laboratory (Bar Harbor, ME). DCC-deficient founders were a kind gift from Dr. Marc Tessier-Lavigne and maintained on a CD-1 background (Charles River Laboratories, Inc., Wilmington, MA). DCC-deficient mice were genotyped as previously described (Fazeli et al., 1997). Heads from netrin-1deficient animals and littermate controls were immersion-fixed in $4 \%$ paraformaldehyde (PFA)/phosphate buffered saline (PBS) at McGill University and genotyped as previously described (Serafini et al., 1996). Engrailed1-cre mice were obtained from Dr. Mark Lewandoski, maintained in a 129/Sv genetic background and genotyped as previously described (Kimmel et al., 2000). Rosa26R and Rosa26EGFP mouse lines expressing $\beta$-galactosidase and GFP, respectively, were genotyped as previously described (Giel-Moloney et al., 2007; Mao et al., 2001; Soriano, 1999; Zambrowicz et al., 1997).

On the appropriate gestational day, pregnant mice were sacrificed by cervical dislocation. The collected embryos were staged and decapitated. The heads were immersion-fixed in a $4 \%$ PFA/PBS solution $(\mathrm{pH} 7.4)$ overnight at $4^{\circ} \mathrm{C}$. Young postnatal mice were anesthetized by hypothermia (Phifer and Terry, 1986) and either transcardially perfused with PBS followed by 4\% PFA/PBS or decapitated and the heads placed in the same fixative. Intact brains were surgically isolated with the aid of a dissecting microscope and transferred to fresh fixative solution at $4^{\circ} \mathrm{C}$.

Anesthetized juvenile and adult mice were perfused through the ascending aorta with room temperature (RT) PBS followed by a fixative solution consisting of $4 \%$ PFA and $0.125 \%$ glutaraldehyde in PBS (pH 7.4) at RT. Intact brains were then removed from the cranium and post-fixed in fresh fixative solution overnight at $4^{\circ} \mathrm{C}$. 
Brains were cryoprotected in $30 \%$ sucrose in PBS for frozen sectioning in the coronal plane on a sliding microtome at $40 \mu \mathrm{m}$ thickness.

\section{Cloning of cDNAs encoding axon guidance molecules}

Total RNA from an E15.5 mouse brainstem was isolated with Trizol (Invitrogen, Carlsbad, CA) and reverse transcribed with random hexamer oligonucleotides. Gene-specific primers were picked using primer3 software (Rozen and Skaletsky, 2000) for each gene of interest to yield approximately $900 \mathrm{bp}$ fragments. The gene-specific primers have been previously reported (Howell et al., 2007). PCR fragments were gel isolated and cloned with a PCR-Script kit (Stratagene, La Jolla, CA). All products were confirmed by sequencing (Northwoods DNA Inc., Solway, MN) and subsequently used for the production of in situ hybridization probes.

\section{In situ hybridization}

Digoxigenin-labeled RNA probes were prepared as described by the manufacturer (Roche Applied Science, Indianapolis, IN), purified with a nucleotide removal kit (Qiagen, Valencia, CA), appropriately diluted with hybridization solution and stored at $-20^{\circ} \mathrm{C}$ until needed. Isolated complete brains from immersion-fixed FVB and CD1 heads between ages of E13.5 and P0 were processed for wholemount in situ hybridization essentially as previously described (Cygan et al., 1997; Howell et al., 2007). Appropriately stained whole brains were digitally photographed with a stereomicroscope (MZFIII, Leica) and an Optronics digital camera. A minimum of three brains at each developmental age were processed together and all reactions were repeated at least three times (i.e.- $n \geq 9$ for each probe at every developmental age analyzed). Control samples reacted with a sense RNA probe gave no hybridization signal in identically processed samples.

\section{Immunohistochemistry}

Serially collected, coronal, free-floating brain sections were used for all immunohistochemical reactions. Sections were rinsed in PBS and nonspecific 
labeling was blocked by immersing the sections in PBS containing $2 \% \mathrm{H}_{2} \mathrm{O}_{2}$ and $5 \%$ methanol for $1 \mathrm{hr}$ at RT. Samples were washed in PBS and then further blocked in PBS containing 5\% heat-inactivated normal serum and $0.4 \%$ Triton X-100 at RT for 1-2 hours. Primary antibodies were diluted in PBS containing $4 \%$ serum and $0.1 \%$ Triton X-100. Samples were incubated overnight in the primary antibody solution at $4^{\circ} \mathrm{C}$. The antibodies used in this study were: NeuN (1:2000, MAB377B, Chemicon), Sox-2 (1:1000, AB5603, Chemicon), Calbindin (1:2000, CB 38, Swant), Parvalbumin (1:2000, PV 28, Swant), Tyrosine hydroxylase (1:5000, 657012, Calbiochem), c-fos (1:1000, SC-52, Santa Cruz Biotechnology), GFP (1:1000, A6455, Molecular Probes). Sections were rinsed with PBS, incubated with appropriate biotinylated secondary antibodies (1:200, Vector Laboratories) in the same vehicle as the primary antibody, rinsed with PBS and incubated with elite $A B C$ reagent (Vector Laboratories) as described by the manufacturer. Immunoreactivity was visualized with $0.05 \%$ 3,3'-diaminobenzidine tetrahydrochloride (DAB, Sigma), $0.01 \% \mathrm{H}_{2} \mathrm{O}_{2}$ and $0.1 \%$ Triton $\mathrm{X}-100$ in $0.5 \mathrm{M}$ Tris ( $\mathrm{pH} 7.65)$. Rinsed sections were mounted serially on glass slides and coverslipped for analysis and image capture. All slides were analyzed and digitally photographed on an upright microscope (AX70, Olympus) with an Optronics digital camera. Primary antibody was omitted in control samples with no immunoreactivity observed in these samples.

\section{Histochemistry}

Fluorescent Nissl staining was performed as directed by the manufacturer (Molecular Probes) on P0 brains from various netrin-1 genotypes sectioned in the coronal plane on a vibratome at $100 \mu \mathrm{m}$ thickness. Fluorescence images were captured with a laser scanning confocal microscope (LSM510 Meta, Zeiss) with the investigator blind to genotype. Identically processed PO FVB and CD1 samples served as fluorescent staining controls. For $\beta$-galactosidase staining, intact brains were isolated from the cranium prior to fixation from P0 animals. Samples were fixed in 4\% PFA/PBS for 1-2 hrs at RT, rinsed with PBS and incubated with X-gal staining solution ( $5 \mathrm{mM}$ Potassium Ferricyanide, $5 \mathrm{mM}$ Potassium Ferrocyanide, $5 \mathrm{mM}$ Magnesium chloride, $1 \mathrm{mg} / \mathrm{mL}$ X-gal in PBS) at $37^{\circ} \mathrm{C}$. Following staining, brains 
were rinsed with PBS and placed in fixative solution containing 4\% PFA and $0.2 \%$ glutaraldehyde in PBS. Whole brains were digitally photographed using a stereomicroscope (MZFIII, Leica) and an Optronics digital camera.

A subset of vibratome sections adjacent to those processed for immunohistochemistry was mounted on glass slides, air dried and stained for Nissl substance with $1 \%$ cresyl violet using standard protocols. Slides were coverslipped for analysis and image capture. Samples for cytochrome oxidase histology were processed essentially as previously described (Wong-Riley, 1979). Briefly, free floating sections were rinsed in PBS and transferred to staining solution containing $0.05 \%$ DAB, $0.025 \%$ cytochrome C (Sigma C-7752) and 4\% sucrose in 0.1 M PBS for 4-6 hours at RT. Following staining, sections were rinsed with PBS, mounted serially on glass slides and coverslipped for analysis and image capture. All slides were analyzed and digitally photographed on an upright microscope (AX70, Olympus) with an Optronics digital camera.

\section{Protein Quantification}

Intact brains were isolated at E14.0 from a pairing of two adult mice heterozygous for the $D C C$ allele and immediately frozen with dry ice. The carcass was used for PCR genotyping. Each brain sample was resuspended by sonication in USB solution containing $6 \mathrm{M}$ Urea, 4\% SDS, $125 \mathrm{mM}$ Tris- $\mathrm{HCl} \mathrm{pH}$ 6.8, $20 \mathrm{mg} / \mathrm{mL}$ DTT, 1X protease inhibitor (\#539131, Calbiochem), centrifuged at 10,000xg for 3 $\min$ and the supernatant removed and stored frozen at $-20^{\circ} \mathrm{C}$. Proteins were separated on $7.5 \%$ Tris- $\mathrm{HCl}$ gel (Bio-Rad Laboratories) and transferred to PVDF membrane (Millipore). PVDF membrane was placed in blocking buffer (LI-COR Biosciences) for $1.5 \mathrm{hr}$ at RT and incubated with primary antibodies in PBT for $1 \mathrm{hr}$ at RT. The antibodies used in this study were: DCC (1:500, SC-6535, Santa Cruz Biotechnology, Inc., Santa Cruz, CA), DCC (1:500, SC-6534, Santa Cruz Biotechnology, Inc., Santa Cruz, CA) and neuron-specific $\beta$-III Tubulin clone D66 (1:1000, T 0198, Sigma, St. Louis, Mi). Membrane was then rinsed with PBT and incubated with appropriate IRDye conjugated secondary antibodies (1:20,000, LICOR Biosciences) for $1 \mathrm{hr}$ at RT. Detection and quantification of individual protein 
bands was accomplished with the Odyssey Infrared Imaging System and analysis software (LI-COR Biosciences) according to the manufacturer's recommendations. Initial experiments conducted with DCC antibody (SC-6535) identified a protein band of similar size to DCC in samples containing no functional copies of the $D C C$ allele. This antibody was generated with a peptide sharing $25 \%$ sequence homology (personal communication from Santa Cruz Biotechnology technical support) to neogenin (molecular weight $190 \mathrm{kD}$; Vielmetter et al., 1994) that is similar to the 190 kD reported molecular weight for DCC (Fazeli et al., 1997). However, when experiments were conducted with DCC antibody (SC-6534), which is not crossreactive to neogenin, no DCC protein signal was detected in $D C C$-deficient samples, consistent with prior publications (Fazeli et al., 1997). The ratio of DCC protein signal to $\beta$-tubulin protein signal was calculated for each sample, grouped according to genotype and analyzed by a student's t-test.

\section{Unbiased stereological estimates}

Serially collected tissue sections, $40 \mu \mathrm{m}$ thickness, were processed as described above for calbindin immunohistochemistry. Unbiased stereology was performed essentially as previously described (Howell et al., 2007; Kulesza et al., 2002). Briefly, we implemented the optical fractionator protocol in Stereo Investigator (MBF Bioscience, Williston, VT). Contours were traced using a 10X objective lens and counting frames $\left(2500 \mu \mathrm{m}^{2}\right)$ were created to sample from each contour. The section thickness was measured at several locations with a 100X oil immersion objective lens (NA 1.35) and determined to be approximately $17 \mu \mathrm{m}$ after shrinkage. The top and bottom $1 \mu \mathrm{m}$ of the sections were reserved as guard zones. Cell counts were made on a total of 4 adult brains for each $D C C$ genotype. We counted approximately 250 calbindin-positive neurons in the MNTB (one side only) from a total of 5-6 sections in each brain. Average cell counts were grouped according to DCC genotype and analyzed by a student's t-test. Average cell counts are rounded to the nearest ten and presented as mean \pm standard error of the mean (SEM) (Gundersen and Jensen, 1987). The coefficient of error ranged from 0.06 to 0.08 for all samples counted. 


\section{Measurement of medial-lateral position of nuclei}

Serially collected tissue sections, $40 \mu \mathrm{m}$ thickness, were processed as described above for calbindin (MNTB and ventral tegmental nucleus), parvalbumin (trochlear nucleus) and tyrosine hydroxylase (locus coeruleus) immunohistochemistry. Sections with bilateral cuts through the desired nuclei were digitally photographed on an upright microscope (AX70, Olympus) with an Optronics digital camera at an appropriate magnification to capture both nuclei in the digital image. A calibration slide was photographed at an identical magnification to accurately calculate distance measurements. The distance between MNTB nuclei (left medial edge to right medial edge) was calculated by averaging the distance between the medial edges in a series of sections (a minimum of 10 sections per brain) from adult animals carrying two $(n=5)$ or one $(n=5)$ functional copies of the $D C C$ allele. Lateral edge difference (left lateral edge to right lateral edge) was also calculated for the MNTB using these same sections. The distance between trochlear nuclei (left medial edge to right medial edge) was calculated by averaging the distance between the medial edges in a series of sections ( 2 to 3 sections per brain) from animals carrying two $(n=7)$ or one $(n=6)$ functional copies of the $D C C$ allele. The distance between ventral tegmental nuclei (left medial edge to right medial edge) was calculated by averaging the distance between the medial edges in a series of sections (a minimum of 4 sections per brain) from animals carrying two ( $n=$ $7)$ or one $(n=7)$ functional copies of the $D C C$ allele. The distance between locus coerulei (left medial edge to right medial edge) was calculated by averaging the distance between the medial edges in a series of sections (a minimum of 4 sections per brain) from animals carrying two $(n=5)$ or one $(n=3)$ functional copies of the $D C C$ allele. All measurements are grouped according to genotype and presented as mean \pm SEM.

\section{Tonotopic organization of the MNTB}

The tonotopic organization of the MNTB was assessed by c-fos immunohistochemistry analysis. Previously published protocols were modified for 
this analysis (Brown and Liu, 1995; Friauf, 1992; Ryan et al., 1982; Saint Marie et al., 1999). Briefly, sound stimuli were created with a commercially available software package (Tucker-Davis Technologies) and imported into Jan Schnupp's Brainware. Sound stimulation hardware consists of an RP2.1 processor, ED1 speaker driver and 2 ES1 free-field electrostatic speakers (Tucker-Davis Technologies). Prior to sound exposure, a single animal was placed in a dark acoustically-shielded room for 60 minutes. Stimuli consisted of pure-tone bursts $(10 \mathrm{kHz}-75 \mathrm{kHz})$ of $400 \mathrm{msec}$ duration with a $150 \mathrm{msec}$ interval. Animals were allowed to freely move about the cage during the 60 min stimulation. Timing and frequency were monitored with an oscilloscope and intensity calibrated to $70-75 \mathrm{~dB}$ SPL with a microphone (Bruel \& Kjaer). Immediately following the stimulation, animals were deeply anaesthetized and perfused through the ascending aorta with PBS followed by a fixative solution consisting of $4 \%$ PFA and $0.125 \%$ glutaraldehyde in PBS at RT. Brains were removed, post-fixed in the same fixative and cryoprotected with $30 \%$ sucrose in PBS for frozen sectioning on a sliding microtome at $40 \mu \mathrm{m}$ thickness. Sections were serially collected. Half of the sections were processed for c-fos immunohistochemistry to identify the region of the MNTB stimulated by the sound stimulus. The remaining sections were processed for calbindin immunohistochemistry to identify the extent and location of the MNTB by measuring the distance from the midline to the medial edge and midline to lateral edge. MNTB distance measurements are grouped by genotype and presented as mean \pm SEM. The location of c-fos-positive neurons was calculated by measuring the distance from the brainstem midline to the medial edge of cellular labeling and the midline to the lateral edge of cellular labeling to obtain a center point and width for each isofrequency zone within the MNTB. These measurements were grouped according to stimulation frequency and genotype and presented as mean \pm SEM.

Initial stimulation experiments with animals carrying two or one functional copy of the DCC allele did not produce c-fos immunoreactive neurons within the central auditory system, including the MNTB, despite appropriate c-fos labeling in FVB control animals. This result appears to contrast those of Brown and Liu (1995) except our stimulation tones were higher than the $6 \mathrm{kHz}$ tones presented in this 
study. Further investigation revealed that CD-1 mice, the $D C C$ maintenance strain, have an early-onset high-frequency hearing loss and are unable to hear frequencies greater than $30 \mathrm{kHz}$ as early as 5-6 weeks of age (Riva et al., 2007; Shone et al., 1991). To circumvent this problem, a founder male heterozygous for the $D C C$ allele was paired with an FVB female, a strain that lacks any reported hearing defects (Zheng et al., 1999). Progeny from this cross were genotyped and an F1 male carrying one functional $D C C$ allele was paired with a wild-type FVB female. Progeny from this second cross (age range P26 to P32) were used for all auditory stimulation experiments. The c-fos immunoreactivity and distribution was comparable to FVB wild-type animals. Like the $D C C$ founder line, this F2 DCC-FVB strain also possesses a laterally displaced MNTB in animals carrying only one functional copy of the $D C C$ allele as compared to littermates carrying two functional copies of the $D C C$ allele.

\section{Image analysis}

All images were collected and stored in Tagged-Image File Format (TIFF). All images were examined with Adobe Photoshop 7.0 (Adobe Systems Inc., San Jose, CA) and brightness, contrast and color balance were optimized uniformly when necessary. Background regions surrounding tissues were set to a uniform appearance with the magic wand, paint bucket and pencil tools. Figure compilations were created in Freehand 11 (Macromedia, Inc., San Francisco, CA) using the optimized TIFF images. 


\section{Results}

\section{netrin-1 and DCC-deficient mice lack identifiable MNTB neurons}

During our characterization of VCN axon pathfinding defects in netrin-1- and DCC-deficient mice (Howell et al., 2007), we found that the architecture of the auditory brainstem, like many other known regions of the brain, appeared disrupted in mice carrying no functional copies of the DCC or netrin-1 allele (Bloch-Gallego et al., 1999; Deiner and Sretavan, 1999; Fazeli et al., 1997; Howell et al., 2007; Serafini et al., 1996; Yee et al., 1999). Most notably, the neurons comprising the MNTB are not readily identifiable in mice lacking functional $D C C$ or netrin-1 alleles (Figure 1). At E17.5, in mice carrying two functional copies of the DCC allele (DCC $+/+$ ), hybridization with an antisense DCC probe encompassing exons 23 to 28 labels a group of cells adjacent to the midline in the auditory brainstem consistent with the MNTB (Figure 1A). At this age, DCC is also expressed in neurons within a more lateral region of the $\mathrm{SOC}$, along with other brainstem neurons that include the cochlear nucleus, pontine nucleus, inferior olive, and cerebellum (Figure $1 \mathrm{~A}$ and data not shown). In contrast, hybridization with an antisense $D C C$ probe fails to label any structure within the auditory brainstem consistent with the MNTB in mice carrying no functional copies of the $D C C$ allele (DCC -/-) (Figure 1B). Continued $D C C$ expression is observed in the cerebellum and cochlear nucleus (data not shown) and expression is maintained in a lateral region of the SOC and inferior olive (Figure 1B). As previously reported, the neurons comprising the pontine nuclei are misplaced in DCC-deficient mice (Figure 1B; Fazeli et al., 1997). To further characterize the apparent loss of MNTB neurons, we analyzed tissue sections through the auditory brainstem for NeuN immunoreactivity (Figures $1 \mathrm{C}$ and 1D) and Nissl staining (Figures 1E and 1F). In P0 controls, both labeling methods identify the MNTB as an oval-shaped collection of neurons adjacent to the ventral midline of the auditory brainstem near the ventral surface (Figures $1 \mathrm{C}$ and $1 \mathrm{E}$ ). This cluster of neurons is not identified using these methods in PO DCC-deficient mice (Figures 1D and $1 \mathrm{~F}$ ). Additionally, the MNTB is readily identified in mice carrying two functional copies of the netrin-1 allele (netrin-1 +/+) at P0 by fluorescent Nissl staining (Figure $1 G$ ). Like animals carrying no functional copies of the $D C C$ allele, the cluster of 
neurons that comprise the MNTB is not identified in pups homozygous for the netrin1 mutant allele (netrin-1 -/-) (Figure 1H).

\section{DCC and netrin-1 gene dosage alters medial-lateral MNTB positioning}

Tissues across all DCC and netrin-1 genotypes were processed in the search to identify the location of MNTB neurons in animals lacking functional copies of the DCC or netrin-1 allele. Initial characterization of netrin-1- and DCC-mutant mouse lines found minor structural changes in some animals carrying one functional copy of the targeted allele during late embryonic and early postnatal development (Fazeli et al., 1997; Serafini et al., 1996). DCC was thought to exhibit recessive inheritance and therefore animals carrying one functional copy of the $D C C$ allele were expected to be identical to animals carrying two functional copies. Along this line, we previously found that the VCN axonal trajectories and the number of VCN neurons were qualitatively and statistically similar, respectively, in mice carrying one or two functional copies of the DCC or netrin-1 allele (Howell et al., 2007). In contrast, the location of MNTB neurons is consistently found to be laterally displaced in mice carrying only one functional copy of the DCC allele by Nissl staining (compare Figures 2A with 2B). Sox-2, an HMG-box transcription factor, is expressed by multiple populations of SOC neurons, including the MNTB, during development (Figure 2D; Morgan et al., in preparation). Similarly, Sox-2 immunoreactive MNTB neurons are also laterally displaced in mice carrying only one functional copy of the DCC allele (compare Figures 2D with 2E).

Select populations of SOC neurons, including MNTB neurons, express the transcription factor, engrailed-1 (En-1), during embryonic development. The progeny from a pairing of a mouse homozygous for an engrailed-1-cre (En-1 cre) targeted allele and a GFP-expressing cre reporter mouse permits GFP immunoreactivity to identify MNTB neurons (Supplemental Figure 1A). An adjacent section processed for

calbindin immunohistochemistry, a $\mathrm{Ca}^{2+}$-binding protein know to be expressed in MNTB neurons (Friauf, 1993), demonstrates that those markers label the same population of neurons (compare Supplemental Figures 1B with 1A). Additional immunoreactivity is observed in more lateral SOC nuclei (data not shown). The 
brains of progeny carrying the En-1-cre targeted allele and the lacZ-cre reporter, ROSA26R, and heterozygous for the DCC mutant allele are processed for X-gal histochemistry to identify MNTB as well as other brainstem neurons across genotypes in the DCC-mutant strain (Figures 2G-2I). X-gal staining is observed broadly throughout the SOC with the most medial signal corresponding to the MNTB in the ventral view of the brainstem carrying two functional copies of the $D C C$ allele (Figure 2G). Similarly, the location of the MNTB signal is laterally displaced in mice carrying only one functional copy of the $D C C$ allele (compare Figures $2 \mathrm{H}$ with $2 \mathrm{G}$ ). In addition, the location of the MNTB is consistently found laterally displaced in animals carrying only one functional copy of the netrin-1 allele (compare Supplemental Figures $2 \mathrm{~B}$ with $2 \mathrm{~A}$ ) at $\mathrm{P} 0$. The magnitude of the displacement in mice heterozygous for the netrin-1 mutant allele is not as large as observed in mice carrying only one functional copy of the $D C C$ allele. A cluster of cells in a lateral region of the $S O C$ is identified by Nissl staining (Figure $2 \mathrm{C}$ ), Sox-2 immunoreactivity (Figure $2 \mathrm{~F}$ ) and $\mathrm{X}$ gal (En-1 cre lacZ) staining (Figure 2I) in animals carrying no functional copies of the $D C C$ allele. A similar cluster of cells is observed in a lateral region of the SOC in netrin-1-deficient animals (Supplemental Figure 2C). This cluster may represent the location of MNTB neurons in netrin-1- and DCC-deficient animals; however, current detection methods are unable to unequivocally differentiate MNTB neurons from other SOC neurons due to the lack of specific markers for these neurons at these early ages.

The consistently observed laterally displaced MNTB was not an expected finding since positional changes are not reported for other nuclei that utilize netrinDCC signaling for development. Therefore, we sought to determine if the lateral displacement is maintained in adult animals or possibly represents a delay in the proper positioning of MNTB neurons in animals carrying only one functional copy of the $D C C$ allele. To accomplish this, we determined the location of MNTB neurons through calbindin (Figures $3 \mathrm{~A}$ and $3 \mathrm{~B}$ ) and parvalbumin (Figures $3 \mathrm{C}$ and $3 \mathrm{D}$ ) immunohistochemistry in adult mice carrying two (Figures $3 \mathrm{~A}$ and $3 \mathrm{C}$ ) or one (Figures 3B and 3D) functional copies of the DCC allele. In each case, MNTB neurons are found at a more lateral position in mice carrying only one functional 
copy of the DCC allele (Compare Figures $3 A$ with $3 B$ and $3 C$ with $3 D$ ). MNTB neurons are also identified with cytochome oxidase histochemistry (Supplemental Figures $3 \mathrm{~A}$ and $3 \mathrm{~B}$ ), NeuN immunohistochemistry (Supplemental Figures $3 \mathrm{C}$ and $3 \mathrm{D}$ ), and Nissl staining (Supplemental Figures $3 \mathrm{E}$ and $3 \mathrm{~F}$ ) in adult animals carrying two (Supplemental Figures 3A, 3C and 3E) or one (Supplemental Figures 3B, 3D and $3 F$ ) functional copies of the DCC allele. The additional labeling methods confirm that MNTB neurons in animals carrying only one functional copy of the $D C C$ allele are positioned lateral to the location of MNTB neurons in animals carrying two functional copies of the DCC allele (compare Supplemental Figures $3 \mathrm{~A}, 3 \mathrm{C}$ and $3 \mathrm{E}$ with $3 \mathrm{~B}, 3 \mathrm{D}$ and $3 \mathrm{~F}$, respectively). To quantify this displacement, the distance between MNTB nuclei was measured in a series of sections processed for calbindin or parvalbumin immunohistochemistry from mice carrying either one $(n=5)$ or two $(n=5)$ functional copies of the $D C C$ allele. A minimum of 10 sections per animal were included in the measurements. The results are diagramed in Figure $3 \mathrm{E}$. We found that the $653 \pm 26 \mu \mathrm{m}$ separating the medial edge of wild-type MNTB neurons in adult mice is significantly smaller than the $985 \pm 40 \mu \mathrm{m}$ separating the medial edge of adult MNTB neurons in animals carrying only one functional copy of the $D C C$ allele ( $p$-value < 0.001). Additionally, the $1758 \pm 29 \mu \mathrm{m}$ that separates the lateral boundary of MNTB neurons in wild-type mice is significantly different from the $1946 \pm 37 \mu \mathrm{m}$ that separate the lateral boundary of adult MNTB neurons in mice carrying only one functional copy of the DCC allele ( $p$-value $=0.007$ ). These findings indicate that this positioning defect is not the result of delayed neuronal migration, but the result of the lost $D C C$ allele affecting MNTB medial-lateral positioning.

One possible explanation for the change in the position of the MNTB is neuronal loss in animals carrying only one functional $D C C$ allele. This loss could be accomplished through the defective migration of a subset of MNTB neurons that prevents them from reaching the MNTB or alternatively, a subset of MNTB neurons may utilize DCC activity as a survival factor such that the loss of one allele prevents these neurons from developing properly (Mehlen and Mazelin, 2003). However, no statistically significant changes were observed in the number of VCN in mice carrying two or one functional copies of the DCC allele (Howell et al., 2007). To 
determine if neuronal loss could explain the change in MNTB positioning, we used unbiased stereology to quantify a potential difference in the number of calbindinpositive MNTB principal neurons from adult animals carrying two or one functional copies of the DCC allele (Figure 3F). We selected tissue sections processed for calbindin immunohistochemistry because it is fairly selective for MNTB neurons, has a high signal-to-noise ratio and, most importantly, appears to label all mouse MNTB principal neurons. We found that adult mice carrying two functional copies of the DCC allele contain 8,110 \pm 105 neurons per MNTB $(n=4)$, while mice carrying only one functional copy of the $D C C$ allele contain a statistically similar number of neurons per MNTB $(8,370 \pm 94, n=4, p$-value $=0.4)$. This indicates that the displaced MNTB in mice carrying only one functional copy of the DCC allele is not the result of a decreased number of MNTB neurons. Taken together, these data support a role for DCC in the medial-lateral positioning of MNTB neurons in the auditory brainstem. To explain these results, we propose that the MNTB resides more laterally in the auditory brainstem due to a net loss of DCC-mediated midline attraction that occurs with the loss of each additional functional copy of the $D C C$ allele.

\section{DCC gene dosage alters DCC protein level}

For this explanation to function properly, the number of functional $D C C$ alleles must affect the level of functional DCC protein that is expressed during development. The level of DCC protein is reported to be decreased by $\sim 70 \%$, relative to wild-type, in the medial prefrontal cortex of mice carrying only one functional copy of the DCC allele at 3 months of age (Flores et al., 2005). However, other regions of the brain were not included in this quantification and the reduction was demonstrated in adult rather than embryonic tissues. Therefore, we used quantitative Western blotting to determine whether differences in the level of DCC protein exist in E14.0 brains across the DCC mutant strain. An equal amount of total protein from E14.0 brains carrying two, one, or no functional copies of the DCC allele was separated by gel electrophoresis, transferred to PVDF membrane and probed with antibodies to DCC and neuron specific $\beta$-III tubulin, an internal loading 
standard (Figure 4A). A single band at approximately $190 \mathrm{kD}$ is observed in brains carrying two functional $D C C$ alleles $(n=5)$ which is identical in size to the band observed in mice carrying only one functional $D C C$ allele $(n=5)$. Consistent with prior observations, no DCC protein signal is observed in mice carrying no functional copies of the DCC allele $(n=4)$ (Fazeli et al., 1997). In all samples analyzed, the DCC protein signal in mice carrying only one functional allele is less than the signal observed in mice carrying two functional copies of the DCC allele (Figure 4A and data not shown). DCC and $\beta$-tubulin protein signals were quantified using a LiCor Odyssey imaging system to calculate a DCC protein signal to $\beta$-tubulin protein signal ratio. Mice carrying only one functional copy of the DCC allele express $49 \%$ of the quantity of DCC protein found in mice carrying two functional copies of the DCC allele (Figure 4B, p-value $<0.001$ ). This result is consistent with our proposal that the loss of one functional copy of the DCC allele decreases the level of DCC protein. The decreased level of DCC receptors is expected to reduce the DCC-mediated midline attractant activity. The net result of this change in the level of DCC receptors is a laterally displaced MNTB in mice carrying only one functional copy of the DCC allele.

\section{SOC neurons express DCC and robo receptors during migration}

MNTB neurons are known to express DCC RNAs at E17.5 (Figure 1A), an age when MNTB neurons nearly occupy their adult location. Migrating MNTB neurons must express DCC RNAs for this signaling system to function in the positioning of MNTB neurons. Therefore, we analyzed the expression of $D C C$ using whole-mount in situ hybridization in the mouse auditory brainstem from E13.5 through $\mathrm{PO}$, the period that encompasses the birth, migration and positioning of SOC neurons. As early as E13.5, a column of cells that extends from the rostral-extent of the brainstem to the future location of the SOC is observed to express DCC RNAs (Figure 5A). The presumptive SOC continues to express RNAs for DCC over the next two to three days, with the highest levels occurring within the center of the $D C C$ expression domain (Figures 5B-D). Unfortunately, no discrete SOC nuclei are identified during these early ages in whole brainstems or coronal sections through 
the auditory brainstem (Figures 5B, 5C and 5D and data not shown). As early as $E 17.5$, two regions of $D C C$ expression are present in the $S O C$ with the medial region corresponding to the presumptive MNTB (Figure 5E). At this stage, DCC expression occurs in a high medial-to-lower lateral gradient across the nucleus (Figure $5 \mathrm{E}$ ). This gradient of $D C C$ expression is maintained at PO (Figure 5F). DCC expression within the MNTB is reduced at P2 and no longer observed at P5 (data not shown). The lateral $D C C$ expression resides within the SOC; however, the paucity of markers for SOC nuclei at these early stages prevents a definitive identification of this expression domain (Figures 5E and 5F). Similarly, DCC expression in the lateral region of the SOC is no longer observed by P5 (data not shown).

SOC neurons also express RNAs for robo1 (Supplemental Figures 4A-C) and robo2 (Supplemental Figures 4D-F) receptors during the migration and positioning of SOC nuclei. As early as E13.5, two columns of cells are labeled with an antisense robo1 (Supplemental Figure 4A) or robo2 (Supplemental Figure 4D) probe. These columns extend from the rostral-extent of the brainstem to the presumptive SOC. The medial column labeled by both probes is similar to the location of the column labeled with an antisense $D C C$ probe (compare Figure $5 \mathrm{~A}$ with Supplemental Figures $4 A$ and $4 D$ ). At E15.5, signal for robo1 appears uniform in the medial SOC while signal in the lateral SOC appears reduced (Supplemental Figure 5B). At E17.5, bands of robo1 signal are present in the SOC and a faint band of robo1-positive cells is observed in the region of the MNTB (Supplemental Figure 4C). The motor nucleus of the facial nerve is also positive for robol expression at these developmental stages (Supplemental Figures 4B and 4C). At E15.5, the highest levels of robo2 signal in the presumptive $S O C$, like $D C C$ at this stage, are observed in the center of the stained region (Supplemental Figure 4E). At P0, the robo2 staining pattern occurs in a high medial-to-lower lateral gradient in a region of the SOC; however, the paucity of markers for SOC nuclei at these early stages prevents a definitive identification of these expression domains (Supplemental Figure 4F). Like DCC expression, RNAs for robo1 and robo2 are not observed in the SOC by P5 (data not shown). 
The expression profiles of $D C C$, robo1 and robo2 are consistent with these receptors mediating medial-lateral positioning of multiple SOC nuclei. We have previously shown that both netrin-1 and slit-1 are expressed at the brainstem midline from E13.5 to P0 (Howell et al., 2007). Therefore, we propose that SOC neurons respond to midline-derived signals through combinations of $D C C$, robo1 and robo2 receptors that specifies the location of SOC nuclei in the medial-lateral plane of the auditory brainstem. Additionally, graded expression of DCC within the MNTB occurs in the same high medial-to-lower lateral tonotopic organization of the nucleus. Therefore, graded $D C C$ expression may participate in the specification of the frequency organization of the MNTB and possibly additional SOC nuclei.

\section{MNTB tonotopic organization is not affected by changes in DCC gene dosage}

To examine the functional significance of a laterally displaced MNTB, we evaluated the tonotopic organization of the auditory system by c-fos immunohistochemistry in $D C C$ heterozygous and littermate control mice. Juvenile animals were presented with pure tone stimuli ranging from $10 \mathrm{kHz}$ to $75 \mathrm{kHz}$. Consistent with previous reports (Brown and Liu, 1995; Friauf, 1992; Ryan et al., 1982; Saint Marie et al., 1999), juvenile mice homozygous for the wild-type DCC allele $(D C C+/+)$ are found to have a tonotopically organized MTNB. Here, neurons responsive to the highest frequency examined $(75 \mathrm{kHz})$ reside at the medial extent of the nucleus (Figures 6D and $6 \mathrm{I}$ ). Neurons responsive to lower frequencies are well organized in more lateral domains of the MNTB (Figure 6I). Neurons responsive to the lowest frequency presented $(10 \mathrm{kHz})$ reside at the lateral extent of the MNTB (Figures $6 \mathrm{~A}$ and $6 \mathrm{I}$ ) with neurons responsive to intermediate frequencies, $45 \mathrm{kHz}$ (Figure $6 \mathrm{~B}$ ) and $60 \mathrm{kHz}$ (Figure $6 \mathrm{C}$ ), residing in the central MNTB in a frequencyordered arrangement (Figure 6I). Decreasing the intensity of the pure tone decreases the width of c-fos-positive MNTB neurons (data not shown). Similarly, increased intensity of pure-tone stimuli produces an increased width of c-fos-positive MNTB neurons (data not shown and Saint Marie et al., 1999). To limit this variable, all stimuli were calibrated and presented at the same intensity (70 - $75 \mathrm{~dB}$ SPL). In our hands, lower stimulation intensities were not sufficient to reliably stimulate c-fos 
protein synthesis at the higher frequencies $(60 \mathrm{kHz}$ and $75 \mathrm{kHz}$ ) presented (data not shown). Using our stimulation protocols, we found increased c-fos immunoreactivity in multiple nuclei throughout the auditory system that include: ventral cochlear nucleus, dorsal cochlear nucleus, MNTB, lateral superior olive and inferior colliculus (data not shown).

Similar to wild-type animals, c-fos immunoreactivity identifies the isofrequency regions of the MNTB in mice carrying only one functional copy of the $D C C$ allele $(D C C+/-)$. Neurons responsive to the highest frequency examined $(75 \mathrm{kHz})$ reside at the medial extent of the MNTB and neurons responsive to the lowest frequency presented $(10 \mathrm{kHz})$ reside at the lateral extent of the MNTB (Figures $6 \mathrm{H}$ and $6 \mathrm{E}$, respectively). Neurons responsive to intermediate frequencies, $45 \mathrm{kHz}$ (Figure 6F) and $60 \mathrm{kHz}$ (Figure $6 \mathrm{G}$ ) reside in a frequency-ordered arrangement in the central MNTB (Figure 6I). Each stimulation frequency produces a band of c-fos immunoreactive neurons that are displaced laterally to those found in wild-type animals (compare Figure $6 \mathrm{~A}$ with $6 \mathrm{E}$, Figure $6 \mathrm{~B}$ with $6 \mathrm{~F}$, Figure $6 \mathrm{C}$ with $6 \mathrm{G}$ and Figure $6 \mathrm{D}$ with $6 \mathrm{H}$ ). However, the relative width of the c-fos-positive neurons in the MNTB is similar in animals carrying two or one functional copies of the DCC allele across all stimulation frequencies (Figure 6I). Mice carrying only one functional copy of the $D C C$ allele have a tonotopically organized, but laterally displaced MNTB (Figure 6I).

\section{DCC gene dosage alters medial-lateral brainstem and midbrain topography}

The lateral displacement of MNTB neurons in adult mice carrying only one functional copy of the DCC allele was unexpected. To the best of our knowledge, this is the first report of a significantly misplaced neuronal structure in animals with this genotype. Therefore, we sought to examine the brains of $D C C$ heterozygous mice to determine if other nuclei were affected by reduced levels of DCC protein during development. In netrin-1-deficient animals, trochlear nucleus neurons are occasionally found in the midline (Serafini et al., 1996). The trochlear nucleus provides innervation to the superior oblique muscle of the eye which is important for downward and rotational components of binocular vision. The trochlear nerve has 
the longest intracranial length and is the only cranial nerve to exit from the dorsal aspect of the brain. Trochlear nucleus neurons are proposed to co-express DCC and Unc5 receptors; thereby explaining why the axons of these neurons are repelled from the midline expression of netrin-1 (Colamarino and Tessier-Lavigne, 1995; Hong et al., 1999; Serafini et al., 1996). Therefore, positioning of the trochlear nucleus may also depend on DCC receptor function. We used parvalbumin immunohistochemistry (Figures 7A and 7B) or Nissl staining (data not shown) to identify the trochlear nucleus in juvenile mice carrying two or one functional copies of the DCC allele (de la Cruz et al., 1998). We found that the trochlear nuclei are separated by $305 \pm 8 \mu \mathrm{m}$ in mice carrying two functional copies of the DCC allele ( $\mathrm{n}$ $=7$, Figures 7A and 7C). This distance is statistically larger than the $252 \pm 4 \mu \mathrm{m}$ measured in mice carrying only one functional copy of the $D C C$ allele $(n=6, p$-value $<0.001$, Figures 7B and 7C). In contrast to MNTB neurons, trochlear nucleus neurons are displaced medially in mice carrying only one functional $D C C$ allele. It is not clear whether these mice possess visual field defects as a result of this displacement.

During this analysis, we identified the ventral tegmental nucleus with anticalbindin immunohistochemistry in juvenile mice carrying two or one functional copies of the DCC allele (Figures 7D and 7E, respectively). The ventral tegmental nucleus is a component of the limbic system (Kocsis et al., 2001; Morgane et al., 2005; Shim and Wirtshafter, 1996). The rhythmic activity in the ventral tegmental nuclei is believed to function in the generation of theta rhythms in the hippocampus (Bassant and Poindessous-Jazat, 2001). The ability to synchronize theta activity in the hippocampus and medial prefrontal cortex may facilitate the transfer of activity in the hippocampus to the neocortex, a process required for memory consolidation (Paz et al., 2008; Vertes et al., 2001). The ventral tegmental nuclei are separated by $271 \pm 2 \mu \mathrm{m}$ in mice carrying two functional copies of the $D C C$ allele $(n=7$, Figures $7 \mathrm{D}$ and $7 \mathrm{~F}$ ). This distance is statistically smaller than the $313 \pm 5 \mu \mathrm{m}$ measured in mice carrying only one functional copy of the DCC allele $(n=7, p$-value $<0.001$, Figures 7E and 7F). Similar to MNTB neurons, ventral tegmental nucleus neurons are displaced laterally in mice carrying only one functional $D C C$ allele. 
Adult $D C C$ heterozygous mice exhibit blunted phenotypic responses to amphetamines and fail to sensitize with repeated exposure (Flores et al., 2009; Flores et al., 2005; Grant et al., 2007). These effects are thought to occur through changes in dopaminergic neuron pathways due to the high levels of DCC expression in these developing neurons (Flores et al., 2009; Flores et al., 2005; Grant et al., 2007; Livesey and Hunt, 1997; Volenec et al., 1998). Additionally, mice carrying only one functional copy of the $D C C$ allele have a reduced number of tyrosine hydroxylase-positive midbrain neurons (Flores et al., 2005). Locus coeruleus neurons require DCC function for the tangential migration needed to reach the pontine tegementum (Shi et al., 2008). In DCC-deficient embryos, a significant number of neurons fail to reach the locus coeruleus (Shi et al., 2008). Therefore, the positioning of locus coeruleus neurons in the pontine tegementum may depend on DCC function and loss of a functional copy of the DCC allele may alter its position. The locus coeruleus is identified by anti-tyrosine hydroxylase immunohistochemistry in juvenile mice carrying two or one functional copies of the $D C C$ allele (Figures $7 G$ and $7 \mathrm{H}$, respectively). The distance separating locus coeruleus neurons in wild-type animals ( $1737 \pm 13 \mu \mathrm{m}, \mathrm{n}=5$, Figures $7 \mathrm{G}$ and $7 \mathrm{I}$ ) is statically similar to the distance observed in animals carrying only one functional copy of the DCC allele (1766 \pm 9 $\mu \mathrm{m}, \mathrm{n}=3$, p-value $=0.16$, Figures $7 \mathrm{H}$ and $7 \mathrm{I})$. Loss of a functional copy of the $D C C$ allele does not appear to affect the location of locus coeruleus neurons in the midbrain tegmentum, even though DCC function is required for proper migration of these neurons. We have shown that loss of a functional copy of the $D C C$ allele affects the proper positioning of multiple nuclei, though not all nuclei, in the brainstem and midbrain. These finding support a dose-dependent role for DCC function in establishing the medial-lateral position of neurons throughout the central nervous system during embryonic development. 


\section{Discussion}

The present study was undertaken to identify guidance cues necessary for the migration and positioning of neurons in the mammalian auditory brainstem. We found that the neurons comprising the MNTB are not identifiable in mice carrying no functional copies of the DCC or netrin-1 alleles. Additionally, MNTB neurons are laterally displaced in animals carrying only one functional copy of the $D C C$ or netrin1 alleles. This lateral displacement is maintained in adult $D C C$ heterozygous animals and a change in the number of MNTB neurons does not account for the lateral shift since littermate controls contain a statistically similar number of neurons. We found that MNTB neurons express DCC RNA during stages when these neurons are migrating and positioning in the auditory brainstem. Consistent with the phenotypic effects observed, animals carrying only one functional copy of the DCC allele express half the quantity of DCC protein found in wild-type animals. Despite a laterally displaced MNTB, the tonotopic organization of the MNTB is preserved. More broadly, we found that medial-lateral positioning defects are not limited to auditory neurons. Trochlear nucleus and ventral tegmental nucleus neurons are displaced medially and laterally, respectively, in animals carrying only one functional copy of the DCC allele when compared to littermate controls. To the best of our knowledge, this is the first report to show that loss of a single copy of an allele significantly alters the position of neurons in the mammalian central nervous system. We propose that the medial-lateral position of central nervous system nuclei is mediated in a dose-dependent manner in response to an individual neuron.s ability to respond to midline-derived cues.

\section{Guidance of MNTB neurons}

MNTB neurons, like other neurons, are born in the subventricular zone. MNTB neurons are born in mice between E9 and E14 with the relative birth order beginning with the MSO and progressing from the MNTB to LSO neurons (Pierce, 1973). Fate-mapping has identified contributions from the wnt-1-positive rhombic lip of R2-6 for the mouse cochlear nucleus (Farago et al., 2006; Nichols and Bruce, 2006). However, no fate mapping studies to date have identified the developmental 
origin of SOC neurons. Currently, the rhombomere of origin is not known for this collection of auditory neurons. Two possibilities may explain the lack of observed contributions to the SOC from R2-6. (1) SOC neurons are derived from a region of R2-6 that is distinct from the wnt-1-positive region. In chick, distinct regions of R5 contribute to the nucleus magnocellularis (NM), homologous to the mouse AVCN, and the nucleus laminaris (NL), homologous to the mouse MSO (Cramer et al., 2000). (2) SOC neurons are derived from rhombomeres other than R2-6. R1 as well as more caudal rhombomeres were not examined in these studies and could therefore contribute neurons to the SOC. Furthermore, these explanations may not be mutually exclusive due to the diverse number of neurons that comprise SOC nuclei. Since the birth location is not known, the migratory route and the molecular signals mediating this migration are not established for SOC neurons. However, our labeling studies with an antisense DCC RNA probe reveal the presence of a column of $D C C$-positive cells that extends from the rostral-extent of the brainstem to the location of the future SOC as early as E13.5. Additionally, robo1- and robo2-positive columns are also observed extending from the rostral-extent of the brainstem to the future location of the SOC. It is tempting to speculate that this represents a migratory stream of cells that will populate all or part of the SOC. In support of this, multiple SOC nuclei express the En-1 transcription factor, a specific marker for R1, (Figure 2G-I and Morgan et al., in preparation). We have shown that X-gal (En-1 cre lacZ) staining labels the MNTB (Figure $2 \mathrm{G}$ and Supplemental figure 1), as well as other SOC nuclei at these early developmental stages that includes the ventral nucleus of the trapezoid body (VNTB) and the lateral nucleus of the trapezoid body (LNTB) (Morgan et al., in preparation). However, the En-1 cre transgenic mouse line used in this study does not function as an R1 lineage label; instead this mouse line labels any cell that expresses the En-1 transcription factor (Kimmel et al., 2000). Furthermore, definitive evidence to support a caudal migration within these columns of cells is not currently available with only these static images.

As development progresses, $D C C$-positive cells in the region of the developing SOC do seem to segregate in the medial-lateral plane as the multiple nuclei that comprise the SOC form. In mice carrying no functional copies of the DCC 
allele, we have identified a cluster of cells in a very lateral region fo the SOC that are positive for Nissl staining, Sox-2 immunoreactivity, and X-gal (En-1 cre lacZ) staining that is not observed in mice carrying two or one functional copies of the DCC allele. These are all markers that were used to identify developing MNTB neurons; however, none of these labeling methods is specific for developing MNTB neurons. As a result, we are not able to differentiate MNTB neurons from VNTB and LNTB neurons which also express these markers (Morgan et al., in preparation). Nevertheless, the appearance of this lateral cluster of cells in mice carrying no functional copies of the DCC allele is consistent with the proposal that MNTB neurons are able to reach a location lateral to where the developing SOC should reside. Once at this location, we propose that MNTB neurons require a functional netrin-DCC signaling system to migrate medially.

We have shown that multiple populations of SOC neurons express a combination of RNAs for $D C C$, robo1 and robo2 receptors during late embryonic development when discrete SOC nuclei appear to form. Other developing systems utilize guidance receptors to determine the location of axonal tracts and cells relative to the midline. In Drosophila, the complement of robo receptors on longitudinal axons specifies the lateral position of longitudinal axons relative to the midline (Simpson et al., 2000a). The most medial longitudinal axon bundle expresses only robo, the most lateral tract expresses robo, robo2 and robo3 and the intermediate longitudinal tract expresses robo and robo3 (Simpson et al., 2000a). In a similar system, mouse SCN axons that have crossed the midline appear to segregate within the lateral funiculus (LF) according to the complement of robo receptors expressed on each axon (Long et al., 2004). Axons expressing only robo1 position within a medial region of the LF while axons expressing only robo2 position within a lateral region of the LF (Long et al., 2004). In addition, axons expressing both robo1 and robo2 position at an intermediate distance within the LF (Long et al., 2004). Furthermore, deletion of robo1 results in a larger number of axons that position laterally within the LF and conversely, deletion of robo2 produces an increase in the number of axons that position medially within the LF (Long et al., 2004). Therefore, Drosophila and mice appear to utilize a similar combination of guidance receptors to 
specify, relative to the midline, the medial-lateral location of an axonal tract and the location of axons that travel within that tract, respectively.

Additionally, the development of the Drosophila salivary gland is dependent on midline-derived attractive and repulsive cues (Kolesnikov and Beckendorf, 2005). Salivary gland precursor cells migrate posteriorly parallel to the midline of the central nervous system (Andrew et al., 2000). Disruption of netrin-frazzled signaling results in lateral movements while disruption of slit-robo signaling results in medial movements (Kolesnikov and Beckendorf, 2005). Therefore, a balance of chemoattractant, netrin-frazzled, and chemo-repellant, slit-robo, activities specifies the medial-lateral position of the Drosphila salivary glands relative to the midline of the nervous system (Kolesnikov and Beckendorf, 2005). Additionally, when netrin or slit is ectopically expressed, the result is the movement of salivary gland precursor cells toward or away from the location of the ectopic expression, respectively (Kolesnikov and Beckendorf, 2005). Therefore, Drosophila embryos utilize a combination of attractive and repulsive guidance cues to specify the location of cells relative to the midline.

Using these systems as a guide, we propose that a combination of axon guidance receptors integrates attractive and repulsive midline-derived cues to determine the medial-lateral location where each neuronal population will reside relative to the midline. In wild-type animals, MNTB neurons express a high medialto-lower lateral gradient of DCC RNA, with weak expression of robo1 RNAs observed. Additionally, we have shown that the level of DCC protein is reduced by $50 \%$ in animals carrying only one functional copy of the DCC allele. In our model, a decrease in the number of functional DCC receptors in a population of neurons produces a net decrease in midline attraction that causes these neurons to position at a greater distance from the midline. Furthermore, loss of both functional copies of the $D C C$ allele in a population of neurons results in a greater decrease in net midline attraction that causes these neurons to position at an even greater distance from the midline. The proposed model is consistent with our observations in the developing SOC concerning the positioning of MNTB neurons. Additionally, SOC neurons expressing robo2 RNAs will position lateral to neurons only expressing robo1 RNAs 
with neurons expressing robo1 and robo2 RNAs occurring at an intermediate location, similar to the positioning of LF axons in the mouse spinal cord (Long et al., 2004). It is not currently clear whether the more lateral SOC nuclei are positioned differently in mice carrying only one functional copy of the $D C C$ allele. These neurons are expected to utilize midline-derived repellant signals for proper positioning within the SOC. Therefore, loss of functional copies of robo receptors would be expected to produce a net increase in midline attraction that would cause these lateral SOC neurons to position in a more medial location.

\section{Tonotopic organization of the MNTB}

The molecular cues that establish the tonotopic organization of central auditory circuits are relatively unexplored in the mammalian central auditory system. The MNTB is tonotopically organized such that the neurons in the medial region are sensitive to high-frequency stimuli and neurons sensitive to lower characteristic frequencies occur in a decreasing lateral gradient (Figure $6 \mathrm{I}$ and Brown and Liu, 1995; Friauf, 1992; Ryan et al., 1982; Saint Marie et al., 1999). The high medial-tolower lateral frequency organization of the MNTB may be established through the high medial-to-lower lateral gradient of $D C C$ expression. Therefore, graded expression of DCC may position MNTB neurons according to their net midline attraction, thus potentially establishing the topography of the MNTB. We found that the tonotopic organization of the laterally displaced MNTB in mice carrying only one functional copy of the DCC allele is preserved (Figure 6I). The high medial-to-lower lateral gradient of $D C C$ expression found in wild-type animals is preserved in the laterally displaced MNTB found in mice carrying only one functional copy of the DCC allele (data not shown). Therefore, graded DCC expression, as a means of specifying medial-lateral location, may indeed participate in the specification of MNTB topography. Although the tonotopic organization of input to the laterally displaced MNTB is preserved, a detailed analysis of the organization of MNTB output circuits to the lateral superior olive (LSO) has not been performed. An analysis of these circuits may assist in the identification of additional guidance cues necessary for establishing auditory circuits. 
To establish a place code such as tonotopy, growth cones must have the ability to target specific neurons to ensure appropriate connections are formed. However, the specificity necessary to target the correct isofrequency zone does not seem possible through the use of secreted proteins since a sufficiently sharp concentration gradient is not likely to be established in this manner. A more attractive signaling system to establish a place code involves ephrin-Eph receptor signaling through specific cell-cell interactions. The utilization of Eph and ephrin gradients to establish retinotopy, the organizing principle of the visual system, has been thoroughly studied (reviewed in McLaughlin and O'Leary, 2005; O'Leary and McLaughlin, 2005; O'Leary and Wilkinson, 1999). More recently, ephrin-eph receptor signaling has been implicated in the formation of mammalian auditory circuits (Cramer, 2005; Miko et al., 2008; Miko et al., 2007).

In mice, GBCs located in the VCN normally project an axon to the contralateral MNTB. However, unilateral ablation of the neonatal cochlea induces GBCs located in the VCN on the non-ablated side to innervate the ipsilateral MNTB (Hsieh et al., 2007; Kitzes et al., 1995; Russell and Moore, 1995). Cochlear ablation in EphA4-null mice results in increased quantities of ectopic sprouting into the ipsilateral MNTB (Hsieh et al., 2007). EphA4 does not appear to be required for the formation of this projection; however, EphA4 does appear to restrict target selection in response to deafferentation. More recently, the tonotopic organization of the DCN and MNTB was analyzed in EphA4 and ephrin-B2 mutant mice (Miko et al., 2008; Miko et al., 2007). In both of these mutants, changes in the number of neurons responsive to acoustic stimuli and the width of the isofrequency region were present in the DCN and MNTB (Miko et al., 2007). Additionally, auditory brainstem responses in these mutant strains had elevated thresholds and reduced peak amplitudes that are consistent with the presence of a hearing deficit (Miko et al., 2008). These findings support a role for ephrin-Eph receptor signaling in establishing topographic circuits in the mammalian central auditory system. However, the single frequency presented to these mutant mice is not sufficient to demonstrate the preservation or loss of the tonotopic organization of the DCN or MNTB. Clearly, a more detailed analysis of central auditory circuits is necessary in these animals. 
Furthermore, netrin-DCC, slit-robo and ephrin-Eph receptor signaling systems all have the potential to participate in the formation of these auditory circuits.

\section{Medial-lateral topography of the central nervous system}

The midline of the central nervous system is a very important structure. Commissural axons allow both sides of the central nervous system to communicate. This is important for the processing of peripherally-derived sensory information and the coordination of bilateral movements necessary for functions such as walking, speech/swallowing and binocular vision as well as other functions. The netrin-DCC and slit-robo guidance systems were originally identified as signaling systems that were important for the establishment of commissural projections (Harris et al., 1996; Hedgecock et al., 1990; Ishii et al., 1992; Kennedy et al., 1994; Kidd et al., 1999; Kidd et al., 1998; Mitchell et al., 1996; Rajagopalan et al., 2000a; Rothberg et al., 1988; Rothberg et al., 1990; Seeger et al., 1993; Serafini et al., 1994; Simpson et al., $2000 \mathrm{~b})$. Their utilization in the central nervous system has been extended to the migration of neurons as well as the positioning of axonal tracts relative to the midline (Bloch-Gallego et al., 1999; Causeret et al., 2002; Chan et al., 1996; Chen et al., 2001; Di Meglio et al., 2008; Geisen et al., 2008; Long et al., 2004; Marillat et al., 2004; Nguyen-Ba-Charvet et al., 2004; Rajagopalan et al., 2000b; Shi et al., 2008; Simpson et al., 2000a; Yee et al., 1999). Now, we report that these guidance systems appear to participate in establishing the medial-lateral topography of the central nervous system by determining the relative location that nuclei will occupy relative to the midline. We found that the MNTB in the lower auditory brainstem was displaced laterally in animals carrying only one functional copy of the DCC allele. However, the position of the locus coruleus, a nucleus that requires DCC function for tangential migration, is not statistically different in mice carrying two or one functional copies of the DCC allele. In addition to the central auditory system, we found that the ventral tegmental nuclei, a component of the limbic system, were displaced laterally and the trochlear nuclei, a nucleus involved in the control of ocular motion, were displaced medially in animals carrying only one functional copy of the $D C C$ allele. Furthermore, similar to the apparent extreme displacement of the MNTB in mice 
carrying no functional copies of the $D C C$ allele, displaced trochlear nucleus neurons are found in the midline in mice homozygous for the netrin-1 mutant allele (Figure 2; Serafini et al., 1996). This finding provides additional support to our proposal for dose-sensitive positioning of nuclei in the central nervous system. An increasing number of studies implicate DCC function in the guidance of axons and neuronal populations throughout the central nervous system. The loss of one functional copy of the $D C C$ allele may be sufficient to alter the anatomy and/or physiology of a neural circuit. Animals carrying only one functional copy of the DCC allele were originally thought to be no different from their wild-type littermates (Fazeli et al., 1997). Increasing evidence indicates that this is no longer accurate.

The trochlear nuclei innervate the superior oblique muscle, an extrinsic muscle of the eye. Proper targeting of this ocular muscle as well as coordination of the other extrinsic ocular muscle movements is critical for the maintenance of conjugate gaze and thereby binocular vision. Displacement of the trochlear nucleus may alter the innervation of the superior oblique muscle. Additionally, displacement of the trochlear nucleus may alter the interconnections of brainstem visuomotor centers that coordinate ocular movements that maintain binocular vision. Either or both of these changes have the potential to affect visual acuity. Visual field or gaze deficits have not been examined in animals carrying only one functional copy of the $D C C$ allele. The ventral tegmental nucleus is a component of the limbic system and has axonal connections mainly with the medial mamillary nucleus (Kocsis et al., 2001; Morgane et al., 2005; Shim and Wirtshafter, 1996). The ventral tegemental nucleus has been proposed to participate in synchronization of theta activity in the hippocampus through these connections with the Papex circuit (Bassant and Poindessous-Jazat, 2001; Morgane et al., 2005). Theta activity is manifested during some short term memory tasks and evidence indicates that theta rhythm is likely involved in spatial learning and navigation (Buzsaki, 2005; Vertes, 2005; Vertes et al., 2001). An examination of these neural circuits implicated in the consolidation of memories has not been accomplished in animals carrying only one functional copy of the DCC allele. 
However, analysis of mosocorticolimbic dopamine circuits is the subject of recent interest due to the blunted behavior responces to amphetamine exposure in animals carrying only one functional copy of the DCC allele (Flores et al., 2005; Grant et al., 2007). Alterations in the development of dopaminergic neurons and neural circuits are proposed to account for these phenotypic changes (Flores et al., 2009; Flores et al., 2005; Grant et al., 2007). DCC and netrin-1 are implicated in the development of mosocorticolimbic dopamine circuits as well as continued expression in adult dopaminergic neurons (Gad et al., 1997; Grant et al., 2007; Lin et al., 2005; Livesey and Hunt, 1997; Osborne et al., 2005; Volenec et al., 1998). The number of dopaminergic neurons in the ventral tegemental area and substantia nigra pars compacta were reduced by $\sim 20 \%$ in mice carrying only one functional copy of the DCC allele (Flores et al., 2005). Additionally, mice carrying only one functional copy of the DCC allele have increased dopamine and dopamine metabolites in the prefrontal cortex suggesting increased dopaminergic activity while decreased dopamine metabolites are observed in the nucleus accumbens, the proposed site of action for recreational drugs, suggesting decreased dopaminergic activity (Flores et al., 2005). These findings implicate DCC function in the development of dopaminergic neural circuits that have implications in the study of drug abuse, schizophrenia and memory. In addition, the presence of single nucleotide polymorphisms in several axon guidance genes, including DCC, was predictive of susceptibility, survival free period and age at onset for Parkinson's disease (Lin et al., 2009). Furthermore, defective slit-robo signaling has a potential function in the pathogenesis of autism through interference with serotonergic neurotransmission or defective neurodevelopment of serotonergic circuits (Anitha et al., 2008). However, further studies into the functional role of DCC and robo receptors in Parkinson's disease and autism, respectively, are necessary. Characterization of signaling events necessary for the development of these neural circuits may lead to a better understanding of how aberrant signals or connections relate to disease. This knowledge may eventually lead to the development of novel treatments that are more specifically targeted toward the underlying disease process. 


\section{Literature Cited}

Altman, J., and Bayer, S. A. (1980). Development of the brain stem in the rat. III. Thymidine-radiographic study of the time of origin of neurons of the vestibular and auditory nuclei of the upper medulla. J Comp Neurol 194, 877-904.

Andrew, D. J., Henderson, K. D., and Seshaiah, P. (2000). Salivary gland development in Drosophila melanogaster. Mech Dev 92, 5-17.

Anitha, A., Nakamura, K., Yamada, K., Suda, S., Thanseem, I., Tsujii, M., Iwayama, Y., Hattori, E., Toyota, T., Miyachi, T., et al. (2008). Genetic analyses of roundabout (ROBO) axon guidance receptors in autism. Am J Med Genet B Neuropsychiatr Genet 147B, 1019-1027.

Bagri, A., Marin, O., Plump, A. S., Mak, J., Pleasure, S. J., Rubenstein, J. L., and Tessier-Lavigne, M. (2002). Slit proteins prevent midline crossing and determine the dorsoventral position of major axonal pathways in the mammalian forebrain. Neuron 33, 233-248.

Bassant, M. H., and Poindessous-Jazat, F. (2001). Ventral tegmental nucleus of Gudden: a pontine hippocampal theta generator? Hippocampus 11, 809-813.

Bloch-Gallego, E., Causeret, F., Ezan, F., Backer, S., and Hidalgo-Sanchez, M. (2005). Development of precerebellar nuclei: instructive factors and intracellular mediators in neuronal migration, survival and axon pathfinding. Brain Res Brain Res Rev 49, 253-266.

Bloch-Gallego, E., Ezan, F., Tessier-Lavigne, M., and Sotelo, C. (1999). Floor plate and netrin-1 are involved in the migration and survival of inferior olivary neurons. J Neurosci 19, 4407-4420.

Boudreau, J. C., and Tsuchitani, C. (1968). Binaural interaction in the cat superior olive S segment. J Neurophysiol 31, 442-454.

Brose, K., Bland, K. S., Wang, K. H., Arnott, D., Henzel, W., Goodman, C. S., Tessier-Lavigne, M., and Kidd, T. (1999). Slit proteins bind Robo receptors and have an evolutionarily conserved role in repulsive axon guidance. Cell 96, 795-806.

Brown, M. C., and Liu, T. S. (1995). Fos-like immunoreactivity in central auditory neurons of the mouse. J Comp Neurol 357, 85-97.

Buzsaki, G. (2005). Theta rhythm of navigation: link between path integration and landmark navigation, episodic and semantic memory. Hippocampus 15, 827-840.

Causeret, F., Danne, F., Ezan, F., Sotelo, C., and Bloch-Gallego, E. (2002). Slit antagonizes netrin-1 attractive effects during the migration of inferior olivary neurons. Dev Biol 246, 429-440. 
Chan, S. S., Zheng, H., Su, M. W., Wilk, R., Killeen, M. T., Hedgecock, E. M., and Culotti, J. G. (1996). UNC-40, a C. elegans homolog of DCC (Deleted in Colorectal Cancer), is required in motile cells responding to UNC-6 netrin cues. Cell 87, 187195.

Chen, J. H., Wen, L., Dupuis, S., Wu, J. Y., and Rao, Y. (2001). The N-terminal leucine-rich regions in Slit are sufficient to repel olfactory bulb axons and subventricular zone neurons. J Neurosci 21, 1548-1556.

Colamarino, S. A., and Tessier-Lavigne, M. (1995). The axonal chemoattractant netrin-1 is also a chemorepellent for trochlear motor axons. Cell 81, 621-629.

Cramer, K. S. (2005). Eph proteins and the assembly of auditory circuits. Hear Res 206, 42-51.

Cramer, K. S., Fraser, S. E., and Rubel, E. W. (2000). Embryonic origins of auditory brain-stem nuclei in the chick hindbrain. Dev Biol 224, 138-151.

Cygan, J. A., Johnson, R. L., and McMahon, A. P. (1997). Novel regulatory interactions revealed by studies of murine limb pattern in Wnt-7a and En-1 mutants. Development 124, 5021-5032.

de Diego, I., Kyriakopoulou, K., Karagogeos, D., and Wassef, M. (2002). Multiple influences on the migration of precerebellar neurons in the caudal medulla.

Development 129, 297-306.

de la Cruz, R. R., Pastor, A. M., Martinez-Guijarro, F. J., Lopez-Garcia, C., and Delgado-Garcia, J. M. (1998). Localization of parvalbumin, calretinin, and calbindin $\mathrm{D}-28 \mathrm{k}$ in identified extraocular motoneurons and internuclear neurons of the cat. $\mathrm{J}$ Comp Neurol 390, 377-391.

Deiner, M. S., Kennedy, T. E., Fazeli, A., Serafini, T., Tessier-Lavigne, M., and Sretavan, D. W. (1997). Netrin-1 and DCC mediate axon guidance locally at the optic disc: loss of function leads to optic nerve hypoplasia. Neuron $19,575-589$.

Deiner, M. S., and Sretavan, D. W. (1999). Altered midline axon pathways and ectopic neurons in the developing hypothalamus of netrin-1- and DCC-deficient mice. J Neurosci 19, 9900-9912.

Di Meglio, T., Nguyen-Ba-Charvet, K. T., Tessier-Lavigne, M., Sotelo, C., and Chedotal, A. (2008). Molecular mechanisms controlling midline crossing by precerebellar neurons. J Neurosci 28, 6285-6294.

Dickson, B. J. (2002). Molecular mechanisms of axon guidance. Science 298, 19591964.

Dickson, B. J., and Gilestro, G. F. (2006). Regulation of commissural axon pathfinding by slit and its Robo receptors. Annu Rev Cell Dev Biol 22, 651-675. 
Farago, A. F., Awatramani, R. B., and Dymecki, S. M. (2006). Assembly of the brainstem cochlear nuclear complex is revealed by intersectional and subtractive genetic fate maps. Neuron 50, 205-218.

Fazeli, A., Dickinson, S. L., Hermiston, M. L., Tighe, R. V., Steen, R. G., Small, C. G., Stoeckli, E. T., Keino-Masu, K., Masu, M., Rayburn, H., et al. (1997). Phenotype of mice lacking functional Deleted in colorectal cancer (Dcc) gene. Nature 386, 796804.

Flores, C., Bhardwaj, S. K., Labelle-Dumais, C., and Srivastava, L. K. (2009). Altered netrin-1 receptor expression in dopamine terminal regions following neonatal ventral hippocampal lesions in the rat. Synapse 63, 54-60.

Flores, C., Manitt, C., Rodaros, D., Thompson, K. M., Rajabi, H., Luk, K. C., Tritsch, N. X., Sadikot, A. F., Stewart, J., and Kennedy, T. E. (2005). Netrin receptor deficient mice exhibit functional reorganization of dopaminergic systems and do not sensitize to amphetamine. Mol Psychiatry 10, 606-612.

Friauf, E. (1992). Tonotopic Order in the Adult and Developing Auditory System of the Rat as Shown by c-fos Immunocytochemistry. Eur J Neurosci 4, 798-812.

Friauf, E. (1993). Transient appearance of calbindin-D28k-positive neurons in the superior olivary complex of developing rats. J Comp Neurol 334, 59-74.

Friauf, E., and Ostwald, J. (1988). Divergent projections of physiologically characterized rat ventral cochlear nucleus neurons as shown by intra-axonal injection of horseradish peroxidase. Exp Brain Res 73, 263-284.

Gad, J. M., Keeling, S. L., Wilks, A. F., Tan, S. S., and Cooper, H. M. (1997). The expression patterns of guidance receptors, DCC and Neogenin, are spatially and temporally distinct throughout mouse embryogenesis. Dev Biol 192, 258-273.

Geisen, M. J., Di Meglio, T., Pasqualetti, M., Ducret, S., Brunet, J. F., Chedotal, A., and Rijli, F. M. (2008). Hox paralog group 2 genes control the migration of mouse pontine neurons through slit-robo signaling. PLoS Biol 6, e142.

Giel-Moloney, M., Krause, D. S., Chen, G., Van Etten, R. A., and Leiter, A. B. (2007). Ubiquitous and uniform in vivo fluorescence in ROSA26-EGFP BAC transgenic mice. Genesis 45, 83-89.

Grant, A., Hoops, D., Labelle-Dumais, C., Prevost, M., Rajabi, H., Kolb, B., Stewart, J., Arvanitogiannis, A., and Flores, C. (2007). Netrin-1 receptor-deficient mice show enhanced mesocortical dopamine transmission and blunted behavioural responses to amphetamine. Eur J Neurosci 26, 3215-3228.

Greenwood, D. D. (1961). Critical Bandwidth and the Frequency Coordinates of the Basilar Membrane. The Journal of the Acoustical Society of America 33, 1344-1356. 
Guinan Jr, J., Norris, B., and Guinan, S. (1972). Single auditory units in the superior olivary complex. II: Location of unit categories and tonotopic organization. Int J Neurosci 4, 147-166.

Gundersen, H. J., and Jensen, E. B. (1987). The efficiency of systematic sampling in stereology and its prediction. J Microsc 147 (Pt 3), 229-263.

Harris, R., Sabatelli, L. M., and Seeger, M. A. (1996). Guidance cues at the Drosophila CNS midline: identification and characterization of two Drosophila Netrin/UNC-6 homologs. Neuron 17, 217-228.

Hedgecock, E. M., Culotti, J. G., and Hall, D. H. (1990). The unc-5, unc-6, and unc40 genes guide circumferential migrations of pioneer axons and mesodermal cells on the epidermis in C. elegans. Neuron 4, 61-85.

Held, H. (1893). Die centrale Gehörleitung. Arch Physiol Anat 17, 201-248.

Hong, K., Hinck, L., Nishiyama, M., Poo, M. M., Tessier-Lavigne, M., and Stein, E. (1999). A ligand-gated association between cytoplasmic domains of UNC5 and DCC family receptors converts netrin-induced growth cone attraction to repulsion. Cell 97, 927-941.

Howell, D. M., Morgan, W. J., Jarjour, A. A., Spirou, G. A., Berrebi, A. S., Kennedy, T. E., and Mathers, P. H. (2007). Molecular guidance cues necessary for axon pathfinding from the ventral cochlear nucleus. J Comp Neurol 504, 533-549.

Hsieh, C. Y., Hong, C. T., and Cramer, K. S. (2007). Deletion of EphA4 enhances deafferentation-induced ipsilateral sprouting in auditory brainstem projections. J Comp Neurol 504, 508-518.

Ishii, N., Wadsworth, W. G., Stern, B. D., Culotti, J. G., and Hedgecock, E. M. (1992). UNC-6, a laminin-related protein, guides cell and pioneer axon migrations in C. elegans. Neuron 9, 873-881.

Keino-Masu, K., Masu, M., Hinck, L., Leonardo, E. D., Chan, S. S., Culotti, J. G., and Tessier-Lavigne, M. (1996). Deleted in Colorectal Cancer (DCC) encodes a netrin receptor. Cell 87, 175-185.

Kennedy, T. E., Serafini, T., de la Torre, J. R., and Tessier-Lavigne, M. (1994). Netrins are diffusible chemotropic factors for commissural axons in the embryonic spinal cord. Cell 78, 425-435.

Kidd, T., Bland, K. S., and Goodman, C. S. (1999). Slit is the midline repellent for the robo receptor in Drosophila. Cell 96, 785-794.

Kidd, T., Brose, K., Mitchell, K. J., Fetter, R. D., Tessier-Lavigne, M., Goodman, C. S., and Tear, G. (1998). Roundabout controls axon crossing of the CNS midline and 
defines a novel subfamily of evolutionarily conserved guidance receptors. Cell 92, 205-215.

Kimmel, R. A., Turnbull, D. H., Blanquet, V., Wurst, W., Loomis, C. A., and Joyner, A. L. (2000). Two lineage boundaries coordinate vertebrate apical ectodermal ridge formation. Genes Dev 14, 1377-1389.

Kitzes, L. M., Kageyama, G. H., Semple, M. N., and Kil, J. (1995). Development of ectopic projections from the ventral cochlear nucleus to the superior olivary complex induced by neonatal ablation of the contralateral cochlea. J Comp Neurol 353, 341363.

Kocsis, B., Di Prisco, G. V., and Vertes, R. P. (2001). Theta synchronization in the limbic system: the role of Gudden's tegmental nuclei. Eur J Neurosci 13, 381-388.

Kolesnikov, T., and Beckendorf, S. K. (2005). NETRIN and SLIT guide salivary gland migration. Dev Biol 284, 102-111.

Kudo, M., Kitao, Y., Okoyama, S., Moriya, M., and Kawano, J. (1996). Crossed projection neurons are generated prior to uncrossed projection neurons in the lateral superior olive of the rat. Brain Res Dev Brain Res 95, 72-78.

Kudo, M., Sakurai, H., Kurokawa, K., and Yamada, H. (2000). Neurogenesis in the superior olivary complex in the rat. Hear Res 139, 144-152.

Kulesza, R. J., Vinuela, A., Saldana, E., and Berrebi, A. S. (2002). Unbiased stereological estimates of neuron number in subcortical auditory nuclei of the rat. Hear Res 168, 12-24.

Kuwabara, N., DiCaprio, R. A., and Zook, J. M. (1991). Afferents to the medial nucleus of the trapezoid body and their collateral projections. J Comp Neurol 314, 684-706.

Leonardo, E. D., Hinck, L., Masu, M., Keino-Masu, K., Fazeli, A., Stoeckli, E. T., Ackerman, S. L., Weinberg, R. A., and Tessier-Lavigne, M. (1997). Guidance of developing axons by netrin-1 and its receptors. Cold Spring Harb Symp Quant Biol 62, 467-478.

Li, H. S., Chen, J. H., Wu, W., Fagaly, T., Zhou, L., Yuan, W., Dupuis, S., Jiang, Z. H., Nash, W., Gick, C., et al. (1999). Vertebrate slit, a secreted ligand for the transmembrane protein roundabout, is a repellent for olfactory bulb axons. Cell 96, 807-818.

Liberman, M. C. (1982). The cochlear frequency map for the cat: labeling auditorynerve fibers of known characteristic frequency. J Acoust Soc Am 72, 1441-1449. 
Lin, L., Lesnick, T. G., Maraganore, D. M., and Isacson, O. (2009). Axon guidance and synaptic maintenance: preclinical markers for neurodegenerative disease and therapeutics. Trends Neurosci 32, 142-149.

Lin, L., Rao, Y., and Isacson, O. (2005). Netrin-1 and slit-2 regulate and direct neurite growth of ventral midbrain dopaminergic neurons. Mol Cell Neurosci 28, 547555.

Livesey, F. J. (1999). Netrins and netrin receptors. Cell Mol Life Sci 56, 62-68.

Livesey, F. J., and Hunt, S. P. (1997). Netrin and netrin receptor expression in the embryonic mammalian nervous system suggests roles in retinal, striatal, nigral, and cerebellar development. Mol Cell Neurosci 8, 417-429.

Long, H., Sabatier, C., Ma, L., Plump, A., Yuan, W., Ornitz, D. M., Tamada, A., Murakami, F., Goodman, C. S., and Tessier-Lavigne, M. (2004). Conserved roles for Slit and Robo proteins in midline commissural axon guidance. Neuron 42, 213-223.

Lorente de No, R. (1933). "Anatomy of the eighth nerve." The central projection of the nerve endings of the internal ear. Laryngoscope 43, 1-38.

Lorente de No, R. (1981). The primary acoustic nuclei. (New York, Raven Press).

Mao, X., Fujiwara, Y., Chapdelaine, A., Yang, H., and Orkin, S. H. (2001). Activation of EGFP expression by Cre-mediated excision in a new ROSA26 reporter mouse strain. Blood 97, 324-326.

Marillat, V., Sabatier, C., Failli, V., Matsunaga, E., Sotelo, C., Tessier-Lavigne, M., and Chedotal, A. (2004). The slit receptor Rig-1/Robo3 controls midline crossing by hindbrain precerebellar neurons and axons. Neuron 43, 69-79.

McLaughlin, T., and O'Leary, D. D. (2005). Molecular gradients and development of retinotopic maps. Annu Rev Neurosci 28, 327-355.

Mehlen, P., and Mazelin, L. (2003). The dependence receptors DCC and UNC5H as a link between neuronal guidance and survival. Biol Cell 95, 425-436.

Miko, I. J., Henkemeyer, M., and Cramer, K. S. (2008). Auditory brainstem responses are impaired in EphA4 and ephrin-B2 deficient mice. Hear Res 235, 3946.

Miko, I. J., Nakamura, P. A., Henkemeyer, M., and Cramer, K. S. (2007). Auditory brainstem neural activation patterns are altered in EphA4- and ephrin-B2-deficient mice. J Comp Neurol 505, 669-681.

Mitchell, K. J., Doyle, J. L., Serafini, T., Kennedy, T. E., Tessier-Lavigne, M., Goodman, C. S., and Dickson, B. J. (1996). Genetic analysis of Netrin genes in 
Drosophila: Netrins guide CNS commissural axons and peripheral motor axons. Neuron 17, 203-215.

Morgan, WJ., Howell, DM., Berrebi, AS., Spirou, GA., Mathers, PH. Protein Expression in the Developing Superior Olive and Ventral Cochlear Nucleus. In preparation.

Morgane, P. J., Galler, J. R., and Mokler, D. J. (2005). A review of systems and networks of the limbic forebrain/limbic midbrain. Prog Neurobiol 75, 143-160.

Nguyen-Ba-Charvet, K. T., and Chedotal, A. (2002). Role of Slit proteins in the vertebrate brain. J Physiol Paris 96, 91-98.

Nguyen-Ba-Charvet, K. T., Picard-Riera, N., Tessier-Lavigne, M., Baron-Van Evercooren, A., Sotelo, C., and Chedotal, A. (2004). Multiple roles for slits in the control of cell migration in the rostral migratory stream. J Neurosci 24, 1497-1506.

Nichols, D. H., and Bruce, L. L. (2006). Migratory routes and fates of cells transcribing the Wnt-1 gene in the murine hindbrain. Dev Dyn 235, 285-300.

O'Leary, D. D., and McLaughlin, T. (2005). Mechanisms of retinotopic map development: Ephs, ephrins, and spontaneous correlated retinal activity. Prog Brain Res 147, 43-65.

O'Leary, D. D., and Wilkinson, D. G. (1999). Eph receptors and ephrins in neural development. Curr Opin Neurobiol 9, 65-73.

Osborne, P. B., Halliday, G. M., Cooper, H. M., and Keast, J. R. (2005). Localization of immunoreactivity for deleted in colorectal cancer (DCC), the receptor for the guidance factor netrin-1, in ventral tier dopamine projection pathways in adult rodents. Neuroscience 131, 671-681.

Paz, R., Bauer, E. P., and Pare, D. (2008). Theta synchronizes the activity of medial prefrontal neurons during learning. Learn Mem 15, 524-531.

Phifer, C. B., and Terry, L. M. (1986). Use of hypothermia for general anesthesia in preweanling rodents. Physiol Behav 38, 887-890.

Pierce, E. T. (1973). Time of origin of neurons in the brain stem of the mouse. Prog Brain Res 40, 53-65.

Plump, A. S., Erskine, L., Sabatier, C., Brose, K., Epstein, C. J., Goodman, C. S., Mason, C. A., and Tessier-Lavigne, M. (2002). Slit1 and Slit2 cooperate to prevent premature midline crossing of retinal axons in the mouse visual system. Neuron 33, 219-232.

Rajagopalan, S., Nicolas, E., Vivancos, V., Berger, J., and Dickson, B. J. (2000a). Crossing the midline: roles and regulation of Robo receptors. Neuron 28, 767-777. 
Rajagopalan, S., Vivancos, V., Nicolas, E., and Dickson, B. J. (2000b). Selecting a longitudinal pathway: Robo receptors specify the lateral position of axons in the Drosophila CNS. Cell 103, 1033-1045.

Ramón y Cajal, R. (1909). Histologie du Système Nerveux de l'Homme et des Vertébrés. (Madrid, Instituto Ramón y Cajal).

Riva, C., Donadieu, E., Magnan, J., and Lavieille, J. P. (2007). Age-related hearing loss in CD/1 mice is associated to ROS formation and HIF target proteins upregulation in the cochlea. Exp Gerontol 42, 327-336.

Rose, J. E., Galambos, R., and Hughes, J. R. (1959). Microelectrode studies of the cochlear nuclei of the cat. Bull Johns Hopkins Hosp 104, 211-251.

Rothberg, J. M., Hartley, D. A., Walther, Z., and Artavanis-Tsakonas, S. (1988). slit: an EGF-homologous locus of D. melanogaster involved in the development of the embryonic central nervous system. Cell 55, 1047-1059.

Rothberg, J. M., Jacobs, J. R., Goodman, C. S., and Artavanis-Tsakonas, S. (1990). slit: an extracellular protein necessary for development of midline glia and commissural axon pathways contains both EGF and LRR domains. Genes Dev 4, 2169-2187.

Rozen, S., and Skaletsky, H. (2000). Primer3 on the WWW for general users and for biologist programmers. Methods Mol Biol 132, 365-386.

Russell, F. A., and Moore, D. R. (1995). Afferent reorganisation within the superior olivary complex of the gerbil: development and induction by neonatal, unilateral cochlear removal. J Comp Neurol 352, 607-625.

Ryan, A. F., Woolf, N. K., and Sharp, F. R. (1982). Tonotopic organization in the central auditory pathway of the Mongolian gerbil: a 2-deoxyglucose study. J Comp Neurol 207, 369-380.

Sabatier, C., Plump, A. S., Le, M., Brose, K., Tamada, A., Murakami, F., Lee, E. Y., and Tessier-Lavigne, M. (2004). The divergent Robo family protein rig-1/Robo3 is a negative regulator of slit responsiveness required for midline crossing by commissural axons. Cell 117, 157-169.

Saint Marie, R. L., Luo, L., and Ryan, A. F. (1999). Effects of stimulus frequency and intensity on c-fos mRNA expression in the adult rat auditory brainstem. $\mathrm{J}$ Comp Neurol 404, 258-270.

Sando, I. (1965). The Anatomical Interrelationships of the Cochlear Nerve Fibers. Acta Oto-Laryngologica 59, 417 - 436. 
Seeger, M., Tear, G., Ferres-Marco, D., and Goodman, C. S. (1993). Mutations affecting growth cone guidance in Drosophila: genes necessary for guidance toward or away from the midline. Neuron 10, 409-426.

Serafini, T., Colamarino, S. A., Leonardo, E. D., Wang, H., Beddington, R., Skarnes, W. C., and Tessier-Lavigne, M. (1996). Netrin-1 is required for commissural axon guidance in the developing vertebrate nervous system. Cell 87, 1001-1014.

Serafini, T., Kennedy, T. E., Galko, M. J., Mirzayan, C., Jessell, T. M., and TessierLavigne, M. (1994). The netrins define a family of axon outgrowth-promoting proteins homologous to C. elegans UNC-6. Cell 78, 409-424.

Shi, M., Guo, C., Dai, J. X., and Ding, Y. Q. (2008). DCC is required for the tangential migration of noradrenergic neurons in locus coeruleus of mouse brain. Mol Cell Neurosci 39, 529-538.

Shim, I., and Wirtshafter, D. (1996). Fos-like immunoreactivity in the mamillary body and thalamus following injections of muscimol into the ventral tegmental nucleus of Gudden in the rat. Brain Res 712, 173-178.

Shone, G., Raphael, Y., and Miller, J. M. (1991). Hereditary deafness occurring in cd/1 mice. Hear Res 57, 153-156.

Simpson, J. H., Bland, K. S., Fetter, R. D., and Goodman, C. S. (2000a). Shortrange and long-range guidance by Slit and its Robo receptors: a combinatorial code of Robo receptors controls lateral position. Cell 103, 1019-1032.

Simpson, J. H., Kidd, T., Bland, K. S., and Goodman, C. S. (2000b). Short-range and long-range guidance by slit and its Robo receptors. Robo and Robo2 play distinct roles in midline guidance. Neuron $28,753-766$.

Smith, P. H., Joris, P. X., and Yin, T. C. (1993). Projections of physiologically characterized spherical bushy cell axons from the cochlear nucleus of the cat: evidence for delay lines to the medial superior olive. J Comp Neurol 331, 245-260.

Sommer, I., Lingenhohl, K., and Friauf, E. (1993). Principal cells of the rat medial nucleus of the trapezoid body: an intracellular in vivo study of their physiology and morphology. Exp Brain Res 95, 223-239.

Soriano, P. (1999). Generalized lacZ expression with the ROSA26 Cre reporter strain. Nat Genet 21, 70-71.

Spirou, G. A., Brownell, W. E., and Zidanic, M. (1990). Recordings from cat trapezoid body and HRP labeling of globular bushy cell axons. J Neurophysiol 63 , 1169-1190. 
Tollin, D. J., and Yin, T. C. (2002a). The coding of spatial location by single units in the lateral superior olive of the cat. I. Spatial receptive fields in azimuth. J Neurosci 22, 1454-1467.

Tollin, D. J., and Yin, T. C. (2002b). The coding of spatial location by single units in the lateral superior olive of the cat. II. The determinants of spatial receptive fields in azimuth. J Neurosci 22, 1468-1479.

Tsuchitani, C. (1988a). The inhibition of cat lateral superior olive unit excitatory responses to binaural tone bursts. I. The transient chopper response. J Neurophysiol 59, 164-183.

Tsuchitani, C. (1988b). The inhibition of cat lateral superior olive unit excitatory responses to binaural tone bursts. II. The sustained discharges. J Neurophysiol 59, 184-211.

Tsuchitani, C. (1997). Input from the medial nucleus of trapezoid body to an interaural level detector. Hear Res 105, 211-224.

Vertes, R. P. (2005). Hippocampal theta rhythm: a tag for short-term memory. Hippocampus 15, 923-935.

Vertes, R. P., Albo, Z., and Viana Di Prisco, G. (2001). Theta-rhythmically firing neurons in the anterior thalamus: implications for mnemonic functions of Papez's circuit. Neuroscience 104, 619-625.

Vielmetter, J., Kayyem, J. F., Roman, J. M., and Dreyer, W. J. (1994). Neogenin, an avian cell surface protein expressed during terminal neuronal differentiation, is closely related to the human tumor suppressor molecule deleted in colorectal cancer. J Cell Biol 127, 2009-2020.

Volenec, A., Zetterstrom, T. S., and Flanigan, T. P. (1998). 6-OHDA denervation substantially decreases DCC mRNA levels in rat substantia nigra compacta. Neuroreport 9, 3553-3556.

Webster, D. B. (1971). Projection of the cochlea to cochlear nuclei in Merriam's kangaroo rat. J Comp Neurol 143, 323-340.

Wong-Riley, M. (1979). Changes in the visual system of monocularly sutured or enucleated cats demonstrable with cytochrome oxidase histochemistry. Brain Res $171,11-28$.

Yee, K. T., Simon, H. H., Tessier-Lavigne, M., and O'Leary, D. M. (1999). Extension of long leading processes and neuronal migration in the mammalian brain directed by the chemoattractant netrin-1. Neuron $24,607-622$. 
Yuan, W., Zhou, L., Chen, J. H., Wu, J. Y., Rao, Y., and Ornitz, D. M. (1999). The mouse SLIT family: secreted ligands for ROBO expressed in patterns that suggest a role in morphogenesis and axon guidance. Dev Biol 212, 290-306.

Zambrowicz, B. P., Imamoto, A., Fiering, S., Herzenberg, L. A., Kerr, W. G., and Soriano, P. (1997). Disruption of overlapping transcripts in the ROSA beta geo 26 gene trap strain leads to widespread expression of beta-galactosidase in mouse embryos and hematopoietic cells. Proc Natl Acad Sci U S A 94, 3789-3794.

Zheng, Q. Y., Johnson, K. R., and Erway, L. C. (1999). Assessment of hearing in 80 inbred strains of mice by ABR threshold analyses. Hear Res 130, 94-107. 
Figure Legends
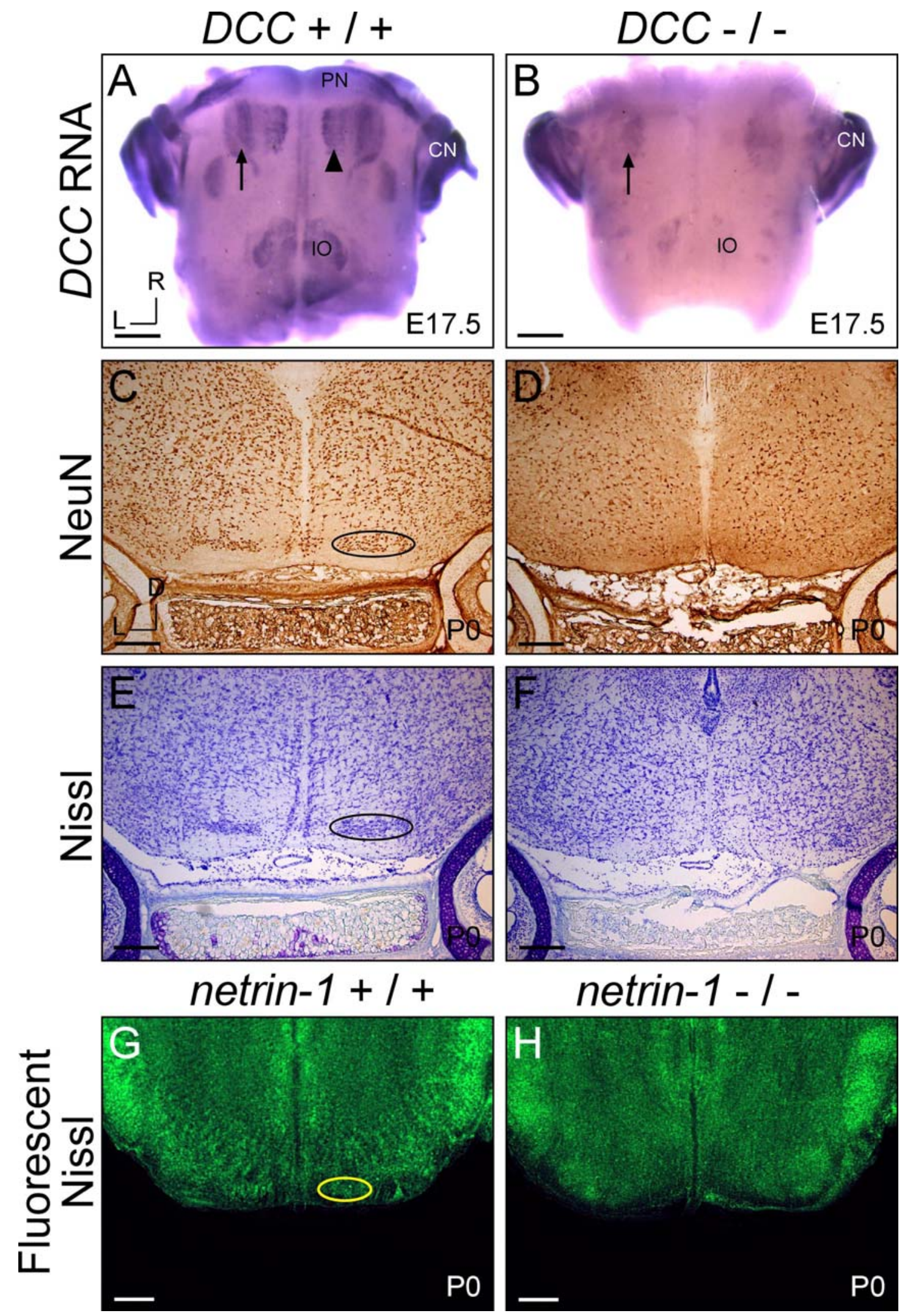

netrin-1 - / -

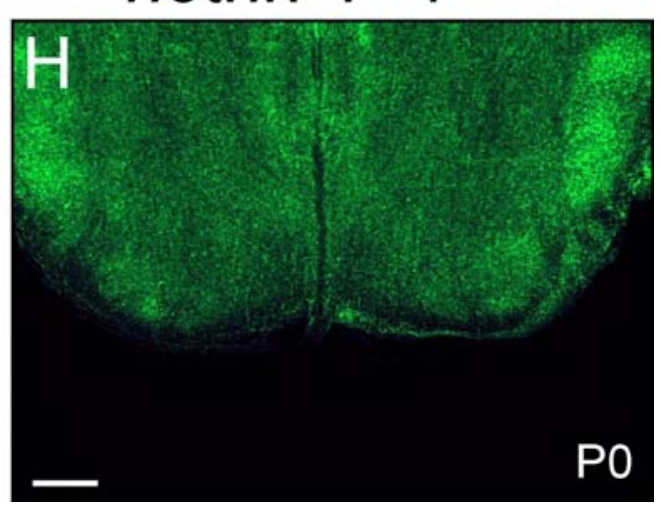


Figure 1. DCC- and netrin-1-deficient mice lack identifiable MNTB neurons. (A and B) Ventral view of E17.5 DCC wild-type (A) and DCC-deficient (B) brainstem hybridized with antisense $D C C$ probe. (A) Multiple structures express $D C C$ within the wild-type ventral brainstem: cochlear nucleus (CN), inferior olive (IO), MNTB (arrowhead) and pontine nucleus (PN). Expression is also present within a lateral region of the superior olivary complex (arrow). (B) DCC expression is not observed in a location consistent with the MNTB in DCC-deficient pups. Weak DCC expression is observed in a location consistent with a lateral region of the superior olivary complex (arrow) and the IO. (C-F) Coronal section through PO DCC wild-type ( $C$ and $E$ ) and $D C C$-deficient ( $D$ and $F$ ) auditory brainstem processed for NeuN immunohistochemistry ( $C$ and $D$ ) or Nissl staining ( $E$ and F). The MNTB (outline within black oval) is identified in the wild-type brainstem by NeuN immunohistochemistry $(C)$ and Nissl staining $(E)$ as a cluster of cells adjacent to the midline near the ventral surface. The cluster of cells comprising the MNTB is not identified in the DCC-deficient brainstem by NeuN immunohistochemistry (D) and Nissl staining $(F)$. ( $G$ and $H$ ) Coronal section through P0 netrin-1 wild-type $(G)$ and netrin-1-deficient $(\mathrm{H})$ auditory brainstem processed for fluorescent Nissl staining. The MNTB (yellow oval) is recognizable as a cluster of cells adjacent to the midline near the ventral surface in the wild-type brainstem $(G)$. The cluster of cells comprising the MNTB is not identified in the netrin-1-deficient brainstem $(H)$. Orientation marker in $(A)$ is used for panels $(A$ and $B$ ) and $(C)$ is used for panels (C$H$ ), Dorsal (D); lateral (L); rostral (R). Scale bar, $400 \mu \mathrm{m}$ (A and B); $200 \mu \mathrm{m}(\mathrm{C}-\mathrm{E})$; $300 \mu \mathrm{m}(\mathrm{G}$ and $\mathrm{H})$. 


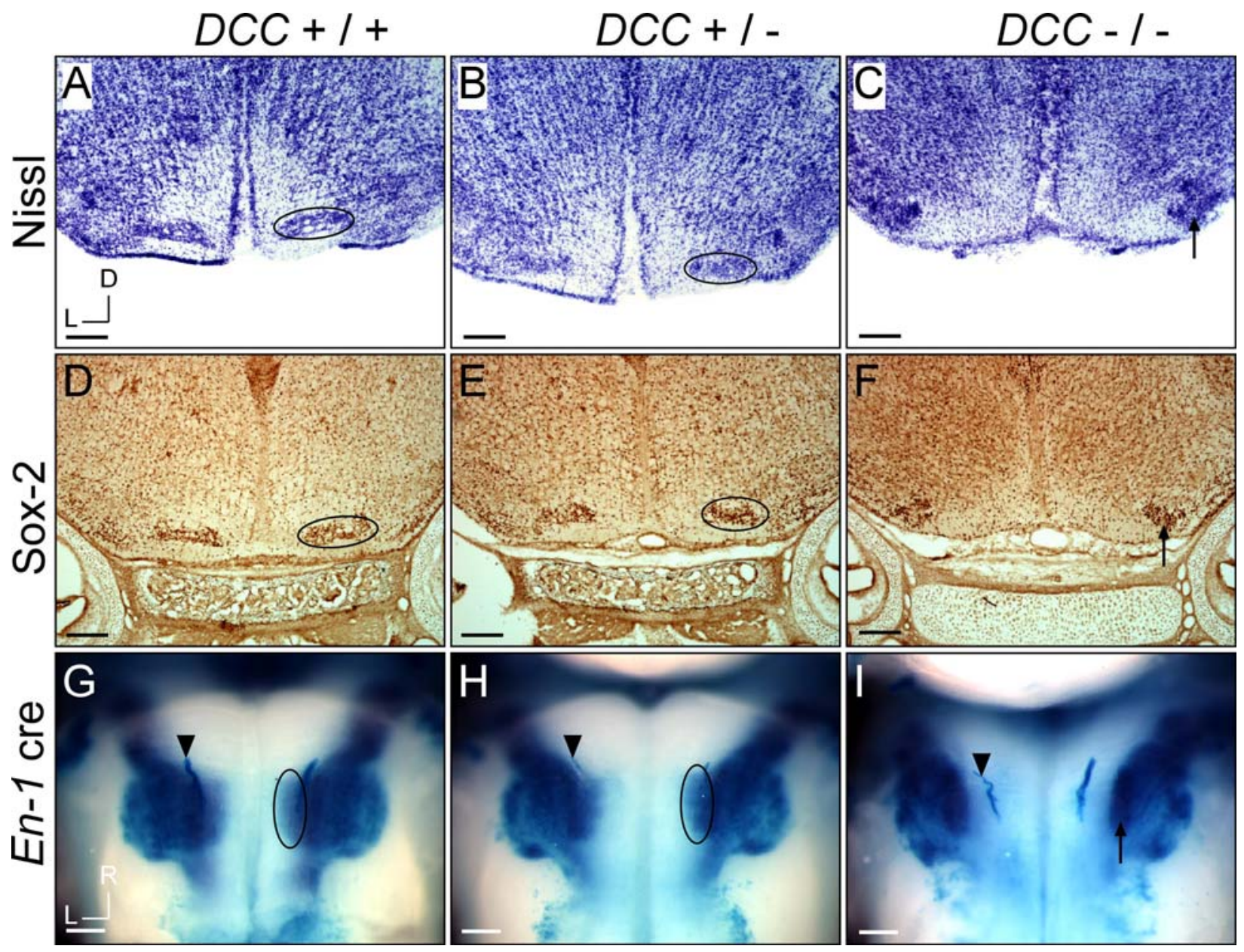

Figure 2. Medial-lateral positioning of the MNTB depends on DCC gene dosage. (A-F) Coronal section through the auditory brainstem of P0 mice carrying two ( $A$ and $D$ ), one ( $B$ and $E$ ), or no ( $C$ and $F$ ) functional copies of the $D C C$ allele, processed for Nissl staining (A-C) or Sox-2 immunohistochemistry (D-F). The cluster of cells comprising the MNTB (oval) is identified in the wild-type brainstem adjacent to the midline (A and $D)$. Mice carrying only one functional copy of the DCC allele have an identifiable MNTB (oval), although these cells are positioned more lateral to the midline ( $B$ and $E$ ). The cluster cells that comprise the MNTB is absent in mice carrying no functional $D C C$ alleles (C and F). (G-I) Ventral view of PO X-gal-stained whole-mount brainstems from animals carrying an Engrailed1-Cre transgene (En-1 cre), a lacZ-Cre reporter (Rosa26R), and two $(G)$, one $(H)$, or no (I) functional copies of the $D C C$ allele. X-gal staining is present within the $\mathrm{SOC}$ in the wild-type brainstem (G) with the most medial signal corresponding to the MNTB (oval). X-gal staining within the SOC is similar; although the MNTB (oval) is displaced laterally in mice 
carrying only one functional copy of the $D C C$ allele $(\mathrm{H})$. The X-gal-stained MNTB is not identifiable in the $D C C$-deficient brainstem (I). The arrowhead identifies the $\mathrm{X}$ gal-labeled abducens nerve. The MNTB appears to be displaced laterally in mice carrying only one functional copy of the $D C C$ allele $(\mathrm{B}, \mathrm{E}, \mathrm{H})$ and is either absent or dramatically shifted laterally in mice homozygous for the DCC mutant allele $(C, F, I)$. The arrow in $\mathrm{C}, \mathrm{F}$, and I indicates a cluster of cells in a lateral region of the SOC by Nissl staining (C), Sox-2 immunohistochemistry (F), and En-1-Cre (LacZ) X-gal staining $(\mathrm{I})$ that could contain shifted MNTB cells. Orientation marker in $(\mathrm{A})$ is used for panels $(A-F)$ and $(G)$ is used for panels $(G-I)$, Dorsal $(D)$; lateral $(L)$; rostral $(R)$. Scale bar, $200 \mu \mathrm{m}(\mathrm{A}-\mathrm{F}) ; 300 \mu \mathrm{m}(\mathrm{G}-\mathrm{I})$. 

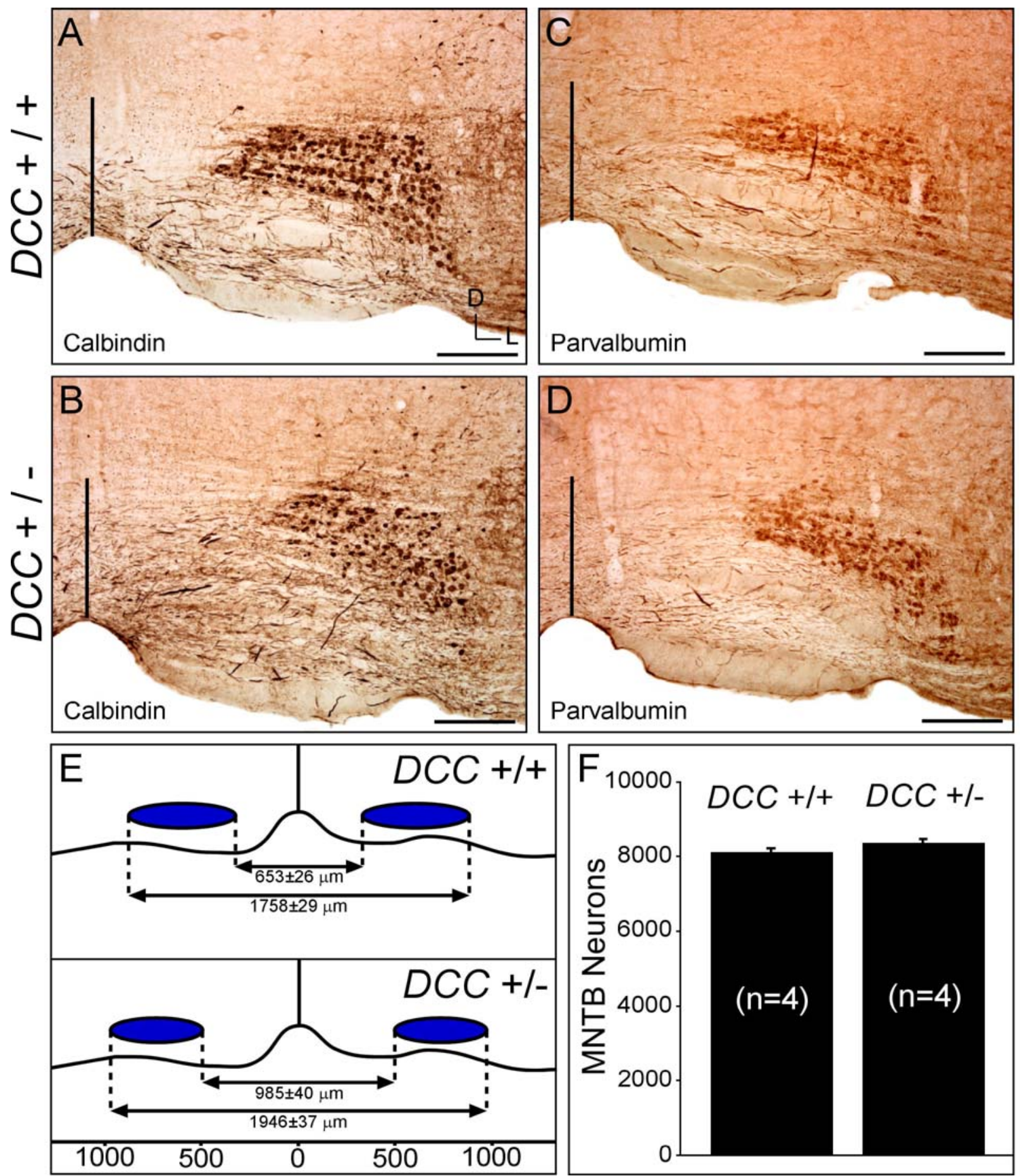

Figure 3. DCC gene dosage changes adult MNTB morphology.

(A-D) Coronal section through the auditory brainstem of mice carrying two ( $A$ and $C$ ) or one $(B$ and $D$ ) functional copies of the $D C C$ allele processed for anti-calbindin ( $A$ and $B$ ) or anti-parvalbumin ( $C$ and $D$ ) immunohistochemistry. The wild-type adult mouse MNTB is an arrangement of neurons adjacent to the midline near the ventral 
surface of the brainstem ( $A$ and $C$ ). Mice carrying only one functional copy of the $D C C$ allele ( $B$ and $D$ ) possess an MNTB that is entirely shifted laterally in the coronal plane. The medial border of the MNTB appears truncated in animals carrying only one functional copy of the $D C C$ allele. Orientation marker shown in $(A)$ is used for all panels (A-D), Dorsal (D); lateral $(L)$. Vertical line indicates the midline. Scale bar, $200 \mu \mathrm{m}$ (A-D). (E) Schematic representation of the MNTB location in mice homozygous $(D C C+/+)$ or heterozygous $(D C C+/-)$ for the wild-type $D C C$ allele. The separation of MNTB nuclei was measured in coronal sections (minimum 10 sections containing MNTB bilaterally per brain) obtained from adult mice carrying two or one ( $\mathrm{n}=5$ for each genotype) functional copies of the $D C C$ allele processed for calbindin and/or parvalbumin immunohistochemistry. The medial borders of MNTB nuclei are separated by $653 \pm 26 \mu \mathrm{m}$ in wild-type animals while $985 \pm 40 \mu \mathrm{m}$ separate MNTB nuclei in heterozygous animals ( $p$-value $<0.001$ ). The lateral boarder of MNTB nuclei are separated by $1758 \pm 29 \mu \mathrm{m}$ in wild-type animals and $1946 \pm 37 \mu \mathrm{m}$ in heterozygous animals ( $p$-value $=0.007$ ). The MNTB nuclei in mice carrying one functional copy of the $D C C$ allele are globally displaced laterally with medial edge being shifted more than the lateral edge. The overall result is a compression of the laterally displaced MNTB. (F) Unbiased stereology estimate of MNTB neurons in mice homozygous $(D C C+/+)$ or heterozygous $(D C C+/-)$ for the wild-type $D C C$ allele. Mice carrying two functional copies of the DCC allele contain 8,110 $\pm 105(\mathrm{n}=$ 4) calbindin-positive neurons per MNTB. Mice carrying only one functional copy of the DCC allele contain a statistically similar number of neurons per MNTB $(8,370 \pm$ $94, n=4, p=0.4)$. Therefore, the lateral displacement and compression of the MNTB in mice carrying only one functional copy of the $D C C$ allele is not due to the loss of MNTB neurons. 

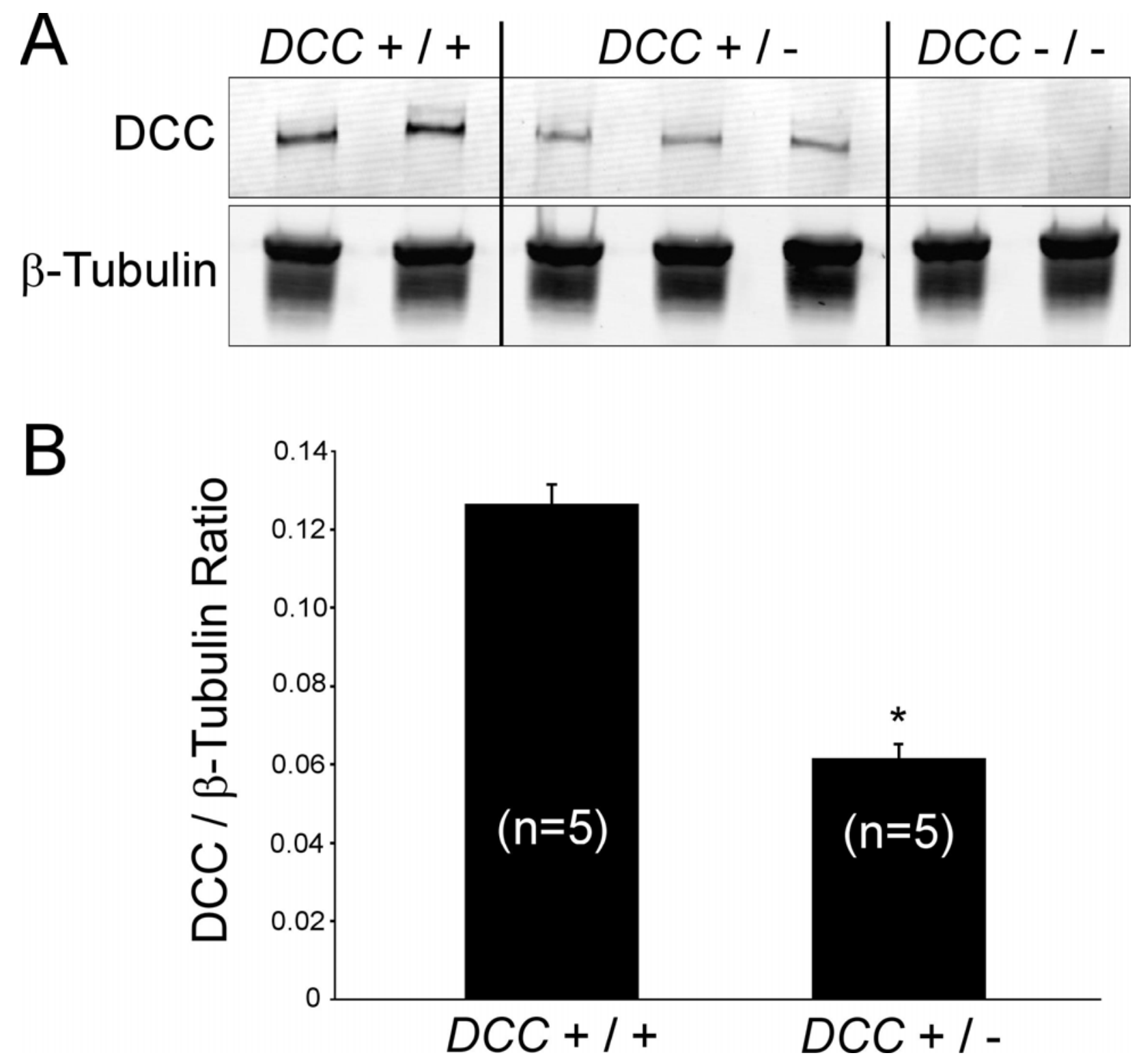

Figure 4. DCC protein expression is proportional to the number of functional $D C C$ alleles.

(A) Total protein isolated from E14.0 brains carrying two $(D C C+/+)$, one $(D C C+/-)$ or no (DCC -/-) functional copies of the DCC allele were separated on a $7.5 \%$ agarose gel, transferred to a PVDF membrane, and incubated with antibodies to DCC and $\beta$-tubulin, an internal loading control. Protein signal was detected and quantified using appropriate infrared conjugated secondary antibodies on a Licor Odyssey imaging system. A representative gel shows that mice carrying two functional copies of the $D C C$ allele have more DCC protein than mice carrying only one functional copy of the $D C C$ allele. No DCC protein signal is detected in mice 
carrying no functional copies of the DCC allele. (B) Quantification of the DCC protein signal to the $\beta$-tubulin protein signal was calculated in mice carrying two $(D C C+/+)$ or one $(D C C+/-)$ functional copies of the $D C C$ allele. The $D C C$ to $\beta$-tubulin protein ratio in mice carrying two functional $D C C$ alleles $(0.127 \pm 0.004, n=5)$ is statistically different from mice carrying only one functional copy of the DCC allele $(0.062 \pm$ $0.004, n=5, p$-value $<0.001)$. Mice carrying only one functional copy of the $D C C$ allele express $49 \%$ the quantity of DCC protein observed in mice carrying two functional copies of the DCC allele. Asterisk ( $p$-value $<0.001)$. 

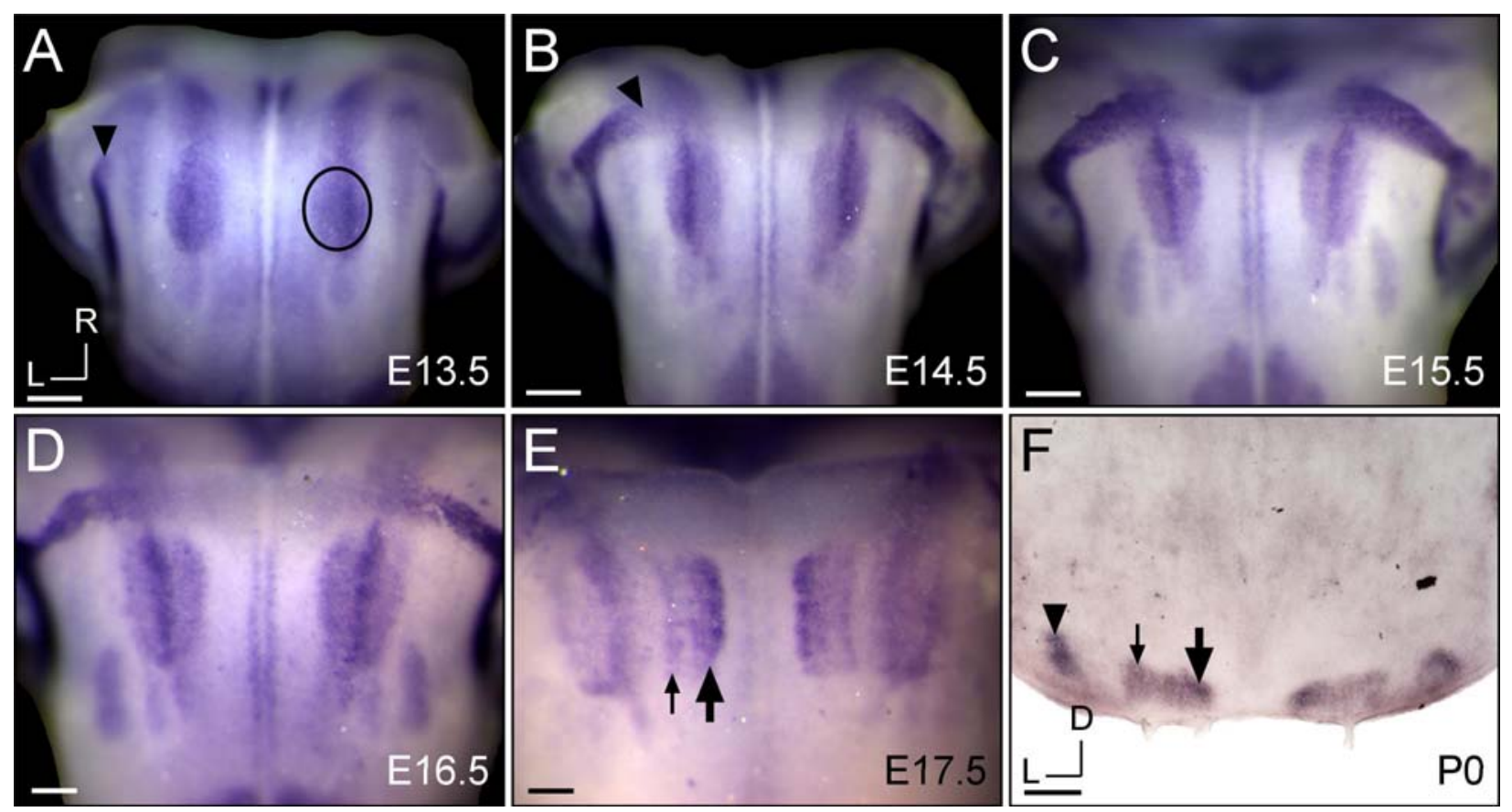

Figure 5. Migrating SOC neurons express DCC.

Ventral view (A-E) or coronal section $(F)$ of the developing mouse brainstem at the indicated age hybridized with a DCC antisense probe. (A) At E13.5, DCC is expressed in a column of cells extending from the rostral brainstem to the future location of the superior olivary complex (SOC, oval). The initial migration of DCCpositive neurons in the pontine migratory stream (arrowhead) occurs at this developmental age. (B) DCC expression at E14.5 is maintained in the column of cells extending to the future SOC. DCC expression within the SOC is not uniform at this developmental age with highest levels occurring at the center of the stained region. Further extension of $D C C$ positive neurons in the pontine migratory stream (arrowhead) is visualized. (C and D) DCC expression within the developing SOC at E15.5-16.5 is maintained with highest levels continuing to occur at the center of the stained region. (E) At E17.5, a medial and a lateral zone of DCC expression is observed within the developing SOC. In the medial zone, DCC expression occurs as a high medial (large arrow) to low lateral (small arrow) gradient within this zone. (F) Coronal section through the PO brainstem indicates the medial zone of $D C C$ expression corresponds to the MNTB. The high medial (large arrow) to low lateral (small arrow) gradient of $D C C$ expression is visualized within the MNTB in this section plane. The lateral zone of $D C C$ expression (arrowhead) resides within the 
SOC; however, definitive identification of this structure is not entirely clear.

Orientation marker shown in $(A)$ is used for panels $(A-E)$, Dorsal $(D)$; lateral $(L)$; rostral $(R)$. Scale bar, $300 \mu \mathrm{m}(A-C) ; 200 \mu \mathrm{m}(\mathrm{D}$ and $E) ; 400 \mu \mathrm{m}(\mathrm{F})$. 

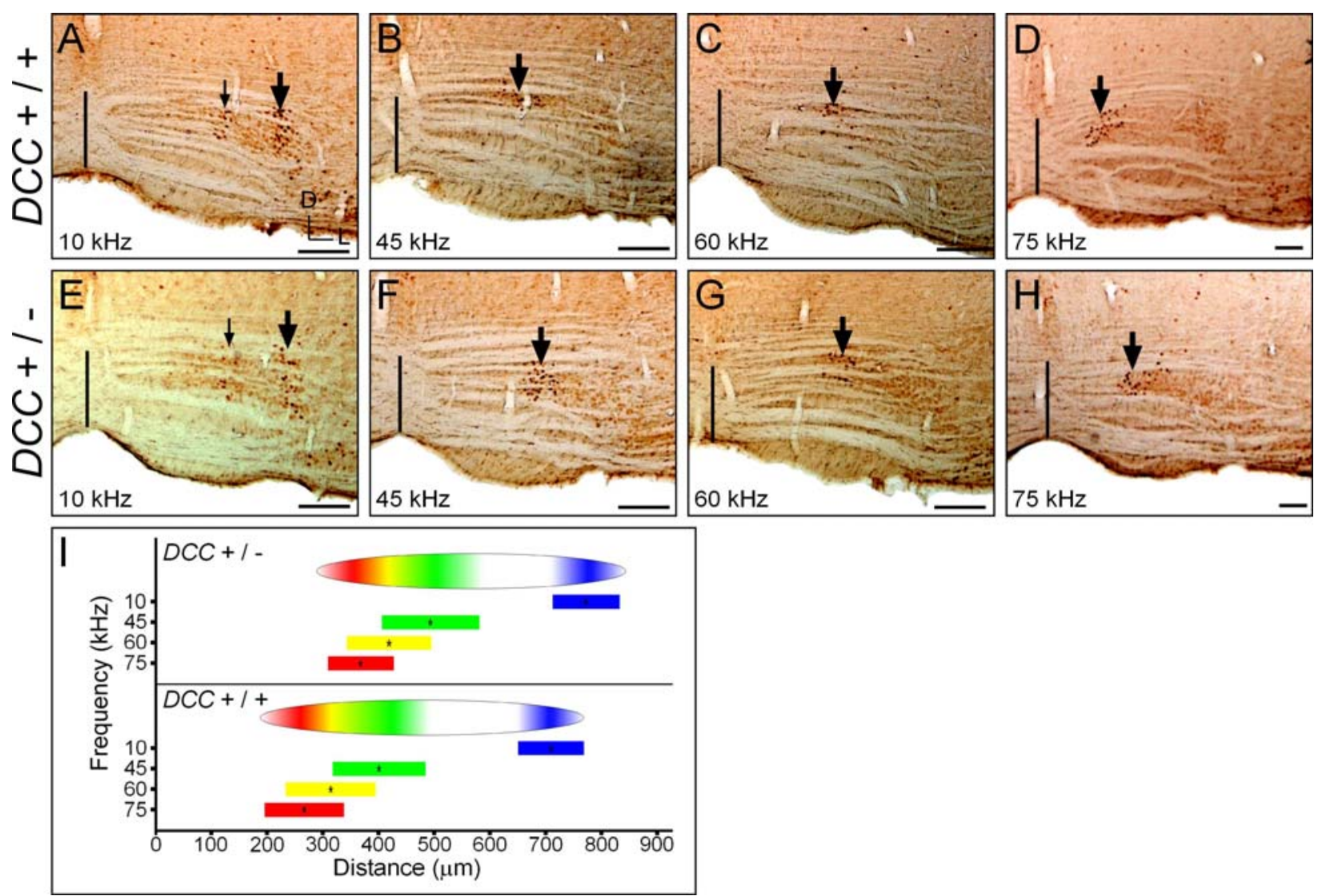

Figure 6. DCC gene dosage alters the tonotopic positioning of MNTB neurons.

Coronal section through the brain of juvenile mice carrying two (A-D) or one $(E-H)$ functional copies of the $D C C$ allele representing a second generation FVB/NJ backcross exposed to pure-tone stimulation frequencies $10 \mathrm{kHz}$ ( $A$ and $E$ ), $45 \mathrm{kHz}$ ( $B$ and $\mathrm{F}), 60 \mathrm{kHz}$ ( $\mathrm{C}$ and $\mathrm{G}$ ) and $75 \mathrm{kHz}$ ( $\mathrm{D}$ and $\mathrm{H}$ ) processed for c-Fos immunohistochemistry. ( $A$ and $E$ ) Stimulation with $10 \mathrm{kHz}$ pure-tones identifies 2 groups of c-Fos positive neurons within the MNTB. The lateral group (large arrow) corresponds to the $10 \mathrm{kHz}$ isofrequency lamina and the medial group corresponds to the first harmonic $(20 \mathrm{kHz})$ isofrequency lamina (small arrow). (B and F) Stimulation with $45 \mathrm{kHz}$ pure-tones identifies a single cluster of neurons (large arrow) within the MNTB in mice carrying two or one functional copies of the DCC allele that occur medial to those observed at $10 \mathrm{kHz}$. (C and G) Stimulation with $60 \mathrm{kHz}$ pure-tones identifies a single cluster of neurons (large arrow) medial to the cluster observed at $45 \mathrm{kHz}$ in mice carrying two or one functional copies of the $D C C$ allele. ( $D$ and $H$ ) Stimulation with $75 \mathrm{kHz}$ pure-tones identifies a single cluster of neurons (large 
arrow) medial to the cluster of neurons observed at $60 \mathrm{kHz}$ that reside near the medial extent of the MNTB in mice carrying two or one functional copies of the DCC allele. In each stimulation frequency, c-Fos-positive MNTB neurons in mice carrying only one functional copy of the $D C C$ allele $(\mathrm{E}-\mathrm{H})$ reside lateral to the domain labeled in identically treated mice carrying two functional copies of the DCC allele (A-D). Additionally, the high medial-to-low lateral tonotopic organization of the MNTB is preserved in the laterally displaced MNTB found in mice carrying only one functional copy of the DCC allele. Orientation marker shown in $(A)$ is used for panels $(A-H)$, Dorsal (D); lateral (L). Vertical line indicates the midline. Scale bar, $200 \mu \mathrm{m}(\mathrm{A}-\mathrm{H})$. (I) Schematic representation of the tonotopic organization of the MNTB in juvenile mice carrying two $(D C C+/+)$ or one $(D C C+/-)$ functional copies of the $D C C$ allele. The range (solid bars) and the median distance (asterisk) from the midline for c-Fospositive neurons is plotted for each pure-tone stimulation frequency $(\mathrm{kHz})$ in mice carrying two or one functional copies of the $D C C$ allele. The oval defines the overall extent of the MNTB, as determined by serial-section anti-calbindin immunohistochemistry, in the mice exposed to pure-tone stimulation frequencies. $D C C+/+$ mice are found to have a tonotopically ordered (high medial-to-low lateral) MNTB when stimulated with frequencies of $75 \mathrm{kHz}$ (red, $\mathrm{n}=4$, median $=267 \mu \mathrm{m}$, range $=136 \mu \mathrm{m}$ ), $60 \mathrm{kHz}$ (yellow, $\mathrm{n}=6$, median $=314 \mu \mathrm{m}$, range $=155 \mu \mathrm{m}$ ), $45 \mathrm{kHz}$ (green, $\mathrm{n}=6$, median $=401 \mu \mathrm{m}$, range $=160 \mu \mathrm{m}$ ) and $10 \mathrm{kHz}$ (blue, $\mathrm{n}=5$, median $=$ $710 \mu \mathrm{m}$, range $=111 \mu \mathrm{m}$ ). The tonotopic organization of the laterally displaced MNTB is essentially preserved in DCC +/- mice stimulated with frequencies of 75 $\mathrm{kHz}($ red, $\mathrm{n}=4$, median $=368 \mu \mathrm{m}$, range $=112 \mu \mathrm{m}$ ), $60 \mathrm{kHz}$ (yellow, $\mathrm{n}=7$, median $=$ $419 \mu \mathrm{m}$, range $=145 \mu \mathrm{m}), 45 \mathrm{kHz}$ (green, $\mathrm{n}=6$, median $=494 \mu \mathrm{m}$, range $=168 \mu \mathrm{m})$ and $10 \mathrm{kHz}$ (blue, $\mathrm{n}=3$, median $=773 \mu \mathrm{m}$, range $=114 \mu \mathrm{m}$ ). 


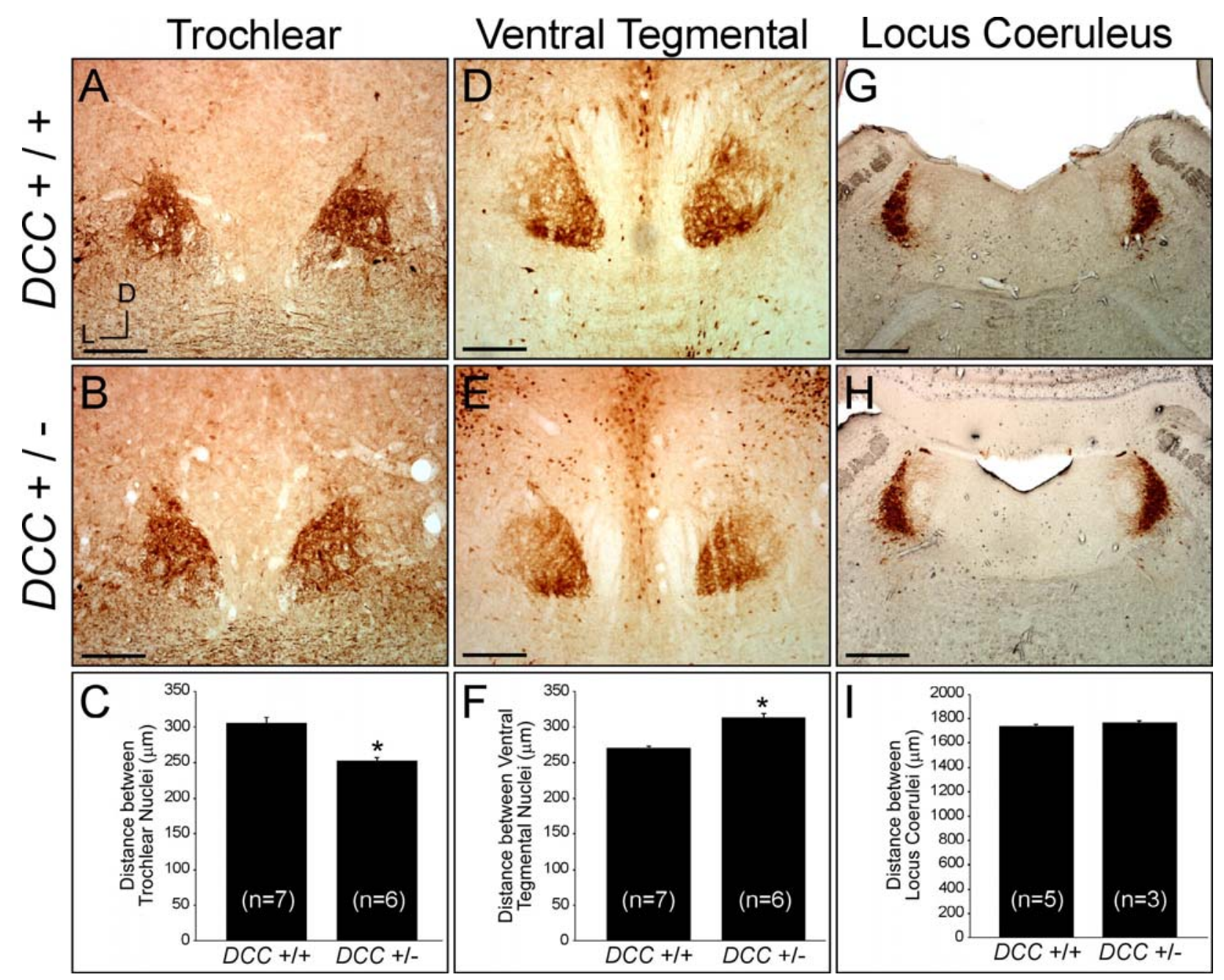

Figure 7. $D C C$ gene dosage alters the position of midbrain nuclei.

$(A, B, D, E, G, H)$ Coronal section through the brainstem of juvenile mice carrying two $(A, D, G)$ or one $(B, E, H)$ functional copies of the $D C C$ allele processed for parvalbumin ( $A$ and $B)$, calbindin ( $D$ and $E$ ) or tyrosine hydroxylase ( $G$ and $H$ ) immunohistochemistry. (A-C) The trochear nucleus is identified by parvalbumin immunohistochemistry in the wild-type and heterozygous brainstem. The trochlear nuclei are displaced medially in mice carrying only one functional copy of the DCC allele. The distance separating the trochlear nuclei is plotted for each $D C C$ genotype. The trochlear nuclei are separated by $305 \pm 8 \mu \mathrm{m}$ in mice carrying two functional copies of the DCC allele $(n=7)$. This is statistically different from the 252 $\pm 4 \mu \mathrm{m}$ measured in mice carrying only one functional copy of the DCC allele ( $n=6$, $p$-value < 0.001). (D-F) The ventral tegmental nucleus is identified by calbindin immunohistochemistry in the wild-type and heterozygous brainstem. The ventral 
tegmental nuclei are displaced laterally in mice carrying only one functional copy of the $D C C$ allele. The distance separating the ventral tegmental nuclei is plotted for each $D C C$ genotype. The ventral tegmental nuclei are separated by $271 \pm 2 \mu \mathrm{m}$ in mice carrying two functional copies of the $D C C$ allele $(n=7)$. This is statistically different from the $313 \pm 5 \mu \mathrm{m}$ measured in mice carrying only one functional copy of the DCC allele ( $n=7, p$-value $<0.001)$. (G-I) The locus coeruleus is identified by tyrosine hydroxylase immunohistochemistry in the wild-type and heterozygous brainstem. The locus coerulei are separated by a statistically similar distance in mice carrying two $(1737 \pm 13 \mu \mathrm{m}, \mathrm{n}=5)$ or one $(1766 \pm 9 \mu \mathrm{m}, \mathrm{n}=3$, $\mathrm{p}$-value $=0.16)$ functional copies of the $D C C$ allele. Orientation marker shown in $(A)$ is used for panels (A, B, D, E, G, H), Dorsal (D); lateral (L). Scale bar, $200 \mu \mathrm{m}(A, B, D, E) ; 500$ $\mu \mathrm{m}(\mathrm{G}, \mathrm{H})$. 


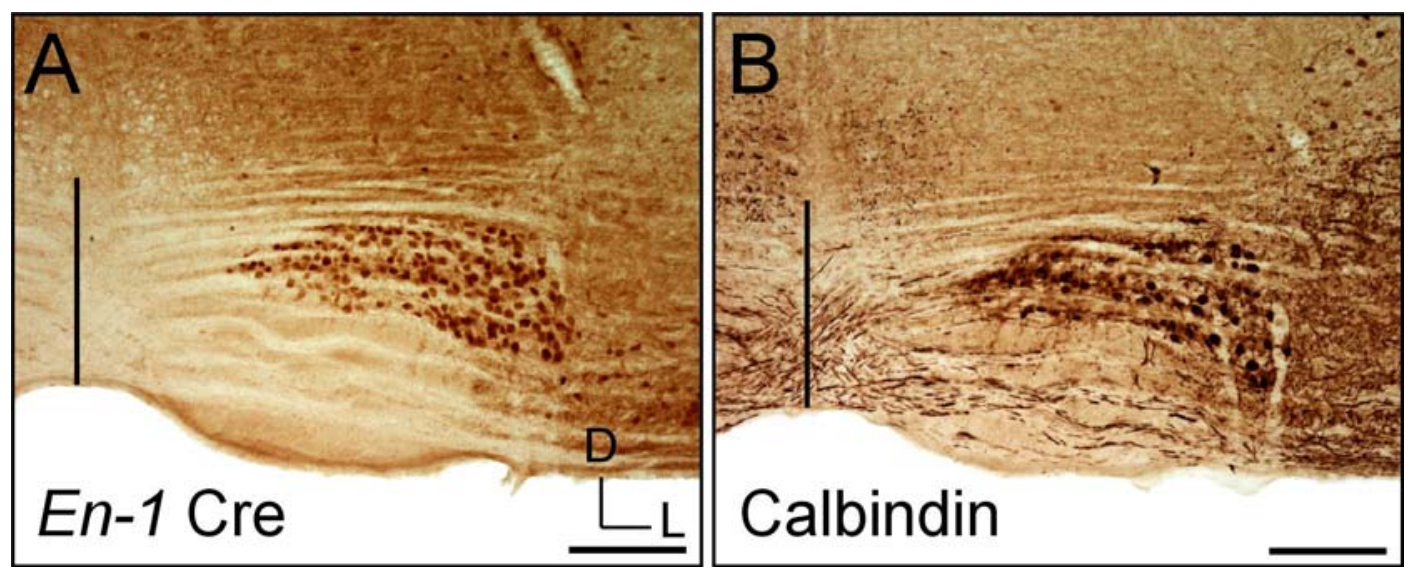

Supplemental Figure 1. Adult MNTB neurons are labeled by Engrailed1-cre reporter system.

(A and B) Adjacent coronal sections through the brainstem of a P21 mouse carrying an Engrailed1-Cre transgene (En-1 Cre) and a GFP-Cre reporter (Rosa26-EGFP) processed for GFP (A) or calbindin (B) immunohistochemistry. Robust labeling of MNTB neurons with anti-GFP antibody is similar to labeling observed with calbindin immunohistochemistry. These results indicate that MNTB neurons express the Engrailed-1 transcription factor during development. Orientation marker in $(A)$ is used for all panels (A and B), Dorsal (D); lateral (L). Vertical line indicates the midline. Scale bar, $200 \mu \mathrm{m}$ (A and B). 

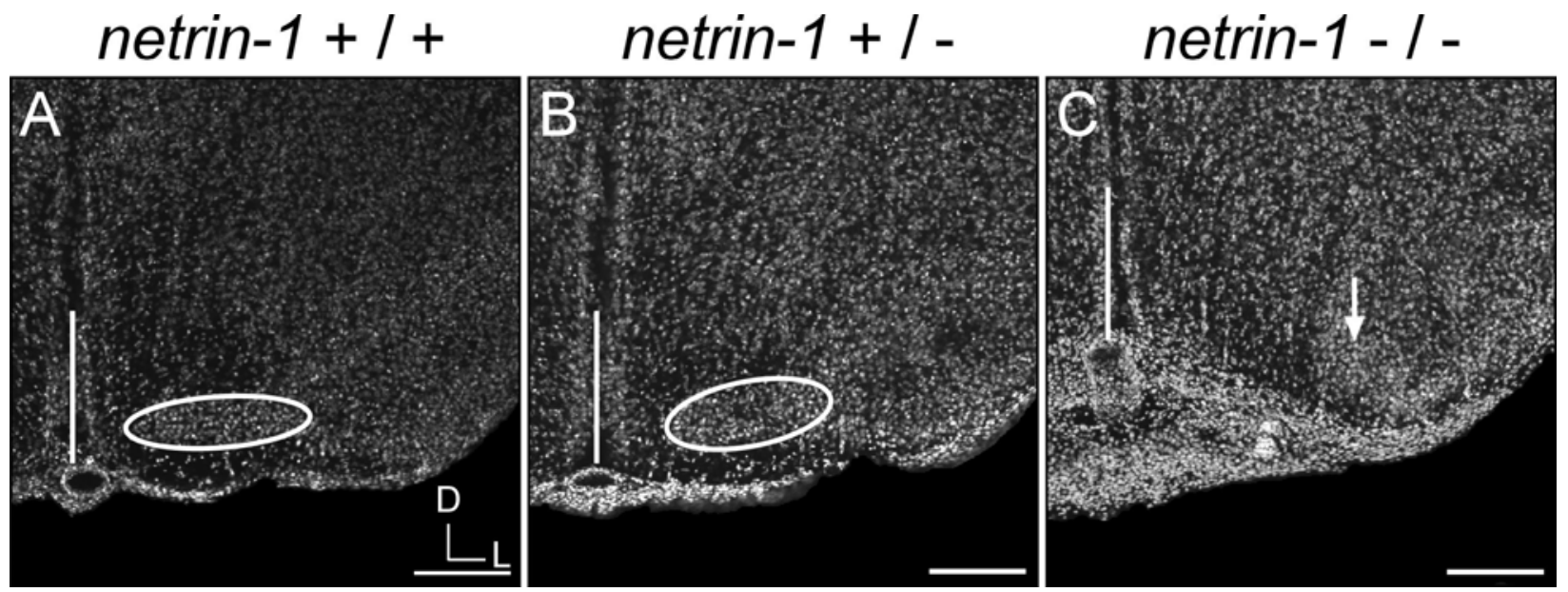

Supplemental Figure 2. Medial-lateral positioning of the MNTB requires netrin-1 function.

(A-C) Coronal section through the auditory brainstem of P0 mice carrying two (A), one (B), or no (C) functional copies of the netrin-1 allele processed for fluorescent Nissl staining. The cluster of cells comprising the MNTB (oval) is identified in the wild-type brainstem adjacent to the midline (A). Mice carrying only one functional netrin-1 allele have an identifiable MNTB (oval), although these cells are positioned more laterally to the midline and appears more compressed in the medial-lateral plane at this age (B). A cluster of cells similar to the MNTB is not located adjacent to the midline of the brainstem in mice carrying no functional copies of the netrin-1 alleles (C). The arrow in $C$ indicates a cluster of cells in a lateral region of the SOC similar to that observed by Nissl staining, Sox-2 immunohistochemistry, and En-1Cre (LacZ) X-gal staining (Figure 2C, 2F, and 2I, respectively) Orientation marker in $(A)$ is used for all panels $(A-C)$, Dorsal $(D)$; lateral $(L)$. Vertical line indicates the midline. Scale bar, $200 \mu \mathrm{m}(\mathrm{A}-\mathrm{C})$. 


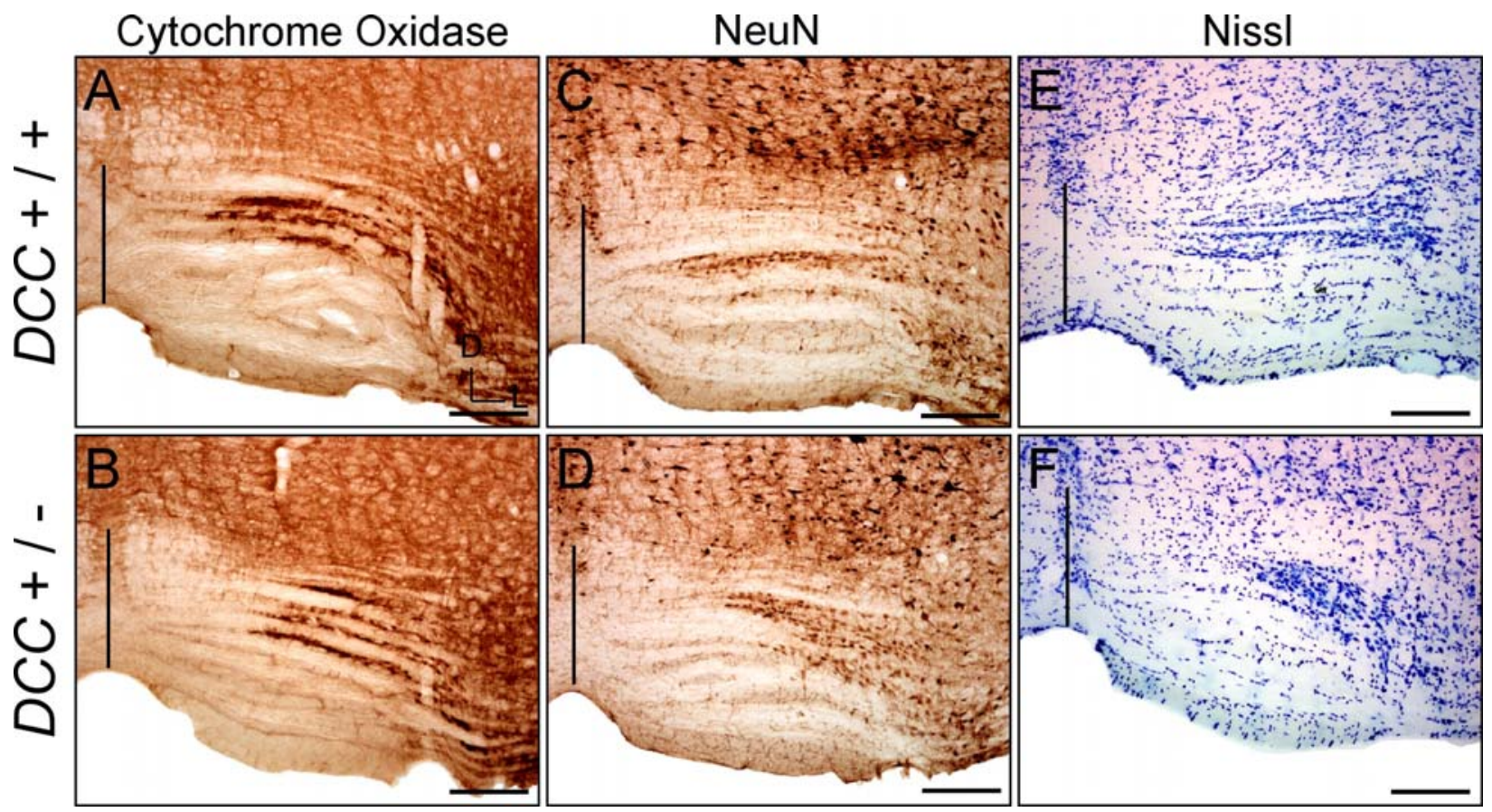

Supplemental Figure 3. DCC gene dosage changes adult MNTB morphology.

(A-D) Coronal sections through the auditory brainstem of adult mice carrying two (A, $C, E)$ or one $(B, D, F)$ functional copies of the $D C C$ allele processed for cytochrome oxidase ( $A$ and $B$ ), NeuN immunohistochemistry (C and D) or Nissl staining ( $E$ and F). The wild-type adult mouse MNTB is an arrangement of neurons adjacent to the midline near the ventral surface of the brainstem (A, C, E). The MNTB in mice carrying only one functional copy of the $D C C$ allele is entirely shifted laterally in the coronal plane $(B, D, F)$. Orientation marker shown in $(A)$ is used in all panels $(A-F)$, Dorsal (D); lateral (L). Vertical line indicates the midline. Scale bar, $200 \mu \mathrm{m}(\mathrm{A}-\mathrm{F})$. 

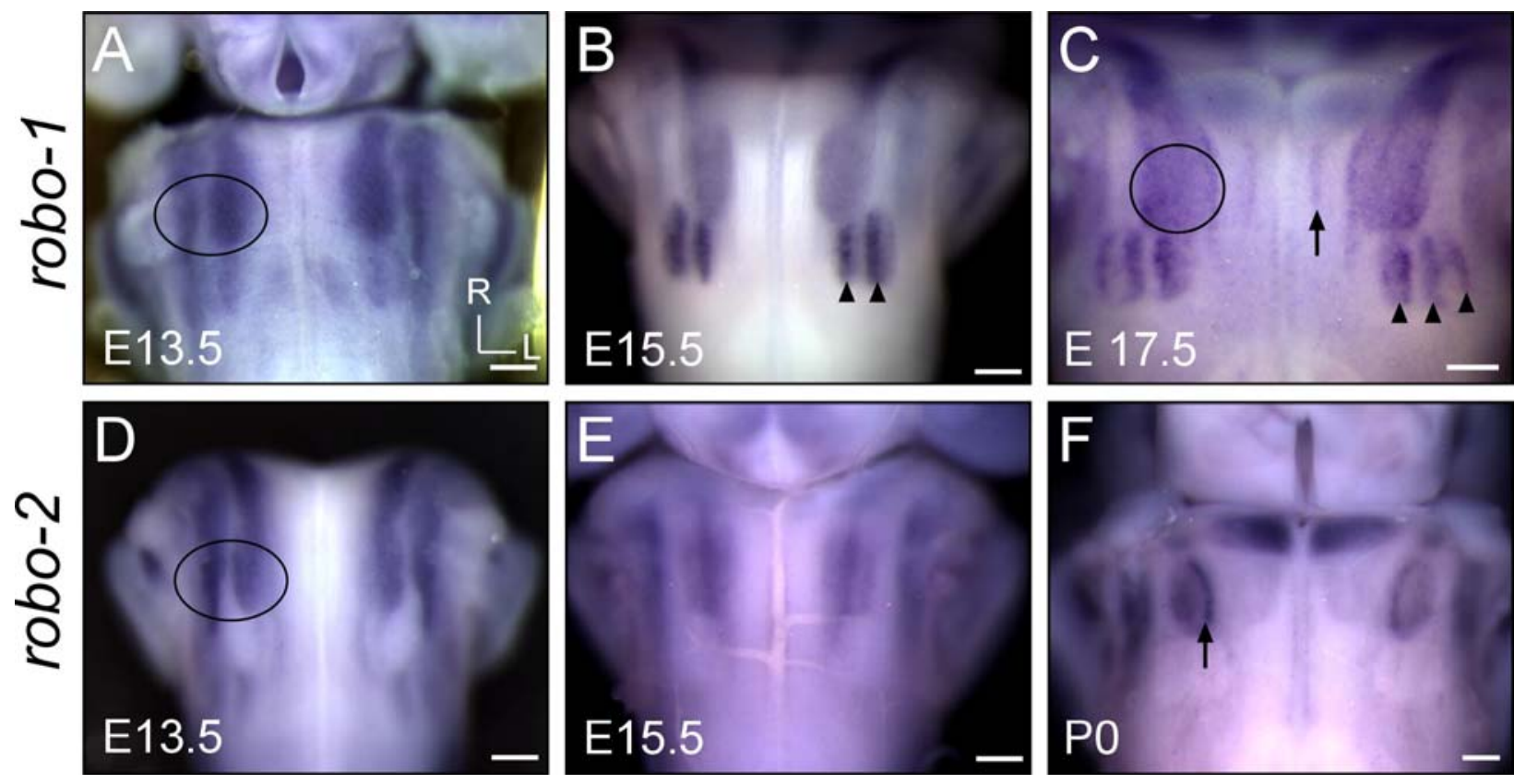

Supplemental Figure 4. robo1 and robo2 are expressed in the developing SOC.

Ventral view of the developing mouse brainstem at the indicated developmental age hybridized with a robo1 (A-C) or robo2 (D-F) antisense probe. (A) At E13.5, robo1 is expressed by two columns of cells extending from the rostral brainstem to the future location of the superior olivary complex (SOC, oval). (B) At E15.5, two regions of uniform rob-1 expression in the location of the SOC are observed. The two clusters of intense robo1 expression observed just caudal to the SOC are consistent with the location of the motor nucleus of the facial nerve (arrowheads). (C) At E17.5, bands of robo1 expression are present within the SOC. A faint band of robo1 expression is present at the medial edge of the MNTB (arrow). Further regions of high and medium robo1 expression occur laterally in the SOC (oval). Three clusters of robo1 expression are observed caudal to the SOC that are still consistent with the location of the motor nucleus of the facial nerve (arrowheads). (D) At E13.5, robo2 is expressed by two columns of cells extending from the rostral brainstem to the future location of the superior olivary complex (SOC, oval). (E) At E15.5, two regions within the $\mathrm{SOC}$ express robo2. Expression of robo2 is not uniform within the medial region; with highest expression occurring in the center of the stained region. Expression of robo2 in the lateral region appears uniform and occurs very lateral in the presumptive SOC. (F) At P0, robo2 expression occurs in a high medial-to-low lateral 
gradient in a central region of the SOC (arrow), however definitive identification of this structure is not known. Orientation marker shown in $(A)$ is used in all panels ( $A$ F), Lateral (L); rostral (R). Scale bar, $300 \mu m(A-F)$. 
CHAPTER 4

\section{General Discussion}




\section{Discussion}

The results presented in this dissertation provide additional insight into the molecular factors necessary for the development of the central nervous system as well as proposing a potential mechanism through which medial-to-lateral patterning of the central nervous system occurs. In chapter 2, we show that developing VCN neurons express RNAs for the molecular guidance cues DCC, robo1 and robo2, as well as, the transcription factor mafB. During this same period of development, netrin-1 and slit-1 RNAs are expressed at the midline of the brainstem. Therefore, all the factors necessary are present at the right time and place to direct contralateral projections in the auditory brainstem. Additionally, VCN axons fail to reach the midline in animals carrying no functional copies of the netrin-1 or DCC allele, indicating that a functional netrin-DCC signaling system is necessary for appropriate VCN axon guidance. In Chapter 3, we go further and show that DCC, robo1, and

robo2 are also expressed in SOC nuclei in a manner that is capable of directing the migration of these nuclei into their adult locations. Furthermore, we show that the netrin-DCC signaling pathway is necessary for the correct medial-lateral patterning for at least one auditory and two midbrain nuclei. Therefore, the potential exists that this signaling pathway, and perhaps the slit-robo pathway as well, is necessary for directing the migration and thus the medial-lateral position of multiple nuclei throughout the central nervous system.

\section{Guidance of VCN axons}

Like SCNs, VCN neurons require a functional netrin-DCC signaling system to reach the ventral midline (Fazeli et al., 1997; Chapter 2: Howell et al., 2007; Serafini et al., 1996). However, some SCNs are able to cross the ventral midline in the absence of netrin-DCC signaling, although no VCN axons extend further than a lateral region of the ipsilateral SOC (Fazeli et al., 1997; Chapter 2: Howell et al., 2007; Serafini et al., 1996;). Additional signaling molecules are utilized by SCNs to mediate the axonal extension toward the floor plate (Augsburger et al., 1999; Charron et al., 2003). These additional signaling molecules are unique in that they were previously identified as morphogens. Dorsal expression of GDF7/BMP7 
functions as a repellant to orient SCN axons toward the ventral spinal cord (Augsburger et al., 1999). To facilitate ventrally directed axons, SCNs are also attracted to Shh at the floor plate (Charron et al., 2003). In the spinal cord, these independent signaling systems, netrin-DCC, Shh and GDF7/BMP7, all cooperate to get SCN axons to the midline.

A similar cooperation may function in the guidance of $\mathrm{VCN}$ axons to the midline. In DCC- and netrin-1-deficient animals, when axons were found to exit the VCN, they always exited in the VAS; dorsally oriented axons were never observed (data not shown and Chapter 2: Howell et al., 2007). Similarly, Poe and BrunsoBechtold (1998) found a diffusible compound other than netrin-1 is produced at the floor plate that attracts VCN axons. Therefore, other attractants are present in the brainstem and an additional activity appears necessary for VCN axons to enter the VAS. That additional activity may be a morphogen(s). The midline of the auditory brainstem expresses RNAs for Shh during initial VCN axon pathfinding (unpublished observations, DMH and PHM). However, like SCN axons, VCN axons could also be directed ventrally through the expression of a chemorepellent in the dorsal midline that could be a classical axon guidance repellent such as a slit family member or a morphogen such as a BMP family member. The utilization of a slit family member as a guidance cue in an axon that has not crossed the midline is unlikely to have a functional slit-robo repellant signaling system (see introduction and discussed further below). A possible combination of cues in this system would be the expression of a BMP family member at the dorsal midline that would act cooperatively with Shh at the ventral midline. VCN axons would then be pushed from behind through a BMPmediated chemorepellent and pulled toward the floorplate by a Shh-mediated chemoattractant. The presence of these additional cues may mediate the initial extension of VCN axons toward the VAS. These cooperative interactions to establish a ventrally directed pathway would explain the observed lack of dorsally misdirected VCN axons in animals carrying no functional copies of the netrin-1 or DCC allele. However, the failure of axons to exit the $\mathrm{VCN}$ in $84 \%$ of the brainstems carrying no functional copies of the netrin-1 or DCC allele is still unexplained (Chapter 2: Howell et al., 2007). 
The midline represents an important intermediate target for all commissural axons. A mechanism for commissural axons to extend through this environment has been proposed (Stein and Tessier-Lavigne, 2001). This mechanism turns off midline attractive signals from netrin-1 through the DCC receptor while preserving the growth stimulatory effect of signaling through the DCC receptor (Stein and TessierLavigne, 2001). An additional mechanism to mediate crossing the midline occurs through robo3/rig-1 expression on commissural axons (Sabatier et al., 2004). Robo3/rig-1 prevents commissural axons from responding to slit family members prior to crossing the midline (Sabatier et al., 2004). Alternative splicing of robo3/rig-1 transcripts at the midline appears to mediate a switch in this receptor from silencing slit to slit-mediated repulsion that is necessary for an axon to extend through the midline (Chen et al., 2008). Furthermore, the brains of mice lacking robo3/rig-1 functional alleles have a large number of projections that fail to reach the midline (Sabatier et al., 2004). Additionally, mutations in the human $R O B O 3$ gene produce multiple midline-crossing defects, but these defects are not lethal (Amoiridis et al., 2006). A functional analysis of the auditory system in these patients is limited to auditory brain stem-evoked potentials. These studies indicated an absence of the trapezoid body or a large number of connections from the VCN to the contralateral SOC, including the calyceal projection, that are important for sound localization (Amoiridis et al., 2006). However, ipsilateral and contralateral central auditory circuits are preserved between nuclei rostral to the SOC (Amoiridis et al., 2006). We know that mouse VCN neurons express RNAs for robo1 and robo2, but expression in the cochlear nucleus has not been reported for robo3/rig-1. Although the required components for a functional slit-robo signaling system are present, the requirement for slit-robo signaling has not yet been established for midline crossing of VCN axons.

Unlike SCNs, the VCN is comprised of multiple cell types that each project an axon across the midline. In the trapezoid body, GBC axons preferentially cross near the ventral surface with SBC and multipolar cell axons crossing at a more dorsal location. The differential expression of robo1 and robo2 by the different cell types of the VCN may mediate this crossing behavior at the midline by specifying the 
distance from the ventral-most extent of the floor plate. Alternatively, axons expressing the same complement of receptors may cluster together or fasciculate during the formation of these projections. An analysis of VCN axonal trajectories in mice carrying no functional copies of robo1, robo2 or robo3 alleles should be performed to determine if slit-robo signaling is required for proper midline crossing. In the spinal cord, slits act redundantly to prevent inappropriate midline crossing. Only slit-1 expression has been reported in the midline of the brainstem (Chapter 2: Howell et al., 2007). However, other slit family members may be expressed at this location. Similarly, an analysis of VCN axonal trajectories in mice carrying no functional copies of slit-1, slit-2, slit-3 or a combination of slit alleles should be performed to define the role of slit-robo signaling in the guidance of VCN axons at the midline. The same factors that participate in VCN midline crossing events at this location are likely to be used by SOC neurons to establish neural circuits. SOC neurons form a complex array of ipsilateral and contralateral connections that are necessary to compute the location of a sound source in three-dimensional space. Currently, the factors that participate in the formation of mammalian SOC circuits are completely unexplored.

Once in the contralateral brainstem, many developing $\mathrm{VCN}$ axons extend in a rostral, lateral and dorsal direction to travel in the lateral lemniscus toward the inferior colliculus. Only two guidance systems are known mediate rostral-caudal or anterior-posterior axon guidance (Bourikas et al., 2005; Liu et al., 2005; Lyuksyutova et al., 2003). The Wnt family can function as an axonal attractant or repellant (Lyuksyutova et al., 2003). Therefore, a Wnt family member that generates an attractive response from VCN axons would be expressed in an increasing posteriorto-anterior gradient while a Wnt family member that generates a repulsive response would be expressed in an increasing anterior-to-posterior gradient. Shh functions as a chemorepellent for post-crossing commissural axons (Bourikas et al., 2005). Therefore, Shh would be expected to push VCN axons up the lateral lemniscus through the expression of a decreasing posterior to anterior gradient of Shh. Therefore, either or possibly both Shh and a Wnt family member could mediate this process. An understanding of the guidance factor(s) directing axons rostrally and 
caudally is important for the development of ascending and descending auditory circuits.

No signaling system has been identified for a number of VCN axon guidance steps. The initial extension of VCN axons occurs in the absence of a functional netrin-DCC signaling system indicating the potential utilization of additional guidance cues (Howell et al., 2007). Additionally, the guidance cues that are mediate VCN axonal extension through the midline or facilitate these axons to take a rostral turn toward the lateral lemniscus have not been entirely established. However, a number of candidate molecules have been identified that may participate in these developmental steps, but they have yet to be tested. A more complete understanding of the signaling necessary to establish auditory circuits may yield novel therapeutic approaches toward the repair/regeneration of damaged pathways. Additionally, these approaches may be applicable toward the repair/regeneration of numerous CNS circuits, since circuits throughout the CNS utilize these guidance cues for proper development.

\section{Medial-lateral positioning of SOC neurons}

Like developing axons, neurons utilize the same complement of signaling systems to reach their adult location in the developing nervous system. The developmental origins of the SOC are currently not known and therefore, the migratory route taken by these neurons is not clear. We have shown that RNAs for the guidance receptors $D C C$, robo1 and robo2 are expressed by multiple populations of SOC neurons (Chapter 3: Figure 5 and Supplemental Figure 4). A column of cells appears to extend from the rostral extent of the brainstem to the level of the SOC for each of these guidance receptors. These columns resemble the appearance of the migratory stream that populates the pontine nuclei (Chapter 3 : Figure 5). The presence of these columns suggests that SOC neurons are born in the rostral brainstem and undergo a rostral-to-caudal migration to populate the SOC. These columns are present as early as E13.5. However, SOC neurons in mice are born between E9 and E14 (Pierce, 1973). We observe a stepwise progression of the pontine migratory stream that takes 2 to 3 days for the earliest migrating neurons to 
reach the pontine nuclei (Chapter 3: Figure 5). This migratory path would be similar in distance to the route proposed for caudally migrating SOC neurons, but no stepwise progression is ever observed for these columns of guidance receptors on the ventral surface of the brainstem. Although SOC neurons would have sufficient time to reach the level of the future SOC; no direct evidence exists that these columns represent migrating cells. Further study will be necessary to identify the birth location of these neurons and characterize the migratory route they take to populate the SOC.

Medial and lateral changes in the developmental staining patterns of these guidance receptors does support a roll for a migratory process within the SOC. Expression of these guidance receptors becomes progressively restricted to specific domains as development progresses, suggesting that a once mixed population of cells is separating to form distinct nuclei that comprise the SOC. The combination of DCC, robo1 and robo2 receptors present on these migrating cells may specify the location of discrete SOC nuclei relative to the midline through the integration of attractive and repulsive signals that each cell receives. Precedence for medial-lateral patterning with guidance receptors is found in the Drosophila nervous system where three longitudinal tracts on each side of the midline are positioned by differential expression of robo receptors (Long et al., 2004; Rajagopalan et al., 2000; Simpson et al., 2000). The most medial tract expresses only robo, the middle tract expresses robo and robo3 receptors and the lateral tract expresses robo, robo2 and robo3 receptors (Rajagopalan et al., 2000; Simpson et al., 2000). In this system, axons experience a net repulsion from the midline that is dependent on the complement and number of receptors that are expressed. In an analogous system, mouse SCN axons that have crossed the midline appear to segregate in the lateral funiculus (LF) according to the complement of robo receptors expressed on each axon (Long et al., 2004). Axons expressing only robo1 are located in a medial region of the LF and axons expressing only robo2 are located in a lateral region of the LF; however, axons expressing both robo1 and robo2 position at an intermediate distance in the LF (Long et al., 2004). Furthermore, deletion of robo1 results in a larger number of axons that position laterally in the LF and conversely, deletion of robo2 produces an 
increase in the number of axons that position medially in the LF. This model accounts for the changes that are observed in the LF in mice lacking functional copies of the robo1 or robo2 allele. Therefore, Drosophila and mice appear to utilize a similar combination of guidance receptors to specify, relative to the midline, the medial-lateral location of a tract and the location of axons that travel within that tract, respectively.

However, a model to explain medial-lateral position of SOC neurons requires the presence of attractant (DCC) and repellent receptors (robo1 and robo2). A more applicable model occurs in the developing Drosophila salivary gland. During development, Drosophila salivary gland precursor cells undergo a posterior migration that is parallel to the CNS midline. A balance of chemoattractant, netrinfrazzled, and chemorepellent, slit-robo, activities facilitates parallel migration of the salivary glands in the wild-type (Kolesnikov and Beckendorf, 2005). The salivary glands are directed laterally when netrin-frazzled signaling is disrupted, while medial movements occur when slit-robo signaling is disrupted. Additionally, ectopic expression of netrin or slit resulted in movement of the salivary gland toward or away from, respectively, the ectopic expression (Kolesnikov and Beckendorf, 2005).

Using these models as guides, we propose a model for the positioning of SOC neurons relative to the midline through the combinatorial expression of attractive and repulsive guidance receptors (Figure 1). Central to this model is that a cell integrates the attractive and repulsive signals to determine a net directional cue that specifies the location a cell will reside relative to the midline. Support for this model resides in the expression profiles of the guidance receptors during development, a similar positioning scheme for longitudinal axons in Drosophila, the utilization of chemoattractant and chemorepellents to position the Drosophila salivary gland and the presence of a laterally displaced MNTB after the loss of only one functional copy of the $D C C$ allele. We found that mice carrying only one functional copy of the DCC allele have half the quantity of DCC protein present in wild-type controls (Chapter 3: Figure 4). A reduction in the number of DCC receptors is expected to produce a net loss of midline-attractant activity. Therefore, cells that utilize this ligand-receptor signal to determine medial-lateral position are displaced 
laterally. In the SOC, the neurons that comprise the MNTB express DCC and loss of one functional copy of the $D C C$ allele displaces the MNTB laterally. This positional change is similar to changes in the Drosophila salivary gland when netrin-frazzled signaling is disrupted thereby supporting a role for netrin-DCC signaling in specifying the medial-lateral position of the MNTB.

To further characterize our model for determining the medial-lateral position of SOC neurons, further variations in the levels of attractant and repellent receptors should be examined. An additional analysis could be performed in compound heterozygous animals that carry one functional copy of both the netrin-1 and DCC alleles. Compound heterozygous animals for netrin-1 and DCC are expected to cause a larger disruption of the SOC than observed for either of the individual heterozygous animals. Specifically, MNTB neurons in adult compound heterozygous animals are expected to position at a more lateral location than the location of MNTB neurons in mice carrying only one functional copy of the $D C C$ allele due to the potential decrease in the midline-derived attractant netrin-1. The extreme positioning expected for MNTB neurons in compound heterozygous animals may disrupt the architecture of adjacent SOC nuclei, thereby complicating their identification and possibly affecting the topography of SOC nuclei. In this case, neurons responsive to low frequencies are farthest from the typical location of the MNTB and likely reside within other SOC nuclei. Sufficient plasticity may not exist to compensate for these obstacles. The organization of functional inputs to the displaced MNTB could be assessed by c-fos immunohistochemistry on compound heterozygous mice presented with pure-tone stimuli.

A key component of our medial-lateral positioning model accounts for the presence of robo1 and robo2 receptors in the developing SOC. Therefore, it would be equally useful to study the architecture of the SOC in mice lacking functional copies of robo1, robo2 or robo3 alleles. According to our model, mice lacking functional copies of the robo1 allele may displace cells medially and laterally depending on the complement of receptors present on a given cell. Loss of robo1 from a population of cells that expressed $D C C$ and robo1 results in the loss of a midline repellent which might produce a medial displacement due to the continued 
expression of the $D C C$ receptor. Conversely, loss of robo1 from a population of cells expressing robo1 and robo2 with/without $D C C$ is proposed to cause these cells to reside in a more lateral region due to the expression of robo2. Loss of robo2 function should result in a net loss of chemorepellent activity that will medially displace structures that are dependant on robo2 activity for positioning. Analysis of the SOC in adult mice carrying only one functional copy of the robo1, robo2 and robo3 should employ similar methods to those used in the analysis of $D C C$-heterozygous animals, including the quantification of protein levels. In these animals, the lateral regions of the SOC are expected to have the greatest positional change. We have shown that MNTB neurons express robo1 (Chapter 3: Supplemental figure 4). Therefore, according to our model, mice carrying no functional copies of the robo1 allele are expected to have a medially displaced MNTB. Further characterization of the role each of these signaling systems plays in the development of the central auditory system is necessary to improve our understanding of auditory circuit development. Additionally, this model for medial-lateral positioning in the auditory brainstem appears to extend to other portions of the central nervous system. The trochlear and ventral tegmental nucleus are displace medially and laterally in mice carrying only one functional copy of the DCC allele (Chapter 3: Figure 7). The trochlear nucleus neurons are believed to co-express DCC and Unc5 receptors that produce a repellent signal in the presence of netrin-1. These neurons experience a net loss of a midline repellent that results in the medial displacement of these neurons. Like the MNTB, the ventral tegmental nucleus is displaced laterally in animals carrying only one functional copy of the DCC allele. Taken together, the utilization of attractive and repulsive guidance cues may represent a general strategy to establish mediallateral patterning of the central nervous system. Understanding the mechanisms that were utilized in the development of a central nervous system pathway may lead to a better approach toward repairing the pathway in the diseased state.

\section{Clinical significance of guidance cues and disease processes}

The DCC receptor may play an important role in dopaminergic neural development, as well as, an additional function in the adult that is necessary for the 
maintenance of these circuits (Lin et al., 2009; Livesey and Hunt, 1997; Volenec et al., 1997). Adult mice carrying only one functional copy of the $D C C$ allele failed to sensitize to repeated amphetamine administration (Flores et al., 2005). The lack of a response to amphetamine, an indirect dopaminergic agonist, was associated with a reduction in the number of midbrain dopaminergic neurons and alterations in dopamine metabolism (Flores et al., 2005; Grant et al., 2007). These animals have increased dopaminergic activity in the medial prefrontal cortex that may explain the reduction of dopamineric activity in the nucleus accumbens. Reduced dopamine transmission in the nucleus accumbens may blunt behavioral responses and prevent sensitization to the effects of amphetamine and possibly other drugs of abuse (Flores et al., 2005; Mitchell and Gratton, 1992; Prasad et al., 1999; Sorg et al., 1997; Sorg et al., 2001). Drugs of abuse mediate their acute reinforcing rewarding behaviors through activation of the mesocorticolimbic system circuits, particularly the ventral tegmental area and nucleus accumbens (reviewed in Adinoff, 2004 and Feltenstein and See, 2008; Salamone et al., 1997). Current research models propose that altered development of these neural circuits occurs in response to the reduced levels of DCC protein present in animals lacking one functional copy of the DCC allele (Flores et al., 2005; Grant et al., 2007; Howell et al., 2007). The potential alterations in the development of dopaminergic neurons throughout the brain have implications for the study and treatment of diseases like schizophrenia and substance abuse (Flores et al., 2009; Kapur, 2003; Lewis and Levitt, 2002; MeyerLindenberg et al., 2002). Additionally, a recent study found that single nucleotide polymorphisms in axon guidance genes were predictive of susceptibility, survival free of disease and age at onset of disease for Parkinson's disease and amyotrophic lateral sclerosis (Lesnick et al., 2008; Lin et al., 2009). Defining the mechanism of these genetic changes may provide valuable insight into the development of these debilitating diseases. Understanding the formation of these neural circuits will hopefully lead to a better understanding of how disease affects these circuits thereby allowing the development of novel treatment modalities that even includes the repair or regeneration of damaged pathways. 
Figures

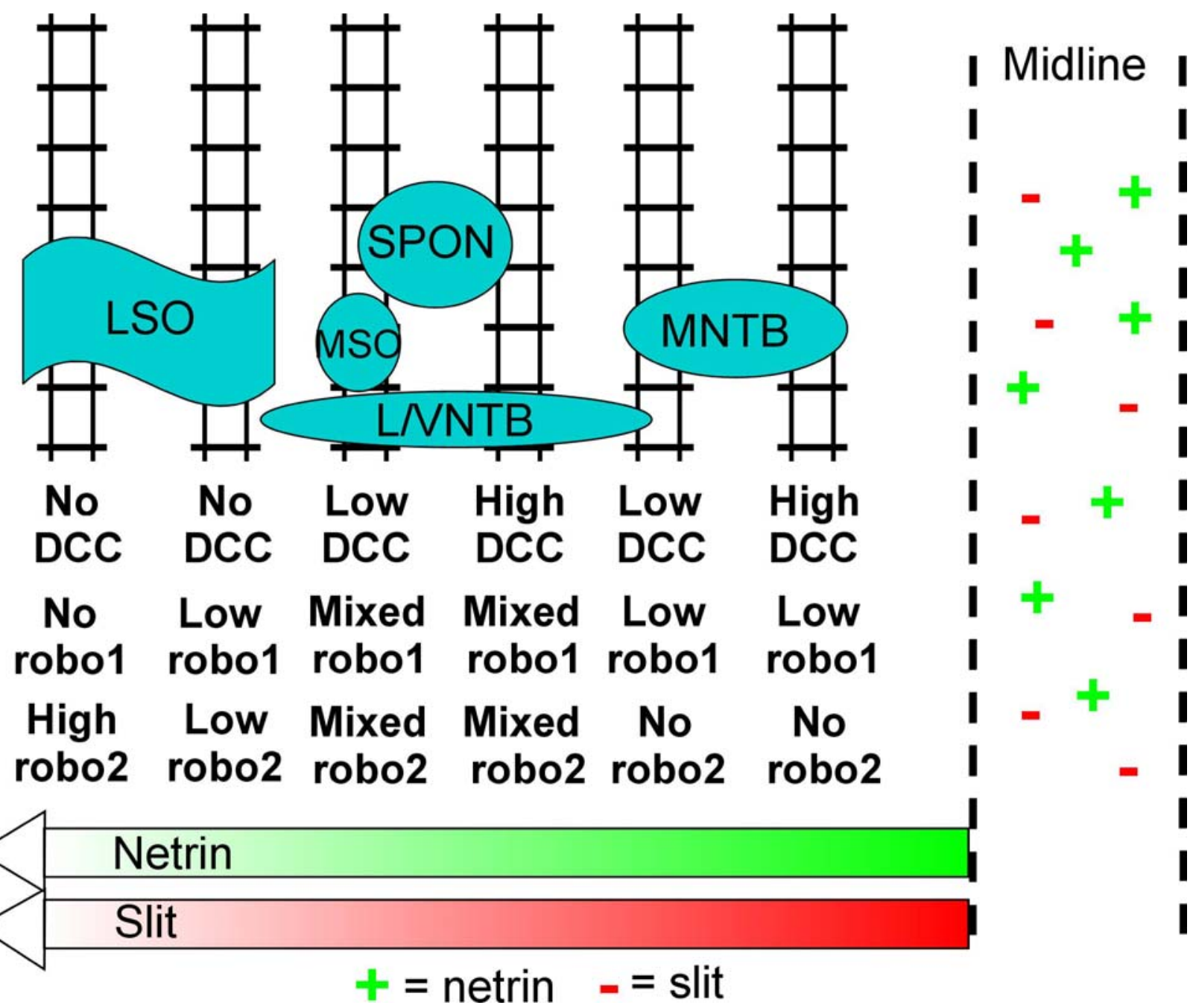

Figure 1. Proposed model establishing the relative position of SOC neurons with guidance receptors. Cells expressing DCC will position medially. Cells expressing robo1 or robo2 will position laterally. Similar to axons in the lateral funiculus, cells expressing robo2 will position lateral to those expressing robo1 with cells expressing robo1 and robo2 residing at an intermediate location. Furthermore, these positions will be modulated by the level of expression; cells with high levels of DCC will position medial to cells with low levels of DCC and cells with high levels of robo receptors will position lateral to cells with low levels of robo receptors. Multiple bands of DCC, robo1 and robo2 expression are visualized within the SOC with antisense RNA probes. The relative expression levels in the model reflect the labeling patterns 
we observe. The MNTB does express DCC and robo1 RNAs, however we are unable to identify the expression domains in the lateral SOC. These nuclei are placed in the model according to their medial-lateral location within the SOC. All components of the SOC are not currently represented. Midline is indicated, netrin-1 (green plus sign) and slit-1 (red minus sign) are produced at the midline and establish a high medial-to-lower lateral gradient (arrows). Abbreviations: LSO, lateral superior olivary nucleus; L/VNTB , lateral/ventral nucleus of the trapezoid body; MNTB, medial nucleus of the trapezoid body; MSO, medial superior olivary nucleus; SPON, superior paraolivary nucleus. 


\section{Literature Cited}

Adinoff, B. (2004). Neurobiologic processes in drug reward and addiction. Harv Rev Psychiatry 12, 305-320.

Amoiridis, G., Tzagournissakis, M., Christodoulou, P., Karampekios, S., Latsoudis, H., Panou, T., Simos, P., and Plaitakis, A. (2006). Patients with horizontal gaze palsy and progressive scoliosis due to ROBO3 E319K mutation have both uncrossed and crossed central nervous system pathways and perform normally on neuropsychological testing. J Neurol Neurosurg Psychiatry 77, 1047-1053.

Augsburger, A., Schuchardt, A., Hoskins, S., Dodd, J., and Butler, S. (1999). BMPs as mediators of roof plate repulsion of commissural neurons. Neuron 24, 127-141.

Bourikas, D., Pekarik, V., Baeriswyl, T., Grunditz, A., Sadhu, R., Nardo, M., and Stoeckli, E. T. (2005). Sonic hedgehog guides commissural axons along the longitudinal axis of the spinal cord. Nat Neurosci 8, 297-304.

Charron, F., Stein, E., Jeong, J., McMahon, A. P., and Tessier-Lavigne, M. (2003). The morphogen sonic hedgehog is an axonal chemoattractant that collaborates with netrin-1 in midline axon guidance. Cell 113, 11-23.

Chen, Z., Gore, B. B., Long, H., Ma, L., and Tessier-Lavigne, M. (2008). Alternative splicing of the Robo3 axon guidance receptor governs the midline switch from attraction to repulsion. Neuron 58, 325-332.

Fazeli, A., Dickinson, S. L., Hermiston, M. L., Tighe, R. V., Steen, R. G., Small, C. G., Stoeckli, E. T., Keino-Masu, K., Masu, M., Rayburn, H., et al. (1997). Phenotype of mice lacking functional Deleted in colorectal cancer (Dcc) gene. Nature 386, 796804.

Feltenstein, M. W., and See, R. E. (2008). The neurocircuitry of addiction: an overview. Br J Pharmacol 154, 261-274.

Flores, C., Bhardwaj, S. K., Labelle-Dumais, C., and Srivastava, L. K. (2009). Altered netrin-1 receptor expression in dopamine terminal regions following neonatal ventral hippocampal lesions in the rat. Synapse 63, 54-60.

Flores, C., Manitt, C., Rodaros, D., Thompson, K. M., Rajabi, H., Luk, K. C., Tritsch, N. X., Sadikot, A. F., Stewart, J., and Kennedy, T. E. (2005). Netrin receptor deficient mice exhibit functional reorganization of dopaminergic systems and do not sensitize to amphetamine. Mol Psychiatry 10, 606-612. 
Grant, A., Hoops, D., Labelle-Dumais, C., Prevost, M., Rajabi, H., Kolb, B., Stewart, J., Arvanitogiannis, A., and Flores, C. (2007). Netrin-1 receptor-deficient mice show enhanced mesocortical dopamine transmission and blunted behavioural responses to amphetamine. Eur J Neurosci 26, 3215-3228.

Howell, D. M., Morgan, W. J., Jarjour, A. A., Spirou, G. A., Berrebi, A. S., Kennedy, T. E., and Mathers, P. H. (2007). Molecular guidance cues necessary for axon pathfinding from the ventral cochlear nucleus. J Comp Neurol 504, 533-549.

Kapur, S. (2003). Psychosis as a state of aberrant salience: a framework linking biology, phenomenology, and pharmacology in schizophrenia. Am J Psychiatry 160, 13-23.

Kolesnikov, T., and Beckendorf, S. K. (2005). NETRIN and SLIT guide salivary gland migration. Dev Biol 284, 102-111.

Lesnick, T. G., Sorenson, E. J., Ahlskog, J. E., Henley, J. R., Shehadeh, L., Papapetropoulos, S., and Maraganore, D. M. (2008). Beyond Parkinson disease: amyotrophic lateral sclerosis and the axon guidance pathway. PLoS ONE 3, e1449.

Lewis, D. A., and Levitt, P. (2002). Schizophrenia as a disorder of neurodevelopment. Annu Rev Neurosci 25, 409-432.

Lin, L., Lesnick, T. G., Maraganore, D. M., and Isacson, O. (2009). Axon guidance and synaptic maintenance: preclinical markers for neurodegenerative disease and therapeutics. Trends Neurosci.

Liu, Y., Shi, J., Lu, C. C., Wang, Z. B., Lyuksyutova, A. I., Song, X. J., and Zou, Y. (2005). Ryk-mediated Wnt repulsion regulates posterior-directed growth of corticospinal tract. Nat Neurosci 8, 1151-1159.

Livesey, F. J., and Hunt, S. P. (1997). Netrin and netrin receptor expression in the embryonic mammalian nervous system suggests roles in retinal, striatal, nigral, and cerebellar development. Mol Cell Neurosci 8, 417-429.

Long, H., Sabatier, C., Ma, L., Plump, A., Yuan, W., Ornitz, D. M., Tamada, A., Murakami, F., Goodman, C. S., and Tessier-Lavigne, M. (2004). Conserved roles for Slit and Robo proteins in midline commissural axon guidance. Neuron 42, 213-223.

Lyuksyutova, A. I., Lu, C. C., Milanesio, N., King, L. A., Guo, N., Wang, Y., Nathans, J., Tessier-Lavigne, M., and Zou, Y. (2003). Anterior-posterior guidance of commissural axons by Wnt-frizzled signaling. Science 302, 1984-1988. 
Meyer-Lindenberg, A., Miletich, R. S., Kohn, P. D., Esposito, G., Carson, R. E., Quarantelli, M., Weinberger, D. R., and Berman, K. F. (2002). Reduced prefrontal activity predicts exaggerated striatal dopaminergic function in schizophrenia. Nat Neurosci 5, 267-271.

Mitchell, J. B., and Gratton, A. (1992). Partial dopamine depletion of the prefrontal cortex leads to enhanced mesolimbic dopamine release elicited by repeated exposure to naturally reinforcing stimuli. J Neurosci 12, 3609-3618.

Pierce, E. T. (1973). Time of origin of neurons in the brain stem of the mouse. Prog Brain Res 40, 53-65.

Poe, B. H., and Brunso-Bechtold, J. K. (1998). Directed outgrowth from a subset of cochlear nucleus fibers in a collagen-gel matrix. Brain Res Dev Brain Res 105, 153157.

Prasad, B. M., Hochstatter, T., and Sorg, B. A. (1999). Expression of cocaine sensitization: regulation by the medial prefrontal cortex. Neuroscience 88, 765-774.

Rajagopalan, S., Vivancos, V., Nicolas, E., and Dickson, B. J. (2000). Selecting a longitudinal pathway: Robo receptors specify the lateral position of axons in the Drosophila CNS. Cell 103, 1033-1045.

Sabatier, C., Plump, A. S., Le, M., Brose, K., Tamada, A., Murakami, F., Lee, E. Y., and Tessier-Lavigne, M. (2004). The divergent Robo family protein rig-1/Robo3 is a negative regulator of slit responsiveness required for midline crossing by commissural axons. Cell 117, 157-169.

Salamone, J. D., Cousins, M. S., and Snyder, B. J. (1997). Behavioral functions of nucleus accumbens dopamine: empirical and conceptual problems with the anhedonia hypothesis. Neurosci Biobehav Rev 21, 341-359.

Serafini, T., Colamarino, S. A., Leonardo, E. D., Wang, H., Beddington, R., Skarnes, W. C., and Tessier-Lavigne, M. (1996). Netrin-1 is required for commissural axon guidance in the developing vertebrate nervous system. Cell 87, 1001-1014.

Simpson, J. H., Bland, K. S., Fetter, R. D., and Goodman, C. S. (2000). Short-range and long-range guidance by Slit and its Robo receptors: a combinatorial code of Robo receptors controls lateral position. Cell 103, 1019-1032.

Sorg, B. A., Davidson, D. L., Kalivas, P. W., and Prasad, B. M. (1997). Repeated daily cocaine alters subsequent cocaine-induced increase of extracellular dopamine in the medial prefrontal cortex. J Pharmacol Exp Ther 281, 54-61. 
Sorg, B. A., Li, N., and Wu, W. R. (2001). Dopamine D1 receptor activation in the medial prefrontal cortex prevents the expression of cocaine sensitization. J Pharmacol Exp Ther 297, 501-508.

Stein, E., and Tessier-Lavigne, M. (2001). Hierarchical organization of guidance receptors: silencing of netrin attraction by slit through a Robo/DCC receptor complex. Science 291, 1928-1938.

Volenec, A., Bhogal, R. K., Moorman, J. M., Leslie, R. A., and Flanigan, T. P. (1997). Differential expression of DCC mRNA in adult rat forebrain. Neuroreport 8, 29132917. 


\section{Appendix A}

\section{Protein Expression in the Developing Superior Olive and Ventral Cochlear Nucleus}




\section{Protein Expression in the Developing Superior Olive and Ventral Cochlear Nucleus}

Warren J. Morgan ${ }^{1,2}$, David M. Howell ${ }^{1,2}$, Albert S. Berrebi ${ }^{1,3,4}$, George A. Spirou $^{1,3,5}$, and Peter H. Mathers ${ }^{1,2,3}$

1) Sensory Neuroscience Research Center, West Virginia University, Morgantown, West Virginia 26506, USA;

2) Department of Biochemistry, West Virginia University, Morgantown, West Virginia 26506, USA;

3) Department of Otolaryngology, West Virginia University, Morgantown, West Virginia 26506, USA;

4) Department of Neurobiology and Anatomy, West Virginia University, Morgantown, West Virginia 26506, USA;

5) Department of Physiology and Pharmacology, West Virginia University, Morgantown, West Virginia 26506, USA

This manuscript is in preparation for submission. 


\section{Abstract}

Development of the mammalian central auditory system is well characterized at a molecular level, particularly during embryogenesis and early postnatal stages. Previous studies have provided us with information on the timing of neurogenesis and origins of cells populating some of the central auditory structures (Farago et al., 2006; Taber-Pierce, 1966; Taber-Pierce, 1967). Investigation of these regions early in development is complicated by the lack of known central auditory markers. Multiple proteins are expressed in the superior olivary complex (SOC) and the cochlear nucleus $(\mathrm{CN})$, and these proteins have served as useful region-specific markers. However, very few markers are known for embryonic and early postnatal stages of the auditory brainstem and even fewer have been investigated throughout development. Therefore, we reasoned that identification of markers of auditory brainstem development would be useful to further our understanding of this crucial system. To this end, we have identified four proteins which label nuclei of the presumptive SOC or ventral cochlear nucleus ( $\mathrm{VCN})$ at various stages of development from embryo through adult. MafB is expressed in the VCN and has varying age-dependant expression in regions of the SOC, including the medial superior olive (MSO), lateral superior olive (LSO), superior paraolivary nucleus (SPON) and lateral nucleus of the trapezoid body (LNTB) from embryonic day 13.5 through adult. Sox2 is expressed in the ventral and medial nuclei of the trapezoid body (VNTB and MNTB) and the LNTB from embryonic ages through adulthood while expression in the VCN is only observed in adults. Kip2 expression varies through development with expression in the MSO in early neonates and in the 
MNTB in the adult. Finally, Pax6 is expressed exclusively in the LNTB around the day of birth. These markers will aid in the study of the specific auditory nuclei where they are expressed across multiple developmental stages. 


\title{
Curriculum Vitae
}

\section{David Michael Howell}

\author{
1011 Autumn Ave \\ Morgantown, WV 26508 \\ Preferred Phone: (304) 692-3529 \\ Email: dhowell1@mix.wvu.edu \\ Email: dhowell1@gmail.com
}

\section{Medical Education}

West Virginia University School of Medicine, Morgantown, West Virginia

08/1998 - Present

M.D./Ph.D. program, 05/2009

Ph.D. Advisor: Dr. Peter H. Mathers - Dept. of Biochemistry

Dissertation: Identification of molecular guidance cues necessary for development of the central auditory system.

\section{Education}

Undergraduate - Virginia Polytechnic Institute and State University, Blacksburg, VA 08/1994 - 05/1998

Biochemistry B.S., 05/1998 - Summa Cum Laude

Chemistry B.A., 05/1998 - Summa Cum Laude

\section{Examinations}

Ph. D. defense: Passed - 02/2009

USMLE Step 2 CS (Clinical Skills): Passed - 08/2008

USMLE Step 2 CK (Clinical Knowledge): Passed - 05/2008

Ph. D. oral qualifying examination: Passed - 05/2001

USMLE Step 1: Passed - 06/2000

\section{Work Experience}

05/1996 - 08/1996 Average Hours/Week: 35

Columbia Saint Francis Hospital, West Virginia

Pathology laboratory technician, Dr. E. A. Hansbarger

\section{Research Experience}

07/2000 - 12/2006 Average Hours/Week: 60

West Virginia University Dept of Biochemistry, West Virginia

Graduate Student - Ph.D. candidate, Dr. Peter H. Mathers

Dissertation: Identification of molecular guidance cues necessary for development of the central auditory system. 
09/1996 - 08/1998 Average Hours/Week: 20-30

Virginia Tech Dept of Biochemistry, Virginia

Undergraduate research, Dr. Robert White

Area of interest: Identification of enzymatic reaction pathways necessary for cofactor biosynthesis in Archaea bacteria

\section{Teaching Experience}

Teaching assistant - MS1 Biochemistry Small Group - 2000 and 2001

\section{Publications}

Howell, DM., Morgan, WJ., Spirou, GA., Berrebi, AS., Mathers. Guidance Cues Regulating Medial-Lateral Positioning of Midbrain and Hindbrain Nuclei. In preparation.

Morgan, WJ., Howell, DM., Berrebi, AS., Spirou, GA., Mathers, PH. Protein Expression in the Developing Superior Olive and Ventral Cochlear Nucleus. In preparation.

Howell, DM., Morgan, WJ., Jarjour, AA., Spirou, GA., Berrebi, AS., Kennedy, TE., Mathers, $\mathrm{PH}$. Molecular guidance cues necessary for axon pathfinding from the ventral cochlear nucleus. Journal of Comparative Neurology. 2007 Oct; 504(5): 533549. Cited in PubMed; PMID: 17701984.

Howell, DM., Graupner, M., Xu, H., White, RH. Identification of enzymes homologous to isocitrate dehydrogenase that are involved in coenzyme $\mathrm{B}$ and leucine biosynthesis in methanoarchaea. Journal of Bacteriology. 2000 Sep; 182(17): 5013. Cited in PubMed; PMID: 10940051.

Howell, DM., Xu, H., White, RH. (R)-citramalate synthase in methanogenic archaea. Journal of Bacteriology. 1999 Jan; 181(1): 331-333. Cited in PubMed; PMID: 9864346.

Howell, DM., Harich, K., Xu, H., White, RH. Alpha-keto acid chain elongation reactions involved in the biosynthesis of coenzyme $\mathrm{B}$ (7-mercaptoheptanoyl threonine phosphate) in methanogenic Archaea. Biochemistry. 1998 Jul; 37(28): 10108-10117. Cited in PubMed; PMID: 9665716.

Howell, DM., White, RH. D-erythro-neopterin biosynthesis in the methanogenic archaea Methanococcus thermophila and Methanobacterium thermoautotrophicum deltaH. Journal of Bacteriology. 1997 Aug; 179(16): 5165-5170. Cited in PubMed; PMID: 9260960. 


\section{Oral Presentations}

Howell, DM. (2004, May). The identification of molecular guidance cues necessary for the development of the central auditory system. Oral Presentation presented at: Society for Developmental Biology - Mid-Atlantic Meeting; Pittsburgh, PA.

Howell, DM. (2003, April). Analysis of Molecular Guidance Cues Directing Axon Extension from the Ventral Cochlear Nucleus. Oral Presentation presented at: WVU HSC E.J. Van Liere Convocation and Research Day; Morgantown, WV.

\section{Poster Presentations}

Howell, DM. (2006, April). Identification of Guidance Molecules Necessary for the Formation of the Superior Olivary Complex. Poster presented at: WVU HSC E.J. Van Liere Convocation and Research Day; Morgantown, WV.

Howell, DM., Morgan, WJ., Berrebi, AS., Spirou, GA., Mathers, PH. (2006, February). Identification of Guidance Molecules Necessary for the Formation of the Superior Olivary Complex. Poster presented at: The Association for Research in Otolaryngology 29th Midwinter Research Meeting; Baltimore, MD.

Howell, DM. (2005, April). Understanding the Developmental Origins of the Mammalian Superior Olivary Complex. Poster presented at: WVU HSC E.J. Van Liere Convocation and Research Day; Morgantown, WV.

Howell, DM., Morgan, WJ., Berrebi, AS., Spirou, GA., Mathers, PH. (2005, February). Understanding the Developmental Origins of the Mammalian Superior Olivary Complex. Poster presented at: The Association for Research in Otolaryngology 28th Midwinter Meeting; New Orleans, LA.

Howell, DM. (2004, May). The identification of molecular guidance cues necessary for the development of the central auditory system. Poster presented at: Society fo Developmental Biology - Mid-Atlantic Meeting; Pittsburgh, PA.

Howell, DM., Berrebi, AS., Spirou, GA., Mathers, PH. (2004, February). Identification of Molecular Guidance Cues Necessary for the Formation of the Calyx of Held. Poster presented at: The Association for Research in Otolaryngology 27th Midwinter Meeting; Daytona, FL.

Howell, DM., Berrebi, AS., Spirou, GA., Mathers, PH. (2003, July). Analysis of Molecular Guidance Cues Directing Axon Extension from the Ventral Cochlear Nucleus. Poster presented at: Society for Developmental Biology - 62nd Annual Meeting; Boston, MA. 
Howell, DM., Berrebi, AS., Spirou, GA., Mahters, PH. (2003, February). Analysis of Molecular Guidance Cues Directing Formation of the Calyx of Held. Poster presented at: The Association for Research in Otolaryngology 26th Midwinter Meeting; Daytona, FL.

\section{Membership and Honorary/Professional Societies}

Golden Key Honor Society

Phi Sigma Honor Society

Phi Beta Kappa

Gamma Beta Phi Society

\section{Other Awards/Accomplishments}

First Place Research Day Poster Presentation - 2006

Summa Cum Laude - 1998

J. L. Howe Award - 1998

Engel Scholarship - 1997

William Burns Downey Memorial Scholarship - 1996

Boy Scouts - Eagle Scout - 1991

Boy Scouts - Order of the arrow - brotherhood rank

\section{Hobbies \& Interests}

Woodworking, electronics/computers, fly fishing, soccer, boy scouts. 